\title{
Black Male Retention Initiatives: Exploring Students' Experiences and Program Effectiveness at Predominantly White Institutions
}

Gabrielle St. Leger

West Virginia University

Follow this and additional works at: https://researchrepository.wvu.edu/etd

\section{Recommended Citation}

St. Leger, Gabrielle, "Black Male Retention Initiatives: Exploring Students' Experiences and Program Effectiveness at Predominantly White Institutions" (2012). Graduate Theses, Dissertations, and Problem Reports. 4922.

https://researchrepository.wvu.edu/etd/4922

This Dissertation is protected by copyright and/or related rights. It has been brought to you by the The Research Repository @ WVU with permission from the rights-holder(s). You are free to use this Dissertation in any way that is permitted by the copyright and related rights legislation that applies to your use. For other uses you must obtain permission from the rights-holder(s) directly, unless additional rights are indicated by a Creative Commons license in the record and/ or on the work itself. This Dissertation has been accepted for inclusion in WVU Graduate Theses, Dissertations, and Problem Reports collection by an authorized administrator of The Research Repository @ WVU.

For more information, please contact researchrepository@mail.wvu.edu. 
Black Male Retention Initiatives: Exploring Students' Experiences and Program Effectiveness at Predominantly White Institutions

\author{
Gabrielle St. Léger
}

Dissertation submitted to the College of Human Resources and Education at West Virginia University in partial fulfillment of the requirements for the Degree of

Doctor of Education in

Educational Leadership Studies, Higher Education Administration

\author{
Adriane A. Williams, Ph.D, Committee Chair \\ M. Christopher Brown II, Ph.D \\ David M. Callejo-Perez, Ph.D \\ Ernest R. Goeres, Ph.D \\ Jacqueline L. Webb-Demspey, Ph.D \\ Department of Curriculum and Instruction/Literacy Studies
}

Morgantown, West Virginia

2012

Keywords: Black Male Students; Diversity Initiatives; Student Retention

Copyright 2012 Gabrielle St. Léger 


\begin{abstract}
Black Male Retention Initiatives: Exploring Students' Experiences and Program Effectiveness at

Predominantly White Institutions
\end{abstract}

Gabrielle St. Léger

Recent initiatives in higher education have been designed to increase Black undergraduate male collegiate retention and persistence through graduation for this historically underrepresented population. Although institutional leaders in higher education have focused on creating more inclusive campuses, designing and implementing programs to retain Black undergraduate men have remained largely under studied. Specifically at predominantly white institutions (PWIs), a step in the process is evaluating and assessing the efforts for effectiveness and impact on students' overall development and success. Programs that have achieved ways to increase the retention rates have information that is useful in reversing low retention and graduation should be empirically studied.

This qualitative study of retention initiatives at two state institutions explores the development of the retention initiative; how initiatives are structured within an institution's overall diversity plan; and what the overall impact is on the participants and the institutional environment. Focus group interviews conducted with student participants, interviews of the institutional leadership involved in implementing the initiative, along with a document analysis of cases are used to answer how Black male retention initiatives affect campus diversity initiatives and advance student development and success. While both cases focused on retention through student engagement, accountability, and leadership development, each case used separate foundational principles to carry out the same mission to retain Black males. Northwestern State University (pseudonym) focused on developing students' cultural awareness and Black identity while Southern State University (pseudonym) focused on building students' sense of humility and interdependency. These case studies and the underlying research prove that leadership support, funding and institutionalization have had and can have a measurable effect on young men of color. Institutional culture matters for individuals, and institutional policy can affect change for good.

These efforts to create inclusive environments for Black undergraduate men at PWIs have required time to develop and to bring about deep and pervasive change to affect this population's collegiate experience. A critical step in the process is evaluating and measuring the effectiveness and impact on students' overall success. Through assessment, programs that have improved Black male retention may serve as benchmarks for reversing low retention and graduation. Included in the study are individual analyses of each institution and a cross-case comparison that provides indepth description of these Black undergraduate male initiatives and specifies implications for institutional leaders incorporating a race and gender based retention program into an overall campus-wide diversity initiative. 


\section{DEDICATION}

To my father, Charles St. Léger, Sr. and mother, Marie-Laetitia St. Léger for having faith toward God and being bold enough to believe in the American Dream, as a couple. For being proud of our Haitian culture. For teaching me to love God first, treasure and respect education, and seek wisdom. I love you both forever. Rest in peace. 


\section{ACKNOWLEDGEMENTS}

Thank you first to my Lord and Savior Jesus Christ, for providing the Holy Spirit which guided me through the long arduous journey. Your grace and mercy, your faithfulness when I was faithless kept me all these years. Thank you for using your created beings throughout this process to help me persevere.

Thank you to my advisors on this journey: Thank you Dr. Jones for believing that I could tackle such a large and important question for the dissertation. To Dr. Williams, you are a brilliant role model and a gift to our profession. I am glad to have your insight and oversight on this project as the journey comes to a close. Thank you for your sacrifice and coming to WVU, you have been a blessing and a true guide. Thank you Dr. Goeres for the right witty words just when I needed it and staying the course with me even unto retirement. Thank you to Dr. WebbDempsey for your belief in my ability and your qualitative wisdom. Thank you to Dr. Callejo for your excitement towards this work and Dr. Brown for your dedication and commitment to excellence. I am blessed to have an awesome committee. To the young men and leaders who offered their time and shared honestly in the spirit of true transparency, I am eternally grateful and honored to tell your stories through my research.

To my West Virginia Family: A heartfelt thank you to all my classmates and friends for the laughs and keeping me sane on Friday nights, especially the road crew: Kim, Kristi, and Susan; Bea for your kind hospitality and the cheese balls after Hartnett; My Zeta Crew: Michelle, Trina, Twyla, for representing scholarship at its best and all the cohort members. Thank you Joyce for your honesty and humbleness at the crossroads, it made all the difference. Thank you to the Office for Social Justice for your financial and moral support through the years: Jennifer 
McIntosh, Charlie Morris, Rob Lyons, and Sharon Mallow, I am thankful for you. Thank you to David Fryson, to my mentor through the years, Dr. Cheryl Torsney-your support means the world to me. Thank you to my friend for life, Professor Robin Jones-you have seen me at my best and truly at my worst and still loved me; to my surrogate WVU father, Coach Garrett Ford — thank you for believing in me and all the great advice! Thank you to my McNair family and Dr. Mei for keeping my desire for the doctorate alive and giving me the tools to achieve it. Thank you to my brilliant sisters and support: Dr. Constinia Charbonnette, Dee Curtis, and Professor Judith Scully. You all hold a special place in my heart for your belief and love for me. Thank you to my role model from a far that then came near Dr. Elizabeth Dooley—-to see you rise was pure motivation. Thanks to all the students, colleagues, critics, and friends in the mountains who are too numerous to list who helped to motivate and keep me through this journey, but definitely special to me. Thanks for sowing seeds in me. Thank you to all my Eta Omicron Chapter and Tau Iota Zeta Chapter Sorors, especially: Crystal, Demetra, Ify, Joy, Latonia, Monique, Nnenna, Tashona, Tiffany, and Traci. Through the years your calls, cards, texts, hugs, and support truly filled me when I was empty. I am happy to call you sisters and to have grown up before you all in the mountains.

To my Ohio Family: Thank you to my sister circle: Dr. D’Andra Mull and Rebecca Sandidge for that talk in the room with no walls at Lincoln Tower, reminding me that I should not be scared of nor make any apologies for my greatness. Thank you to Nicole Nieto, my MCC Buddy for life, to Ms. Janice Tyler, and to Richard Hollingsworth for believing in my "A+ mind". Thank you to Willie Young, Art Malloy, Robert Page, Jr., Ron Parker, Larry Williamson Jr., Robert Bennett, Tai Cornute, Todd Suddeth, Dr. James Moore, III, and Dr. Mac Stewart for being Black men to admire. Thank you to Dr. Frank W. Hale Jr. for planting seeds, sowing my 
mind's ground and labeling me special, you are missed. Thank you to all my students who move me to do this work: Ciara, Judy, Stacyann P., Adison, Trinidy, my Stephanies, Donna, Jasmine, KayCee the Diva, Bennett, TJ, Habiba, Monica. You young ones will be better than me and you continue to push me to be my best. Ohio, thank you for such a rich experience and shaping my professional and scholarly identity.

Thank you to my ROCK Family: New York, Alvin, Round Rock, and abroad for your prayers and support. Thank you to Dr. Dana Carson for tremendous inspiration and pushing me to think like God sees me. I am thankful to be a part of the vision and pray this work will bring God glory. Thank you to my Pastor, Louis H. Straker, Jr., for having a heart for God and a vision for young college students. I am grateful to serve in the Kingdom with you. Thank you to Elders Monroe and Higgins for the smiles, support, and prayers when I needed them so badly!

Thank you to my Sprinklisms Family: Thank you to my friend Jonathan Sprinkles for always pushing to make it happen. You persistently believed in me and kept me steady in this journey. Thank you for going the extra mile, for being an original, for being a visionary, for being my comic relief, and for being a part of my foundation. Thank you to Kantis, Aimee, and Chiquitta for sticking it out with me through these years. I'm blessed to call you teammates and even more so to call you friends. You rock!

Lastly, thank you to my St. Léger Family: Thank you for always pulling through and believing in me, your little-not-so-short-hyper-genius sister. I do not know what I did to get placed in this family, but it has been a blessing all my life; through the good and bad times (yes Max, even when you tore my bike a part). Thank you all for being my first teachers and believing in my lifelong dream of becoming Dr. St. Léger. It's been a long time coming since 5 
years old. I love you all: Marjorie, Charles, Jr., Sandra, Danielle, and Maxime, Sr. Thank you to my nieces and nephews who inspire me: Tyree, Briana, Shallah, Jeunveye, Tati, Max, Jr. Joieux, Madison, Jerry, Damien, and Joshuah. You will keep me pushing the limits to show you what a St. Léger is made of. A special thanks to Max, Sr. and Charles, Jr. for inspiring my research with your lives. When I wanted to give up, I remembered your brilliance and how it should be honored. Family, this one's for Mommy and Poppy. 


\section{Table of Contents}

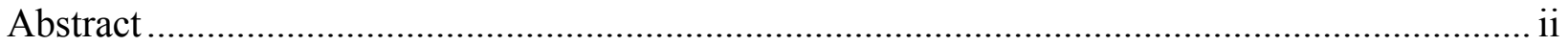

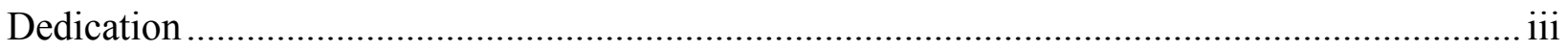

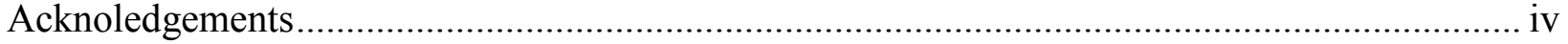

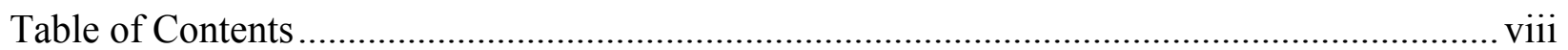

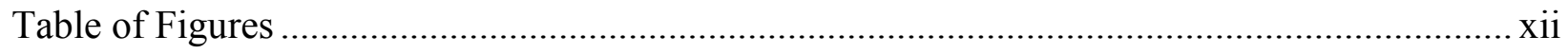

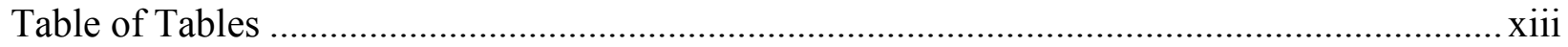

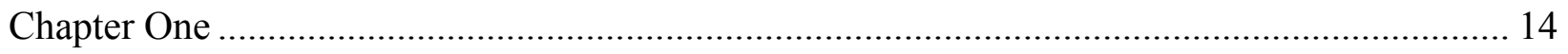

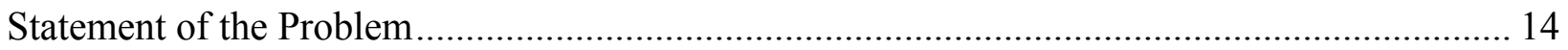

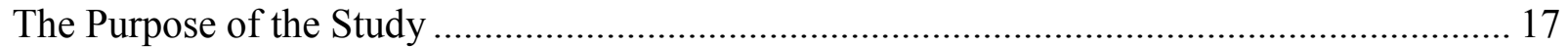

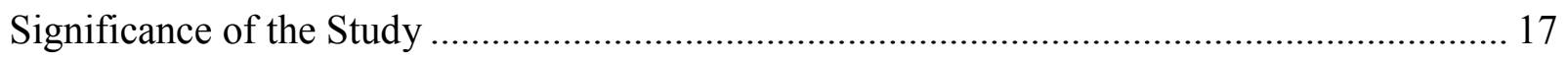

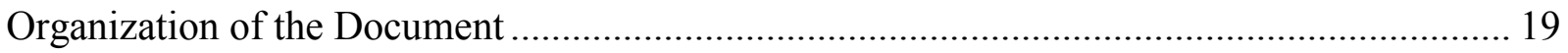

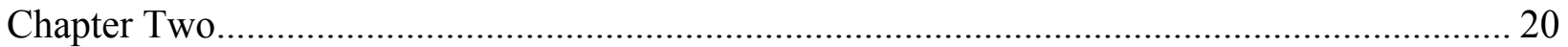

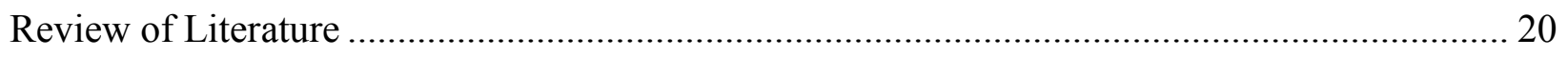

Diversity Initiatives on College Campuses ..................................................................... 21

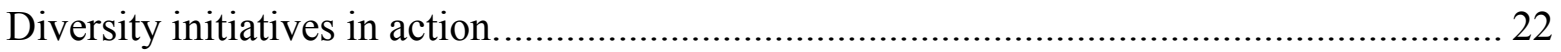

Recommendations and guidelines for diversity in higher education............................... 24

Benefits of diversity in higher education ............................................................ 31

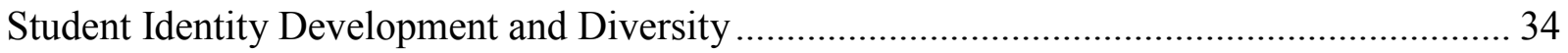

Theories of and Reasons for College Student Departure ................................................. 37

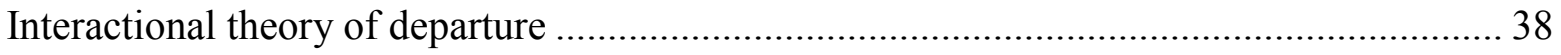

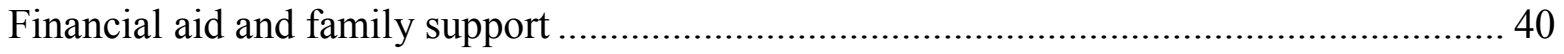

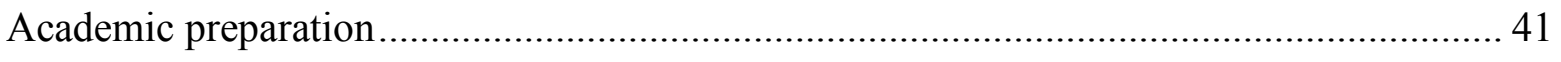

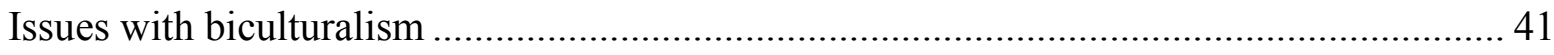

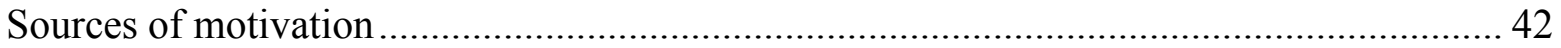

Psychological model for college student retention ................................................... 43

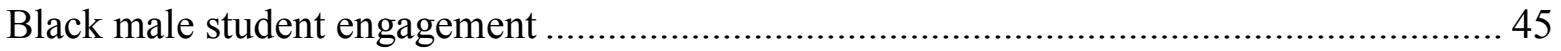

Geometric model of student persistence and achievement......................................... 45

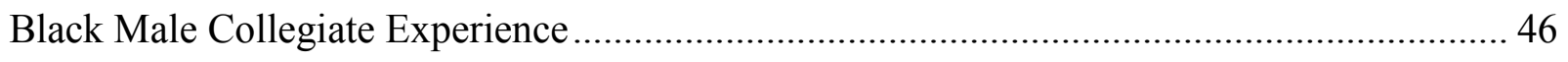

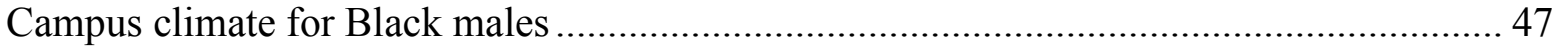

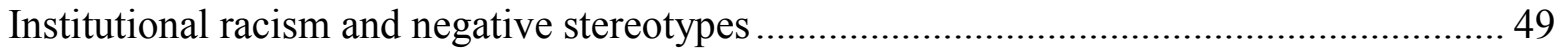




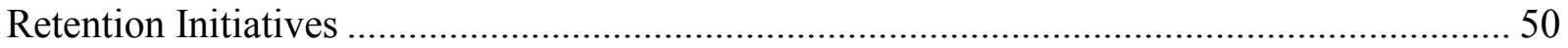

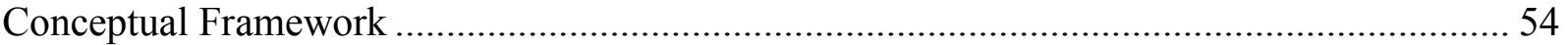

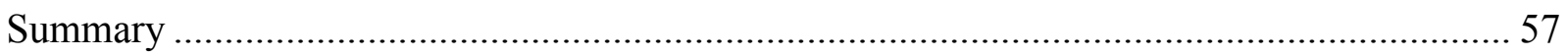

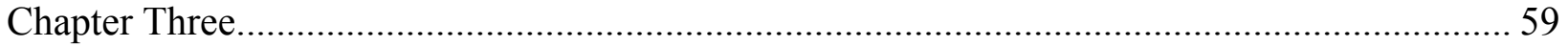

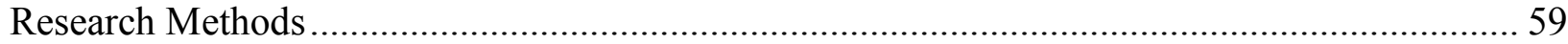

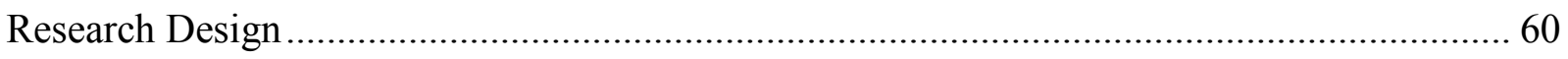

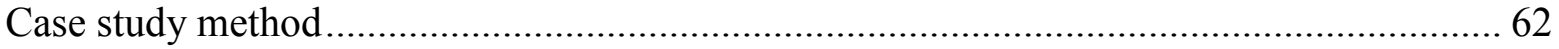

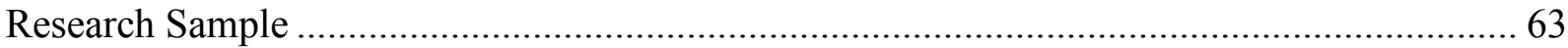

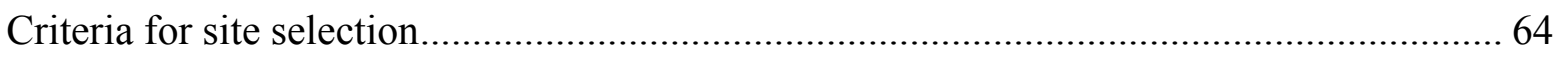

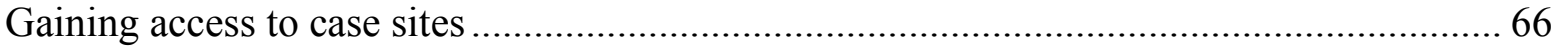

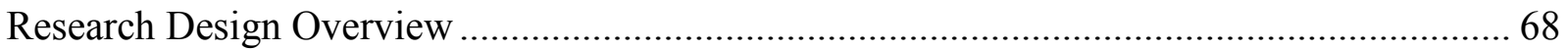

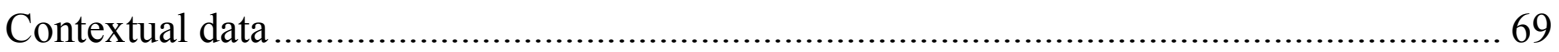

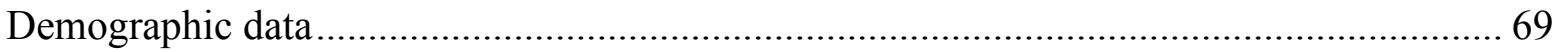

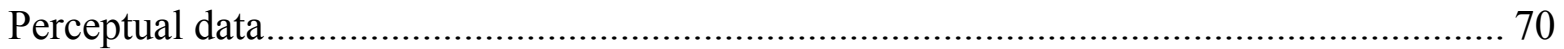

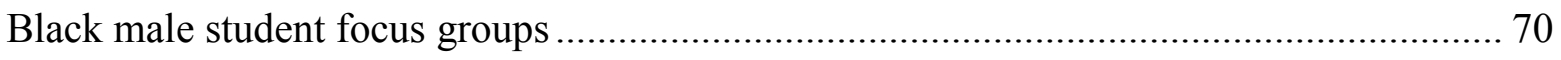

Sampling procedure for focus group interviews....................................................... 71

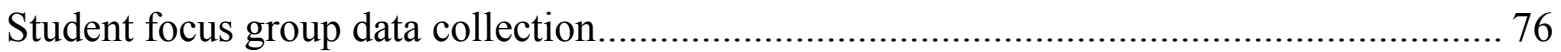

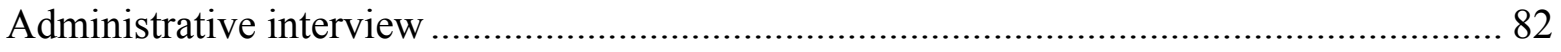

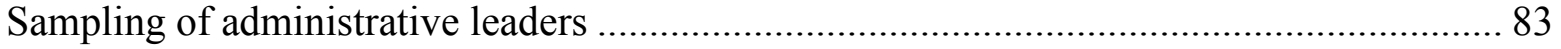

Administrative interview data collection.............................................................. 86

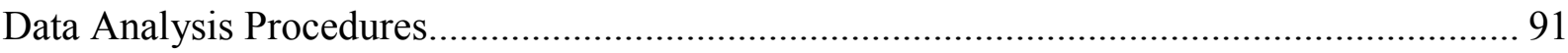

Analysis of data from focus groups and interviews .................................................... 92

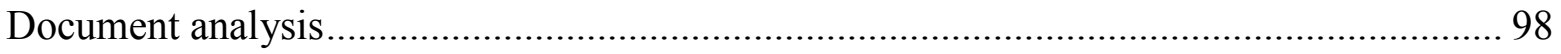

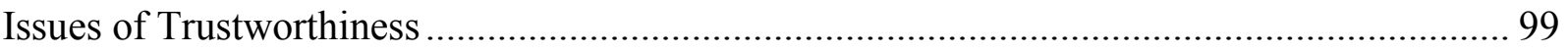

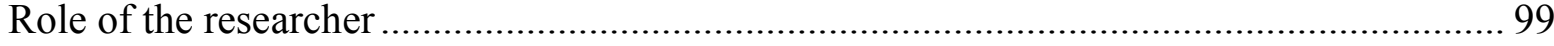

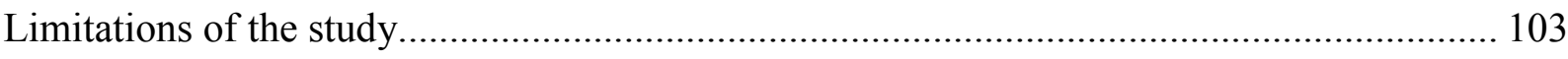

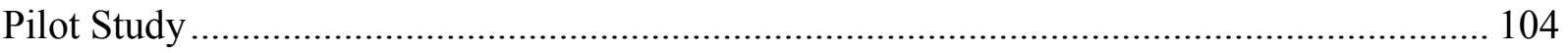

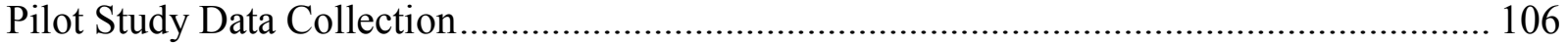

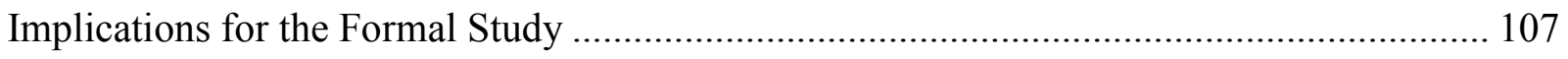

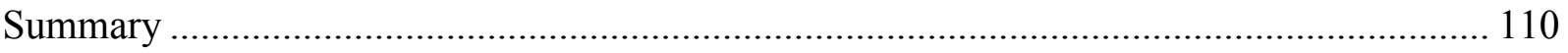

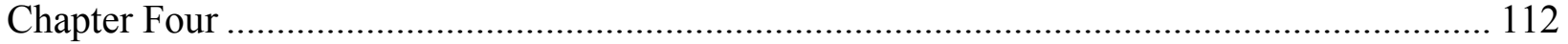


Case One: Northwestern State University ................................................................... 112

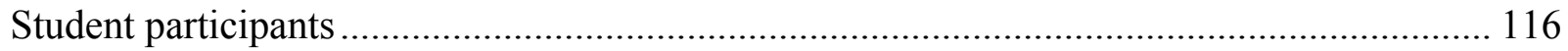

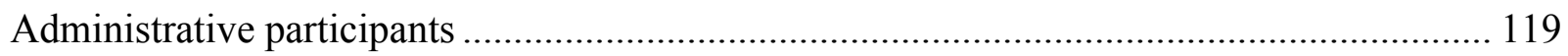

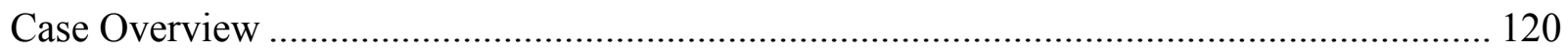

Mission of the Black Male Exchange ........................................................................ 123

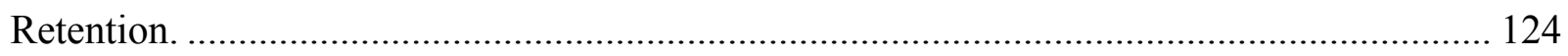

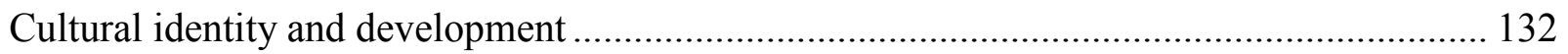

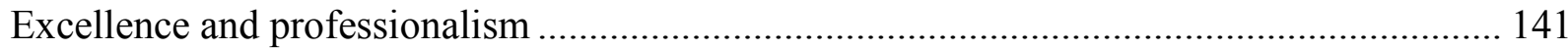

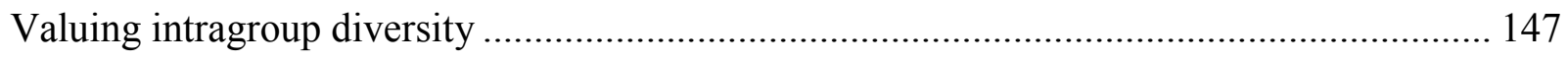

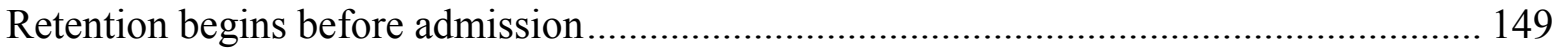

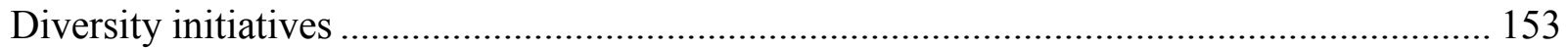

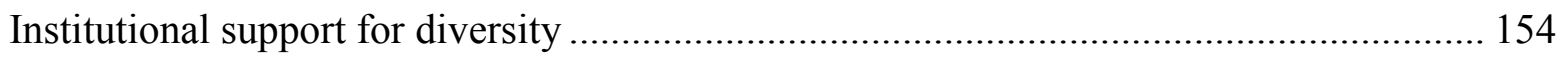

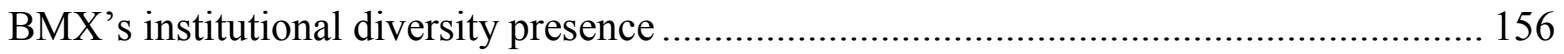

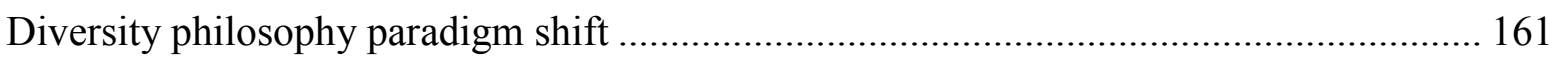

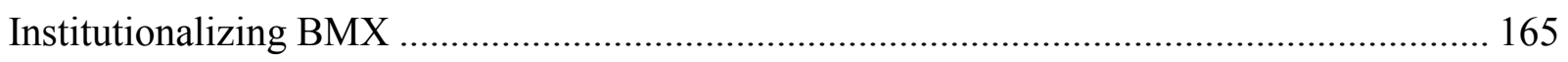

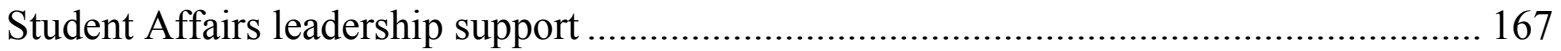

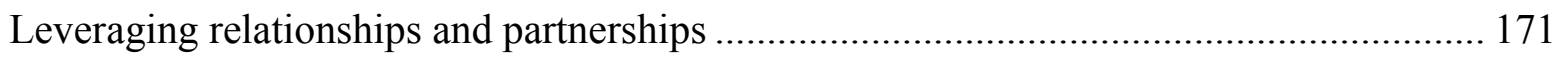

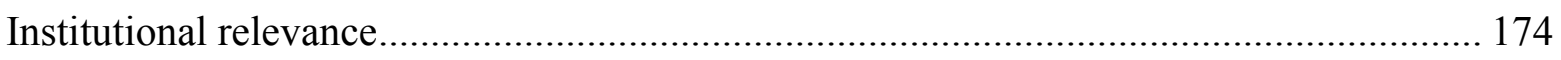

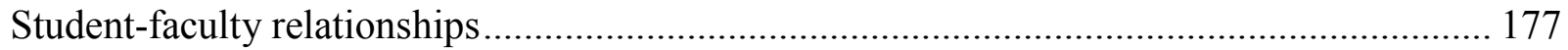

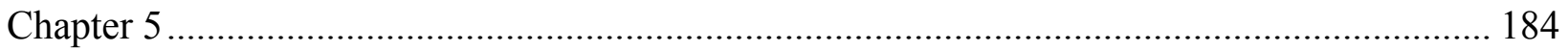

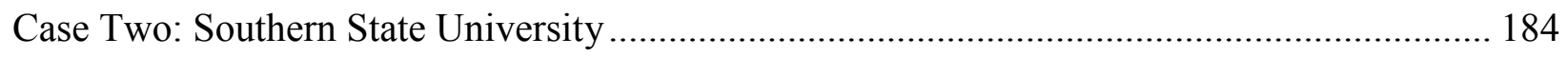

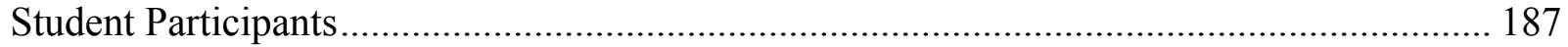

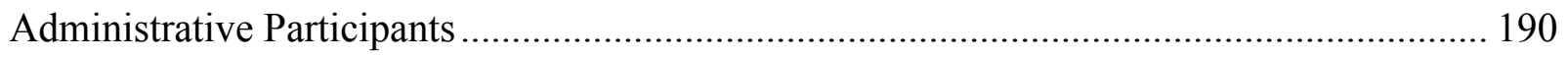

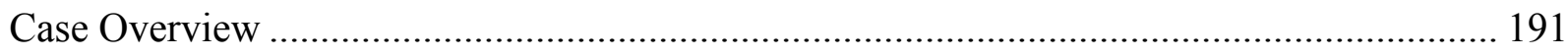

Mission of the Black Male Resource Institute ................................................................ 193

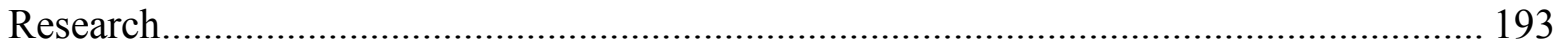

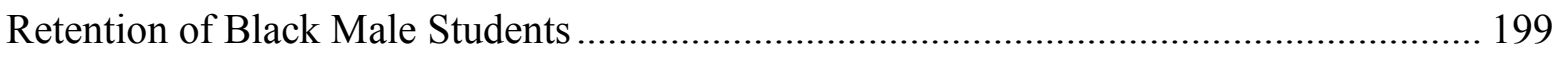

Diversity Initiatives at Southern State University ....................................................... 223

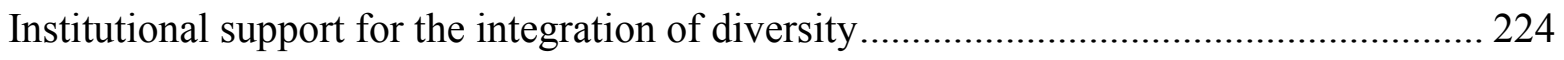

Established standards for communicating the institutional support for diversity ............. 228

Diversity planning assisted in cross-divisional attention to retention issues..................... 232 


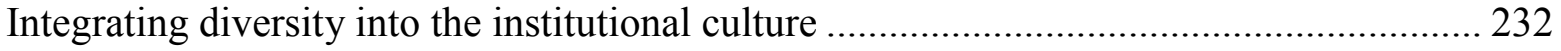

Institutionalizing the Woodson Center at Southern State ............................................... 236

Support, resources, and campus mobilization ............................................................ 240

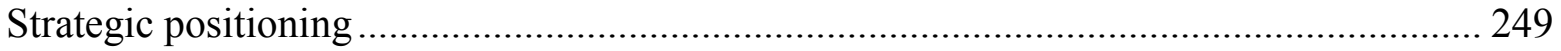

Evaluation and Assessment of Student Learning ............................................................ 252

Means for evaluation: Retention, Surveys, Focus Groups ......................................... 255

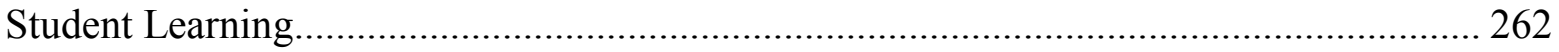

Development of Evaluation and Assessment Practices ................................................ 270

Students recognized the Center's role in their development ....................................... 272

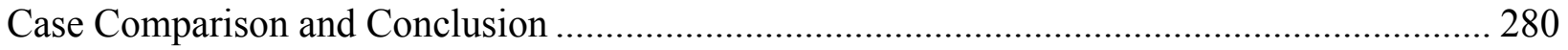

Comparing the Programs: BMX and the Woodson Center................................................. 280

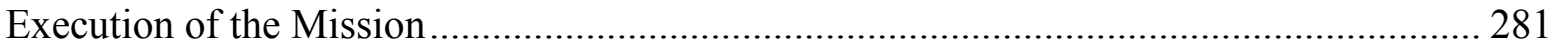

The Momentum towards Institutionalization .......................................................... 292

The Retention Initiative within the Diversity Initiative................................................. 296

Reviewing Evaluation and Assessment Practices ...................................................... 299

Implications for Policy, Practice and Research............................................................... 302

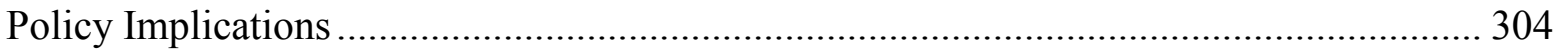

Implications for Practice in Higher Education ........................................................ 307

Implications for Future Research ......................................................................... 314

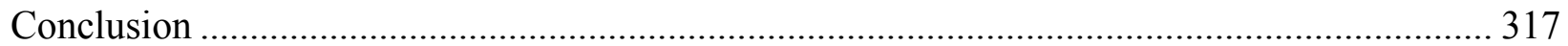

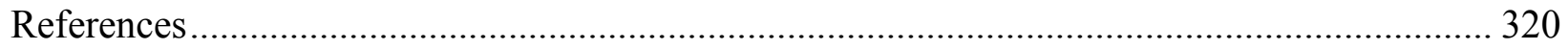

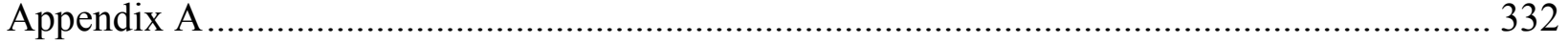

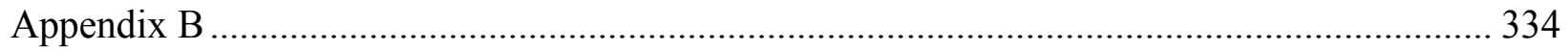

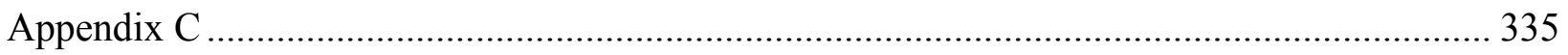

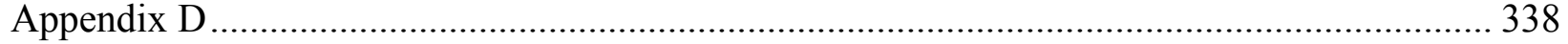

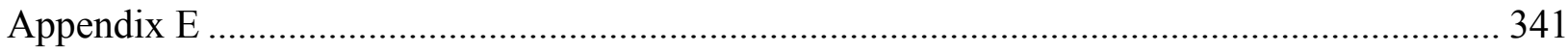

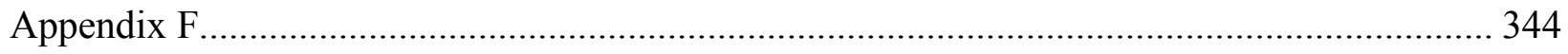

Appendix G 


\section{Table of Figures}

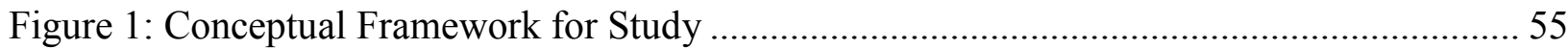

Figure 2: Geometric Model of Student Persistence and Achievment.......... Error! Bookmark not defined. 26 


\section{Table of Tables}

Table 1: Black Male Student Interview Protocol Questions.................................................... 77

Table 2: Administrative Semi-structured Protocol Questions ................................................ 87 
Chapter One

\section{Statement of the Problem}

The publishing of critical works on race and higher education by Cuyjet and his associates (1997, 2006) and other scholars (Majors \& Mancini Billson, 1992; Hrabowski, Maton, \& Greif, 1998; Garibaldi, 2007) has encouraged student affairs and academic affairs professionals to gain an understanding of the experience of Black undergraduate men in American institutions of higher education, most notably in the last two decades. Over the last two decades, these published works have defined a more accurate perception of problems related to the undergraduate Black male population for faculty, practitioners, and administrative leaders to consider when designing programs and services that help retain Black male students to graduation. These programs and services generally fall within an institution's diversity agenda or initiatives due to the historical and very present issues that this underserved population faces while matriculating through college.

Although institutional leaders are focused on creating more inclusive campuses, challenges remain associated with designing and implementing programs to retain Black undergraduate men. Specifically at predominantly White institutions (PWIs), challenges relate to implementing and assessing the success of the programs created to aid in Black male retention and persistence towards graduation that have yet to be explored systematically and empirically. Other challenges consist of institutionalizing the programs in order to ensure the longevity of these retention initiatives and services that enhance the persistence of Black males and achievement of their educational objectives. Especially in times where institutions are experiencing economic hardship and public scrutiny, these programs must use data and present 
results in support of claims that they make a difference in the experiences and success rates of Black males, or risk the possibility of funding cuts and discontinuation.

Instituting and maintaining effective retention initiatives in higher education are neither immediate nor effortless. Creating changes on college campuses that lead to better climate and positive learning outcomes for students is a slow progression that requires strategic planning and effective leadership on all levels and in all divisions of the institution, especially when tackling issues affecting student populations with historical persistence problems and low retention rates. Diversity initiatives, particularly those focused on improving the experience and retention of historically underserved students at PWIs, are challenged by these institutions' long-established culture, governance, and structures. These underserved student populations need appropriately structured and sufficiently funded institutional support to adjust effectively to college, to engage positively with the college environment, to be successful academically, and to persist to graduation.

The growth of the underserved population of Blacks and other students of color at PWIs is a direct result of higher education systems attempting to rectify past inequities. From 1976 to 2004, undergraduate enrollment for minority students increased to $32 \%$ of the total enrollment, rising to almost 4.7 million students (National Center for Educational Statistics [NCES], 2007). This number is projected to continue to increase according to NCES calculations. Although totals for all undergraduate students of color increased in number and surpassed the rate of increase of White undergraduate students, Black students had the lowest percentage increase of enrollment for minorities. 
In more recent years, issues related to the Black undergraduate male experience have been a focus for practitioners and researchers due to the low retention rates recorded year after year by colleges and universities of all classifications across the United States. When data are disaggregated by gender, Black males compared to their female counterparts only comprise $36 \%$ of the total undergraduate enrollment of Black college students. This gender gap is the largest of all racial and ethnic groups (NCES, 2007). Black males are among the least retained groups of college undergraduates. The numbers are startling. Black male undergraduates' attrition rate is the highest of all student populations, and statistics have revealed the national crisis of retention that all institutional types are struggling with, especially at PWIs. Harper (2007) reported that $68 \%$ of Black undergraduate men do not graduate within six years, and an overwhelming majority of enrolled Black undergraduate men are enrolled at PWIs.

Faculty and administrators developed programs, services, funding opportunities, and other incentives to draw students of color to their institutions and to help them successfully navigate and graduate from PWIs. Since the campus environment of PWIs can contribute to the low retention rates of Black undergraduate men, academic leaders are creating initiatives to diversify and support campus populations of Black students and other students of color to help them adjust and succeed. To create inclusive campus climates that foster success for historically underserved Black undergraduate men, institution leaders need to promote major transformational changes. Eckel and Kezar (2003) defined transformational change, "as affecting institutional cultures, as deep and pervasive, as intentional, and as occurring over time" (p. 27). These efforts to diversify and create inclusive environments for Black undergraduate men at PWIs require time to develop, and strong leadership to bring about deep and pervasive change to affect this population's experience. A critical step in the process is assessing the efforts for 
effectiveness and impact on students' overall success. Without proper evaluation and assessment practices in place, many of these retention initiatives will not exist long enough to show sufficient impact. The likelihood of institutionalization for Black male retention initiatives is reduced when programs are short-lived.

\section{The Purpose of the Study}

The purpose of this study was twofold. First, this study formally examined how retention initiatives' components and services were developed and assessed for impact upon Black males. Secondly, this study examined the experience of Black male undergraduates (at predominantly White campuses) who participated in the initiatives' programs and services to determine what they gained from involvement and how it affected their development and overall success during their college enrollment. In addition, students' perceptions regarding how these programs enhanced their adjustment to college and their persistence were examined. This study was designed to answer the research question: "How do Black male retention initiatives affect college campus diversity efforts and promote student development and success?"

\section{Significance of the Study}

Research has focused on the experience of Black undergraduates. Some of these studies focused solely on the Black undergraduate males who were actively engaged in programs or initiatives found to improve their persistence (Fortson, 1997; Maton, Hrabowski, Ozdemir, \& Wimms, 2008; Lee, 1999; Strayhorn, 2008). Research efforts have also examined the aspects or components of programs and the campus environments that are considered significant elements to effective retention initiatives (Taylor \& Miller, 2002, Swail, Redd, \& Perna, 2003). There has been an insufficient amount of focus on how the creation, design, and implementation of these programs for this particular population reach a significant and identifiable amount of success 
(Patton, Morelon, Whitehead, \& Hossler, 2006), nor has there been substantial research that discusses what participants gain or learn through these programs. Through this study, I have gleaned insights regarding successful program design, implementation, and institutionalization that contribute to campuses' strategic approach to specific diversity initiatives and retention initiatives for Black undergraduate men at PWIs.

During this investigation, I explored the program structure of identified successful retention initiatives for Black undergraduate men in a systematic attempt to understand how they are organized. This study examines:

- the major student outcomes the initiatives intend to achieve;

- program components used to accomplish those outcomes;

- institutional structures and partnerships necessary to achieve program goals; and - what assessment indicators are used to determine their success.

The results can assist faculty, staff, and other campus leaders at PWIs in determining the programmatic structures, components, and assessments that are essential to assure successful retention of Black undergraduate men and to enhance their adjustment to the college environment. By identifying successful evaluative and assessment practices in regards to these retention programs, newly established programs can strengthen projected learning outcomes, incorporate partners and sectors of the institution necessary for growth of these programs, and increase the probability of sustaining these initiatives.

Campus leaders and administrators charged to manage retention initiatives can use the information presented in the study to focus their Black male initiatives on factors identified as essential to retaining Black undergraduate males and possibly other at-risk student populations 
identified at their institutions. Finally, institutions that have yet to develop retention initiatives for Black undergraduate men, or are examining the possibility of specialized programmatic initiatives for this population, will have information on how to establish programmatic structures and how to promote the learning and development of Black undergraduate men.

\section{Organization of the Document}

This chapter briefly outlined the stated problem and current issues pertaining to Black undergraduate male retention in higher education. It also introduced the challenge of evaluating, assessing, and institutionalizing retention initiatives at PWIs and the research questions that guided the examination of the problem. Chapter Two serves as a detailed literature review of related research elucidating the efforts to improve the college experience for Black undergraduate men through retention initiatives, the progress towards improving the institutionalization and transformation of colleges and universities towards diversity and inclusion, and the effective campus retention practices and their evaluation. Chapter Two also presents the conceptual framework, which was developed from the literature. Chapter Three explains the cross-case research design: providing the qualitative research methodology employed, the selection of case institutions, sampling practices, and the data analysis process. Chapters Four and Five present the case studies chosen for the research. Finally Chapter Six provides a concluding comparison of the two cases and implications for future practice, policy, and research. 


\section{Chapter Two}

\section{Review of Literature}

Innovative programs focused on retaining Black males are a contemporary trend in higher education. In my study, I have analyzed the success and impact of these programs designed to increase the retention of Black male undergraduate students at PWIs; this study has yielded valuable information about the development and sustainability of these initiatives. Most of the recent research has not focused specifically on the retention of Black males. Some researchers (Smith, 1995; Hurtado, Milem, Clayton-Pedersen, \& Allen, 1999; Smith \& Wolf-Wendel, 2005) have studied the creation of inclusive campus environments and the execution of campus diversity initiatives at PWIs. They have identified the major issues that should be resolved as faculty and administration implement changes. Further analysis of diversity initiatives' design, implementation, evaluation, and assessment provided insights toward developing a more complete understanding of how retention programs for Black males exist within the diversity initiative plans at PWIs and the success and effectiveness of these specific retention efforts for this poorly retained population.

In this chapter, I review relevant literature focused on the design and success of retention efforts within higher education. This review includes an exploration into the practices of faculty, administrators, and staff in determining the success of their retention programs and services and the components that are important to consider when carrying forward retention efforts. I discuss Black male attrition, persistence, and various aspects of the Black male collegiate experience that generate the need for these programs at colleges and universities. Retention programs and services are one aspect of a campus initiative typically designed to improve the environment and experience for all members of the community, especially underserved student populations. The 
synthesis of these research areas provides useful information regarding the design and success of retention programs intended to increase Black males' positive collegiate experience and improve persistence through graduation. It informs the comprehensive conceptual framework used in this exploratory cross-case study.

\section{Diversity Initiatives on College Campuses}

For the purposes of this research, campus diversity initiatives are defined based on the research of Musil, Garcia, Hudgins, Nettles, Sedlacek, \& Smith (1999) as comprehensive programs, services, and opportunities provided on college campuses inside and outside of the classroom. These initiatives are designed to increase the retention and success of marginalized, underrepresented students and to improve the campus climate for all members by promoting positive, intergroup relations. Academic leaders who promote these initiatives also seek to increase diversity across the curriculum in content, faculty composition, pedagogy and teaching methodology, as well as research and scholarship. A frequent goal of diversity initiatives is to improve their overall effective implementation and the ideal of diversity as a part of central functioning, vitality, and viability of an institution. In addition to the aspects of campus diversity initiatives designed to increase access to college, retention, and college success of marginalized underserved student, this research study also focused on improving campus climate and intergroup relations. The AAC\&U (1995) defined diversity as:

The variety created in any society by the presence of different points of view and ways of making meaning which generally flow from the influence of different cultural and religious heritages, from the differences in how we socialize woman and men, and from the differences that emerge from class, age, and developed ability. (p. xx) 
Diversity in higher education is considered in several contexts based on how students and others at institutions are impacted by the presence on campus of those who identify differently than the majority. First, a campus can have "structural diversity or representational diversity," defined as the numerical count of underrepresented students in the total student population (Hurtado, Milem, Clayton-Peterson, \& Allen, 1999; Smith \& Schonfeld, 2000). This is only a numeric value and does not take into account whether or not there is interaction among the diverse students that make up the student population. "Informal interactional diversity" is another form of diversity that mostly occurs outside of the classroom and allows for more frequent and intentional quality interaction between different student groups (Gurin, 1999). The third type of diversity is "classroom diversity," which encompasses the content knowledge of diverse topics incorporated into the curriculum (Chang, 1996). All of these distinct definitions used in higher education are important when constructing effective campus diversity initiatives with the goal to produce positive outcomes for students' overall development.

Diversity initiatives in action. When institutions embrace the responsibility to create inclusive and diverse environments, it is crucial to redefine the institutional mission. Often the mission of higher education is to prepare the future citizenry for active and productive engagement and leadership in society. It is the responsibility of faculty, staff, and administrators to embrace the idea of diversity at the highest level of the institution including its mission and vision statements. The inclusion of diversity as central and valued within the mission and purpose of an institution is considered essential to the development of supportive climates where all members of the institution have the opportunity to succeed. Success for underrepresented students along with all students learning the skills and information needed to live in a more multicultural society should clearly be a part of an institution that is embracing its responsibility 
to maintain a healthy, safe, and diverse environment. Smith (1995) provided four dimensions of diversity (representation, response to intolerant climate, educational/scholarly mission, and organizational/intellectual transformation) for institutions to consider when framing the discussion and identifying the phases that evolve over time at institutions of higher education. With regard to the third dimension of educational/scholarly mission, Smith stated:

'Educational mission' can and must play a central role in engaging diversity on campus, and it has the potential to involve broad cross sections of faculty and staff who understand that the intellectual and educational dimensions of diversity are critical. (p. 227)

Representation, the first dimension most commonly addressed, focuses on building up structural diversity and allowing those who have traditionally not been able to attend institutions of higher education. This dimension focuses on access to higher education and presents the opportunity for underrepresented students to consider postsecondary education as a benefit and to be exposed to an array of academic fields that they were not aware of and did not realize were possible pursuits. Representation helps address issues with structural diversity, increasing the number of underserved students attending, and subsequently increases the probability of informal interactive diversity occurring on college campuses.

The second dimension — response to intolerant climate—addresses the issues of hostility and discrimination that comes when new populations are introduced into the campus environment. The services, programs, and support needed to deal with the results of intolerance, racism, sexism, and other oppressive dominant behaviors are addressed within this dimension, as campuses broaden their concern and action towards creating a safe diverse campus community for all. 
The third dimension, already discussed, addresses the educational/scholarly mission. The fourth dimension according to Smith (1995) has yet to be addressed. It is the transformation in how colleges or universities integrate diversity into all aspects and practices of institutional life. This dimension encourages institutions to answer the question, "What would our institution look like if we were truly educating a diverse student body to live and work in a pluralistic society?" (p. 228). Researchers and institutional leaders use this framework as they examine how diversity develops on campuses and how to create successful diversity initiatives. It serves as a central concept in the data analysis for this study.

Recommendations and guidelines for diversity in higher education. In December 1984, the American Council on Education (ACE) made one of the first formal calls to higher education to address diversity initiatives. A Statement on Educational Diversity, Equity, and Quality by ACE's Office of Self-Regulation Initiatives provided guidelines to help colleges and universities encourage equality and diversity. ACE presented concise guidelines for institutions to follow when considering ways to fully include people of color, women, and differently able persons into the academy. Some strategies have included

- addressing diversity in student programming;

- reviewing practices for the recruitment of underrepresented students, faculty, and staff;

- demonstrating intentional sensitivity and support for diversity in the evaluation of scholarly work; and

- developing curricula that encompass research and expanding academic programs for the study of gender issues and racial/ethnic studies.

ACE has provided suggestions for evaluating personnel and supporting administrative leadership practices that emphasize total campus involvement when creating diversity initiatives. 
The authors urged institutions of higher education to raise their standards for promoting gender, ability, and ethnic diversity to a higher level compared to the minimal legal standards, which only extend to increasing numbers in an attempt to achieve one dimension of diversitystructural diversity. ACE stressed that institutional leadership should be genuine in support of equity and emphasizes that "the visible personal commitment of institutional leaders may well be the single most important factor in insuring equal opportunity in our educational institutions" (p. 1). ACE noted that academic leaders should communicate their commitment to diversity through multiple venues including delivering public speeches; creating, supporting, and enforcing equity policies and practices; developing guidelines for personal behavior; promoting accountability; and implementing formal assessment practices. This document assisted in setting the bar for institutions and professional associations to increase their diversity efforts by creating an atmosphere in higher education that truly supports enhancing the educational experience for all. It also provided a reasoned argument emphasizing the importance of institutionalizing diversity efforts.

Kanter (1983, p. 299) in Curry (1991) defined institutionalization as innovation supported by the organizational culture to the degree that it is part of legitimate and ongoing practice and is valued by others in the organization. Institutionalization requires support of the innovation, and thus the innovation must be integrated with other aspects of the organization. Diversity in and of itself is an ideal. If institutions, through their leaders, take ownership of diversity as a value, then it is considered when implementing initiatives, creating strategic goals, and delegating resources. If institutions embrace diversity as a crucial part of their culture, then it is more likely that programs and services that promote diversity on college campuses will be institutionalized. ACE's statement provided clear justification for diversity as essential to the functioning of 
colleges and universities. The authors were among the first to stress the specific responsibility that higher education leaders have to promote communities that give equal opportunity and access to educational success. They explicitly identified retention programs and services created for the underrepresented populations as one way to aid in moving from diversity as an ideal to institutionalization. Support services, recruitment, and retention initiatives should reflect the commitment of the institution to "promote the educational value of cultural, ethnic, and racial diversity within the student body" (p.3).

A careful review of calls for reform, especially since 1990, revealed that the American Association of Colleges and Universities (AAC\&U) has been the primary national organization to focus on integrating diversity across colleges and universities. In this section of the literature review, it is crucial to understand the contributions offered by AAC\&U. A 1995 report was the first of several compiled by a national panel of scholars from the higher education community charged with examining the commitment to diversity. It revealed several important points about the historical conflict, current work, and transformation needed in order for institutions of higher education to properly address diversity within the system. The report stated that campuses must address two different responsibilities in creating a pluralistic society, where true democracy can be achieved by all citizens regardless of past inequities and injustices imposed on individuals for membership in certain identity groups. The AAC\&U stated that campuses need to "create new opportunities... for both public and campus learning about the United States as a diverse democracy” and to commit to creating, “inclusive educational environments ' in which all participants are equally welcomed, equally valued, and equally heard" (p. xxi). According to the panel of experts, leaders in higher education needed to "engage the centrality of diversity in higher education's responsibilities to democracy" (p. 40) and work "against dichotomies of mind 
and of politics that allow students to be defined stereotypically as unidimensional rather than multidimensional" (p.41).

Musil et al. (1999), in the first monograph in a series of three examining diversity initiatives, stressed:

If diversity is the norm and will continue to be so, higher education has a special role to play, the public believes, in ensuring that such differences become a source of strength, that is, a resource rather than a problem (p. 9).

The authors stated that higher education is the "powerful laboratory for defining new democratic practices of equality, opportunity, and inclusion" (p. 9). The work of Musil and her colleagues on the seminal research series supported by the AAC\&U entitled Understanding the Difference Diversity Makes: Assessing Campus Diversity Initiatives has given the most comprehensive look at multiple approaches to addressing the issues related to fostering diversity. Through their research, they have provided a perspective for how campus diversity initiatives are emerging in higher education, how academic leaders and practitioners at institutions can comprehensively assess the current diversity initiatives, and how leaders may identify future research areas on diversity.

Findings from their research showed those institutions that gave opportunities for faculty development tended to have instructors who acquired the skills to implement diversity across disciplines to help reshape curricula. Faculty members became better-informed student advisors and were willing to do more interactive group projects to promote more student-centered learning in the classroom. Faculty engaged students in more diverse subject areas within their discipline. Faculty learned to have sustained conversations about curricular changes through faculty development opportunities. As faculty learned new ideas, they implemented diversity in 
required courses for freshman and across the undergraduate curricula by year and discipline.

These curriculum changes helped students to engage in issues of diversity in multiple courses throughout their collegiate career. It reinforced classroom diversity, helping students to think critically about how diversity permeates all aspects of American and global society.

An institutional focus on climate and intergroup relations showed academic leaders how climate is correlated with retention and overall educational success. When the overall institutional environment is examined systematically through formal assessment, it provides data that can be used in creating new programs to combat climate issues. Musil and her associates also emphasized that doing such formal assessment of climates, such as audits of the students, faculty, and staff at an institution, can "identify pressing problems or particular groups who may be experiencing a hostile climate" (p. 29).

Increasing awareness among faculty and staff of the importance of strengthening the relationship between the college campus and the surrounding community is an additional area that has emerged as a central action step in campus diversity initiatives. Musil et al. (1999) noted that increasing healthy partnerships between campus and community help to quell possible conflicts between the two and to aid in admission of more local college-age students. Since the majority of institutions in the study had differences between the cultural makeup of the surrounding community compared to the college student population, increasing partnerships helped create a more diverse student body. Researchers found that successful partnerships focused on outreach and volunteering in formal programs that invited community leaders and institutional members to connect. These programs ultimately helped students better understand the culture of the surrounding local community. Four major dimensions of institutional interconnectedness emerged as distinct and essential for sustaining campus diversity initiatives: 
(a) access and success for underrepresented students, (b) climate and intergroup relations, (c) education and scholarship, and (d) institutional vitality and viability (p.5). The dimensions first introduced by Daryl Smith (1995) were prevalent in the multi-institutional study and reconfirmed for leaders in higher education a valid comprehensive framework for making the argument for implementing campus diversity initiatives across all contexts. If these dimensions are addressed, the dissonant minority voices of the academy have multiple opportunities to challenge traditions, curriculum, teaching and learning, and scholarship. They can help shape how institutions make meaning of diversity on their respective campuses and formulate the specific ways diversity initiatives are implemented.

Access and success was a dimension of Smith's (1995) framework focused on the inclusion of historically underserved groups at institutions and their overall educational success. This dimension focuses on retention rates and numbers of students in attendance in college, the type of college hosting these historically underserved students, and their graduation success. Research examining retention initiatives falls under this particular dimension. The campus climate and intergroup relations dimension focuses on the entire campus environment and its effect on students. Research under this dimension examines how students who are marginalized based on race, ethnicity, gender, sexual orientation, physical abilities, and religion, among other factors, are experiencing the college environment. The examination of climate and intergroup relations shows how these groups are developing and interacting among and between each other and with the majority population and how inclusion is fostered across the campus community. The campus climate can ultimately impact the decision for a student to remain enrolled or leave an institution. Education and scholarship are the third dimension, which encompasses a review of the curriculum, scholarship produced by faculty, and the opportunity for formal study of 
underrepresented groups across disciplines to ensure that diversity permeates the implementation of the educational mission of an institution. Teaching and learning are examined within the college classroom to determine how diverse the content is and how different learning styles of students are addressed in pedagogy. Institutional viability and vitality are the final dimension, which focuses on whether or not institutions of higher education have a clearly defined mission that considers diversity, inclusion, and the promotion of a pluralistic global society as essential. Diversity is a central part of institutional vision, mission, and purpose as colleges and universities continue exploring methods of promoting diversity across all stakeholder groups (Smith, Garcia, Hudgins, Musil, Nettles, \& Sedlacek, 2000).

Through Smith's (1995) framework, higher education leaders have recognized how campus climate effects intergroup relations and retention and how innovative programs can help enhance diversity. This framework represents a comprehensive approach to develop, maintain, and assess diversity initiatives with respect to specific campus dynamics without losing sight of the fundamental question of access or increasing structural diversity. Without a population of underrepresented students succeeding academically and socially on college campuses, any diversity initiative will fail to reach the institutional and societal benefits diversity provides. Through funding and leadership from the AAC\&U, Musil and her associates' review of numerous efforts across many institutions showed that over the last 30 years in higher education, "engagement with diversity became more intentional and sustained" and "a recognition that diversity is essential to excellence" (Musil et al., 1999, p. 9). Their multi-institutional research reemphasized the positive learning and democratic outcomes found by Gurin (1999), Terenzini et al. (2001), Kuh (2003) and others. They too posited that diversity “encourages a deeper understanding of students and the ways in which their complex and dynamic identities influence 
what they learn and how they learn it" (Musil et al., p. 9). In addition, the authors stated that diversity "drives higher education towards excellence in teaching and learning" (Musil et. al, 1999, p. 9).

Benefits of diversity in higher education. Many advocates for diversity believe that higher education has the responsibility to increase students' understanding towards a greater personal civic and social responsibility, based on the major demographic changes in our society as a more diverse multicultural and multiethnic democracy (American Council on Education, 1984; Association of American of Colleges and Universities, 1995; Hurtado, 1999). College campuses mirror the diversity present in larger society and serve as a microcosm for social issues and tensions. In this section, I reviewed numerous research studies to show the impact of diversity initiatives and multiculturalism on the undergraduate student experience.

A number of the studies on the effects of diversity on campuses found that all studentshistorically underrepresented as well as majority students—-benefit from exposure to and interaction with diversity in college, both socially and academically. Studies have shown that both underrepresented students and White students benefit from the promotion of a positive interracial campus environment (Astin, 1993; Chang, Astin, \& Kim, 2004). A study conducted using Cooperative Institutional Research Program (CIRP) data from the Higher Education Research Institute (HERI) at the University of California Los Angeles showed positive increases in cultural awareness and college satisfaction for students who had direct involvement with specific in-class and co-curricular experiences (Astin, 1993). This multi-institutional, longitudinal study showed positive cognitive and affective development over the course of four years for students who had direct experiences with diversity (through coursework, cultural programming and events, discussions, and interaction with different racial groups). There was a 
statistically significant increase for students in the following areas: cultural awareness, satisfaction in the college experience, and commitment of students to promoting racial understanding. Astin and his colleagues (Change, Astin, \& Kim, 2004), again using the CIRP data, elaborated further the positive effects on students' intellectual, social, and civic development through cross-racial interactions. There was a markedly positive correlation between all forms of cross-racial interaction identified in the study (studied with, dined with, dated, or interacted in class with someone from a different racial/ethnic group) and the growth of intellectual ability, social ability, and civic interest.

Other empirical studies on diversity initiatives have reinforced these findings of positive effects on student learning (Gurin, 1999; Gurin, Dey, Hurtado, \& Gurin, 2002; Smith \& Schonfeld, 2000). Researchers discussed the effects of diversity initiatives on learning outcomes (active thinking, intellectual engagement and motivation) and democracy outcomes (perspective taking, citizenship engagement, cultural understanding, and judgment of the compatibility among different groups in a democracy) (Gurin, et al., 2002, p. 334). Their research discerned the effect diversity initiatives have on student learning outcomes and their experiences. The research also showed these experiences in college help to develop skills, attitudes, and behaviors that aid students in becoming leaders in a pluralistic society after college. Formal investigations on diversity's positive impact on college environments and students have demonstrated benefits in different domains within institutions with the greater part of the benefits stemming from institutions' intentional effort to create "engagement with diverse peers in the informal campus environment and in college classrooms" (Gurin, et al., 2002, p. 333).

These findings of specific learning outcomes and their impact on students were consistent with other research that focuses on diversity experiences in higher education (Antonio, 2001; 
Chang, 2002; Kuh, 1993 \& 2003; Terenzini, Cabrera, Colbeck, Bjorklund, \& Parente, 2001).

These studies found that students who are exposed to different cultural backgrounds tend to advance their problem-solving skills, critical thinking, and other learning outcomes as well as the development of citizenship responsibilities. Undergraduates develop an appreciation and value for intercultural and racial relationships that are enhanced by their exposure to diversity experiences in the college classroom and through informal interactions with students from different ethnic/racial backgrounds. Antonio (2001) discovered that students who engage in interracial interactions are more likely to have gains in cultural awareness and leadership. Kuh (1993) found that throughout classroom experiences, students learn to appreciate their peers who have different racial, ethnic, and cultural backgrounds, which in turn aids in the development and cultivation of students' tolerance and ability to have better relationships despite cultural differences. In addition, Kuh found through data gathered with the National Survey of Student Engagement (NSSE) that students who have diversity experiences in college are more engaged students. Terenzini et al. (2001) also demonstrated the effect that structural diversity, the presence of racially and ethnically diverse students, has in the classroom in regard to student learning with their study of engineering students across seven different institutions participating in the Engineering Coalition of Schools for Excellence in Education and Leadership (ECSEL). The study showed a small yet significant gain in problem-solving and group skills where there is a presence of structural diversity in the classroom setting, specifically in those classrooms that had "medium diversity," where 33 to $38 \%$ of students enrolled were students of color, or at predominantly minority-serving institutions where 33 to $38 \%$ of the students enrolled were White students. 


\section{Student Identity Development and Diversity}

Ideally, there should be numerous opportunities on college campuses for students to explore and interact with others outside their cultural comfort zone and familiarity. The collegiate years are most likely the first time that students are exposed to a great number of different cultures and people. Students are at a stage in their identity development where it is possible to engage in positive exploration of otherness. Developmental theorist Gordon Allport (1954) stated that each person develops his or her own self-identity. Students adapt to their environment through their experiences. When discussing the nature of self-identity development and the stages that occur in young adulthood, Allport stated that a person's prejudices and ideas about others "are acquired chiefly in fulfillment of his own needs. Yet the context of his learning is always the social structure in which his personality develops" (p. 324). Colleges can develop the social structure that consciously includes a critical mass of and exposure to diverse people, ideologies, and cultures. But without a critical mass of diverse students successfully matriculating through college, the probability of this exposure and the potential for positive developmental growth is drastically decreased.

Allport's theory on identity development is consistent with other developmental psychologists' ideas of disequilibrium (Piaget, 1971) and periods of psychosocial moratorium (Erikson, 1950), where the opportunity presents itself for positive interactions promoting diversity and a break from the homogenous upbringing students come into college knowing and living. College students' identity development is shaped by their environment and home culture, and they carry that identity with them when they come to campus. A more recent theory specifically about the psychosocial identity development of African-Americans is the Model of Psychological Nigrescence. Cross (1995) stated: 
Nigrescence is not a process for mapping the socialization of children, it is a model that explains how assimilated as well as deracinated, deculturalized, or miseducated Black adults are transformed, by a series of circumstances and events, into persons who are more Black or Afrocentrically aligned (p. 98).

In a revision to the original theory from 1971, Cross discussed the first stage, preencounter, as a "resocialization experience” (Cross, 1995, p.97) for African-Americans. Blacks' primary identity prior to this point in their lives falls on a spectrum of attitudes about race in relations to their identity to either have a low salience for Blackness or host severe anti-Black attitudes due to miseducation and Eurocentric socialization; their primary identity is on other identity affiliations not connected to Blackness.

The Encounter stage induces a metamorphosis for Black individuals where there are multiple events that expose them to challenges in their understanding and belief system in regards to Blackness that eventually is shattered over a period of time and events. These are “eye-opening episodes" (p. 105) that have an initially confusing and possibly a depressing effect on the individual. Cross stated that individuals experiencing this stage are "generally very quiet, but internally a storm is brewing" (p. 105). An overwhelming amount of emotional anxiety catapults these individuals into confronting their former ideology about Blackness, a hatred and disgust for White people and dominant culture results in an obsessive desire to become the "right kind of Black person" (p. 105).

The most intensive stage, where Black individuals explore Black culture in its entirety to exhaustion/obsessiveness and later move to a more stable, healthier understanding and engagement with Black culture is the Immersion-Emersion stage. Based on the individual's experience in this stage, Cross pointed out that it can lead to many outcomes: regression back to 
pre-encounter beliefs and practices, fixation on all things Black at an intense level, or stagnation (p. 111-112). Cross posited that Blacks can "move in and out of oppressive Black situations or who have greater access to insights that point to more progressive attitudes" (p. 112). These include college students, middle class Blacks, Black scholars, and others who have some form of social and economic mobility. They are less likely to remain in a fixation transitional stage where hatred for Whites and White culture is extremely intense and move on to the next stage of Internalization.

Internalization, the fourth stage, comes after the transitional stage and presents Black individuals as resolved in the acceptance of their Blackness as an internalized identity in their everyday affairs and as one of many saliencies where the level of importance of their Blackness varies based on other identities and the importance they play in the individual's world. Cross explicitly stated that Blackness, regardless of the intensity or level of importance it has in an individual's identity once internalized, serves three functions:

(a) to defend the person from negative psychological stress resulting from having to live in a society that, at times, can be very racist;

(b) to provide a sense of purpose, meaning, and affiliation; and

(c) to provide psychological mechanisms that facilitate social intercourse with people, cultures, and human situations located outside the boundaries of Blackness. (p.117)

For students who enroll in college, their higher education experiences can provide an environment where Black identity is awakened, challenged, and developed by positive and negative events and circumstances. College campuses enrolling Black students and other racial and ethnic minorities can create environments and activities that enhance the campus climate and environments to promote their success and positive identity development. 
College is the time when students go through an exploratory stage and can "provide many students with an opportunity to experiment with new ideas, new relationships, and new roles" (Gurin, Dey, Hurtado, \& Gurin, 2002, p. 335). A diverse experience in college becomes a way for students to engage and work through times of disequilibrium or moratorium and transition to a new appreciation for different perspectives and an elevated level of processing and thinking. An institution that successfully recruits and retains a diverse student body can help all who identify within the community gain a new appreciation for different perspectives. Promoting opportunities to interact with Black males adds to the level of diversity and an increased likelihood of advancing an appreciation of their perspectives on the college campus.

\section{Theories of and Reasons for College Student Departure}

All students entering college need to feel a sense of connectedness to the institution in order to overcome psychological and social barriers that potentially impede their academic and overall success and likelihood to persist through graduation. Several theories and models developed by researchers reveal the aspects, reasons, and patterns of successful progression through college and also reasons for student attrition (Tinto, 1993; Bean \& Eaton, 2000). These theories are based on organizational, psychological, and sociological orientations. With any theory, there are shortcomings because the human experience is very individualistic and complex and directly understanding the relationships between institutional characteristics and individual student factors requires ongoing analysis (Braxton \& Breir, 1989; Braxton, Hirschy, \& McClendon, 2004). All college students make adjustments as they develop their identity and integrate into their respective institutional culture. Precollege factors along with institutional factors have a great affect on the outcome of student persistence. When students do not achieve 
sufficient levels of integration and congruence with the college environment, the outcome is most likely departure prior to completion of educational objectives and obtainment of a degree.

Interactional theory of departure. Tinto (1993) specifically focused on the effect and degree of successful levels of social and academic integration as a direct relationship to student commitment to graduation and commitment to the institution in his Interactional Theory of Departure. He stated that the greater the integration the more likely the student will persist, because the level of commitment to completion and commitment to the institution itself is higher. His theory has addressed the external and internal factors that can affect departure for students and holds a sociological foundation. External factors like financial situation upon entering college, family background, work experience, and home community and culture have been identified as influencing departure for students and effecting students' initial commitment to persist. Internal factors such as belief in one's ability, confidence, self-efficacy, and selfesteem influenced students' persistence over time. Tinto believed that students must go through a rite of passage; a process of separation from home social systems, then transition into accepting and successfully acquiring the norms, values, and culture of the college environment, to finally be incorporated into the social and academic norms of the institution system. When students are successfully incorporated, there is a greater commitment to persist.

Braxton, Sullivan, \& Johnson's (1997) review of Tinto's theory provided evidence of a stronger empirical relationships among students' initial commitments to the institution, commitments to the goal of graduation, and with levels of social integration, than a stronger empirical relationship to their level of academic integration. Although Tinto's Interactional Theory has dominated most of the retention/departure research for 30 years, overall empirical testing of Tinto's theory has left much for scholars to discover and confirm validity when 
applying his theory to diverse university settings (i.e. residential colleges, liberal arts colleges, commuter colleges, and two-year institutions) and diverse student populations (i.e. adult learners, students of color, commuter students, differently abled students). In regard to residential colleges and universities, Braxton, Hirschy, \& McClendon (2004, p. 21-22) improved upon Tinto's theory by identifying six factors that have influenced social integration at these particular types of institutions: (a) commitment of the institution to student welfare; (b) institutional integrity; (c) communal potential; (d) proactive social adjustment; (e) psychological engagement; and (f) ability to pay. A synthesis of the body of literature related to these factors and Tinto's theory has shown the greater the student satisfaction with all six factors, the greater degree of social integration. Braxton, Hirschy, \& McClendon (2004, p. 28-29) also concluded several conceptual orientations that underlie the six influencers of departure including economic orientation (undergirds ability to pay), organizational orientation (undergirds commitment of the institution to student welfare and institutional integrity), psychological orientation (undergirds proactive social adjustment and psychological engagement), and sociological orientation (undergirds communal potential).

Braxton, Hirschy, \& McClendon (2004) noted a specific issue with students of color at PWIs in regard to ability to pay and their communal potential. They stated that most students of color had a higher sensitivity to the cost for college. They further concluded that the process of successful connection to a particular sub-community within the environment with an affinity to their similar values and beliefs was more difficult to navigate and discover at PWIs, considering the likelihood that the sub-community did not have a dominant status in the social community at the institution. Students of color seeking other students of color will have to be proactive in their 
efforts to maintain social connections with other students of color on campus where they are a numerical minority as well as a racial minority.

Financial aid and family support. Studies that considered the influence of financial aid on persistence make possible links to this factor attributing to Black undergraduate men and other underserved students' low retention at PWIs (Murdock, 1990; Perna, 1998). The cost of attending college has continued to increase and can be a barrier for students based on the level (two-year institution vs. four-year institution) and type (public vs. private) of postsecondary education they choose. Apparent and hidden costs associated with postsecondary education makes federal financial aid in the form of grants and loans a resource used and necessary to subsidize the cost of higher education for lower income students and historically underserved students of color (Kim, 2004). NCES (2006) found that Blacks received the highest amounts of total aid (including federal grants and loans) of all student populations by race/ethnicity — $89 \%$ of those pursuing higher education. Although not an isolated reason for departure, the affordability factor of higher education cannot be ignored when identifying reasons for early departure. Without resources to maintain enrollment status, some Black men are left with no choice but to withdraw.

Family assistance, both financial and moral, can contribute to college success. Few studies have explored this relationship specific to Black males, but it is believed that parental involvement in the college decision-making process increases the likelihood that Blacks choose to attend college (Cabrera \& LaNasa, 2000; Horn, 1998; Hossler, Schmit \& Vesper, 1999; Hossler, Braxton \& Cooper-Smith, 1989; Perna, 2000). Beyond the college decision-making process, there is support provided by families of Black men that help to boost their confidence and self-efficacy while they are enrolled. A challenge for some undergraduate Black males is 
balancing family responsibilities (i.e. helping out financially, staying in consistent contact while away at school, or helping to raise younger family members) that require them to juggle the collegiate life plus the external demands placed on them from members of their family support structure. These demands can impede their involvement and their engagement with the college environment.

Academic preparation. Some researchers have found Black undergraduate men underprepared for the academic rigor of college and the social atmosphere of PWIs, which affects their level of success (Tinto, 1993). Academic preparedness is one of the main predictors of college success. Moreover research has shown that the experience of Black male students in the public school system has a profound effect on their ability to succeed in college (Schott Foundation for Public Education, 2006). In reviewing NCES (2006) persistence indicators, Blacks had a higher percentage rate of expulsion and suspension from public schools than any other race/ethnicity. A disproportionate number of Blacks have been retained in primary and secondary schools, and Black males in particular accounted for a high number of the reported percentage. Researchers found high numbers of Black males in the P-12 pipeline take remedial or developmental courses. These experiences can contribute to the lack of preparation, low selfefficacy, low self-esteem, and are probable reasons for the attrition rate and lack of success in retaining Black undergraduate males.

Issues with biculturalism. An additional task for minorities that further complicates their adjustment is managing and maintaining their home culture and values while managing the adjustment into the predominantly White college environment. Biculturalism (Rendón, Jalomo, \& Nora, 2000) for students of color is a conflict that could impede the process of full incorporation into the college environment. According to Tinto's theory (1993), the rite of 
passage from home social systems into the college culture is necessary for full commitment to the institution and to the goal of graduation. Rendón et al. (2000) noted that Tinto's theory emphasized the individual's responsibility to adjust and not the institution's responsibility to the student in the adjustment process. Tinto's theory did not clearly take into account the institution's role for student success and did not take into consideration the different experience that racial and ethnic minority students have transitioning into the culture of PWIs that could exacerbate the departure decision.

Rendón et al. (2000) stated that Blacks and other students of color commonly experience biculturation. The concept of biculturation originated from Valentine (1971), described as Blacks being able to socialize simultaneously into two different cultures; it is the "ability of a minority individual to step in and out of the repertoires of two cultures that were seen as distinct and separate" (Rendón et al., 2000, p. 134). When applied to students of color in college, these students must learn to live and be a part of their PWI's culture while they maintain the identities, values, and home culture they bring to college, which are not always in total alignment with the values and customs of their institutional culture; these students live in two realities. Some Black students can perceive their institutions as not providing adequate services and safe campus environments. They experience a consistent level of hostility, mistrust of individual and institutional intent and perceive a lack of concern for their success (Sedlacek, 1987).

Sources of motivation. There is little consideration for what Guiffrida (2006) deemed significant differences between the motivational orientation of White students and students of color for attending and succeeding in college (p. 453). Guiffrida stated that Tinto's model "was intended to describe developmental progression within a culture rather than assimilation from one culture to another" and "minority students' cultural backgrounds often differ from the 
Eurocentric frameworks upon which the norms and values at predominantly White institutions (PWIs) are based" (p. 451). Guiffrida further argued that Tinto's theory, being based on commitment to the institution, academic goals, and graduation, "fails to provide an understanding of student's motivational orientation" (p. 452). A student's proclivity in motivational orientation can be intrinsic, "learning because one finds the content interesting" (Guffrida, 2006 p. 453), or extrinsic, "learning as a means to an end" (Guffrida, 2006 p. 453), and based on differing cultural norms that pride individualism versus collectivism and competition versus cooperation.

Research has recently begun to examine revisions to Tinto's theory towards a more culturally sensitive and advanced theory that takes into consideration how motivational orientation affects commitment and persistence. Many minority cultures overwhelmingly favor a proclivity towards cooperation and collectivism that potentially conflicts with the individualistic and competitive culture and values that are promoted in Eurocentric PWIs. This cultural norm, along with other issues faced by students of color can lead to increased difficulty in their adjustment. More research is required to understand how motivation and social systems affect persistence in addition to students' social and academic commitment to the institution and graduation.

Psychological model for college student retention. Bean \& Eaton (2000) proposed a psychological approach to theorizing student retention and causes of departure as opposed to Tinto’s (1993) sociological approach. The authors have stated that there are individual psychological factors affecting the retention (successful academic and social integration) of students and the decision to stay or leave an institution. Retention is based on the students' attitude toward the institution, the coping strategies and skills they possess to overcome stresses 
and challenges associated with the transition and integration, and their personal belief about their locus of control: internal or external. Students with an internal locus of control believe their ability to adapt, integrate, and succeed in college is dependent on their own actions that lead to successes and failures. Students who operate with an external locus of control believe that their success is based on fate or chance (Bean \& Eaton, 2000, p. 77).

Individual students are shaped by psychological factors that develop through their precollege experiences. Pre-college experiences influence students' beliefs about their self-efficacy (assessment of their own confidence to academically achieve and socially adapt to college) and their normative beliefs (contrived from the ideas and values of important figures like parents). Their past behaviors and attitudes that they operate from when working to academically and socially adjust to an institution are also included in their pre-college experiences. Experiences in the college environment that produce positive psychological outcomes increase the likelihood that a student will be able to properly adjust to an institution by achieving academic success and social integration, feeling a sense of belonging at the institution, and subsequently forming positive attitudes about the institution that lead to retention. How well the pre-college experiences prepare or complement the adjustments necessary for student success in college, may well determine the outcome of successful integration to the new environment.

Rodgers and Summers (2008) have examined Bean and Eaton's (2000) psychological theory of departure specifically on how it correlates to the African-American collegiate experience at PWIs. In their revision of the model, they took into account how the race and culture of the Black students interact with the culture and environment of the PWI. They specifically addressed belongingness and integration of African-American students based on personal attitudes and perceptions of campus climate and social support from significant 
members of the PWI community (faculty, staff, and administration). They have asserted that retention models should consider the distinctive experiences Blacks have at PWIs and the effects of biculturation and ethnic identity when designing programs with the goal to increase positive development of this student population.

Black male student engagement. Lack of student engagement and involvement in both co-curricular activities and the classroom are other contributing factors to Black undergraduate men's failure to persist (Kuh, 2007). Research on student engagement has concluded that students who identify with student organizations, have structured engagement with faculty, participate in mentoring opportunities or leadership development opportunities have a higher probability to persist (Kuh, Cruce, Shoup, Kinzie, \& Gonyea, 2007). Without student organizations and leadership opportunities, student-faculty engagement opportunities, and what Kuh et al. (2007, p. 22) labeled "educationally purposeful activities," Black undergraduate men find themselves isolated on campus and more likely not connected to the institutional environment and the values that the institution holds as important and central to its mission and vision to prepare students for life after graduation. Subsequently, Black males like other unengaged students, will be more likely to depart college without a degree when they do not identify and connect on a significant level with the institutional culture.

Geometric model of student persistence and achievement. In a study focused on students of color attending PWIs, Swail, Redd, and Perna (2003) have identified the three major factors effecting the persistence and achievement, which they label the Geometric Model of Student Persistence and Achievement. This model posited that there are three major categories of factors - cognitive, social, and institutional — that influences the ability and success of student integration to their institution. Cognitive factors include the students' academic ability, 
knowledge, and their overall capacity of multiple intelligences. Social factors include the students' ability to effectively interact with others, personal attitudes, and cultural history. The third, institutional factors, is defined as policies, practices, programs, and initiatives enacted by the college or university exemplifying the culture of the institution that directly or indirectly impact the persistence and achievement of students (Swail, Redd, \& Perna, 2003, p.76-77). This theory is consistent with Tinto's theory (1993) and Bean and Eaton's (2000) psychological theory in that it balances both psychological and sociological factors that influence persistence and commitment to graduation and considers the addition of cognitive factors as well.

According to the framework, there must be a level of equilibrium independently achieved with all three factors (cognitive, institutional, and social) and the individual variables within each set of factor in order for a student to persist and achieve. Achievement of equilibrium and stability for students is an individualized process based on a student's overall needs, social and academic skills, cultural background, resources the student enters with and develops over time during his or her college career, and what the institution provides for students to adjust and make the relationship a good fit that leads to persistence. Too many negative variables within and between any of the given set of factors can cause disequilibrium and affect a student's likelihood to persist and achieve (Swail, Redd, \& Perna, 2003).

\section{Black Male Collegiate Experience}

Recent scholarly investigations have evaluated aspects of the collegiate experience of Blacks (Allen, 1992; Jones, 2001; Harper, 2006; Strayhorn \& Terrell, 2007), women (Hall \& Sandler, 1982; Kinzie, Umbach, Thomas, Kuh, \& Palmer, 2007), and other identified historically underserved student populations who enroll in institutions of higher education and have unique undergraduate experiences such as Asian-Americans (Tan, 1994; Lagdameo, Lee, Nguyen, 
Liang, Lee, Komdama, et al., 2002) and differently abled students (Beilke \&Yssel, 1999). The majority of these studies conclude that these groups are marginalized in academic and social settings on campus, which has negatively affected their pursuit for a college degree. Their collegiate experiences differ greatly from the more likely positive experiences of the dominant student population at PWIs, and their consistent ongoing negative experiences can lead to early departure.

Campus climate for Black males. Campus climate has been one of the four dimensions often cited as a major factor in the success of diversity initiatives (Smith, 1995; Hurtado, Milem, Clayton-Pedersen, \& Allen, 1999; Musil, et al., 1999). Campus climate as defined by Edgert (1994) "is a collage of the interpersonal and group dynamics that comprise the experience of participants in a collegiate setting” (p. 53). Edgert (1994) further discussed the importance of institutional self-assessment of campus climate, stating that it "influences student performance and the decisions students make about their educational and career options" (p. 53) which "may enhance institutional effectiveness and efficiency in terms of student flow measures such as retention and graduation rates" (p.54).

Campus climate is one factor, of many, that affects how students experience college. Hurtado et al. (1999) provided a holistic framework explaining the extent that campus climate affects the experience for all members of higher education, historically underrepresented students and majority White students. Their structural approach to dissecting the elements that influence climate specifically for a diverse campus community has included the institution's historical legacy for inclusionary or exclusionary practices, structural diversity of student, faculty, and staff, the psychological climate of the perceptions of racial tension, discrimination, and attitudes and prejudices, and the actual behavioral elements of interaction across race in the classroom and 
outside the classroom (p. 4). Hurtado et al. (1999) suggested the coordination of activities and support programs specifically for students of color are crucial to promote student success. They concluded that organizations such as Black Student Associations and similar groups aid in increasing students' of color social involvement, informal interactions with faculty and use of general support services (p. 77). PWIs have major challenges to address due to their historical exclusionary practices and racism that is pervasive in and out of the classroom. Despite attempts to implement services and programs that help to foster a healthy campus climate and promote healthy behavior between and among different people within the institutional community, there still is a dichotomy in the experiences of White students and historically underrepresented students that impinges on the persistence and achievement of the latter group.

Students of color perceive and experience racist attitudes and incidents on campus more than White students. Multiple quantitative studies surveying undergraduate students about their collegiate experience have found that Blacks hold the highest or one of the highest results when measuring negative campus racial environment or experience (Fischer, 2007; Rankin \& Reason, 2005; Suarez-Balcazar, Ornellana-Damacela, Portillo, Rowan, \& Andrews-Guillen, 2003). There are compounding factors that increase the likelihood that Black males experience a hostile and isolating campus climate that impedes their ability to succeed academically and achieve positive social adjustment to the environment which can increase the possibility for early departure.

Black undergraduate males leave college prior to obtaining their degree for numerous reasons. The issue of climate is affected by the embedded historically and traditionally exclusionary practices at PWIs and the level of diversity in student enrollment and faculty and staff. The perceptions of racial tension and discrimination and attitude of others towards Black undergraduate males, and the social interaction of Black males across race - in and outside of the 
classroom — can have lasting negative effects on the overall experience of Black undergraduate males at PWIs. These compounding issues of campus climate can cause Black males to struggle with completion of their degrees and subsequently may lead to early departure.

Institutional racism and negative stereotypes. Further potential reasons for high attrition include the perpetuated system of institutional racism and prejudicial acts of individual racism that Blacks experience inside and outside the classroom (Fleming, 1984; Allen, 1992; Fries-Britt \& Turner, 2001). Institutional racism is a term coined during the Civil Rights Movement of the 1960s by Black activist Stokely Carmichael and has since been studied by sociologists and other scholars as a social phenomenon affecting American culture. Academic leaders and others practice institutional racism when they question the legitimacy of allocating resources to retention initiatives, debate and resist institutionalizing these programs, and when they display overt or subtle opposition to the efforts for the institutional culture to accommodate a more equitable experience for all. In addition, some resistance to helping students of color might not be overt, and yet still may be perceived when there is no visible support for diversity within the mission and vision of the institution, its curriculum during times of change and reevaluation, or in the focus and voice of institutional leadership's priorities in strategic shortterm or long-term plans.

Prejudicial attitudes and discriminatory practices are embedded in the social and political structures of the United States, including our education system. As a result of the long-held systemic, inequitable practices and policies, underrepresented people of color are denied equitable rights and opportunities placing them at a disadvantage for achieving personal success and economic and social mobility. 
Harmful stereotypes perpetuated by the media and other avenues of communicating social norms to American society at-large can negatively influence the campus climate for Black males. These ongoing negative public persona imposed on society can affect Black males' selfperceptions about their abilities to succeed (Helms, 1990: Steele, 1997; Hrabowski, Maton, \& Greif, 1998; Fries-Britt \& Turner, 2001). As a result of the threat to living out this negative selffulfilling prophesy and consistent exposure to negative stereotypes, many Black males have a distinct amount of negative issues to overcome in addition to overcoming the expected stressors of adjusting to collegiate life that all undergraduate students experience. Black males on predominantly White campuses experience isolation and discrimination (Davis et al., 2004; Feagin, Vera, \& Imani, 1996; Allen, 1992; Wilson \& Banks, 1992; Loo \& Rolison, 1986). As Black males are repetitively exposed to racism and others' prejudicial attitudes, these students can internalize a significant number of negative stereotypes causing them to believe these inferior thoughts. Some Black men have a tendency to become psychologically disadvantaged and can possess distorted self-perceptions that have adverse effects on their academic performance (Freire, 1993). Without proper interventions, this potentially leaves a significant portion of the population more susceptible to departing institutions prior to graduation due to feeling overwhelmed by the necessary regiment needed to achieve overall college success and the task of managing the social constructs present at most PWIs.

\section{Retention Initiatives}

For the purposes of this research, retention initiatives are defined as organized institutional interventions in the form of programs and services to help increase the likelihood that students remain enrolled and persist toward graduation. Retention initiatives provide students with resources to make the necessary academic and social adjustments to succeed in the 
college environment. These programs and services help ensure student success, which Kuh, et al. (2007) defined as "academic achievement, engagement in educationally purposeful activities, satisfaction, acquisition of desired knowledge, skills, and competencies, persistence, and attainment of educational goals" (p. vii). There are a variety of models for retention initiatives based on the leadership and management of the institution. Retention programs are one of many ways that institutions create an atmosphere encouraging student success along with successful recruitment and satisfaction of qualified and engaging faculty.

Programs and services incorporated in retention initiatives are based on empirical research that identifies areas of student development and are found to improve the integration and adjustment of college students. They are also designed and supported based on the values and culture of an institution demonstrated by the resource allocations, institutional structure, and actual espoused institutional goals. Torres (2003) stated that retention programs "are more likely to work when they are seen as a vital part of the college mission" (p. 335). Many programs included in an institution's retention initiative incorporate peer and faculty mentoring programs; faculty-guided, undergraduate research opportunities; academic success programs that focus on advising, tutoring, and supplemental learning; and student support services that include leadership development, residential learning communities, student organizations, and multicultural programming. These services and programs help students navigate the options to engage and the opportunities that are available to them inside and outside of the classroom. Retention initiatives are best executed when the institutional structure supports a collaborative effort to bring these programs and services to the students.

Retention initiatives play a vital role in the successful academic and social adjustment that is necessary for persistence, especially for students of color. With structurally diverse 
campuses now more common, it is important to focus retention efforts on the minority student population in need of an inclusive campus environment for successful academic and social adjustments. Retention efforts are best executed as a concerted effort from the top administrators to the staff working directly with students. Torres (2003) clarified the importance of the collaborative effort, specifically for underrepresented students, stating, "institutions that truly wish to address diversity issues must see this [student success and retention] as a complex process that involves the entire institution" (p. 337).

The main purpose of retention initiatives has always been to help increase the level of persistence yet there is an overwhelming gap in the research regarding the effect that institutional retention programs have specifically on persistence. Patton, Morelon, Whitehead, and Hossler (2006) extensively reviewed over 100 articles from top-tier and second-tier higher education journals and found only 16 articles represented rigorous research that specifically focused on the effectiveness of campus retention programs on student persistence. They stated their most important finding from previous research studies was "the dearth of evidence to support the claims proffered on the efficacy of a wide range of campus-based retention initiatives" (p.10). They also concluded that there was a great need for institutions to assess the effectiveness of retention programs, noting that even the 16 articles reviewed in their study showed weak to moderate evidence of the retention programs' improvement on student retention rates and their likelihood to persist.

Braxton, Brier, and Steele (2008) synthesized previous research to provide guidelines improving professional practice of retention initiatives. Reducing departure of students was a goal shared by many functioning divisions of the institution. Specifically they suggested "institutions need to demonstrate respect for students as individuals, being sensitive to their 
needs and concerns" (p. 381) and "practice institutional integrity by assuring the congruence of institutional actions with the goals and values espoused by the institution" (p. 387) and concluded that "no single domain of a college or university bears responsibility for reducing student departure" (p. 393). An institutional effort is necessary to retain students of color that calls on faculty and administrators collectively to devise a framework that ensures consistent improvement of programs designed to improve the academic and social adjustment for students of color.

The use of a framework establishes institutional principles for retention practices, and specific program objectives that are necessary in formalizing systematic assessment of retention initiatives (Braxton, Brier, \& Steele, 2008; Harris, 1991; Tinto, 1993; Wang, 2001). Although the recommendation for regular, systematic assessment is consistently noted as necessary, the specific assessment and evaluation practices of retention initiatives at PWIs for students of color has not been well examined (Harris, 1991).

Swail, Redd, and Perna (2003) identified the following five categories for institutions to focus resources and programs: (1) student services; (2) academic services; (3) curriculum and instruction; (4) recruitment and admissions; and (5) financial aid. Each of these categories is further broken down into specific objectives that are essential to the successful implementation of a systemic program to retain students of color regardless of their specific academic focus. The retention framework keeps students at the center of the model by emphasizing the need for an established and consistent student monitoring system. Examining the student experience is crucial to assess the achievement of intended outcomes. Swail et al. (2003) further expressed a need for institutional leadership to show commitment to the program to ensure institutionalization, to give ownership of the retention efforts to faculty and administrators 
actively working with the students, and to provide the necessary resources to develop and successfully carry out the initiative (p. 114-115). This research-based framework was later expanded from a focus on retaining engineering and science students of color to campus-wide minority retention programs.

Swail, Redd, and Perna's (2003) Geometric Model of Student Persistence and Achievement served a significant role in the primary conceptual framework for this research (see figure 1). The comprehensive model assists in the successful execution of a campus diversity initiative and keeps the student experience, (in this study specifically the Black male student experience) as the central focus. The overall purpose of a campus diversity initiative is to successfully achieve all levels of diversity (structural, interactional, and classroom diversity). This begins with successful retention of diverse students. A retention initiative must combat the issues of negative campus climate and promote and increase the access and success of historically underserved student populations. A retention program specifically designed to increase the success and graduation of Black males takes into consideration the cognitive, social, and institutional factors affecting their success and plays an important role in the entire campus diversity initiative.

\section{Conceptual Framework}

The conceptual framework used in this study synthesizes the idea of campus diversity initiatives, types of diversity, the Geometric Model for Student Persistence and Achievement (with a specific focus on institutional factors) and how these elements affect the development of a Black male retention initiative. My framework includes the four areas of focus in a successful campus diversity initiative that Musil, et al. (1999) identified as important components (representation/access and success, climate/intergroup relations, institutional 
mission/vitality/viability, and education/scholarship). All four areas of focus are necessary to achieve a successful campus diversity initiative and the ultimate goal of promoting systemic structural, informal interactive, and classroom diversity.

Actions taken to achieve successful levels of representation and to increase the access and success of students of color are possible using the Geometric Model of Persistence and Achievement. The Swail et al. (2003) model is a way of achieving this major goal of campus diversity initiatives as well as a means of creating a safe and inviting campus climate that both welcomes and encourages intergroup relations. According to the conceptual framework guiding this study, there is an indirect relationship between the Geometric Model and healthy campus climate and intergroup relations.

The conceptual framework recognizes that cognitive and social factors affect the student experience at an institution and focuses on institutional factors: financial aid, recruitment and admission practices, academic services available, student services offered, and the curriculum and instruction structures at the institution. These institutional factors are identified as important to retaining students and helping their persistence and achievement and also serve as the checkpoints for administrators to base the student monitoring system. These institutional factors can be used to measure the success of the students engaged with the retention initiative. According to Swail, Redd, and Perna (2003), these are factors that Black male retention programs should consider incorporating in some form and on some level as part of their program. They are the institutional factors that should be considered when programs are designed and the factors that will determine whether students persist and achieve their educational objectives. 


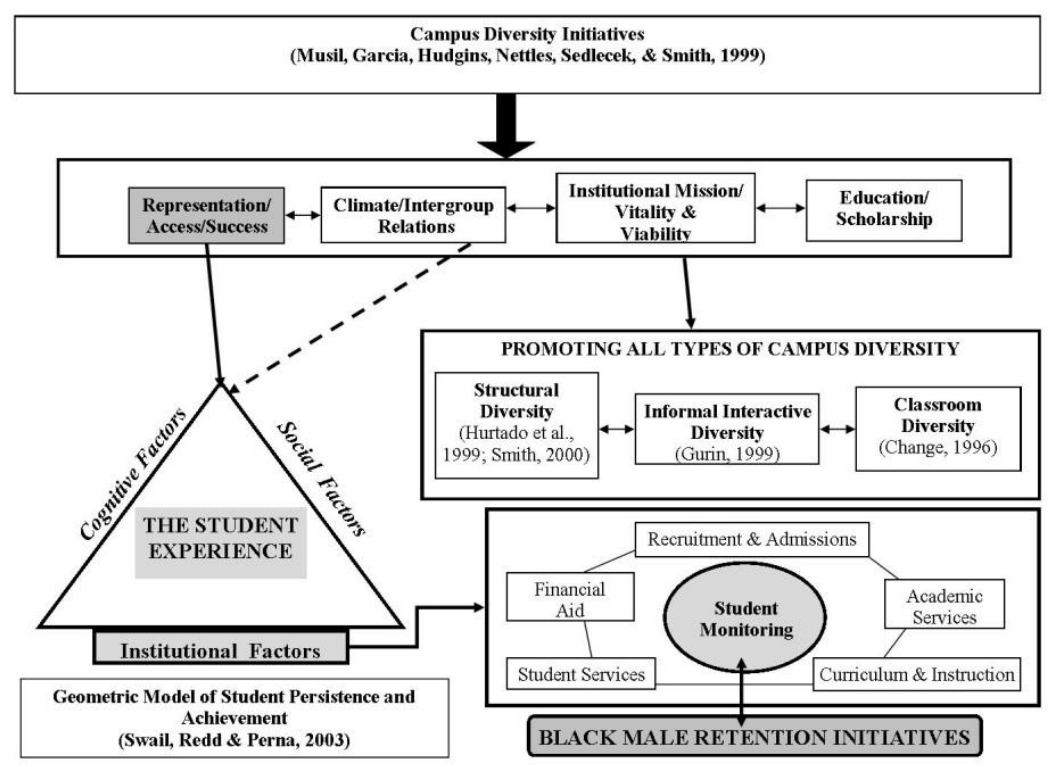

Figure 1. The conceptual framework guiding the study of Black male retention initiatives was derived from examining the relationship between the established four components of campus diversity initiatives as defined by Musil, et al. (1999), specifically representation/access/success component, and the institutional factors identified in Swail, Redd, and Perna (2003) in their the Geometric Model of Student Persistence and Achievement. The institutional factors of financial aid, student services, recruitment and admissions, academic services, and curriculum and instruction all affect the student experience at the core of the Geometric Model. The Black Male Retention Initiatives practice a Student Monitoring System to make sure the institutional factors that are identified as important are being regularly gauged and adjustments made to the exposure students have to these institutional factors.

My primary data measured student services, academic services, curriculum and instruction, recruitment and admissions, and financial aid identified by Swail, et al. (2003) as the 
institutional factors affecting achievement and persistence of students of color. This conceptual model guided this study with the understanding that "the complexity of the human condition makes it difficult to definitely prove the validity of one psychological or sociological model over another" (Swail, et al., 2003, p.iiv). The Geometric Model was created with students of color in mind and involves institutions as active and responsible participants in the success of the student, which helps the broader institutional goal of achieving a successful campus diversity initiative.

\section{Summary}

Traditional college environments at PWIs are not necessarily conducive to Black male undergraduate student success. Conventional programmatic initiatives that serve as institutional retention efforts have not been able to serve a critical mass of Black undergraduate men and keep them persisting toward graduation. These programs encounter challenges in reaching the goals of recruiting a diverse student body that creates the necessary structural diversity, engaging the students in intergroup relations and keeping those students matriculating successfully toward graduation. Research findings show that higher education leadership needs to better understand and relate directly to Black males if institutions sincerely value what this group brings to a diverse campus community (Lett \& Wright, 2003). These students need appropriate services to help them succeed in college and actively contribute to the learning process from the beginning of their academic programs through the completion of the degree. Institutions can provide students with supplemental tutoring or review sessions on course material, formal mentoring programs, and leadership development programs, as well as social outlets that are viable components to retention initiatives.

Retention initiatives are part of a broader mission to help create inclusive environments for marginalized, at-risk students and can help these students learn and reach social and 
academic goals. Retaining at-risk students is a priority for some institutions, which have made the commitment to dedicate significant resources to creating and implementing specific initiatives to retain their undergraduate Black males. Leaders at these proactive institutions can demonstrate their sincere commitment by developing programs and services that are specifically structured to help Black male undergraduates succeed. Such initiatives, when sustained over time, can have a positive effect on the lives of their students and the campus community.

There is no single correct formula for solving the issue of retention and assuring success for Black undergraduate males. While some institutions create programs and provide specific services to this population, other institutions struggling with retention issues can benefit from an exploration into universities with experience in designing and implementing retention initiatives. This investigation of leaders who have implemented these retention initiatives can yield meaningful insights to help Black males succeed at PWIs. 


\section{Chapter Three}

\section{Research Methods}

In this chapter, I present the rationale for and the details of the research design, including information pertaining to the case studies, sampling procedure, data collection, and analysis procedures that I employed in the study, and a descriptive summary of the pilot study. I conclude the chapter with an explanation of the study limitations. This study consisted of two major efforts. First, I formally examined how the retention initiatives' components and services were developed, evaluated, and assessed for impact upon Black males. Secondly, I examined the experience of Black male undergraduates (at predominantly White campuses) who participated in the initiative to determine what they gained and how involvement affected their development. In addition, I examined students' perceptions regarding how these programs enhanced their adjustment to college, overall success, and their persistence.

I designed the study to answer the question: "How do Black male retention initiatives affect college campus diversity initiatives and promote student development and success?" I explored the program structure of identified successful retention initiatives for Black undergraduate men at PWIs in a systematic investigation of how they were organized, including the major student outcomes they intended to achieve and the program components employed to accomplish those outcomes. Part of the initial study explored the assessment indicators used to determine program success, along with identifying effective evaluation practices. Assessment and evaluation practices were less prominent in the Northwestern State University case at the point of data collection and were not included in data analysis. This was different for the Southern State University case, where assessment and evaluation practices were prominent and informed the program leadership. 
The results of this study provided insights regarding successful program design and implementation that help in the process of institutionalizing a strategic approach to specific campus diversity and retention initiatives for Black undergraduate men at PWIs.

\section{Research Design}

According to Patton (2002), qualitative inquiry is a descriptive form of research that first seeks to explain a phenomenon based on specific questions asked of the phenomenon to make meaning. Qualitative inquiry is congruent with the constructivist paradigm where the researcher "works with categories and interpretations that are grounded in the data, analyze data through inductive means... and concerns themselves with the discovery of meaning” (Manning \& Stage, 2003 p. 21). Due to very few research studies that have investigated retention initiatives for Black males, an exploratory approach was necessary to understand this phenomenon of Black male retention initiatives with respect to campus diversity initiatives and student success and development. Several different approaches could have been used to gather the data and answer the research question, yet the main goal was to determine how administrators, leaders, and students make meaning and explain the phenomenon in as much depth as possible.

Qualitative inquiry employs measures for information-rich, in-depth analysis in order to produce as full and accurate a description as possible of the phenomenon under study (Patton, 2002). Qualitative inquiry relies heavily on the personal experiences, creditability, and the skill of the researcher in the field gathering, analyzing, and interpreting data. The researcher is the primary instrument and the lens that the data analysis process is carried through; therefore my point-of-view and personal experiences greatly influenced the study and the way the phenomenon is presented. The creditability of my portrayal of the participants' perceptions and 
the role that my biases and lens played in the trustworthiness of the research is examined later in the chapter under Researcher Identity and Issues of Trustworthiness.

Qualitative inquiry possesses unique characteristics and serves a specific purpose in research as "people-oriented” research (Patton, 2002). Qualitative inquiry focuses on:

(a) examining the closeness to the people and situation being studied in order to understand it in depth;

(b) capturing what is actually taking place and not predicting what could be possible, through direct observation of the phenomenon, analysis of related materials to the phenomenon, or questioning of participants; and

(c) collecting a great mass of firsthand, actual description from participants, activities, and all parts that makes up the whole experience (p. 27-28).

Patton (2002) further explained qualitative research as the best fit for methodology when research questions under study are:
About people's experiences; inquiry into the meanings people make of their experiences; studying a person in the context of her or his social/interpersonal environment; and research where not enough is known about the phenomenon for standardized instruments to have been developed (or even to be ready to be developed). (p. 33)

Extensive empirical research has yet to be conducted about specific retention initiatives for Black males, because specific retention initiatives for Black undergraduate males at PWIs are a relatively new phenomenon. There are still many PWIs that have yet to allocate institutional resources, financial and human, toward efforts to formalize programs and services with the 
specific mission and goal to retain Black males. I conducted this study to assist in understanding how these retention initiatives are developed and situated within an institution, and also to explore how participants experience the services and programs offered.

Case study method. I used two information-rich case studies in order to analyze the phenomenon of retention initiatives specifically designed for Black males. Yin (2003) stated, "the first and most important condition for differentiating among various research strategies is to identify the type of research questions being asked" (p.7). "How do Black male retention initiatives affect college campus diversity initiatives and promote student development and success?" is a question that can be answered through case study method. Yin (2003) stated that "'how' and 'why' questions are more explanatory and likely to lead to the use of case studies...This is because such questions deal with operational links needing to be traced over time, rather than mere frequencies or incidences" (p. 6). Case study method is used when examining or exploring a contemporary phenomenon to help explain aspects of it in relation to theory and/or practice. Case study method is used when the researcher has little control over the phenomenon or lacks the opportunity to manipulate it.

I relied on gathering data from events and people involved through interviews and document analysis at each institution, which included a web-based query on each case. Student focus groups and individual, semi-structured interviews with students and administrators were used to collect data; this allowed for data triangulation. These data also provided me a full description for the cases chosen. The two institutions were chosen as cases, demonstrating a level of stability and signs of movement toward institutionalizing based on their longevity and institutional support for their success. Using a two-case study design and intensity sampling, the sites selected for the study represented information-rich cases. Each case study was focused not 
only on the development, implementation, and evaluation and assessment of the program, but also included analysis of the participating Black male undergraduates' experiences. The initiatives' effects on the males' adjustment and collegiate success were an embedded layer of analysis. Each case is discussed in a separate chapter where I present the individual institutional experience. I also wrote a cross-case analysis of the two institutions, providing a richer presentation of Black male retention initiatives and major findings about the phenomenon found in the two cases.

Review of the findings will help institutions that are concerned with improving their retention of Black males and plan to either initiate institutional action to change the negative pattern of attrition or to make improvements to current initiatives. Patton (2002) promoted that “detailed case studies can be even more important when evaluating outcomes attainment for program improvement" and "getting into case details better illuminates what worked and didn't work along the journey to outcomes" (p.152).

\section{Research Sample}

According to Yin (2003), conducting at least two cases for a multi-case design can increase the strength of external validity surrounding the findings. Although it was not my primary goal to increase the probability of direct replication and to increase the external generalizability of this research, two cases were selected for this study. The primary goal in this study was to provide an exploratory multi-case study. I used a conceptual framework developed from the literature review as a guide when analyzing how these established initiatives develop within an institutional context, and how the Black male undergraduates experience the initiative and its effect on their matriculation through college. Any generalizations that can be drawn from this study would be considered theoretical or analytical versus statistical (Yin, 2003, p.10). 
Criteria for site selection. Purposeful sampling was used to select information-rich cases. Using this form of sampling, "one can learn a great deal about issues of central importance to the purpose of the inquiry" (Patton, 2002, p. 230). Specifically, I used intensity sampling to select the cases. Cases chosen using this sampling method were rich examples that display "sufficient intensity to illuminate the nature of success or failure, but not at the extreme" (Patton, 2002, p. 234). Considerable study of the phenomenon and relationship-building with leaders of the initiatives were necessary prior to deciding on cases that fulfill the criteria as informationrich, yet not extreme cases that successfully yield a full exploration of the research question.

The cases chosen for this study met several specific criteria in order to increase the richness of the information gathered from data collection and analysis. Each case first fit the criteria of a PWI that hosts a retention initiative for Black males on their campus. The introduction of the initiative to the PWI was institutionally driven, meaning institutional leaders and administrators, not students, initiated the creation of the retention initiative. Institutional initiation ensures a level of support and a process to allocate resources, both human and financial, toward the initiative that can be reviewed and analyzed. As demonstrated in the pilot study, where the university did not meet the criteria of being institutionally driven, not having the institutional support created a dynamic of anxiety and concern about the future funding for and support of the initiative from the administrative leaders interviewed. The two cases had at least one full-time staff member with the majority ( $70 \%$ or more) of their responsibilities focused on managing, developing, and implementing the initiative. The initiatives chosen as cases for this research specifically stated their mission was to retain Black males and improve their campus experience and likelihood to graduate. The initiatives were in operation at the institution for at least three years at the time of data collection to help increase the likelihood: (1) that contextual 
information in the form of documentation (i.e. recruitment material and media materials, annual reports, evaluations, action plans, critical correspondences, strategic plans, and other written documents) were available for document analysis; (2) that a sufficient number of freshmen and upper classmen have had the opportunity to interact with the initiatives; and (3) that the development and growth of internal and external partnerships and iterations of adjustments and revisions to program components were able to be included in the study.

Based on the latest Carnegie Classification of Institutions of Higher Education (2005), the institutional sites in this study were classified as public controlled, four-year institutions with a high undergraduate enrollment profile. They had a full-time undergraduate profile ranking where at least $80 \%$ of the undergraduates attended as full-time students. These parameters helped to maximize the number of Black male undergraduates available for participation in the retention initiative and subsequently in the research study. Choosing PWIs that have the Carnegie Classification of public controlled, four-year institutions with a high undergraduate enrollment profile and with at least $80 \%$ attendance as full-time students was a delimitation that I placed on the study. This study did not set out to explore the participants' experiences at other types of institutions. The goal was to identify two institutions within the delimitations placed on the study that fulfilled all the specific institutional category classifications, the criteria and characteristics of Black male retention initiative under examination, and where I could gain the most access for data collection.

After an extensive review of four-year, public controlled institutions with high undergraduate enrollment profiles, two institutions met all the criteria for site selection along with providing me with access for data collection. Northwestern State University and Southern 
State University ${ }^{1}$ were the case studies examined in this multi-case, qualitative research study. Based on 2007 data from NCES I received through personal communication with the staff (July, 2009) and requested from their most updated database, Northwestern State University campus had a total of approximately 1,900 Black undergraduate students where 900 were male students. Southern State University had an approximate total of 3,400 Black undergraduate students with 1,500 being male. The number of the Black males enrolled at the institutions did not reflect the actual numbers who were actively participating in a moderate to high level of engagement with the retention initiative; that number of active students was smaller than the total population of Black male students. Neither institution were able to supply me with the exact number of Black male students who had engaged in the initiative over the years of its existence, which was an early indication of a lack of systematized evaluation and assessment practices.

Gaining access to case sites. Several, preliminary, face-to-face meetings and phone conversations with staff members of the initiative at each institution helped me gain access to influential informants. My work partnering with the initiative as a student affairs administrator at one of the case sites also assisted in gaining trust with the staff at that particular institution. I also attended conference sessions where both institutions' staff presented on each of the initiatives, and I contributed to their discussion sessions about Black male retention to earn creditability and trust of the staff as a serious researcher of the topic. I worked to build these connections and relationships over a course of several years prior to sending out the formal request to use the two initiatives as case sites.

I had to overcome the main concern the staff had about honoring the students' individual stories and being sensitive to tell the accurate and full story of the initiatives. At one case site I

\footnotetext{
${ }^{1}$ Pseudonyms are being used for institutions and individuals.
} 
recall the conversation that solidified their trust in me. At Northwestern State University, the staff member explained to me the purpose of their book series on race and male identity development and shared some of the experiences the students had on campus with racism and the campus police after reading one of the books. He noted my excitement that critical texts had a noticeable effect on how students responded to the campus police and that the book series meeting became a place where students shared their introspective thoughts to being harassed by police with other students and the staff. Sharing this incident with me during his explanation of what the retention initiative provided for students opened him up to understand the type of student experiences and development that I anticipated would be highlighted with my research. I was able to share with him my rationale for conducting the research and information about my two brothers and their experiences. We related to each other as social science researchers, sharing our interests. He concluded at the end of the call that he would assist me in gaining access to students for my research because he believed that I would listen to the students and provide a fair analysis of the data I collected.

My professional record as a student affairs administrator working to develop Black male retention programs and presenting on the topic at regional and national student affairs personnel conferences helped me gain creditability. The formal requests were sent and approval was granted once I gained trust and a positive rapport with the staff. An invitation to participate in the study was given to the appropriate academic leader of the institution (see Appendix A) for official institutional support, and I provided a template of the institutional approval letter used to document their support of the study (see Appendix B) to West Virginia University's Institutional Research Board. 


\section{Research Design Overview}

This section of the chapter provides an overview of the research, including the data collection methods for the case study design, and how faculty, administrators, and students were chosen and contacted to volunteer for the study. Various methods of data collection and data sources were used to increase the accuracy and credibility of findings. For the purpose of having strong triangulation of data, the data collected for this study included focus group interviews of participating Black male undergraduates; semi-structured, open-ended interviews with identified individual student participants, administrators, institutional leaders, and faculty who developed the retention initiatives; and analysis of relevant documentation, including web-based materials, for each case study site. This section outlines the process for all three methods of data collection.

Bloomberg and Volpe (2008) stated that contextual, demographic, perceptual, and theoretical data are relevant in qualitative data collection. These four types of data are necessary in order to produce a full understanding of the phenomenon under study. Theoretical data explain what has already been discovered and researched about the topic under study and provides the theories and concepts related to the topic. In the process of analyzing data, theoretical information provides the support for interpretation, synthesis, conclusions, and subsequent recommendations that are made (Bloomberg \& Volpe, 2008, p. 71). Theoretical information has been extensively covered in the review of literature presented in the preceding chapter. A review of the theories of college departure, student engagement, student retention, development and execution of diversity initiatives, campus climate, as well as previous research on the experience Black male undergraduates at PWIs have helped to shape the protocol for interviews and the analytical questions created to analyze the data and conclude findings. The other three relevant forms of data are discussed in more detail in this chapter. 
Contextual data. Contextual data "describes the culture and environment of the setting, be it an organization or an institution" (Bloomberg \& Volpe, 2008, p. 70). Contextual data on an organization were collected through document analysis and also when I directly engaged with aspects of the phenomenon. An extensive review of descriptive and/or evaluative internal and external documents is a common method for collecting the necessary contextual data needed to understand the culture and environment that influences the behavior or phenomenon chosen for study. An extensive document analysis at each case site was one of the three methods used in this study to collect contextual data about the institution. Contextual data were focused on the culture of the institution, the campus climate, diversity initiatives, Black male retention initiatives, and the characteristics of the individuals involved. My observational field notes created while on-site at both Northwestern State and Southern State assisted me as I described the environment and culture of each case. Interviewer notes taken during the interviews and focus groups also assisted me in gathering contextual data helping me describe the context in which these two initiatives exist.

Demographic data. I collected demographic data to understand possible interactions of individual participants with the environment. Having information of age, ethnicity, background, and educational experiences of the participants helped to explain findings that emerged. This information was typically collected using a data sheet that each participant filled out either before or after their interview or focus group or by directly asking participants during their interviews and focus groups (Bloomberg \& Volpe, 2008). I administered a demographic questionnaire to student participants prior to engaging in the focus groups and individual student interviews (see Appendix C). I also asked administrators and faculty participants several questions about their careers in higher education during their interviews that could help me 
explain findings that emerged from the data they provided. I used both forms of collecting demographic information — survey and interview questions, —in this study.

Perceptual data. According to Bloomberg and Volpe (2008), perceptual data is the most important form of information collected in qualitative research. Perceptions are not facts, yet supply participants' understanding and interaction with the phenomenon under study to the extent that this information is what the participants view as factual. Interviews and focus groups are used to capture participants' perceptions in regard to:

- How experiences influenced the decisions they made;

- Whether participants had a change of mind or shift in attitude;

- Whether participants described more of a constancy of purpose;

- What elements relative to their objectives participants perceived as important; and

- To what extent those objectives were met. (Bloomberg \& Volpe, p.70)

I used both focus groups and semi-structured interviews as opportunities for me to capture the perceptions of both the administrators and university leaders involved with the retention initiative and the Black male undergraduate students who take advantage of the programs and services.

Black male student focus groups. I conducted focus group interviews of Black male undergraduates who were active participants in the retention initiatives. Kelly (2003) defined focus groups as "designed to elicit perceptions, information, attitudes and ideas from a group in which each participant possesses experience with the phenomenon under study" (p.50). Since students are discussing ideas in a group setting, it creates a safe environment for sharing personal information and experiences and having in-depth and open conversations. The participants were selected based on their experiences and level of engagement with the retention initiative at their 
respective institutions, therefore making them the most informed individuals to address questions designed to help provide a full case narrative. My focus group setting encouraged participants closest to the phenomenon to express their thoughts and personal understanding, while being challenged and supported by others who have gone through similar experiences. They were able to draw on each other's responses in providing a full personal account about their college experiences.

Facilitators of focus groups draw on the interaction between participants that develops surrounding the research topic, on the individuals' strengths when showing commitment to their views, and the subtleties in expression that help to develop the fullness of the particular samples' experience with the phenomenon. When similarities and differences are discovered in focus group discussions, researchers gain a greater understanding of the phenomenon being studied. The final protocol constructed for the focus group data collection is included in the appendix (see Appendix D).

Sampling procedure for focus group interviews. I contacted the appropriate academic administrators charged with managing the initiatives and requested them to nominate and contact the Black undergraduate males who met the participant criteria. Soliciting undergraduate males with moderate to high participation in the retention initiative for the study yielded descriptive information about the phenomenon that only active participants could provide. According to Patton (2002), "Information-rich cases are those from which one can learn a great deal about issues of central importance to the purpose of the inquiry, thus the term purposeful sampling" (p. 230).

Black undergraduate males who met the following criteria of information-rich participants served as part of the sample: 
(a) Self-identify as Black;

(b) Identified by the administrators charged with running the program as participants with moderate to high engagement with the retention initiative at their respective institution;

(c) Classified as freshmen, sophomore, juniors, or seniors (or a similar sequential undergraduate ranking system);

(d) Full-time student status; and

(e) At least 18 years of age.

These criteria were shared with the institutional liaisons who assisted me at each university. I relied on the liaisons to send out the request for student volunteers to participate. The level of interest from the active Black male undergraduates at both institutions was high because the liaisons were staff members with direct responsibility to the initiative and had a high level of contact and trust with the students. I borrowed the staff's credibility to assist in securing a high number of student participants.

At Northwestern State University, the liaison and his student staff handled setting up the student focus group times after strategizing with me what times in the students' schedules would provide the best turnout. He then emailed me the room, focus group times, and contact information for each student, allowing me to follow up with email reminders and confirmations. At Southern State University, I was able to provide the liaison with my on-campus interview times prior to traveling to campus, and he confirmed the blocked schedule and the interview room. Students were given my contact information via email and were asked to communicate directly with me to set up their focus group times. I checked in with him letting him know when students scheduled with a focus group to keep track of follow-up. He then followed up with the 
non-responsive students who were receiving the email announcement and reminders to volunteer for the study.

Both liaisons used the IRB-approved, student invitation script I provided for the initial request to participate. It was sent via email to each potential participant requesting them to volunteer for the student focus groups at scheduled times that were found to be the most opportune based on their campus activities. Both institutions sent out the formal, approved invitation to participate in the study to all Black male students on their email list who receive regular updates about the initiative. Both institutions assured me that the young men on their email list were active and viable participants.

Taking into consideration the involvement and time constraints of college students that limit their availability and the travel resources available to me limiting me to one on-campus visit, individual face-to-face interviews were also arranged with those undergraduate participants identified as information-rich cases who could not make the scheduled focus group times. I used an adapted protocol in the cases where individual interviews were conducted (see Appendix E), permitting the data collected during the individual interviews to be analyzed with the focus group data.

Every attempt in research design and execution was made to secure the participants for the focus group interviews. I digitally recorded each focus group discussion and individual student interview to increase the accuracy of data interpretation and analysis. I used semistructured, open-ended interview protocols to conduct the student focus groups and individual interviews. The goal was to host six focus groups per case site with no more than four participants per group to maximize the opportunity for individual focus group participants' responses. 
I was able to host four focus groups of Black male undergraduates while on-site at Northwestern State University. Two focus groups had four Black male students participate and the remaining two had two students each per focus group, which made it more of a small group interview. I was also able to conduct six, individual, face-to-face student interviews of current Black male students and three interviews, two via phone and one in person, with Black male alumni who were available. These three alumni were heavily involved with the initiative while enrolled at Northwestern State and the first student leaders of the sanctioned student organization associated bearing the same name of the initiative. I was also able to interview two female alumnae working locally in the area who returned to campus to provide me their perspective of the Black male initiative in its early years of development. The Black male alumni leaders and current staff members of the initiative identified these two women as important contributors to the early years of the initiative. Because I established the delimitating criteria that the student sample for this particular study would only include current, full-time, Black male students, I limited the data analysis for this study to the student focus groups and the identified rich informants from the currently enrolled individual student interviews.

All interviews and focus groups were conducted on campus in the same location. The interviews were conducted in the Multicultural Services Office classroom space. The offices of the Black male initiative staff were housed in the Multicultural Services Office. The large lecture room space provided to me the week I was on campus was where the initiative's student organization hosts their book study discussions, general body meetings, and other smaller events. The room was set up with tables that formed one large perimeter rectangle, and focus groups and interviews were held with students sitting in close proximity to me around one of the smaller sixfoot tables. 
I designed the interview protocols for the focus groups to average a period of ninety minutes and not to exceed two hours to insure that each focus group participant had sufficient time to contribute their perceptions and responses to the questions asked. The actual average focus group duration at Northwestern State was one hour and 40 minutes with the longest being two hours and 51 minutes. The average individual student interview lasted 60 minutes with the longest individual interview lasting one hour and 21 minutes. All interviews included in the data analysis for this study took place in the spring semester of 2010 on the campus of Northwestern State University. Data collected at Northwestern State University from 12 currently-enrolled students who participated in the focus groups and one individual student interview were used for data analysis in this case study. The individual student interview included in the data set was of the current president of the student organization associated with the retention initiative at NSU. He was referenced by other active students in the focus group to have played a significant role in their level of participation in the initiative and recognized as a leader and peer role model. He was also consistently mentioned as an example of student success by the administrators when they spoke of the successful outcomes of the initiative.

I was able to host five focus groups of Black male undergraduates while on-site at Southern State University in the spring semester of 2010. Two focus groups had four student participants, two had three student participants, and one had two student participants. I also held eight individual student interviews. Seven of the eight were with currently enrolled Black male undergraduates, and one interview was with a Black male undergraduate student who had transferred to a local smaller institution. While he was enrolled at SSU, he served in several leadership capacities on campus and was highly engaged in the retention initiative and was a 
student leader on campus. Current students and the initiative staff identified him as an active student in the initiative while at SSU, but who did not matriculate successfully.

The focus groups lasted an average of one hour and 43 minutes with the longest focus group lasting two hours and 24 minutes. The average individual student interview lasted 44 minutes with the longest being one hour and 13 minutes. I limited data analysis to the five focus groups (a total of 16 student participants) for the study. The focus groups and student interviews were held in several locations on campus during the weeklong visit to SSU. The majority of the individual student interviews and all focus groups were held in two different small conference rooms within the building where the initiative is housed. The conference rooms held no more than eight to ten people comfortably. Two individual student interviews were held in a private small study room at the Black Cultural Center at SSU.

Student focus group data collection. I developed the interview protocol to elicit descriptive, first-hand information that answered the research question about how Black male retention initiatives affect campus diversity initiatives and promote student development at the chosen case sites. The interview protocol specifically concentrated on the data needed to answer the research question about what the participants were experiencing and learning due to their involvement in the retention initiative, how their involvement in the programs and services helped with their adjustment to college, and how their participation affected their overall success in college. Using a semi-structured interview protocol allowed for participants to share information needed to answer the questions, and also permitted me to discover emergent themes and ideas that I might not have considered based on the review of the literature on the Black male collegiate experience and issues of retention. I digitally recorded each focus group. I also captured each focus group experience through my reflections and observations throughout the 
week on-site at the retention initiative offices at Northwestern State and Southern State universities.

The focus group interview protocol for Black male undergraduate participants consisted of the final 23 questions shown in Table 1. I collected demographic information from students via the first question in the student focus group and the adapted interview protocol. The remaining 22 questions of the focus group and individual student interview protocol were specifically crafted to gather data on major concepts I identified to help me answer the research question. The feedback provided by student participants in the pilot study also assisted in the revision of the student focus group and individual interview protocols used in the study. 
Table 1

Black Male Student Interview Protocol Questions Aligned with Major Research Concepts

\begin{tabular}{|c|c|c|c|c|c|}
\hline No & Protocol Question & $\begin{array}{l}\text { Student } \\
\text { Retention }\end{array}$ & $\begin{array}{l}\text { Student } \\
\text { Success }\end{array}$ & $\begin{array}{l}\text { Climate } \\
\text { and } \\
\text { Culture }\end{array}$ & $\begin{array}{c}\text { Program } \\
\text { Structure/ } \\
\text { Implementation }\end{array}$ \\
\hline 1 & $\begin{array}{l}\text { Please state your name, rank, } \\
\text { hometown, and major. }\end{array}$ & & & & \\
\hline 2 & $\begin{array}{l}\text { Why did you decide to attend } \\
\text { college? }\end{array}$ & $\mathrm{X}$ & $\mathrm{X}$ & & \\
\hline 3 & $\begin{array}{l}\text { Why did you choose [said } \\
\text { institution]? }\end{array}$ & $\mathrm{X}$ & $\mathrm{X}$ & $\mathrm{X}$ & \\
\hline 4 & $\begin{array}{l}\text { How would you describe the student } \\
\text { experience at [said institution]? }\end{array}$ & $\mathrm{X}$ & $\mathrm{X}$ & & \\
\hline 5 & $\begin{array}{l}\text { What has been the most rewarding } \\
\text { part of being at [said institution]? }\end{array}$ & & $\mathrm{X}$ & $\mathrm{X}$ & \\
\hline 6 & $\begin{array}{l}\text { What adjustments did you make to } \\
\text { be a successful student here at [said } \\
\text { institution]? }\end{array}$ & $X$ & $X$ & & \\
\hline 7 & $\begin{array}{l}\text { What have been the challenges that } \\
\text { you've faced as a student at [said } \\
\text { institution]? } \\
\text { \{Probe: Are there any current } \\
\text { challenges?\} }\end{array}$ & $\mathrm{X}$ & $\mathrm{X}$ & $X$ & \\
\hline 8 & $\begin{array}{l}\text { Given the adjustments and } \\
\text { challenges you've faced, what has } \\
\text { helped you overcome them? }\end{array}$ & $\mathrm{X}$ & $\mathrm{X}$ & & \\
\hline 9 & $\begin{array}{l}\text { How have you made connections } \\
\text { with others here at [said institution]? } \\
\text { \{Probe: how have you made your } \\
\text { friendships in college?\} }\end{array}$ & $X$ & & & \\
\hline 10 & $\begin{array}{l}\text { Can you describe your interactions } \\
\text { with faculty at [said institution]? }\end{array}$ & $\mathrm{X}$ & & $\mathrm{X}$ & \\
\hline 11 & $\begin{array}{l}\text { From your perspective, what } \\
\text { purpose does [said initiative] serve? } \\
\text { \{Probe: What are the goals of [said } \\
\text { initiative]?\} }\end{array}$ & $\mathrm{X}$ & $\mathrm{X}$ & & \\
\hline 12 & $\begin{array}{l}\text { How has the [said initiative] helped } \\
\text { you with the adjustments and } \\
\text { challenges you've faced here at [said } \\
\text { institution]? }\end{array}$ & $\mathrm{X}$ & $\mathrm{X}$ & & \\
\hline 13 & $\begin{array}{l}\text { What events or services have you } \\
\text { taken part in that are offered by the } \\
\text { initiative? }\end{array}$ & $\mathrm{X}$ & & & $\mathrm{X}$ \\
\hline
\end{tabular}


Table 1. (continued)

Black Male Student Interview Protocol Questions Aligned with Major Research Concepts

\begin{tabular}{|c|c|c|c|c|c|}
\hline No & Protocol Question & $\begin{array}{l}\text { Student } \\
\text { Retention }\end{array}$ & $\begin{array}{l}\text { Student } \\
\text { Success }\end{array}$ & $\begin{array}{l}\text { Climate } \\
\text { and } \\
\text { Culture }\end{array}$ & $\begin{array}{c}\text { Program } \\
\text { Structure/ } \\
\text { Implementation }\end{array}$ \\
\hline 14 & $\begin{array}{l}\text { What have you learned from } \\
\text { participating in [said initiative]? }\end{array}$ & $\mathrm{X}$ & $\mathrm{X}$ & & $\mathrm{X}$ \\
\hline 15 & $\begin{array}{l}\text { How have you changed your routines } \\
\text { and behaviors as a result of [said } \\
\text { initiative]? } \\
\text { \{Probes: What have you done } \\
\text { differently now that you've participated } \\
\text { in the program?\} } \\
\text { \{What are some differences you've } \\
\text { noticed in yourself?\} }\end{array}$ & & $\mathrm{X}$ & & $\mathrm{X}$ \\
\hline 16 & $\begin{array}{l}\text { How often do you interact and engage } \\
\text { with the programs and services offered } \\
\text { by the initiative? }\end{array}$ & $\mathrm{X}$ & & & $\mathrm{X}$ \\
\hline 17 & $\begin{array}{l}\text { What new knowledge and skills have } \\
\text { you learned from participating in [said } \\
\text { initiative]? }\end{array}$ & & $\mathrm{X}$ & & $X$ \\
\hline 18 & $\begin{array}{l}\text { What social connections have you built } \\
\text { as being a part of the initiative? } \\
\text { \{Probe: Are there other social } \\
\text { connections that you now have at [said } \\
\text { institution]? }\end{array}$ & $\mathrm{X}$ & & & $\mathrm{X}$ \\
\hline 19 & $\begin{array}{l}\text { Suppose I am an African-American, } \\
\text { male, high school student trying to } \\
\text { understand what it takes to succeed in } \\
\text { college; what advice would you give to } \\
\text { me about how to be successful in } \\
\text { college? }\end{array}$ & $\mathrm{X}$ & $\mathrm{X}$ & & \\
\hline 20 & $\begin{array}{l}\text { What do you think are the benefits of } \\
\text { having [said initiative] at [said } \\
\text { institution]? } \\
\text { \{Probe: What are the strengths of [said } \\
\text { initiative]?\} }\end{array}$ & $\mathrm{X}$ & & $\mathrm{X}$ & $\mathrm{X}$ \\
\hline 21 & $\begin{array}{l}\text { What do you think are the benefits of } \\
\text { having [said initiative] at [said } \\
\text { institution]? } \\
\text { \{Probe: What are the strengths of [said } \\
\text { initiative]?\} }\end{array}$ & $X$ & $\mathrm{X}$ & & $\mathrm{X}$ \\
\hline
\end{tabular}


Table 1. (continued)

Black Male Student Interview Protocol Questions Aligned with Major Research Concepts

\begin{tabular}{llcccc}
\hline No & \multicolumn{1}{c}{ Protocol Question } & $\begin{array}{c}\text { Student } \\
\text { Retention }\end{array}$ & $\begin{array}{c}\text { Student } \\
\text { Success }\end{array}$ & $\begin{array}{c}\text { Climate } \\
\text { and } \\
\text { Culture }\end{array}$ & $\begin{array}{c}\text { Program } \\
\text { Structure/ } \\
\text { Implementation }\end{array}$ \\
\hline 22 & $\begin{array}{l}\text { Is there anything else you want to } \\
\text { share about your participation in the } \\
\text { initiative? }\end{array}$ & $\mathrm{X}$ & $\mathrm{X}$ & $\mathrm{X}$ & \\
23 & $\begin{array}{l}\text { Is there anything else you want to share } \\
\text { about your college experience? }\end{array}$ & $\mathrm{X}$ & $\mathrm{X}$ & \\
\hline
\end{tabular}

Note. Questions are listed on table in the order of the protocol that was used during data collection with students. The four subtopics of student retention, student success, climate and culture of the campus, and program structure/implementation assisted in answering the research question and managing the data analysis process.

The four concepts of student retention, student success, campus culture and climate, and program structure and implementation were the overarching concepts that I focused on when creating the content of the focus group and interview protocols. The protocol questions and additional probes helped me connect how each particular concept related to or was present when exploring the Black male retention initiatives. I asked students particular questions to gain an understanding of how each concept was represented in the initiative. Table 1 highlights how each of the questions on the protocol relates with at least one of the major concepts that are linked to the overall research question, the related literature review, and the resulting conceptual framework created to guide this study. The conceptual framework encompassed:

- the coordination of overall campus diversity initiatives that included a focus on student success and access, campus climate, accepted curricula, pedagogy and scholarship, and institutional vision and overall mission; 
- the types of diversity created that resulted from actively engaging in a campus diversity initiative (structural, interaction, and classroom diversity);

- the different factors as defined in the Geometric Model of Student Persistence and Achievement (Swail, et al., 2003), specifically institutional factors that affect the success of retention initiatives created for underserved populations;

- how those defined institutional factors and other emerging factors affected the structure of initiatives specifically designed to retain Black males as part of an institutional diversity plan; and

- the development and success of the students who participated in the initiatives. The conceptual framework showed a strong relationship between student success, retention through to graduation, the structures and programs designed to achieve student success, the overall climate and culture of the institution, and how diversity is acknowledged and represented by members of the community. These four major concepts also helped me in creating the analytic questions that were later used to code and analyze the data collected.

I gathered data on the concept of student retention in asking questions 2 through 4,6 through 14, 16, and 18 through 23 . Improved student retention is one of the expected goals and outcomes for retention initiatives. It is the reason why these programs are created on college campuses. The majority of the questions on the protocol were created to address how students perceived their successful retention starting from their first decision to attend college to their decision to choose their current institution; the description of their student experience overall; and meaningful connections made at the institution and within their participation in the retention initiative. 
Student success is a concept that is broad and important to college leaders for all students and is particularly important to the efforts of retention initiatives for historically underserved students. If students are able to succeed in college, they are more likely to persist. I asked questions on the protocol that addressed how students viewed their success and what institutional and non-institutional factors affected that success, including the opportunity to discuss factors related to the initiative and other non-related factors. I allowed for students to openly share facets of their college success when writing questions 2 through 8,11 and 12, 14, 15, 17, 19, and questions 21 through 23.

The climate and culture at an institution influence students' ability to succeed in college, especially historically underserved students. Their academic and social connection to the institutional culture from the faculty and their peers, to the traditions and the policies (specifically in regards to diversity initiatives), affect their likelihood to identify as a member of the community and their persistence. I intended for questions 3, 5, 7, 10, 20, 22, and 23 for students to describe what about the institution drew them to it initially and what about the institution kept them persisting.

Knowing about the program structure and how it was implemented is important to answering the research question. How the students experienced the program, since it was designed for their successful retention, was important for me to explore in order to address the research question. Questions 13 through 18 and 20 and 21 were designed to help me solicit information about how the students engaged with the programs and services offered by the initiative and its effect on their college experience.

Administrative interview. An additional form of data collection came from semistructured, open-ended interviews with administrative leaders and faculty. The interview 
protocol allowed participants to craft their own answers in their own words. The creation of the final protocol required me to take care in creating the included questions to produce the same stimuli per participant (Patton, 2002, p. 344), and to produce data that can be analyzed within each case and thoroughly in the cross analysis between case sites. The data collected from these interviews helped to answer the research question from the administrative point-of-view directly from the leaders who developed and managed the retention initiatives that address the low retention rates of Black males. I digitally recorded each interview, and I wrote my reflection and observations while on-site at both campuses during the interview and afterward to capture and immediately reflect my time with each administrative participant.

The use of the same semi-structured, open-ended interview protocol created the parameters of what data would be collected based on the nature of the questions included in the protocol (see Appendix F). I used the same four major concepts from the conceptual framework created from the literature review. Using the same interview protocol at the start of data collection from each administrator and faculty at each site increased the consistency during data analysis later in the research process when completing the cross analysis of the two cases.

Each interview with administrators and other university leaders involved in the initiative was expected to last approximately 60 minutes. Both questions and the supplementary probes used in the interview protocol were important in developing a full description of the phenomenon (Patton, 2002). This allowed participants to move outside of what I anticipated to provide richer feedback.

Sampling of administrative leaders. I used purposeful sampling with the help of my institutional liaisons to identify administrators and faculty who had a role in any stage of the development and execution of the initiative. I received names and contact information from my 
institutional liaisons. Both the liaisons at each institution and I sent invitations by email and hard copy letters to participate in the study. At NSU, some of the identified informants had left the institution, so I contacted them via email and phone. The institutional liaison followed up with emails and phone calls to the potential participants a second time for those who had not responded, reminding them of my request to volunteer for the study. I scheduled interview times based on participants' availability while I was at each institution. I conducted a total of six administrative interviews at Northwestern State University and 25 administrative interviews (three of which were done by phone) at Southern State University.

I initially anticipated that approximately six to seven interviews with relevant administrators, leaders, and faculty involved with the programs would be conducted at each site, with the opportunity to include other participants who were not originally identified as points of contact through additional snowball or chain sampling. Using this method of sampling helped me connect with and interview as many administrators and faculty who would be labeled by Patton (2002) as "critical cases" or "information-rich key informants." Informants "not only provide the case study investigator with insights into the matter but also can suggest sources of corroboratory or contrary evidence — and also initiate access to such sources" (Yin, 2003, p.90). The line of questioning presented in the protocol provided the opportunity for the participant to also serve as an informant in this case. I used snowball sampling and specifically asked participants "Is there anyone who you think would be an additional good contact to find out more about the retention initiative?" to solicit more information-rich participants.

At Northwestern State University, there were a limited number of administrators involved in the retention initiative on a significant level, from its beginning to the present time, compared to Southern State University. My campus liaison at SSU provided an extensive list of partners 
who were connected at some point in the history of the initiative. These administrators and faculty were connected on varying levels of engagement. Some assisted in conducting workshops, sat on panels serving as experts on particular topics, or had the campus responsibility to provide additional services to help students academically or socially adjust to college. A majority of administrators identified by my campus liaison were available during my time on campus or made themselves available for phone interviews.

The interviews at Southern State University that I included in the analysis for the study lasted an average of one hour and 16 minutes, with the longest being one hour and 33 minutes. During my three campus visits to Southern State University, I was able to conduct a total of 22 administrative interviews and held an additional three phone interviews of administrators and other community members who were recommended through snowball sampling. Upon review of the transcripts and recordings of the interviews, the greater part of them yielded insignificant amounts of data to help me answer the research question. I found a majority of the administrative or faculty informants identified by interviewees and my campus liaison gave me limited information to help answer the research question. During the interviews, these administrators, faculty members, and former campus partners consistently deferred answering my questions and referred me to the current or past administrators with direct responsibility for overseeing the initiative.

In my effort to manage the data received, I decided to focus the analysis very closely to one of the original criteria I used for case site selection - the initiative having at least one fulltime staff member who has at least $70 \%$ of their job responsibilities to manage the retention initiative. I included staff who currently and at some point in their SSU career had direct 
responsibility to create or manage the initiative in my analysis. This left me with five administrative interviews included in the analysis for the SSU case.

Interviews at Northwestern State University included in the analysis lasted approximately one hour and 54 minutes, with the longest administrative interview being three hours and 19 minutes (conducted at two separately scheduled times). In total, I interviewed six administrators during my campus visit. All interviews were done in person. Of the six interviews, three of the administrators were directly responsible for the initiative, either currently or in a past position at Northwestern State. The other three were administrators who provided an insignificant amount of information about the initiative during their interview. Their lack of experience directly with the management of the initiative did not allow for them to answer the majority of the protocol questions with authority and clarity, and I did not include them in the analysis. Those excluded consistently referred to the three administrators who currently have or have had in the past direct responsibility to carry out the initiative. I used those three information-rich participants for the analysis; they provided valid and relevant answers to the protocol questions.

Administrative interview data collection. The interview protocol consisted of 24 questions as seen in Table 2. I designed the protocol to collect data related to the research questions about leaders who develop initiatives to address retention of Black males. The first three questions helped me gather demographic information about the administrators and faculty members who were identified as having a significant role in the development and management of the initiatives. These demographic questions covered participants' years of experience in higher education, current title, and time at the PWI that houses the retention initiative under study. The final two questions closing the interview were open-ended questions that allowed participants to add any new information about the initiative that could potentially yield data related to any of the 
four major concepts I identified to help me answer the research question. The remaining 19 questions were crafted to gather data on one or more of the major concepts of student success, student retention, program structure and implementation, and campus climate and culture. 
Table 2

Administrative Semi-structured Protocol Questions Aligned with Major Research Concepts

\begin{tabular}{|c|c|c|c|c|c|}
\hline No & Protocol Question & $\begin{array}{c}\text { Student } \\
\text { Retention }\end{array}$ & $\begin{array}{l}\text { Student } \\
\text { Success }\end{array}$ & $\begin{array}{l}\text { Climate } \\
\text { and } \\
\text { Culture }\end{array}$ & $\begin{array}{c}\text { Program } \\
\text { Structure/ } \\
\text { Implementation }\end{array}$ \\
\hline 1 & What is your current title? & & & & \\
\hline 2 & $\begin{array}{l}\text { How many years have you been } \\
\text { in higher education? }\end{array}$ & & & & \\
\hline 3 & $\begin{array}{l}\text { How long have you been at } \\
\text { [said institution]? }\end{array}$ & & & & \\
\hline 4 & $\begin{array}{l}\text { What led to the creation of the } \\
\text { current retention initiative for } \\
\text { African-American males here at } \\
\text { [said institution]? }\end{array}$ & $\mathrm{X}$ & & $\mathrm{X}$ & $\mathrm{X}$ \\
\hline $5 a$. & $\begin{array}{l}\text { Who developed the retention } \\
\text { initiative? }\end{array}$ & & & $X$ & $X$ \\
\hline $5 b$. & $\begin{array}{l}\text { What were their } \\
\text { responsibilities? } \\
\text { \{Probe: Who else was } \\
\text { involved?\} } \\
\text { \{Probe: What did they do?\} }\end{array}$ & & & & \\
\hline 6 & $\begin{array}{l}\text { What was your involvement in } \\
\text { the creation and execution of } \\
\text { the retention initiative? }\end{array}$ & & & $X$ & $\mathrm{X}$ \\
\hline 7 & $\begin{array}{l}\text { Who is currently involved in } \\
\text { executing the programs and } \\
\text { services? } \\
\text { Probe: What are their current } \\
\text { responsibilities to the } \\
\text { initiative? }\end{array}$ & & & $X$ & $X$ \\
\hline 8 & $\begin{array}{l}\text { In what ways does the retention } \\
\text { initiative support the } \\
\text { institutional mission? }\end{array}$ & $\mathrm{X}$ & $\mathrm{X}$ & $\mathrm{X}$ & $\mathrm{X}$ \\
\hline 9 & $\begin{array}{l}\text { What other diversity activities } \\
\text { and initiatives are at [said } \\
\text { institution]? }\end{array}$ & & & $\mathrm{X}$ & $X$ \\
\hline 10 & $\begin{array}{l}\text { What, if any, effect has this } \\
\text { initiative had on the diversity } \\
\text { agenda at [said institution]? }\end{array}$ & $X$ & $X$ & $\mathrm{X}$ & $X$ \\
\hline
\end{tabular}


Table 2 continued

Administrative Semi-structured Open-ended Protocol Aligned with Major Research Concepts

\begin{tabular}{|c|c|c|c|c|c|}
\hline No & Protocol Question & $\begin{array}{c}\text { Student } \\
\text { Retention }\end{array}$ & $\begin{array}{l}\text { Student } \\
\text { Success }\end{array}$ & $\begin{array}{l}\text { Climate } \\
\text { and } \\
\text { Culture }\end{array}$ & $\begin{array}{c}\text { Program } \\
\text { Structure/ } \\
\text { Implementation }\end{array}$ \\
\hline 11 & $\begin{array}{l}\text { What are the current mission and } \\
\text { goals for the retention initiative? }\end{array}$ & $\mathrm{X}$ & $\mathrm{X}$ & $\mathrm{X}$ & \\
\hline 12 & $\begin{array}{l}\text { What kinds of partnerships across } \\
\text { the campus have developed to } \\
\text { assist in carrying out the goals of } \\
\text { the program? } \\
\text { Probe: Which of those } \\
\text { partnerships are primarily with } \\
\text { academic affairs? } \\
\text { \{Probe: Which of those } \\
\text { partnerships are primarily with } \\
\text { student affairs? }\end{array}$ & & & $\mathrm{X}$ & $X$ \\
\hline 13 & $\begin{array}{l}\text { Suppose I am a new freshman } \\
\text { African-American Male that has } \\
\text { just been accepted to [said } \\
\text { institution]; Take me through a } \\
\text { year of the initiative. \{Probes: } \\
\text { What expectations of the program } \\
\text { should I have? What will I do as a } \\
\text { participant in the programs and } \\
\text { services?\} }\end{array}$ & $X$ & $X$ & & $\mathrm{X}$ \\
\hline 14 & $\begin{array}{l}\text { Based on your experience, what } \\
\text { would you say are the strengths of } \\
\text { the initiative? }\end{array}$ & $X$ & $X$ & $X$ & $X$ \\
\hline 15 & $\begin{array}{l}\text { What are the major challenges to } \\
\text { developing and maintaining a } \\
\text { retention initiative for African- } \\
\text { American males at a } \\
\text { predominantly White institution? }\end{array}$ & $\mathrm{X}$ & $X$ & $\mathrm{X}$ & $X$ \\
\hline 16 & $\begin{array}{l}\text { What have students learned from } \\
\text { actively participating in the } \\
\text { programs and services offered by } \\
\text { the initiative? } \\
\text { Probe: How do you know they } \\
\text { have learned this? }\end{array}$ & $\mathrm{X}$ & $X$ & $\mathrm{X}$ & \\
\hline
\end{tabular}


Table 2 (continued)

Administrative Semi-structured Open-ended Protocol Aligned with Major Research Concepts

\begin{tabular}{|c|c|c|c|c|c|}
\hline No & Protocol Question & $\begin{array}{c}\text { Student } \\
\text { Retention }\end{array}$ & $\begin{array}{l}\text { Student } \\
\text { Success }\end{array}$ & $\begin{array}{l}\text { Climate } \\
\text { and } \\
\text { Culture }\end{array}$ & $\begin{array}{c}\text { Program } \\
\text { Structure/ } \\
\text { Implementation }\end{array}$ \\
\hline $17 \mathrm{a}$. & $\begin{array}{l}\text { What information about } \\
\text { student learning and } \\
\text { development have you } \\
\text { collected from participants? }\end{array}$ & $\mathrm{X}$ & $\mathrm{X}$ & $\mathrm{X}$ & $\mathrm{X}$ \\
\hline 17b. & $\begin{array}{l}\text { When do you collect this } \\
\text { information? }\end{array}$ & & & & \\
\hline 18 & $\begin{array}{l}\text { Can you share examples of } \\
\text { changes or revisions that } \\
\text { have been made to these } \\
\text { programs and services based } \\
\text { upon data or information you } \\
\text { have collected from } \\
\text { participating students? } \\
\text { \{Probe: Can you expand } \\
\text { upon your example?\} } \\
\text { Probe: What was changed? } \\
\text { Why? And when were the } \\
\text { changes made?\} }\end{array}$ & & $\mathrm{X}$ & $X$ & $\mathrm{X}$ \\
\hline $19 \mathrm{a}$ & How is information shared? & & & $\mathrm{X}$ & $\mathrm{X}$ \\
\hline $19 b$ & $\begin{array}{l}\text { How often is there } \\
\text { information about the } \\
\text { initiative's progress shared } \\
\text { with others at the university? }\end{array}$ & & & & \\
\hline $19 \mathrm{c}$ & $\begin{array}{l}\text { Who receives information } \\
\text { about the initiative? }\end{array}$ & & & & \\
\hline 20 & $\begin{array}{l}\text { What institutional actions } \\
\text { have been necessary to } \\
\text { sustain these programs and } \\
\text { services over time? }\end{array}$ & & & $\mathrm{X}$ & $\mathrm{X}$ \\
\hline 21 & $\begin{array}{l}\text { How does the support given } \\
\text { to the Black male initiative } \\
\text { compare to support given to } \\
\text { other aspects of the diversity } \\
\text { agenda at [said institution]? } \\
\text { \{Probe: If there is a } \\
\text { difference in support, what } \\
\text { do you think is the } \\
\text { difference?\} }\end{array}$ & & X & $\mathrm{X}$ & $X$ \\
\hline
\end{tabular}


Table 2 (continued)

Administrative Semi-structured Open-ended Protocol Aligned with Major Research Concepts

\begin{tabular}{llcccc}
\hline No & \multicolumn{1}{c}{ Protocol Question } & $\begin{array}{c}\text { Student } \\
\text { Retention }\end{array}$ & $\begin{array}{c}\text { Student } \\
\text { Success }\end{array}$ & $\begin{array}{c}\text { Climate } \\
\text { and } \\
\text { Culture }\end{array}$ & $\begin{array}{c}\text { Program } \\
\text { Structure/ } \\
\text { Implementation }\end{array}$ \\
\hline 22 & $\begin{array}{l}\text { What should I have asked } \\
\text { you that I didn't think to ask? }\end{array}$ & $\mathrm{X}$ & $\mathrm{X}$ & $\mathrm{X}$ & $\mathrm{X}$ \\
\hline $\begin{array}{l}\text { I am also conducting a } \\
\text { review of relevant } \\
\text { documents about the } \\
\text { program. Are there any } \\
\text { documents you think are } \\
\text { important that I review that } \\
\text { will help provide a full } \\
\text { picture of the initiative? } \\
\text { Is there anyone who you } \\
\text { think would be an additional } \\
\text { good contact to find out } \\
\text { more about the retention } \\
\text { initiative? }\end{array}$ & & & & \\
\end{tabular}

Note. Questions are listed on table in the order of the protocol that was used during data collection with administrators. Questions covered program development, program assessment and evaluation, student learning and development, and other aspects of institutionalization process.

\section{Data Analysis Procedures}

In this section I discuss the analysis procedures in detail. I include explanation of how the raw focus group and interview data were processed and the issues that came with securing professional assistance in this step. I describe how documentation was used to create the case study stories, as well as discussing how I created the summarized story that served as a guide for each case and a confirmation for accuracy of the case description. I give details about the process of reviewing data prior to coding and analysis. I explain the process of developing the management system for the large amount of data used in the study and the creation of analytic 
questions to guide the analysis process. I also provide information on the previous studies from which my process was modeled and how I devised the coding process and condensed the codes into the major themes and findings.

Analysis of data from focus groups and interviews. I had the data collected from focus groups and individual interviews transcribed verbatim by two professional transcription services. I secured the two services after several failed attempts to find transcriptionist who could comfortably manage and accurately transcribe the Black male student interviews and focus groups. Several professional transcriptionists did not believe they had the talent and confidence to listen through and transcribe the interviews due to the open and authentic dialect that the Black males used. They were not familiar with the students' vernacular and had difficulty making sense of the recordings. After a search for the right transcriptionists to take on the task, I chose two separate companies to help in the timeliness of receiving completed transcriptions of all interviews and focus groups. Once I received the final transcriptions, I reviewed each one and checked for accuracy by listening to the audio files and correcting any errors in interpretation that the transcriptionists made. This was especially important knowing the difficulty in securing professionals who were able to correctly transcribe the recordings verbatim. There were still several significant contextual issues I edited for in the final transcripts, because of the lack of experience of the transcribers with the Black male dialectal patterns. They did not accurately transcribe the Black male students' accounts, which required me to do a close reading and editing of their transcriptions.

In preparing to present the findings from the data in a meaningful way in the subsequent chapters, I created a process to manage and organize the large amount of data collected. After completing the review of all transcriptions and certifying their accuracy, I created the analytic 
questions that guided my close reading of the data. The analytic questions served the purpose of guiding the coding process. According to Bloomberg and Volpe (2008), qualitative research by nature is intrinsically "flexible" with no "strict guidelines and standards for qualitative analysis" and subsequently, "every qualitative researcher will approach the analytic process somewhat differently” (p. 75). I used an iterative, inductive, coding process guided by analytic questions I produced from the research question. The data were cyclically reviewed by answering the analytic questions that I produced from the research question. I considered the conceptual framework, my knowledge of the phenomenon, field observations and experiences, and related documentation to generate the coding process for each specific concept present in the research question that was specifically addressed in the analytic questions. The findings for each case emerged from the iterative coding process and refining and condensing of the codes into themes.

This analytic process was loosely influenced by Srivastava and Hopwood's (2009) suggestion of a reflective iterative framework to help analyze qualitative data in a regimented process. They suggest asking certain questions of the data, in a loop-like and cyclical routine to develop the patterns, categories, and themes that explain the phenomenon based on what the researcher wants to know and asking questions of the data in a way that answers the research question. They suggest using the three questions that Patton (2002) poses as reflective categories of questions. I varied my approach, not using the three suggested categories of questions, but instead created specific questions that I asked of the data to guide the coding process and subsequently produced the findings. Each question I posed to the data allowed me to review the data and ask specific questions about concepts present in the initial research question: "How do Black male retention initiatives affect campus diversity initiatives and promote student development and success?” 
Neumann's (2009) analysis methods heavily influenced my adapted data analysis process. Once discovered, Neumann's process for data analysis was a fitting method based on the complex concepts that I needed to draw relationships between to make sense of the data. Her study examined the scholarly learning of professors as they progress in their career and professional maturity. Neumann's (2009) explanation of her analysis is summarized here:

Data analysis included identifying, grounding, and confirming themes of experienced change through professors' early post-tenure careers. Analysis proceeded iteratively: multiple rounds of data review allowed insights to build on one another and provided opportunities for comparative checking, thereby permitting correction, revision, addition, and confirmation, cycle to cycle. Any one analytic round might involve identifying a pattern of interest, responsive to the study's aim and evident (though diversely) across multiple cases; formulating a propositional claim for that pattern's existence, possible meanings, and significance in the context of People's State university; testing the claim against the data that initially gave rise to it and then against other data from other sample cases; rewriting the claim in light of the data drawn from the rest of the sample; and tacking back to the data that had originated the claim for retest. In searching for databased patterns, I attended consistently to negative (discrepant) data, using such data to interrogate further the meaning of the proposed pattern and the certainty of the claim at issue. In brief the People's State University Project helped me discern a conceptual door that the later Four Universities Project then opened. (p. 235)

For this study I adapted the methodology of analysis. I analyzed each case separately in its entirety once the analytic questions were created. I started by doing a close read of all the interview and focus group transcriptions included in the analysis to produce an overall case 
story. I took into consideration what the data were saying about the phenomenon, making notes of patterns and major themes throughout the close reading. The case story served as the guiding parameters and foundation to the case as I continued with the data analysis process, where next I asked the analytic questions of the data, and then created the codes that led to the findings. The summary considered all the relevant data I collected and helped me to identify outliers and the contradictions in what I discovered as the common account of each case. The case story initiated and then verified the development of major themes that were present in each case.

I derived the analytic questions used in the iterative process based on the research questions I initially identified early in the study prior to revising the one main question of the study. These analytic questions corresponded with the broader research concepts present in the actual research question and served as the overarching categories and basis for the subsequent questions I created to apply to the data during analysis. For instance, one analytic question asks the data "How do these programs and services support mission and diversity initiatives?" Within this one larger question, I asked four sub-categorical questions about mission and diversity, based on data I received from participants:

(1) What do administrators say about mission?

(2) What do administrators say about diversity initiatives?

(3) How do administrators connect programs and services to mission?

(4) How do administrators connect programs and services to diversity initiatives?

The other larger administrative questions covered evaluation of the program, institutionalization of the program, and program assessment and revisions. The overarching student questions covered the initiatives' effect on what students were learning, how they were 
persisting in college, and how they were developing and succeeding. Each question covering the student data also had sub-categorical questions that I asked of the data.

Each of the analytic questions and sub-categorical questions I used to analyze the data had varied levels of bearing on each of the cases. The questions that were most relevant were used in the coding process. Direct quotes from the data were pulled and used to answer the analytic questions. If no quotes from the most information-rich participants were provided to answer the analytic question, that concept did not materialize in the overall case findings. I developed the coding and the subsequent condensed codes that served as the source for the case findings directly from quoted data. The presence in the data of the overarching research concepts, covered by the analytic questions, determined the level of applicability of that concept for each case. For instance, the amount of data that helped to explain the analytic questions specifically addressing evaluation and assessment practices for each case varied based on the information provided by the administrators interviewed and the documentation made available to me. The presence of assessment and evaluation in the research findings depended on the data that administrators at each case provided identifying their evaluation and assessment practices.

The analytic questions were each applied to the entire data set separately in individual cyclical iterations to create separate codes per analytic question, which helped form the final case findings. I first applied the analytic questions relevant to administrators and then applied the analytic questions relevant to students. Both sets of administrative codes and student codes were individually condensed and then collectively compared to produce the findings.

Each analytic question warranted the creation of two separate spreadsheets to track the codes and quotes that corresponded to the codes created. The first spreadsheet was the tool used to record the number of quotes per code and record all the quotes related to the particular 
analytic question applied to the data categorized by assigned code. I used the second summary spreadsheet for the analytic question to condense the codes into broader categories. The summary provided me a record of the frequency of the initial codes that comprised each of the condensed categories and the frequency and total number of instances of the codes once the codes were condensed into categories. Each spreadsheet corresponded to each analytic question. I had a total of 20 spreadsheets (two sets of 10 sets) for each of the cases.

From the categories I labeled in the spreadsheet, along with the documentation collected at each case site to support the relationships that emerged in the use of the spreadsheet tool, I was able to articulate the findings. The findings came based on the relationship between the categories created from the initial coding of each analytic question in the summary spreadsheet. I was able to clearly see where the emphasis was in the coding frequency and the relationships that overlapped or were definitively separate and strongly represented in the codes. I looked to data from the document analysis and my observational notes and reflections from the case visits to confirm, expound on, or contradict the relationships that came from the coding of interview and focus group data.

I used the whole raw data set for each case and my observational notes and reflections to assess gaps found with the codes before findings were finalized. When codes that I anticipated being present after all analytic questions were applied to the data did not materialize, it caused me to return and review my case stories that were written after a thorough read of the interview transcripts and review of the documents. My summarizing of the cases helped manage the conflicts that showed up in the data coding. In addition, I practiced reviewing my observational notes that also helped resolve contradictions in the coding. The case stories that I created solely from a thorough reading of both cases' raw data assisted me in managing the weight of the 
contradictions that arose in the coding compared to the case stories. Contradictions in the coding were also managed through reviewing and reflecting on my conversations and experience with the liaisons as the site visits were planned.

Document analysis. The completion of the triangulation of data came from the data collected in the form of documents. Yin (2003) stated that, "the most important use of documents is to corroborate and augment evidence from other sources" (p. 87). Documentation is critical in any case study in that it helps confirm information from other sources or guides the researcher into a deeper investigation of a phenomenon. Data collection of this type can take many forms and this study included all past and present written documents provided to me on each site and all web-based documentation. I requested written proposals, annual reports, strategic plans, student evaluations, newspaper clippings and other articles, recruitment and marketing materials, web sites, student reflections, memoranda, letters, agendas, announcements, meeting minutes, and other written reports or research studies of each initiative. During each site visit, I requested all relevant internal and external documentation to do a thorough review to link back to the other two forms of data collection (the focus group interviews of student participants and the interviews of the administrators and faculty involved in the retention initiative). The institutional liaisons played the largest role in helping to secure all relevant documentation for the analysis. To neutralize the potentially biased information provided to me by my institutional liaison and to be thorough in my document search, I also conducted a web-based review of each institution's website for information about the initiatives and did a general web-based inquiry to find out what information was made widely available on the Internet about the initiatives. Southern State University administrators provided me annual reports on diversity for the last five years, campus diversity newsletters, enrollment and graduation statistics by race and gender, evaluation 
summaries of the initiative's programs, and other presentations made by the staff of the initiative both internal and external to Southern State. I was able to secure enrollment and graduation information from Northwestern State University through their institutional research office. The institutional liaison provided me with the constitution of the student organization along with hard copies of the archived newspaper the student organization produced in the first two years of its existence. I also secured a copy of both institutions' diversity plans to assist me in producing the findings for the study.

\section{Issues of Trustworthiness}

Bloom and Volpe (2008) stressed the necessity for qualitative researchers "to seek to control for potential biases that might be present throughout the design, implementation, and analysis of study" (p. 85). Issues of proving creditability, dependability, and transferability are ways that trustworthiness is addressed in qualitative research. In regard to transferability, I propose that the cases are presented with thick descriptions to fully represent the phenomenon overall. I used a systematic way to analyze the data of each case, including multiple forms of data collection practices. The remainder of this section of Chapter Three discusses how I managed trustworthiness in this study and the consistent potential issues of personal biases that are common with qualitative research.

Role of the researcher. In qualitative inquiry, the researcher is the instrument used to collect, analyze, and interpret data (Patton, 2002). Patton (2002) further stressed "the credibility of qualitative methods...hinges to a great extent on skill, competence, and rigor of the person doing the field work" (p.14). I provide a profile of myself in an effort to decrease the issue of credibility. 
I have always had an interest in how education systems affect Black males. It stemmed from the observations I had of my two biological brothers. They both chose a military career and opted out of attending college. They have since retired from the military and have become family men, each with one daughter and three sons. My six siblings and I all grew up in the same household where education was set as a priority and something to aspire to obtain at the highest level. My three sisters and I all have earned at least bachelor's degrees. Specifically, I have a Bachelor of Arts in English, a Master of Arts in secondary education with a concentration in language arts; my oldest sister has a Bachelor of Arts in theatrical arts; my other sister holds a Bachelor of Fine Arts in art history and studio art and two Masters of Science degrees, in Educational Administration and the other in Instruction; my third sister earned a Bachelor of Science in interdisciplinary studies with a concentration in biology, physics, and psychology and is a Doctor of Osteopathic Medicine currently licensed to practice in New York, West Virginia, Maryland, Virginia and Pennsylvania. When I saw the paths that both my brothers took with 12 years of age difference between the two, I realized something gender related was occurring.

I started seriously questioning the education system's effect on Black males again in college when I realized there were a smaller number of Black males at my undergraduate institution and an even smaller number of them active in the student organizations I participated in. When I started my career in higher education as the graduate assistant in charge of a freshman orientation program for Black students, it was obvious that the incoming class had more females than male freshmen. There was a pattern that was clear to me and disturbed me because it reflected the patterns in my immediate family.

I have had varied professional experiences in higher education concerning the subject of Black Male retention. In producing this dissertation, I have extensive experience working 
directly with and supporting Black males at PWIs through programs and services and on a oneon-one basis as a mentor. I have been employed at two, large, state-funded institutions in two different states; each institution had a very low number of Black undergraduate males enrolled at my time of employment and each identified having an issue with retaining these students through to graduation. I have always felt a responsibility as a Black female professional to ask the questions to my professional peers, both Black and non-Black, one-on-one, and when conducting committee work or in meetings about Black male retention to spark conversation and to get their perspectives on the issue.

I have conducted qualitative research and previously presented at professional conferences about what makes Black males successful at PWIs, while I worked as a full-time administrator at two different higher education institutions. I have created student organizations on both campuses with the sole mission of helping Black students connect with and adjust to the campus community. I always took a particular interest in the lack of engagement of Black males specifically within these groups; noting that the majority of membership and furthermore those who assume leadership positions (formal and informal) were Black female students.

I have a positive opinion about current efforts to provide retention initiatives to help these students at PWIs. I have a personal belief that some leaders acknowledge this as an important issue to address with financial and human resources and time, while I believe that others are fixated on the institutional racism that still is prevalent at many PWIs, which prevents them from seeing the value in investing in programs and services like retention initiatives. I believe there are some who do not actively pursue ways to increase their success and retention due to cultural barriers and lack of comfort in working with Black males. I feel that they honestly do not know where to begin with the problem on their campus. After attending conferences and 
openly speaking with my White colleagues from other institutions around the country about the problem, I realize it is a mixture of all of the above in higher education with regards to how professionals view the low number of Black males retaining through to graduation.

Having worked directly with Black male undergraduates for the past ten years, I have some understanding of what their experiences have been at PWIs, which has helped me in collecting and analyzing data and in coming to plausible conclusions and recommendations. My work within multicultural affairs in the past has helped me to see the broader picture and to place this issue within the larger context of diversity initiatives. I have been influenced by the work of Adrianna Kezar about the influence of leadership on diversity initiatives and about transformational change in higher education. I believe the historical issue of poor retention of Black males is a systemic problem that has to be solved through the decision of leaders and centers of influence on campuses.

For practitioners and others who are interested, I expect that this particular study will provide a better understanding of the Black male undergraduate experience. My perspective is one of optimism for the future although access programs created through affirmative action legislation to correct past inequities are currently being challenged by new legislation that negates race-specific programs and race-specific resources in higher education. It is my understanding that there are two strongly opposing positions on how resources should be allocated in a low-resource-availability era of higher education.

I journaled while conducting this research to help me structure my concluding recommendations and to better recall the individual experiences I had with participants collecting data on-site. I anticipated keeping a record of reflections and responses to the cultural and 
political aspects that inevitably affected my perspectives when collecting data and proceeding with the qualitative inquiry. I have encountered unexpected challenges (for instance issues with securing a transcriptionist to properly handle the Black male student interviews) and considered several strategies to address these challenges. I cannot ignore the present level of attention that Black male attrition has received in higher education during the collection and analysis of data. There have been several publications that have asked important questions about what is happening with these young men and the systems of higher education that accept them as students. All have been valuable, and this research is the first of many projects that I will conduct to help increase the likelihood of graduation and reduce attrition prior to degree attainment.

\section{Limitations of the study}

All studies have shortcomings. Bloomberg and Volpe (2008) stated, "regardless of how carefully you plan a study, there are always some limitations" (p.79) and that limitations show that the "study is situated with a specific context" (p. 79). In planning for the limitations, I recognized the limiting factors of qualitative research, more specifically using focus groups, interviews, and document analysis as data collection methods. Qualitative research, by its nature, tells the story of a phenomenon. It is unlike quantitative research that lends itself to numerical answers and is favored when conducting research with the purpose "to measure the reactions of a great many people to a limited set of questions, thus facilitating comparison and statistical aggregation of data" (Patton, 2002, p. 14). Qualitative research limits its generalizability due to the nature of in-depth exploration and question of a small representative group under study. The method of qualitative research that uses interviews, focus groups, and document analysis like this study are time intensive and specific, unlike quantitative research, and thus limits a broad exploration of the phenomenon under study. 
A limiting factor with using the semi-structured, open-ended interview protocol is that it limits the ability of the interviewer and individual participants to pursue aspects of the phenomenon that fall out of the parameters of the structured questions. In an effort to reduce this limitation, the final question in the protocol asking participants specifically "What should I have asked you that I didn't think to ask?" was included. This open-ended question can possibly yield responses that are related to all the research questions posed in this study or illuminate other aspects of the phenomenon under study that I did not anticipate emerging from the literature review and past personal and professional experiences with the issue of Black male retention.

The challenges of managing group dynamics was present in focus group interviews and can be a limitation to the study. There is always a threat of 'group think' or an emerging group culture that overshadows the responses the individuals contribute to the whole. I had to manage the possibility of dominating voices in the focus group and be as skilled as necessary to make sure that everyone participated at a comfortable level, that all the protocol questions were introduced, and everyone was given the opportunity to answer all questions. There was also a limitation of receiving sincere responses among the participants for fear of peer scrutiny (Stake, 2000). I had the responsibility as the interviewer to be a skillful facilitator to reduce the level of limitations with the focus groups.

\section{Pilot Study}

The pilot study was conducted at Eastern State University (pseudonym) with a Carnegie Classification (2005) of Research University with very high research activity. Its size and setting is labeled as a public, large, four-year institution with a high residential population, where at least half the students live on campus and a high undergraduate population. The undergraduate profile was selective and had a high transfer student rate. 
The pilot study was conducted in the early spring semester of 2010, and Eastern State was chosen for the pilot based on the study's criteria and also based on my geography, proximity, and access.

Eastern State was located on a suburban campus on the east coast and was chosen for the pilot study site for several reasons. First and foremost, the institution hosted an active retention initiative for Black males that had been in existence since 2005. The initiative was housed within the Black Cultural Center and had two full-time staff members, the Director and Assistant Director of the Black Cultural Center, who held responsibilities to carry out the day-to-day activity of the initiative and served as facilitators. The primary mission of the retention initiative was focused on brotherhood, scholarship, and the retention of Black males. Eastern State held similar institutional criteria to the final two case studies that were chosen for the study. Those criteria were a public, four-year and with high undergraduate enrollment. Eastern State had a total student enrollment of approximately 34,000 students, including approximately 24,000 undergraduates in the fall 2009 semester. The total Black student population (undergraduate and graduate) is $12 \%$ for a total of approximately 3,300 students.

Eastern had the majority of the same criteria that were set for the two case sites; however, the retention initiative was not institutionally initiated (it was one that started based on student request for a group or regular gathering of Black males on campus to combat low retention rates). To further determine whether the pilot study institution was appropriate for the study, I visited in the fall 2009 semester for a preliminary face-to-face meeting with the Director and Assistant Director of the Black Cultural Center, where the initiative was housed on campus, to find out more about the retention initiative's history, current status, and willingness to serve as a pilot study site. Upon completion of the preliminary meeting, the Director agreed to serve as the 
institutional liaison upon IRB approval granted from West Virginia University. Once proof of IRB approval was submitted to Eastern State University, the Director served as the point of contact to the other administrators and students chosen for the pilot study. The IRB-approved email invitation for both administrators and students to respond to was distributed to the entire email list by the Director of the Black Cultural Center to those participants in the Black male retention initiative. The liaison secured the rooms for the campus visit and the participants for the focus groups and interviews. The liaison sent follow-up emails to students to secure enough participants for the two student focus groups. The liaison made follow-up phone calls to faculty and staff participants to secure administrative participants.

\section{Pilot Study Data Collection}

Participants for both administrative and student interviews were chosen based on the guidance given to the researcher from the institutional liaison. Three face-to-face interviews with administrators at Eastern State University and two student focus groups were conducted and digitally recorded. Individual interviews with the Director and Assistant Director of the Black Cultural Center and a program manager for one of the research divisions in electrical computer engineering who serves as a mentor in the program were conducted in a closed conference room in the Black Cultural Center. The student focus group participants included two seniors, one sophomore, and one junior who were all active participants in the Black male retention initiative. The two focus groups were conducted in a closed conference room in the Black Cultural Center, with two students per group participating for a total of four student participants in the pilot study.

The duration of the three administrative interviews averaged one hour and 27 minutes. I completed the semi-structured interview protocol and an additional protocol was created to 
critique both the interview questions and procedures and cover letter provided during the administrative interviews. Both protocols can be found in appendices F and G, respectively.

The duration of the student focus groups averaged one hour and 31 minutes. I completed the semi-structured interview protocol, an additional protocol to critique the interview questions and procedures, the cover letter provided to each participant, and the student demographic questionnaire each student participant filled out. Both protocols and the student demographic questionnaire can be found in appendices D and C, respectively.

\section{Implications for the Formal Study}

The primary purpose for the pilot study was to ensure the clarity and suitability of questions in the protocols, student demographic questionnaire, and data collection procedures. Feedback provided to the researcher from both student and administrative participants at Eastern State University were the main rationalizations for the revisions made to the protocols and questionnaire used at the research case study sites. Reflection and review with the dissertation committee chair after the pilot study was conducted served as an additional step of material review that affected the final protocols and questionnaires going forward in the actual study.

Based on the feedback from the three administrators, no changes were made to the administrative interview protocol. All three administrators noted that the questions were thought out and well developed. The institutional liaison, the Director of the Black Cultural Center stated, that "they were very thorough...very comprehensive."

The Director also noted an additional question that could be added is "How has the university changed its position as it relates to the Black male retention initiative?" Clarifying this statement for me, the Director stated, "in terms of really giving financial money to the program to see that we are a viable program; to be able to do services for Black males." In Eastern State's 
case, the initiative was started by students, and the Black Cultural Center took on the project; but he stated that financial support has been a problem that he has noted across the country with comparable Black male retention programs. He felt the topic was addressed in the questions about support to the program, but was concerned about getting information about financial support changing for the worse based on recent institutional decisions about diversity at Eastern. This question was not added to the final administrative protocol, because one of the major criteria for the cases studies chosen for the study was that it was institutionally driven and initiated, not student-initiated, and that resources (financial, human, and otherwise) were provided for the program to succeed.

Also noted is that both the Assistant Director and the Director of the Black Cultural Center stated that they did not want the university to recognize the organization as a sanctioned university organization and would rather retain their autonomy from the university so that the organization can be governed within the Black Cultural Center and sustained within their Center's budget without outside oversight. They felt the autonomy protected the organization, and it was necessary due to the politics surrounding diversity at the present time and in the past at Eastern. Shortly before the pilot study was conducted on Eastern State's campus, the chief diversity officer was asked to resign and the replacement for his responsibilities was made with a part-time position. Also several faculty and administrators of color were let go and two student protests in front of the main academic administrative building about the recent changes had taken place in opposition to the recent changes.

The one program manager interviewed was disappointed that he was unable to answer the questions in the protocol related to assessment and evaluation of the retention initiative, specifically, the questions asking: "What information about student learning and development 
have you collected from participants?", "Can you share examples of changes or revisions that have been made to these programs and services based upon data or information you have collected from participating students?", and "How is the information [assessment of student learning and development] shared about the initiative?" In addition, the question comparing how the support given to the Black male initiative to other aspects of the diversity agenda at Eastern State was not one to which the program manager could respond based on his relationship with the institution. This would be a similar situation at case study sites as interviews of administrators who do serve as partners and who do not have direct management and oversight responsibilities of the initiative. He stated, “some of the stuff I didn't know about the university, so it's difficult for me to answer it." He also stated that in regards to the length of the interview, "the time was fine. I could talk about this topic all day."

After analysis of the feedback obtained during the pilot study data collection, several changes were made to the student protocol and the student demographic questionnaire. Students in both focus groups noted that the initial questions "What have you learned from participating in [said initiative]", "What is the difference, if any, as far as what you do now as a student that you didn't do before participating in the retention initiative?" and "How have you changed your routines and behaviors as a result of [said initiative]?" were very redundant. One senior student participant stated, "some of the questions were repetitive." Their unanimous decision based on how they answered all three questions in the focus group discussion was to remove the questions that asked, "What is the difference, if any, as far as what you do now as a student that you didn't do before participating in the [said initiative]? One participant stated, "I feel like you're going to get to that with the other two questions. That's how I answered them." I also noted in reviewing the protocol on-site at Eastern State, that the question on the pilot study protocol asking "Can 
you share with me what ways the initiative can better help you adjust and succeed in college?" was repeated twice. The final student protocol expressed these changes and can be reviewed in Appendix D.

Other changes to the data collection materials occurred with the student demographic questionnaire. Based on how the four students in the pilot study completed the questionnaire, the researcher clarified several items. In order to collect accurate demographic data while on-site, the researcher emphasized in several locations on the questionnaire for the students to check one category (High School Background, Race/Ethnicity, Family Structure, Sexual Orientation, Socioeconomic Background, and Parental Education) and to list all of their scholarships, awards and honors received since enrolling. Also the researcher provided examples of activities commonly provided by retention initiatives activities, programs, and services (for example tutoring, mentoring, retreats, leadership workshops, intramural athletics) to help frame the final question on the questionnaire, which asks participants to list which activities provided by the initiative they have joined. The final Student Demographic Questionnaire that was used at the two case study sites can be reviewed in Appendix C.

\section{Summary}

In Chapter Three, I have provided a thorough description of the research methodology. Qualitative inquiry was chosen to provide a thick description of the phenomenon being studiedretention programs for Black male undergraduates at PWIs. The case study method included exploratory research on two separate cases at large public, residential state universities. I conducted focus groups of undergraduate male participants, semi-structured, open-ended interviews of administrators, faculty, and leaders at the institution involved with the initiative along with a supporting document analysis and provided the full description of each case and a 
cross analysis between the two. The triangulation of these data collection methods assisted me in accounting for creditability of the study along with my journal and field notes.

As with any study, there are limitations that were addressed. These included the use of interviews and focus groups that yielded an in-depth description of the phenomenon and the majority of data for the analysis. These data were not able to be generalized for all institutions and all Black male retention initiatives, yet have the possibility of transferability. In regards to ethical considerations, confidentiality, anonymity, and protection of the data collected were taken into serious consideration along with the IRB process and approval that was necessary to complete the study. 


\section{Chapter Four}

\section{Case One: Northwestern State University}

Northwestern State University (NSU) holds an institutional classification by the Carnegie Foundation (2005) as a Research University with very high research activity, publicly controlled as a large, four-year, non-residential institution, where fewer than $25 \%$ of students live on campus. It has a high full-time undergraduate population (at least $80 \%$ of total student population), with a selective admissions requirement and a high percentage of transfer undergraduate students entering each fall. It has multiple physical campuses and an additional virtual campus, all governed under one administration. All physical campuses are situated in an urban setting. According to the NSU's online historical account, it is founded under a state legislative bill signed by both legislative bodies and the governor in the late 1800's as a normal school to prepare public school teachers and to teach the mechanical and agricultural arts. NSU remained a teachers college until 1945 and gained university status in the 1950's with an official name change prior to the end of the decade (NSU Department of Archives website, 2010).

The Black male initiative has been housed at the campus serving the largest number of students. Under the current leadership, the institutional vision is to lead all large research universities in being an inclusive community, one that focuses its responsibilities to solve local and global issues from many academic and social perspectives for the benefit of public good. The vision is driven by four goals under the current administrative leadership that includes increasing access and quality of education provided to all students; achieving a national comprehensive institution status; achieving top national standing in academic quality across all academic programs; and increasing their local and global social responsibilities (NSU website, 2010). 
Based on the latest reported institutional statistics in the 2008-2009 Fact Book, NSU had approximately 12,700 full- and part-time employees, including over 3,000 faculty. Fall 2009 total student enrollment was the highest in the institution's history with over 65,000 students. Approximately 55,000 students attended at the largest campus where the Black male initiative, the Black Male Exchange, was housed. Of total students combined at all NSU's campuses, approximately 53,000 were undergraduate students, 12,000 were graduate students (Northwestern State University website, 2010). Approximately 49\% of the total students enrolled in the fall of 2009 were male, and 51\% were female. Minority students comprised $29 \%$ of the total undergraduate student enrollment and $18 \%$ of the total graduate students, with over 1,300 undergraduate international students and over 2,200 graduate international students enrolled (Northwestern State University, website, 2010). Black students comprised about 5\% of the total undergraduate enrollment (approximately 2,700 students) and 3\% of the graduate enrollment (approximately 400 students) at NSU, reaching nearly 3,000 students total. The total incoming first-time freshmen class for fall 2009 was over 9,000 students and approximately 500 of those were Black students. The university has been accredited by one of the organizations that meet the standards of the Council for Higher Education Accreditation.

Northwestern State University offered over 200 undergraduate majors, and more than 100 graduate and doctoral programs that were housed in approximately 20 different colleges and schools, with the largest being the College of Liberal Arts and included an administrative division of graduate studies. The six-year graduation rate for first-time, full-time, new freshmen (FTFTE) provided by the NSU Office of Institutional Analysis from the Fall 2003 was 56\%. Black students' six-year graduation rate for the 2003 cohort was $42 \%$ and Black male students' six-year graduation rate for the 2003 cohort was 39\%. Retention rates reported for the same 
cohort of all FTFTE students were $81 \%$. The average overall retention or persistence rate for NSU was $81 \%$. Retention or persistence rates reported by Institutional Analysis for all Black students in the 2005 cohort were $71 \%$, and for the 2006 cohort were $68 \%$. Over the last five years of reported retention or persistence rates for Black students averaged $74 \%$ with the last two years reported (2008 and 2009) at $78 \%$ and $80 \%$, respectively. Placing these statistics in numerical context for Black student graduation rates, out of the approximately 300 attending Black undergraduates in the 2003 FTFE cohort, 42\% (approximately 125 students) successfully graduated within six years of their first time enrollment at NSU; of all Black FTFTE students entering in 2003, approximately $60 \%$ were Black female students and $40 \%$ were Black males. Black females were $64 \%$ of the 125 graduating Black students from the 2003 cohort, and Black males were 34\% (Northwestern State University website, 2010).

When I first stepped onto Northwestern State's largest campus, it was difficult for me to determine what was considered campus and what was considered city. The building structure of the residence halls, the off-campus housing (where I stayed), the academic buildings, and administrative buildings matched the surrounding city buildings that were on the outskirts of the campus. If it were not for the NSU brick and concrete slabs on the ends of the campus, there would be no way to differentiate the campus from the city. There were newer franchise retail storefronts that were targeting college campuses. Stores like Pita Pit, Jimmy John's, and Papa John's Pizza were on the main strip and easily accessible all week and all hours of the day and night. Anytime I went to grab a bite and decompress from the day, students were presentoutside sitting in the eating area, walking the streets in groups, or sunning on the plush lawns provided outside of residence living. The students were moving at a fast pace, wherever they 
were off to, many on bicycles and more than expected on skateboards with their ergonomic bags strapped to their backs.

The campus was massive in land area and was growing into the city. It was not the East Coast, Ivory Tower institution of old where it sat far off, separated from the community. NSU has become a part of the community, where it was hard for me to tell who was affiliated to NSU and who was not, as I looped the exterior borders on the campus bus. Students sat on the bus with their iPods and cell phones barely looking up to say good morning or good afternoon. The drivers on the bus were another story though; they were friendly and the best guides for me to know where to get off the loop and when the next bus would be stopping through on the route schedule.

When sitting in the Associate Dean of Student Life's office, we overlooked what students called the Quad, and what he called his "laboratory." There I was able to see the center of the action and the fast-paced campus movement. Even with over 60,000 students, he was able to point out the student leaders to me by name and organization affiliation as they quickly walked the Quad to their next class. He pointed out Black faculty members walking with White students, and other figures that were walking through the quad to get to their next destination. He also pointed out the air-conditioned Union, where all student activity was located to the left of the Quad. I took a moment to walk through it, finding it matched the vastness of the campus. The eatery was full of students grabbing a bite, the second floor was where student leaders gathered and held meetings. Administrators mixed with students during lunch hour, since many offices were housed in the Union as well. There was constant movement on the campus during my days at Northwestern. 


\section{Student participants}

Twenty-one students were interviewed for the study at Northwestern State University (NSU) in the spring semester of the 2009-2010 academic year. Nine students were individually interviewed for approximately one hour each. The remaining twelve students participated in a total of four focus group interviews, where the discussions lasted an average of one hour and 40 minutes. No focus group exceeded four participants. This study focused on the information gained from the four focus groups and the student president of the Black Male Exchange (BMX). Participants were purposefully selected through an email recruitment message sent to the members of BMX from the program coordinator and advisor. The student intern for BMX's precollege program also assisted in the recruitment of college student participants for interviews and focus groups. Several student participants were asked and agreed to participate while I was on campus for data collection.

Twelve students self-identified as African-American, four self-identified as Black. Five student participants self-identified as bi-racial, with their ethnic backgrounds self-reported as "Afro-American," "French and Spanish" for one, "Black and White" for two participants, and "African-American and German" for the last bi-racial student participant who identified specific ethnicities. Other ethnicities identified by student participants are "Dominican and Black" for one African-American participant, and "Jamaican" for one participant who self-identified as Black. One participant identified as gay, and the remaining 20 identified as heterosexual or straight.

Sixteen participants attended public high schools and five participants attended private high schools. The mean self-reported, high school, grade point average for 20 of the 21 
participants was 3.32 on a 4.0 scale. One student reported a 4.16 high school grade point average on a 5.0 scale.

Twelve of the student participants were raised in two-parent homes. Five participants were raised in a single-parent home headed by their mother. One participant was raised in a singleparent home headed by his father and noted that he chose to live with his father, but his mother was still very active in his life. One participant was primarily raised by his older sister, and one participant was raised in two separate households, noting both his parents remarried and had a set of siblings in both households.

In reference to the participants' socioeconomic status during their upbringing, 10 participants were raised in middle working class homes, seven in low-income homes, and four participants were raised in upper-middle-class homes.

A total of six participants reported the highest educational level achieved by their mother as some college. Four reported the highest level of achieved by their mothers as high school graduate, four had mothers complete their Bachelor's degrees, and four other participants' mothers' completed their master's degrees. Two student participants reported the highest level as associate's degrees, and one reported his mother as achieving some high school education. No participant reported his mother as earning a professional degree.

Eight participants reported that their fathers graduated high school. Six participants reported that their fathers earned bachelor's degrees. Three participants' fathers earned master's degrees. Two participants reported their fathers as completing some high school education. One student participant reported his father completing some college, and one participant reported his father completing an associate's degree. No student reported his father as earning a professional degree. 
At the time of data collection, seven participants were seniors, two were juniors, six were sophomores, and three were freshmen. Three participants, who served as the first executive board members of the student organization and student leaders at NSU, recently graduated and volunteered to come back to participate in the study.

With the approximately 200 majors offered to undergraduate students in almost 20 colleges and schools that spanned across five campuses, the participants majored in programs across the College of Engineering, Institute for Art and Design, School of Business, College of Liberal Arts and Sciences, and the School of Sustainability. Eight participants were majoring in programs in the College of Arts and Sciences, while another seven participants were studying majors in the School of Business. Three participants were majoring in programs under the Institute for Art and Design, two were majoring in programs under the College of Engineering, and one participant was studying a major in the School of Sustainability with a minor in African and AfricanAmerican studies. A total of four student participants elected to take a minor. The participants' self-reported mean cumulative college GPA was 2.86 on a 4.0 scale.

The study participants averaged a mean of three clubs and organizations in which they held membership at NSU, with the highest number of organizations or clubs being five by one participant. The lowest number of student organization membership for student participants was one organization for four of the participants, who reported their only involvement was with BMX. In taking leadership in the organizations or clubs they belonged to, the average student participant reported having two leadership positions. Two participants reported a high of four leadership roles each in their respective organizations and clubs, and four students reported taking on no leadership positions. In reporting their university honors, awards, and achievements, the participants had an average of one reported with a high of seven reported by one student, and 
a low of no awards or scholarships was reported by eleven participants. Specifically for their activity with BMX, the students reported participating an average of four programs or services planned or cosponsored by the student organization with a high participation rate of nine activities, programs, or services offered by BMX reported by one student participant.

\section{Administrative participants}

I interviewed six administrators (pseudonyms used) individually for the study at Northwestern State University (NSU) in the spring semester of the 2009-2010 academic year. Each interview lasted for approximately an hour and followed a semi-structured protocol. Participants were purposefully sampled based on their interaction with the retention initiative and selected with the help of the institutional liaison.

Three of the six had current or past positions with responsibilities directly related to running BMX and were used as the focus of information for this study based on relevance to the research questions and the initiative. The remaining three participants at NSU did not have responsibilities directly related to running the day-to-day operations of the retention initiative and were not considered in the analysis in this study after review of the information they provided. The positions and titles of the six administrative participants varied from Associate Dean to Ph.D candidate. Other titles reported included program director, program coordinator, student success coordinator, assistant director. The average length of time the participants have been in higher education was 11 years, with the most being 27, and the least being four years. The average length of time the administrator has spent at NSU for their years in higher education was 11 years with the low being four and the highest being 27 years. 


\section{Case Overview}

Northwestern State University's retention initiative, the Black Male Exchange (BMX), has focused on developing student participants' cultural awareness to raise self-esteem and promote positive identity development. Administrators and students have understood the mission to recruit, retain and graduate Black males, who excel in their contributions to their community. The two parts of the initiative, the precollege pipeline program and the college student organization, both have been recognized as key components that make the mission possible. Major initiative partnerships included offices within Student Affairs, the high schools within the city district, and the Black leadership in the community.

Northwestern State University's diversity paradigm has shifted focus over the last five years, since the beginning of the current NSU president's term. The older diversity paradigm was centered on ethnic, gender, and race issues; the new paradigm more recently has focused on overarching issues of class, access, literacy, poverty, sustainability, and other issues with global effects. Despite the shift, there has been a vested interest in the BMX. The leadership of the initiative has been concentrating on assessing the program's placement and its validity in the new approach to equity and access.

The students attributed their adjustment and continual success toward matriculation to their engagement with BMX. They held the staff of the program in high regard as cultural experts, mentors, role models, and Black men who genuinely care about their holistic well-being. In moments of despair about financial concerns, academic stress, and personal relationships, staff has aided students and has helped to bring resolution to student issues. The students placed great importance on their relationship with BMX staff. For some, it superceded the relationship they had with faculty. Even though BMX staff has promoted the importance of faculty interaction, 
developing faculty relationships remained a challenge and barrier for some of the students. The BMX staff's level of care for individual students has included a formal monitoring system of social media posts on Facebook, as well as grooming the members of the student organization to hold each other accountable for taking the same level of care. Not only have staff asked about grades and checked in with students, they also have asked student leaders to model the same behavior within the group. The sense of brotherhood and love among staff and students seemed to have surpassed the traditional Black Greek brotherhood, which for decades, was the prominent way to experience the network and bond between Black male students.

Administrators reported campus-wide awareness of student pride in their academic performance and overall professionalism. Students had an opportunity to be on a fast track to take leadership within the organization, which assisted them in increasing positive student engagement, gaining self-confidence, and developing leadership skills. Black male students active in the initiative purposefully have sought to eliminate negative stereotypes with consistent, articulate, and well-designed arguments about controversial cultural topics in class discussions; in the annual cultural and educational programs sponsored by the student group; and in their professional demeanors. The students in the college organization promoted a counter-story to the negative stereotyping of what it means to be a Black male in college to the campus community, to participants in the high school pipeline program, and the Black community.

Although a number of students participated in the high school, precollege program and subsequently enrolled at Northwestern State University and felt welcomed when they joined the college organization, still a portion have chosen not to join once enrolled at NSU. Administrators recognized the need to figure out a better way to identify the students within a cohort. Recognizing the physical number of students in the cohort will assist in monitoring the student 
experience and reporting the impact that BMX is making on campus. They also recognized the need to reach out and to increase the presence of BMX at the other three physical NSU campuses. Other Black male students, who were first introduced to the initiative in their freshmen year, were drawn to the organization based on consistently positive annual programming. Others have felt that they were developing multiple dominant identities, which compete and were in conflict, resulting in a lack of engagement with the organization and doubts of belonging. Student leaders have recognized that not everyone is doing his part as a member to uphold the values and standards the original student leaders set as the precedent — establishing a level of accountability and genuine brotherly care.

Providing evidence of impact on student success and development will be necessary based on the institution's new diversity paradigm. Administrators discussed the urgency to prove that the total number of students affected by the program justified the level and amount of resources invested in the initiative. Formal and sophisticated assessment practices needed to be developed. The current practice of counting the number of participating Black males who returned the following fall with satisfactory academic success needed to be developed. The anecdotal stories of student success and observations of individual student growth served as indirect measures of assessment.

Data collection and analysis led to several important outcomes when presenting the description of the Black Male Exchange in this study. The data I collected and analyzed from the Black Male Exchange at NSU provided information about the mission of the retention initiative and the actions and direction taken to fulfill it. There were several ways that the BMX mission connected with the overall institutional mission. Both student and administrative interviews contributed to my understanding of how mission was viewed, achieved, and the individual 
impact the mission made in the lives of student participants. Information shared by

administrators and a review of Northwestern State's website also revealed how BMX was viewed and how it connected the larger campus diversity initiative. Diversity has been valued at Northwestern State and has been an important factor to institutional leaders as it has grown and approached the strategies to achieve being an inclusive community. I gained an understanding of the institutionalization process and development of the initiative from the data analysis of my administrative interviews. Based on Curry's (1993) description of the process to institutionalize innovative programs, there were specific steps discussed by administrators that have shown a significant commitment to institutionalize BMX at Northwestern State. Students shared the importance of developing faculty relationships. Students have understood the benefits of such relationships, but they have found it difficult to engage faculty and navigate those relationships.

\section{Mission of the Black Male Exchange}

The mission of the Black Male Exchange at Northwestern State University has focused on retaining Black undergraduate male students to graduation. The initiative introduced to and engaged men in cultural identity as a pathway to retention. Additionally, administrators consciously promoted, planned, and executed programming professionally and modeled excellence and professionalism for the student members. Administrators expected a high standard of excellence and professionalism from the student members. BMX valued the individual intra-diversity that comprises the membership of the college group and viewed it as a way to counter negative stereotypes of Black males and to exemplify the diversity within the Black male population at NSU. Administrators and current students both understood that for BMX to maintain a successful program, there was a need to start engaging Black males before post-secondary education and to increase college access for Black male high school students. 
Retention. BMX had a clear and definitive goal of retention. When asked, all administrators and students interviewed similarly stated the mission of the initiative. They all included the language "increasing retention of Black male students" as part of the mission when responding. The focus on retention was also expressed on two levels: secondary and postsecondary education. Retention as a focus was clearly stated in how they spoke about the program and also in what was written about the program. The printed mission of the program reiterated the statements of all the administrators, including statements about "increasing retention," as well as "increasing recruitment" and "graduation rates of African-American males." There was no difference in language between the students' and administrators' spoken versus written missions.

The administrators defined retention as a part of the mission and in the actions taken to achieve retention goals. Retention goals have been defined by Northwestern State University in terms of rates. Mr. Brown provided insight on institutional measurements and retention rates. At the time of data collection, Mr. Brown served as the coordinator for all African-American students on campus out of the Multicultural Center. He has served all of his six years in higher education at Northwestern State. Prior to Northwestern State, he was in the retail business and owned his own franchised business. As an undergraduate student, he was an active student leader in several organizations, including president of the undergraduate chapter of a historically Black Greek-lettered organization. He came to NSU after being a community organizer and, when hired, he used all of his past experiences to create the current BMX structure.

As the first and only past coordinator of the initiative, Mr. Brown described the institutional rates, stating "The institution has a goal...Retention is $90 \%$ and graduation is $70 \%$." There have been numerical goals set by the institution for initiatives that include retention in their mission. 
BMX was included and has used the rates as the standard of measurement for successful retention.

Mr. King directed me to review the online institutional retention and graduation rates of Black male students and how they compared to the institutional standards. At the time of data collection, Mr. King was the Associate Dean of Students. His career in higher education totaled almost 19 years, with most of his professional experience being at NSU. He attended Northwestern State as an undergraduate student, was active in student organizations and was initiated while an undergraduate at NSU as a member of the same historically Black, Greeklettered organization as Mr. Brown. He briefly left NSU for graduate school out-of-state, during which time he met Mr. Brown. He returned after completion of his master's degree in a professional position in admissions and then moved to multicultural affairs and finally to the central student affairs administration as Associate Dean of Students.

According to data provided by Northwestern State University's Institutional Analysis Office, the one-year persistence or retention rates for first-time Black male freshmen since the start of BMX in 2004 has steadily increased from about $71 \%$ in 2005 to $77 \%$ reported in 2008 . Student leaders were aware of the retention rates, as well as the low graduation rates. Emmanuel, the current president of BMX, stressed raising the graduation rate as a goal he set at the beginning of his term. At the time data was collected, Emmanuel was a graduating, in-state senior majoring in finance; he was one of a few Black males graduating from the School of Business. He self-identified as bi-racial and was raised in a two-parent, upper-middle class home with his Black father and his White mother of German heritage. Both of his parents had college degrees (his father a master's degree and his mother a bachelor's degree). Prior to assuming the presidency of BMX, Emmanuel served the organization as the vice-president and the 
parliamentarian. He believed the last reported graduation rate for Black males to be $15 \%$ at the beginning of his term (actual graduation rate was16\%) and stated:

It's been a big deal...I think that was the number I heard last year. It's pretty low, over six years, 15 or $20 \%$. And hopefully, I mean, there's going to be a lot of stuff that I've done within my group - I mean, certainly we've lost one or two, but not a lot. So I work to correct it. It's always a problem. So I wanted to change that.

Mr. King provided additional information about the institution's resources and statistics used in confirming the successful retention effort of BMX:

...we could look at enrollment, look at the early warnings. What was the response? What percentage of early warning students took advantage of tutorial support? You then look at enrollment, spring re-enrollment. I mean spring enrollment. How many of the admitted fall students enrolled in the spring? Then you can do a fall GPA assessment, academic hours achievement, spring same thing. And then you get your first real telltale the 21 st day of the following fall when you see what percentage of them came back. That ultimately is what's looked at when looking at how a student is retained.

Mr. King further described how BMX and NSU carried out retention efforts through resource management and referrals across the institution:

They come with a set of dreams that we connect to academic opportunities, and then we have a responsibility to communicate, articulate those opportunities, and then work with the student on how to get there and as barriers present themselves, For example, if it's academic, we move towards resources. If it's psychological, we move towards resources. If it's financial, we move towards resources. ... That's the university. 
Mr. King provided an example of balancing and managing what Swail, Redd, and Perna (2003) defined as "reciprocity" in their model of student persistence and achievement, where "the individual impact of variables can combine and work with or against other variables" (p.81). Their research took into consideration the balance necessary between academic resources and student services resources, which were identified in their model as components within the institutional factors affecting student persistence and achievement. According to these researchers, colleges and universities have the responsibility to provide these components and resources to students as the foundation of the student experience. The student experience is at the center of the Geometric Model of Student Persistence and Achievement. 
Figure 2. Geometric Model of Student Persistence and Achievement

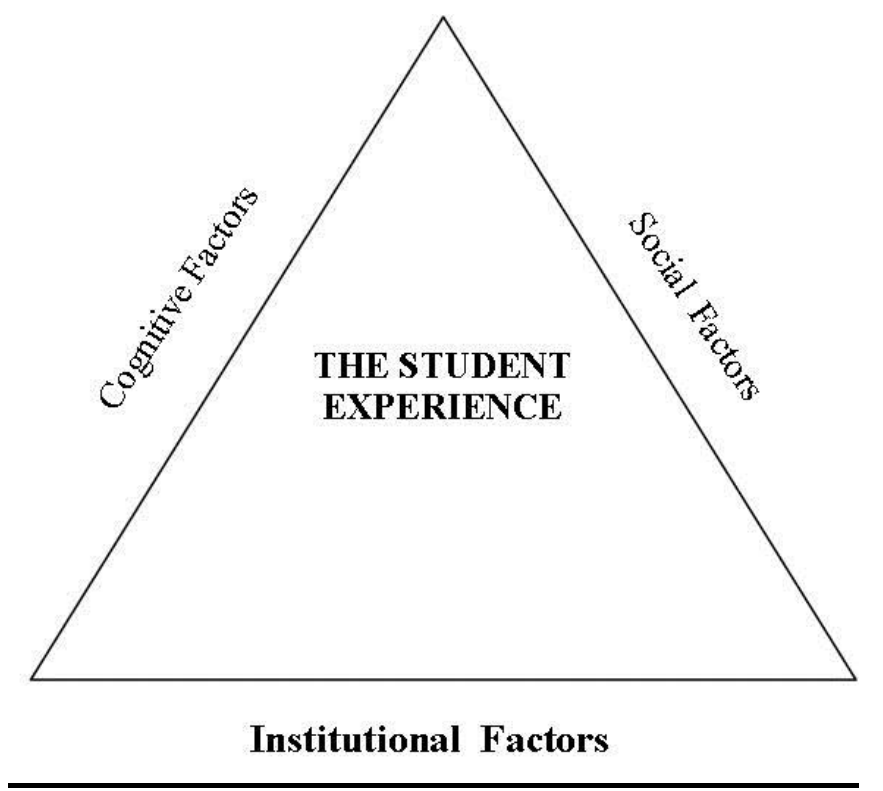

Figure 2. Geometric Model of Student Persistence and Achievement (Swail, Redd, and Perna, 2003). Cognitive factors include students' knowledge and academic ability with which they enter college; social factors include parental support, peer support, career goals, and skills in handling social situations; institutional factors includes the academic and social resources provided by the institution as support for student persistence. All three have equal importance when calibrating individual student needs for college success. Adapted from Swail, W.A, Redd, K.E., \& Perna, L.W. (2003). Retaining minority students in higher education: A framework for success. $A S H E$ ERIC Higher Education Report 30(2). San Francisco: Jossey-Bass.

Mr. Douglass was the current program coordinator for the initiative. He has been in higher education for four years, all in the position of Program Coordinator for BMX. He is a recent graduate of Northwestern State and was an active participant in BMX as an undergraduate student. He was a transfer student as an undergraduate and discovered BMX through fraternity affiliations he made when he first came to Northwestern. He was the undergraduate intern who 
assisted the program in creating and growing their relationships with the surrounding public schools to recruit parents and high school students to participate in the precollege program component. He was in the same historically Black, Greek-lettered organization as Mr. King and Mr. Brown; they were all fraternity brothers. Mr. Douglass addressed BMX's outreach and support efforts used to achieve their retention goals:

Students on campus know that BMX is a support group. If there are any issues that students are dealing with, they know who they can turn to. If it's through the grapevine where it goes from a freshman to a sophomore, to a junior, to a senior, and then ultimately it gets to me or, [Mr. Brown], or [Mr. King], and we haven't addressed those students' issues by simply saying, "Hey, what is that student's name, what is their number?" We just outreach to them to really address those issues. That's not uncommon. That happens all the time...We're saying, "Hey! If you have any challenges here, please reach out to us. This is our advisor; this is where their offices are." So students know that if, "Hey, I have some issues on campus I know who to turn to." One example of this outreach effort was shared by a member named Nic, a sophomore business and mass communication major. Nic was originally from Chicago, IL. He moved with his mother starting the last three years of his high school career and was able to take advantage of in-state tuition at NSU. Nic shared that originally, he had no intentions of attending college. It was his mother who planted the seed and asked him during his sophomore year of high school if he planned to go to college. He had a fear of being accepted by others in his family who did not attend college, including his mother and father. He was the first and only Black male to go to college in his family. Once those fears were calmed by his mother's assurance, he enrolled at NSU. 
Nic explained, at one point in time, he was contemplating leaving NSU. After a post on Facebook about his potential decision to leave, he was immediately contacted by fellow BMX members and via phone by Mr. Douglass:

I was going to transfer. And then Mr. Douglass called me up, so I had an incoming call. I was just getting off of work and I'm like who's this? So, I answered it, and he [Mr. Douglass] was like, "What's up?" I was like, "Yeah, how are you doing?” He's like, “Oh, yeah, do you have time to meet with me tomorrow?" So I met with him the next day, and then from there I had a meeting with him on Friday and then I met him again, and then I'm going to email him this week because I'm going to see him Friday. So it was like they knew instantly...I had a whole Facebook status about it. It was like one of the main reasons why I had to meet with Mr. Douglass, was to prioritize my plan. I mean once I got it off my chest, I felt a lot better, and now I know I can go and just call him up. This served as an example of a very close monitoring system of the student experience that Swail, Redd, and Perna (2003) stated should be at the center of any campus retention initiative. Mr. Douglass and the other students watched what members said and posted on social media outlets as a way to keep up with how each individual member was managing their day-to-day college career to stop any issues early that might affect their ability to persist.

Other support for retention as key to the mission of BMX came from unsolicited statements administrators made. When asked what the expectation of a new student participant in the initiative should be when entering NSU, Mr. King stated:

The expectation would be that the young man would become a part of our communication club, and that [they] will instantly begin to become aware of different things that are going on that could supplement their academic experience at the 
institution. And begin to fill some of the downtime with constructive options- those that are learning, fun, informal social opportunities. So that they would ...begin the college process in the fold of something that's affirming the academic and social to them in a very positive way.

Mr. King's response showed the deliberate care for both academic and social integration of Black male students. It reinforced Tinto's (1975) major premise to his longitudinal model of dropout, where he stated, "given individual characteristics, prior experiences, and commitments, the model argues that it is the individual's integration into the academic and social system of the college that most directly relates to his continuance in that college" (p. 96).

The retention goals of the mission also supported the student services component of the Geometric Model of Persistence and Achievement explained by Swail, Redd, and Perna (2003). They included campus climate, accessibility to the campus and resources, accessible and affordable on-campus housing, and counseling services as aspects of student services components important to student retention. Specifically, they posited that student services help to promote a positive campus climate. Campus climate has been reflected "by how the institution treats and supports students and by the positive nature of peer relations on campus" and "is important to the self-esteem and confidence a student generates" (p. 107).

Mr. King's response also incorporated the academic components that students may take advantage of after admission to an institution (i.e., academic advising, research opportunities, tutoring, mentoring, and supplemental instruction); these are all factors that make up the framework of the Geometric Model of Student Persistence and Achievement. The administrators addressed the academic support provided to Black male students through BMX that assisted in 
their retention through to graduation. This academic support was given by both administrators and fellow Black male student members.

Students complimented Mr. King's responses when discussing their persistence. Students have managed feelings of isolation and thoughts of leaving NSU by getting involved, connecting with members of BMX, and connecting with the staff of BMX. One out-of-state sophomore, Ernest, expressed his freshman year isolation. Ernest was a double major in film and media studies and criminology. He had an overall, self-reported GPA of 2.6 and planned to work for the FBI after graduation. He went to a private high school and was raised in a two-family home, where his mother received an associate's degree and his father a master's degree. Although he attributed his persistence at NSU to his involvement in BMX, he had not taken any formal leadership positions. He was an active participant in the annual events and a regular participant in the monthly book study sessions. In discussing his isolation and initial plans to leave NSU, he stated:

BMX really was one of the sole reasons, that's why I had decided to come back to NSU, like in August. Majority of my freshman year I kind of just felt alone. I just wanted to go back home, so I'll get to be with those people I feel comfortable around. But being more involved with BMX, I had that family feeling, and I think that it's really good. It brought me back really. It got me through a lot of my challenges being here, I didn't run away from them.

BMX served as the entryway for these students to get the help needed to overcome their retention issues.

Cultural identity and development. Another important element to the BMX mission has been the use of cultural identity as a pathway to retention. The administrators discussed 
introducing the men to and engaging them in their cultural identity as a way to retain students and help with their development. The responses provided about cultural identity and development were unsolicited as part of their response to other questions about their historical involvement in the creation and current responsibilities of BMX, the strengths of the initiatives, and what students learned by being a part of BMX. Questions about how students have connected to the institution and to BMX and how they have overcome challenges in college also revealed information about their cultural identity development. Mr. Brown, as the first full-time coordinator of BMX, created its current programming structure under the following belief he expressed during his interview:

I'm under the school of thought, inclination, orientation that if a community is organized under a particular identity, that there should be a considerable amount of time where they dialog about that identity and explore that identity... So I am very much trepidatious [sic] about organizations that say, "We are about Black men," but they're not having any constant dialog amongst themselves. Not with the greater community, but amongst themselves about what it means to be both Black and what it means to be male, especially in a contemporary society.

Both Mr. Douglass and Mr. King credited Mr. Brown with developing the initial structure as the first, full-time staff member in charge of BMX. He implemented cultural exploration and identity development as principal components to the initiative. The programming and meeting structure of the college organization has not changed dramatically over the years, and the cultural exploration focus has remained a strength, according to Mr. Douglass:

[Brown] really invoked a more cultural awareness into the program as well, understanding that a lot of the issues that Black males have is really an identity issue. 
And also they're constantly contending with others, what kind of ascribes to what makes a Black male. The cultural identity piece actually empowers a young man to love himself, to understand it's okay to be a person of African-American descent. And as well being a person of African descent, theirs leaves a legacy of excellence. And so with that legacy of excellence that we have inherited, they know that they're following the footsteps of many great people.

Mr. Douglass later added, "One of the biggest things, the attributes that [Brown] contributed, is really instilling and embedding that cultural awareness piece, because that really addresses the internal problems that young Black males are dealing with.” Administrators articulated examples of how cultural identity has been expressed through the nature of BMX programming throughout the academic year. Mr. Douglass explained the intentionality of their community programming to center around Black cultural issues that extend beyond NSU into the Black community:

We are very culturally centered, and we are community centered, so a lot of what we do I we really want the community—-the extended black community—in [state] to be involved with us, to see us as a group of young men who are doing the right thing, who are trying to address some issues plaguing society.

When asked, in general, what students learn from being in BMX, Mr. King said:

One thing we want them to learn is that culture in a very deep nuanced way exists, and that it's legitimate. And that they don't have to hide from it or be embarrassed from it. Once they really get into it, it's a very strong source of power...We want them to be exposed. We don't define what they're exposed to per se; we just want them to be exposed to complex thinkers, critical texts, and critical texts around culture. 
This understanding of cultural identity is shown in Ivan's responses, a senior double-majoring in African-American and religious studies. He was currently the paid, undergraduate, student intern with the program who assisted in planning and recruiting for the precollege program. He participated in both the precollege program in high school and joined BMX once enrolled at NSU. He also joined the same historically Black, Greek-lettered organization as Mr. King, Mr. Brown, and Mr. Douglass when he entered NSU. He was an academic scholarship recipient at NSU, who came from a low-income background. Ivan was primarily raised by his older sister. During the focus group discussion, he articulated his pride in his identity and how his cultural self-awareness through BMX had grown and had prompted his participation in cultural programs:

So we have cultural programs, which I was talking about earlier. And those things are so important because that makes the difference...the cultural piece really makes a difference for all of us because we've learned, and not to sound arrogant, like Troy already said, but, like in BMX, like if you are part of BMX you really learn that being a Black male is the best thing that's going to ever happen to you. Like where you come from, nobody can touch you. No other group can touch you. No other civilization can touch you. No other culture can touch yours. Like, you come from a long reigning - you come from a list, a lineage of greatness; through all the mess that you've been told, through the all the myths, you still come from a long list of greatness. And so for me, BMX is like, I can give it now to BMX like that; that they helped shaped my identity. So I'm proud to have locks and proud to have Black skin and proud to be a Black male and proud to be in college. I'm proud to sit next to my Caucasian counterparts. I'm proud to engage in debate. I'm proud to have different views. I guess I can say I'm proud to see the world 
the way I want to see it. I'm proud to have Afro-Centric view. I mean that is all part of BMX. I would never get that anywhere.

Mr. King additionally clarified that the basis of all the programming had a cultural focus: "That's what we face here with programs; we're not an entertainment group. We're going to deal with culture and education.”

Cultural identity development was achieved through student programming and one-onone interaction with the students, emphasizing cultural recognition, and intentional dialog and communication about culture. Mr. Brown provided information on programming, referring to each of the annual events and meetings of BMX as "points of contact" with the students. In the early structuring of the initiative, Mr. Brown's intentions in planning the organization's annual program was not to over-engage students and to have each point of contact grow and develop cultural identity for members:

I had decided that the one thing that was plaguing college students was, sometimes they were in an organization that met too much. They always had meetings either weekly or two-weekly, and sometimes those proved to be unsuccessful and inefficient. So I said we want to have one meeting. One meeting a month and affairs that we handle at the meeting will be administrative, announcements, and program updates.

BMX has hosted a members' meeting, one cultural and educational or social program per month for the NSU community, and then a third book study group where a text surrounding Black culture, manhood, or other relevant topics was read over the academic year by the group members. In the recent past, the book study group has read texts written by political activist and essayist Kevin Powell, African cultural historian Anthony Browder, psychologist and professor Dr. Na'iam Akbar, and the Black historical figure Dr. Carter G. Woodson to name a handful of 
the many authors. These texts (one or two per year, depending on the length of book chosen) was read outside of required academic work and discussed throughout the semester through monthly group dialog and in one-on-one discussion with administrative staff.

In a review of the listed sponsored programs provided on the BMX website, all eight, current, annual programs had a Black cultural aspect to either the overall theme of the program or the educational goals. Out of the eight annual programs, only two were labeled as social and one of those two programs had a cultural theme related to it. The group had intramural football and basketball teams that members can play on each semester, in addition to cultural programs to engage the NSU community with BMX members. Several programs were specific to discussing Black male culture and identity and were held as single-gendered workshops.

The book study group setting was where the students were provided a safe place with elder black male experts to explore what administrators called "Black Manhood Development." Mr. Brown explained how this focus on Black Manhood provided identity development for the participants:

They learn that complexity of the identity of being both Black and male. They also learn they don't have to be definitive about their cultural heritage and that they can empower and engage and interface with their peers, on a balanced footing, without having to feel like they have to defend what Black people do in general society or they're in a position where they have to have [emphasis added] a dialog about it.

The introduction to cultural awareness through literacy has been one part of BMX programming that has increased self-awareness and cultural identity development. The development of cultural awareness has helped members manage the isolation and hyperexposure in classroom settings. Many members who have participated in the monthly 
independent book study group have attributed their personal development to the sessions. The book study discussions helped members manage the uncomfortable classroom situations they have encountered surrounding cultural issues and created a new value for cultural literacy competence. It has been viewed as a way to empower Black male students in classroom situations where they normally have felt powerless and where professors and non-Black students have looked to them for explanations of Black culture.

Andre, a sophomore criminal justice and history major, explained how BMX has changed his view about the value of reading. Andre recently joined his historically Black, Greek-lettered fraternity (not the same organization as the BMX administrators). The following year for BMX, he was to serve as the student representative for the precollege workshops. He would be in charge of working with the program coordinator, Mr. Douglass, to run the high school workshops and for planning the academic recognition program at the end of the year for graduating seniors. Andre's increase in reading outside of required academic work was attributed to BMX and a new understanding of personal power through literacy:

I read a lot more just because of BMX. I can't always make it to the book sessions. I read because I feel like no one can ever take that from you. That is one thing I was always taught, when you read, that's knowledge that you arm yourself with and no one can take that from you, no matter how much you read no one can take that from you, and I use it as such. I feel like when I am learning and when I am reading, just for me because I want to know about something, I feel like I have gained a much better perspective on the issue and I like to continue with that and BMX allows me.

In the same focus group, Jermaine, senior member of BMX, discussed how his increased reading outside of coursework has helped his confidence in managing marginalization in the classroom. 
He served as the current student representative for the precollege workshop sessions. He was a communications major and had branched off to leadership outside of BMX, serving as NSU's campus student activities planning board chair for diversity programs. He was an out-of-state student who grew up living with his dad (although his mom was active in his life) and selfidentified as low income. Both of his parents have had some college education. He was most proud of helping to get eight of the high school male students in this year's precollege cohort to graduate and successfully to gain admission to NSU for the upcoming fall term. He explained the connection of literacy to the overall mission of BMX:

The goal essentially is to get African-American men to graduate from college. But it's not just like, knowledge is power; it is like applied knowledge is power. So what you take from it, you take something from it and you have to apply it in some facet of life. No matter, it can be a teacher, professor, finance lawyer, like you'll have that consciousness I should say, whereas Mos Def says, "Black on both sides." Whereas you know your history, so that when you are in your class and you are at the top of your Black issues, and you are the only Black student and everybody look at you, you won't feel uncomfortable, like okay, "Let me explain." I think that ultimately that is the goal there. He further described the purpose of reading for cultural understanding by clarifying the connection between personal identity development and literacy:

And it is not to create superiority or anything like that. For the record, it is so that you are armed to take on the world. So you are not 45 and wondering why you feel like something is missing, and you don't feel like, I don't know, like made you realize you don't wake up like, wow. It is just so you have a sense of culture, some base of something, some knowledge. 
Providing Black male students with information and understanding about cultural issues through programming and book study sessions has helped them manage in-class and out-of-class experiences with faculty and peers where they are in the minority as far as numbers. The negative stereotypes that are present in society about Black males were present at NSU, but because of the Black Manhood Development, the weight of being the only Black person in the classroom didn't feel as much of a burden. BMX has helped NSU promote positive campus diversity through meaningful informal interactive diversity and classroom diversity by having informed Black male students positively contribute to cultural discussions to help expand, not only their development and understanding of culture, but others' as well. Black male students have been able to actively combat negative stereotypes held by others about Black males by engaging confidently when they are introduced. As described by Ivan:

When I moved out here, it was like I was suffering from withdrawal, like what should I do? Oh my gosh! This is crazy! It's like one Black person every ten square of miles. So, what does it mean to be Black? What does that mean? How does that affect me? So when I got to this university, I had to find out, okay. There's certain things that's already been said about our community. So, I'm already being perceived a certain way. So I walk into a classroom and it's me and it's 75 to 100 people and one of three Black people, and that is if I'm lucky. So I'm like, who am I... Like, who is this person? Why am I here? Why am I the black spot in the classroom? Just like the black hole, it's like you see all this white and then "Oh he stands out." And then it doesn't help that I have chosen to let my hair grow or dress a certain way, those things that really don't help from their perspective, but they don't understand because they're not a part of my culture. But then when I talk, that's where the difference is mainly, because I start articulating, and I start 
breaking down the arguments. Then they're like, “Oh, maybe he does belong here.” So I think that was the single most - that was the greatest adjustment we'll have to make; was you have to know who you are, and you're representing more than just you. You're representing a vast amount of people. And we're so diverse.

Mr. Brown provided a rationale for the specific programs designed for only Black male student participants to engage them in learning about Black Manhood. He described the importance of providing a space to dialog about issues and aspects of Black male culture stating: ... at that point that's when they talk with somebody who challenges them about hypermasculinity, challenges them on homophobia, challenges them on sexism, challenges them on being satisfied with mediocrity as a standard, challenges them on their image mimicking pop culture. We really don't think it's best that African-American men to be challenged on those issues in an open forum in an open space. Not because we want to protect anyone's egos, we just think it's better placed and you get more maximization out of a closed session, ... basically we are doing a self-critique among men of color and thinking where our challenges are and how we can develop those.

Excellence and professionalism. BMX administrators consciously have promoted, planned, and executed programming to model excellence and professionalism for the students. They also expected excellence and professionalism from members. Based on information collected directly from administrative interviews, it has been important to counter the public perception of Black males on campus. This was reinforced by student comments in the focus groups when addressing the challenges and adjustments they had to face during their college experience and how BMX has assisted in their success. 
The standard of excellence required of student members from administrators comes through in challenging the students to excel in programming, leadership development, and academics. Mr. Douglass stated that the focus of the initiative's standard of excellence was based on student academic and leadership expectations of BMX. Student members were incorporated into the program planning process early in their collegiate career and took the lead on developing all of the events that currently have historical and traditional merit on campus. Mr. Douglass stated that student leadership development over time has been one of the strengths of the program:

We see the quality of student leadership increase, because now the expectations are, "You are a student, but you're also a student leader." So they must academically excel, but also they're going to lead their peers by example. They embody the whole notion of servant leadership. Because of that, it has an impact on the type of program, programs of quality. So the whole notion of them starting [meetings or events] late, that is something that we just dispel.

The staff of BMX has modeled the standards of professionalism expected by the students. Jermaine, a graduating senior who served as the NSU student activities planning board diversity programming chair, attributed his current standard of excellence to Mr. Brown's example:

Mr. Brown does not play with time, and I am embarrassed when I am late, so he is like you know, "you don't want to like mess it up," especially with the event planning and stuff. Like you feel like it is so much pressure, that you do not want to mess up so [you] really go beyond, up and above, to make sure you really got yourself as tight as possible. So even if you do mess up, they can see you put $110 \%$ into it. 
The students, as Mr. King positioned it "are the face of BMX" and they made it a point to also attend and actively participate in other campus events as known members of BMX. Emmanuel, the current president, spoke about his responsibility to represent BMX and support programs outside of BMX planned by other Black student organizations:

I'm pretty involved with BMX...Most of the stuff I do revolves around that. It's a service organization, so service, retention. I mean, I'm always on campus doing a lot of activities, a lot of multiple activities all the time...I'm the president right now of BMX, so the last couple of years actually [I] go represent them, go support other people's "orgs" and their events.

What the institution knew was that BMX members exemplify a standard of excellence and professionalism shown by the leaders of the group and administrative staff. Mr. King stated: Their dominant association is high academic achievement, a sense of chivalry, interestingly, a sense of well-rounded young people who are leaders. And because most of $[\mathrm{BMX}]$, probably $90 \%$ of what $[\mathrm{BMX}]$ does in terms of the public face is led by students, so it has that affinity, very strong platform of representing Black manhood.

Mr. King viewed BMX as the entryway for the students to engage the larger institution on a level of academic and professional excellence not normally expected from Black males at PWIs:

We want them to engage their University, to realize BMX is just one component of it. And that they pay the same tuition and have the same academic expectations, and that they should take full advantage of their University.

BMX has served as a launching pad for the students to increase their leadership skills, academic performance, and overall professionalism. Members of BMX can more comfortably engage with the NSU community without focusing on the public's negative stereotypes of Black 
men, based on statistics and past low performance. Some BMX members have joined historically Black, Greek-lettered organizations after being involved with BMX. Others have branched off into leadership positions on the campus activities student programming board as well as in residence life. They have continued their involvement with BMX as they expanded and explored other opportunities to engage with the campus. They have been involved and engaged in the institution beyond BMX and have been able to influence the perceptions of Black men on campus. As Mr. Douglass succinctly stated at the close of our interview, BMX "is countering these data that plague Black men."

Mr. King spoke specifically about the current president of BMX and his "rise to leadership" at NSU, using it as an example of many of the Black male student leaders that have come before him:

It gives a platform for these people to rise; for example Emmanuel. Emmanuel, we were at a crossroads with Emmanuel. We were having a conversation with him about should he run for the University Student Body President, or should he run for BMX? And [he] said, "I wanted the BMX experience.” Now Emmanuel would be stellar regardless. But BMX gave a platform for us to discover Emmanuel and for Emmanuel to grow and supplement... what he brought to the table, through BMX. And so it connects us to the profound, great students that are out there. Otherwise, Emmanuel could have had just a unique experience. Whether or not he would have found his way to student government or another university department, I don't know. He might have just had a different type of experience in this parallel universe. Whether he would have been as solid, I don't know. But he was introduced to us through the vehicle of BMX. 
Emmanuel purposefully chose to develop his leadership on campus through BMX. As a graduating business major, the choice was considered unconventional by some:

I always think about... if there was another group that did something similar, and it wasn't for Black men, I would have definitely leaned towards BMX, but probably still would pursue it...So I suppose, if I was going to be the stereotypical business student, I would have came in, like, volunteered for a Relay-for-Life type organization versus a typical, actually mainstream, kind of thing like that. Would have joined a professional organization in financial management, I didn't choose to do that. I could have-most of my counterparts are probably in like five or six different clubs...but that's not what I did. But at the same time, I don't apologize for that at all. Just the simple fact that they see how I tell them what I do: "What do you do?" "Oh, I'm the president of BMX" "Oh really?!"...So reconciling that and my identity with other people's expectations, I mean, well not even reconcile, but just knowing how to handle that.

BMX has been a vehicle for Black male students to engage with the institution on a regular basis, which, based on the history of engagement of Black male students at PWIs, would not typically happen. BMX has served as an entry point for Black male students to engage at a high standard of excellence and leadership. It has provided opportunities for other NSU student organizations to recruit and entice a pool of eligible Black male student leaders who are trained for high levels of leadership through BMX programming. Kinzie, Gonyea, Shoup, and Kuh (2008) explained that student engagement consists of two features, "the extent to which students take part in educationally effective practices and the degree to which the institution organizes productive activities for student learning” (p. 23). BMX has served as NSU's institutional answer to engaging Black male students. These educational opportunities are ways to place into practice 
Chickering and Gamson's (1987) Seven Principles for Good Practices in Undergraduate

Education. Institutions have used their principles to help revise curriculum, instruction, and pedagogical methods in higher education and improvements in the college classroom.

Furthermore, the American Association of Colleges and University's (AAC\&U) 2007 report entitled College Learning for the New Global Community posited that there is increasing evidence that certain student engagement experiences are inextricably connected to persistence and retention of students. Their assessment incorporated many academic-based opportunities, including but not exclusive to: service learning opportunities, learning communities, first-year seminars, undergraduate research, internships, and study abroad.

Two out of seven of Chickering's principles were practiced by the administrators of BMX as they engaged Black male students at NSU in its extra and co-curricular programming: (1) communication of high expectations; and (2) respecting diverse talents and ways of learning. These two principles have been embedded in the way BMX carries out their mission. What was not highlighted in the AAC\&U report or the other research on good practices that encourage persistence and retention was the influence that identity-based student organizations have on student engagement and leadership development. The report mainly focused on classroom engagement. BMX serves as an example of the impact that a co-curricular student organization with a mission of excellence and professionalism can have on retaining historically underserved students at PWIs.

Students understood the BMX standard well and made every attempt to carry it out. They seriously took into consideration the responsibilities of planning BMX events, and personified the purpose of the organization on campus as a known member, which built maturity in their character and identity. They held each other accountable. One incident that several of the focus 
groups mentioned was related to members' Facebook postings and pictures. A meeting was called by older members to let the younger members know the proper way to represent themselves as members of BMX. Senior member Ivan recounted the meeting:

We called the meeting, and we opened different Facebook pages. We got pictures. We got images, all that kind of stuff. And we stressed this is not to put anybody down. This is not anything that's attacking you individually if you see yourself. You're not attacked for what it is. It's our responsibility to pass on this knowledge so that you guys know what we represent and what we're about and then when people who know that you are part of BMX, you have to uphold yourself a certain way. Now when we are together it's nothing. It's whatever. But when we are with other people, we have to watch our conduct. And so we had a meeting and it was more so of a proper protocol type meeting, I guess, if you guys should want to call it. It was a "How to conduct yourself as a BMX member representing BMX."

The staff accountability and peer accountability has created a level of confidence and an organization atmosphere that members labeled as a brotherhood.

Valuing intragroup diversity. The administrators and Black male students promoted and respected the individuality of its members. It was embedded in their mission and how the organization's members presented themselves on campus to incoming potential Black male student members and all of the Northwestern State University community. They were cautious not to surrender to misleading stereotypes that identify Black men as monolithic in nature, but to exist as a multifarious culture with rich dynamic history that each Black male presents. This respect for distinctiveness, Mr. Brown believed, created well-rounded individuals who knew how 
to engage their NSU community and provided NSU with an understanding of the diversity within the group:

You know one of the things we teach them is we're not just trying to be good Black men. We're trying to have harmonious human relationships, and having harmonious human relationships is challenging in a society where people are always in conflict. So there are some things we're going to have to challenge about ourselves. So that's another thing, so you know we have openly gay brothers in BMX, we put no pressure on them as far as that, we have brothers who are conservative, we have brothers who are aggressive, we have brothers who are Black nationalists, we have brothers who are honor students. So we have brothers across the board, and there's no "fitting into," this is a BMX man, other than our standards of excellence of program initiatives and the way it was engaged was with confidence. So you know you'll see diversity when you interview all these guys. These guys are all over the map, all over the board geographically, thought-wise, how they can articulate themselves, their interests.

Administrators spoke of the individuality of character and background of the members that provided great diversity in the makeup of student members and how students interacted with each other and with the NSU community. Administrators were intentional about allowing the organization to appeal to all different types of Black male students and considered the diverse makeup of students one of the strengths of the program for many reasons.

The first reason for promoting intragroup diversity in members was that the men have the opportunity to develop into individuals in a space where they can engage with other Black males comfortably, who think, act, and come from different backgrounds. Second, they were challenged in that space with guidance to grow and take what they have learned into other 
interactions within the NSU community. Mr. Brown affirmed this as a unique strength of the gender-ethnic specific initiative:

The strength of $[\mathrm{BMX}]$ is diversity; it recognizes diversity in the Black males. A lot of times programs are designed and they already have this prototype in mind of what a Black male needs, and it doesn't allow for everything from an extreme honor student to be able to show their talents, as well to anybody who just wants to play ball. And [BMX] allows that, the diversity. That's the key strength... Another thing about that is that [BMX] doesn't impose their prototype of what it means to be an African-American male on these men who just engage in dialog about various events, various experiences, various beliefs, and how that goes into shaping our identity. But we, unlike a SAAB [Student African-American Brotherhood $]^{2}$ or something like that, we don't say you have to wear a shirt and tie, we don't say you have to, you know, pray, we don't say you have to say take this particular pledge, there's no $[\mathrm{BMX}]$ pledge, there's no $[\mathrm{BMX}]$ vow, you know, there's nothing like that. You come as you are, be who you are and just let us know that you want to be engaged and challenged, if some things, some beliefs, some attitudes or behaviors are harmful.

Retention begins before admission. Administrators and current members understood the need to start engaging students before postsecondary admission in order to maintain a successful initiative. The written mission has been extended to include retention of high school and college Black male students. BMX carried out this aspect of the mission through an extensive precollege program modeled after an established Latina retention program, Éxito de Hermana (pseudonym). NSU considered the program a best practice for recruitment and retention of historically

\footnotetext{
${ }^{2}$ Student African-American Brotherhood (SAAB) is an organization established first in 1990 at Georgia State University by Dr. Tyrone Bledsoe. It specifically was established to assist African-American male students to excel in college. It is headquartered at the University of Toledo. (retrieved from http://www.saabnational.org on March 18, 2011)
} 
underserved populations based on over 20 years of success. Mr. Douglass explained the importance of developing this component using already successful models:

For the most part we took the model. We took their recruiting model from applications, some of their high school connections, the way that they utilized the university resources, such as undergrad, admissions, to kind of help recruit students to the program. We looked at some of their curriculum for our student workshop curriculum and the college prep. The standard financial aid, admissions, scholarship, grants, life, but then we took and said there are some unique challenges that young Black males are dealing with and facing. So we modified and addressed those issues by creating different curriculum for Black males. The college preparation aspect of the program supported the larger institutional mission to engage with the surrounding community outside of NSU and broaden access to higher education for historically underserved groups. Mr. Brown explained the importance of connecting to the community and providing information about access to postsecondary education:

$[\mathrm{BMX}]$ tried to keep in front of those things so far as interpreting their financial aid award; we try to get in front of those things as far as what it actually takes to graduate. Most college students who enter the institution don't understand that it takes you 120 credit hours to graduate from the institution. We tell them that straight up, and we tell them this is how you get to 120 hours. And so we help the institution, because the institution is serving the population and a lot of people who are in the general population, especially the first generation students [who] aren't aware of the intricacies of the university, and some of the standards and some of the requirements. 
Access to college has been interpreted as a major component of the mission based on the institution's resource allocations. Annually, one member of BMX has been hired as a paid student intern and has worked with the program coordinator to organize the recruitment of Black, male high school students and their parents. This intern specifically has assisted the staff in managing the scheduling of workshops that cover admission requirements, funding opportunities, the application processes for college, and information about campus life and culture at NSU. The program coordinator, NSU admissions office, financial aid representatives, university recruitment staff, and members of the college organization took time during their Saturdays to host the workshops at the local high schools for students and parents.

During my time on campus at NSU, I observed Ivan, the BMX student member who served as the precollege program intern, calling high school guidance counselors from the surrounding city area. The student intern hosted ten conversations in the one sitting I observed. He specifically asked to speak with guidance counselors at the high schools or had the direct number to the counselors' office. He introduced himself as the BMX student intern, and many of the counselors knew who he was or about the precollege program. He used the call as an opportunity to provide these new or already partnered counselors with the new deadlines for parents and high school students to apply for the program. In the conversations, Ivan responded to questions about the current staff members and the current number of enrolled students and dates for some of the college organization's programs. The student intern also answered questions about upcoming workshop dates for the precollege program. The calls mostly served as updates. On fewer calls, I heard him leave a message for the counselors stating that he was introducing the program to the new schools, and they were targeting that particular school for expansion of the program to reach more Black male high school students and their parents. The 
intern was able to give a short briefing about the program to the newer contact, stating that it was a retention program for Black male students that reached down into the high schools to help them understand the enrollment process and college life at NSU.

Mr. King was intentional about this aspect of the initiative when he created it; he "wanted something that addressed the pipeline issue as well as the college organization." According to Mr. Brown when explaining the history of the initiative, access was a major component from the beginning. Mr. King first launched the college organization, and in the second year of the initiative, launched the high school precollege program. He waited one year to prepare the launch to make sure that the program was "authenticated" in the Black community. Strategically, the administrators took time to develop relationships and work with leadership in the city high schools, Black community, and admissions and outreach offices at NSU to specifically prepare and recruit Black male students, who are historically underprepared for the college admission process, to participate in the precollege program:

At the beginning, BMX makes it very clear that we are doing this because we want to challenge first generation learners. We see the tremendous value in education and how it changes lives. We see this as a continuation of the work of cultural heroes before us. And we want you to come to [Northwestern State University]. We are not a program that says, we are promoting higher education, but if you like what you see, come on out. We're very clear from the beginning. We want you to come to this University.

This focus on access to higher education supports Swail, Redd, and Perna's (2003) recruitment and admissions component of the institutional factors in their model. Specifically, BMX's precollege program has aligned with these researchers' suggestions for recruitment and admissions responsibilities. BMX had a specific role in the institution's recruitment of Black 
male students. Swail, Redd, and Perna recommended that this role be clarified; those with recruitment and admission responsibilities should help "identify students whose career and educational goals are closely matched to the institutional mission and second to admit only those students to college" (p.97). Based on their research, precollege and recruitment initiatives should target particular student demographics as an important part of the recruitment and admissions component.

In addition to Swail, Redd, and Perna's model for student persistence and achievement, access and success were one of the four dimensions of diversity identified as critical on a larger scale when examining campus diversity initiatives (Musil, Garcia, Hudgins, Sedlecek, \& Smith, 1999). Some researchers have seen access and success (and subsequently retention and persistence) as the first dimension essential to any campus diversity initiative (Smith, 1997). Increasing access was deliberately included as a specific component of BMX, which supported Northwestern State University's campus diversity initiative - as well as the mission of the program - and served to increase structural (or representational diversity) at NSU in a way that supported the individual Black male students in their engagement to and understanding of the climate and community at the institution.

\section{Diversity initiatives}

The investigation of Northwestern State University's campus diversity initiatives revealed several major findings about its relation to the Black male retention initiative. First, Northwestern State University has provided strong institutional support for diversity initiatives. Second, the majority of the BMX staff did not have strong knowledge of all the diversity initiatives at the institution, nor was BMX one of the visibly highlighted diversity programs within the campus diversity initiative as a retention, access, or student success program. Finally, 
there has been a paradigm shift in the institutional philosophy of diversity from a focus on racial, ethnic, and gender issues, to one with elevated focus; whereas race and gender issues have been the underlying focal points in the recent past, current attention has shifted to issues of class, access, literacy, poverty, sustainability, and civic engagement.

Institutional support for diversity. Northwestern State University has demonstrated dedication to developing their established campus diversity initiatives. From NSU top leaders to the administrators for BMX, there was a commitment to developing an inclusive campus. The president of the institution was recognized and awarded for his leadership in diversity efforts and for his public assertions of the importance for institutions of higher education as a leader of diversity efforts throughout his nearly ten-year term. He has publically stated the importance of diversity to create an excellent $21^{\text {st }}$ century institution. At a neighboring institution's diversity event, he stated that more top leaders needed to verbally commit to diversity and to include it in the vision and mission of their institutions and in decision-making and daily activity. Under his leadership, there has been increased establishment and maintenance of programs, research centers, services, and other initiatives focused specifically on "representation" and "inclusion." These two terms have been fundamental to the extensive university diversity plan that has guided the efforts to create an institution poised to be the leader in creating new models of inclusion on many levels including teaching, research, and hiring practices (NSU Diversity Plan).

The institution has taken a comprehensive approach to diversity with a plan focused on improving representational (or structural) diversity, the intergroup dialogue, and cross-cultural relationship building (or informal interactional diversity). NSU has established programs and services to promote student, faculty, and staff interactions, and the systematic monitoring of a safe and inclusive campus environment. Their policy review intentionally included diverse 
people in the process to influence the creation of new policies and revisions of established ones. NSU has modeled best practices that researchers Musil, Garcia, Hudgins, Nettles, Sedlecek, \& Smith (1999) identified as essential dimensions of an effective campus diversity initiative. The themes of representation and inclusion at the foundation of the university's plan have been evident in the display of different diversity initiatives at NSU. The diversity web page highlighted numerous current initiatives with the purpose of increasing awareness of and access to higher education. Through partnerships with other institutions, the state, and K-12 schools, NSU diversity initiatives have provided funding opportunities and different programs and services to assist in preparation for higher education for specific underserved racial groups and all students from low socioeconomic backgrounds.

Under the leadership of the current president, NSU has clearly defined an office of diversity that organizes the efforts publically on NSU's website. The diversity web page for NSU showcased links for internal and external resources about diversity and included open access to the full written NSU diversity plan. The page was divided up in sections that allowed viewers to see the different resources for improving diversity, spanning academics, student affairs, local community and state research and recruitment partnerships, as well as partnerships with other institutions of higher education. Some of the diversity programs were in existence prior to the current president's term, but many were created under his leadership and as a result of the new diversity plan enacted during his term. There was a mixture of research centers and institutes focused on studying social issues and making improvements. Listed on the page were links to student and faculty development programs and leadership training programs designed for historically underserved populations, as well as student research exploration programs (specifically into the STEM fields for students of color and women). To demonstrate NSU's 
commitment to inclusivity, I found listings of faculty and student services specific to different races, in addition to units monitoring and promoting gender equity and sexual orientation.

Along with the more historical race-based programming and advocacy services, visitors to the website could also find diversity resources focused on showcasing the opportunity for NSU community members to engage the institution through organized offices, programs, institutes, and research centers. These institutional units connected to NSU's campus diversity initiatives promoted the ideas and study of community development, social justice, political awareness, and religious conflict. Some of the initiatives highlighted on the diversity website were responsible for training members of the NSU community to promote and participate in civic engagement, cultural awareness and tolerance, and inclusive practices, which focused on solving issues of historical social discrimination that create cultural disparities.

BMX's institutional diversity presence. Over 55 different links of academic and cocurricular programs, services, research centers, and the like were on the diversity web page for the public to view and find out more about the individual components that make up the campus diversity initiative. The maintenance of the diversity web page has been a specific goal under the communication component of the diversity plan; the goal has been to have "a coherent inventory of diversity-related events, offices, programs, and groups with the university" (NSU Diversity Plan). Even with the substantial number of programs listed, it was still not exhaustive of all the different programs committed to increasing representation and inclusion.

In reviewing the diversity web page closely, BMX was not listed and did not have a separate link on the page that links both NSU community members and those outside of the institution to their diversity efforts for retaining Black males. The multicultural unit within Student Affairs that physically houses the BMX was not listed as a separate link on the diversity web page of 
NSU either. This absence depicts an additional level of separation from the main institutional diversity designated website. Although NSU had a strong showing of multiple ways to engage diversity, the visibility of BMX and the multicultural unit that housed the initiative was nonexistent on the official reference page for diversity at Northwestern State.

The weak connection between BMX and the campus diversity initiative was further demonstrated when the administrators of BMX provided an abbreviated inventory of the diversity work at NSU during their interviews. Although the school had an extensive and transparent list of offered programs, services, and initiatives for diversity posted on NSU's website, two of the three BMX administrators interviewed were unable to identify a substantial number of the listed resources once I cross-referenced their responses to the diversity web page. A small number of the programs identified by BMX administrators as diversity initiatives outside of BMX yet internal to NSU were listed on the university's diversity web page. Many other programs identified by administrators were not included on the diversity page, but were established prior to the current president's term and with the purpose of assisting specific races and ethnicities. Administrators also identified some programs designed to promote gender equity (specifically in the sciences).

In their listing and description of diversity initiatives outside of BMX, there was little mention of the more globally conscious and responsive initiatives. The number of programs and services mentioned by administrators during interviews was a limited representation of what NSU offered and promoted on the diversity web page. What the leadership at NSU chose to highlight as the main diversity programming, services, and initiatives did not include what administrators identified as the important diversity components outside of BMX. This indicated a disconnection between what the institution viewed as priority elements of their campus diversity 
initiative and what the BMX administrators viewed as the diversity programs that take precedence when identifying important programs and initiatives. The only administrator who spoke about civic and global diversity efforts at NSU was the Associate Dean of Students, Mr. King. He was able to give the most comprehensive list of all three administrators and included not only the race-based programs and services for Native Americans, Blacks, Asians, and Latinos, but included the LGBTQ advocacy office along with Northwestern State University's center for civil rights that worked with parents in the community on education issues. He mentioned a newer program started under the current president that was an economic/class-based scholarship program. Mr. King also identified a shift in how diversity initiatives have been defined, including access initiatives that consider economic barriers and not just ethnicity and color:

There's also the ...Scholars Program. Now that is not a minority program. That's a class, excuse me, an economic program. So each year, any student coming from a family that earns less than $\$ 60 \mathrm{~K}$ will essentially have all of their direct costs, an average of their direct costs covered for all four years. And given the economic history of the world, that tends to be overrepresented in terms of students of color, but it's not an ethnic or a racebased initiative. But it is a huge outreach effort to address accessibility, overcoming the barrier of economics.

Although Mr. King and Mr. Brown both highlighted in their list of diversity initiatives that NSU had "a campus environment team having to deal with free speech issues," there was a stark discrepancy from Mr. King's description of NSU diversity initiatives and campus inclusivity efforts compared to Mr. Brown's short and limited response. When Mr. Brown was asked, 
"What other diversity activities and initiative are here at [Northwestern State] University?" he responded:

Our department Multicultural Student Services, we also have the American Indian Academic Services Department, and the way our department is shaped, Multicultural Student Services. We have what we call student success coordinator that has a variety of responsibilities. They target a certain population for retention initiatives: Latino, Native American, Asian Pacific Islander and African -American. Those are the key ones. We used to have some initiatives before that no longer exist. One called the inner group relations center, and they kind of dealt with incidents that were racially or gendered charged and then we used to have the campus environment team, but I don't know exactly what they do. But right now we're the only game in town as for as diversity outside of things of African-American Studies, things like that.

Mr. Brown did not mention any of the more civically focused programs or services mentioned by Mr. King. None of the administrators referenced the diversity web page of the institution as a resource for me to include in my research. Based on the lack of connection of BMX to the main diversity web page, it appeared that the leadership of the institution has not yet made a strong connection of BMX to the institutional campus diversity initiative in language and positioning. An extensive number of diversity programs were highlighted online, but possibly many like BMX were not, which may have caused a disjointed structure and incomplete depiction of the campus's diversity programming and services.

Although not on the institution's main diversity web page, BMX did have a web presence and connection to several units at the institution. Administrators stated that it was recognized as 
both an access initiative and an outreach initiative. Both access and outreach have been related to Northwestern State University's diversity plan by providing a presence for NSU in the surrounding community. The diversity plan asked members of the Northwestern State community, in regards to representation of people, "What changes can be made in recruitment and retention to achieve representational diversity?"

Mr. King provided his understanding of how BMX has contributed to the institutional goals of diversified demographics specific to the recruitment of Black male students through the precollege program:

We're doing this as a demonstration of owning our charge to be culturally relevant and embedded in the community from which we exist. And what that means is it is problematic for a University the size and the scale and the relevancy [of NSU] to simply have all of our programming, all of our resources, all of our initiatives, insulate and circulate in this space. At some point, we have to be relevant to the community, accessible to the community, and embedded in the community. And so this is NSU's articulated demonstration that we want to join with parents in this particular instance, and you can say the same thing for a host of other initiatives with different target audiences that we want to join with Black families to have their sons get through high school and come to NSU.

Mr. Brown also viewed BMX's access and retention focus as contributing to the institution's overall goals:

We also support the institution because [Northwestern State University] is dedicated to serving citizens of the state to the best of their ability. Through the precollege program and the college program, we actually are helping with that pipeline. We're dispelling 
myths that exist in some of our communities about what it takes to excel in higher education. We're cutting through some red tape.

Mr. Douglass reiterated the sentiments of relevance to the institutional diversity initiative that is shared by other staff in stating:

With [BMX], it ensures that there is going to be a steady pipeline of young Black males who are going to come to NSU and ultimately graduate from NSU. That's going to increase the number of Black males who are here, who graduate, who are alumni and will ultimately contribute to NSU by being successful in their own professional life, but also giving back to NSU.

Although not explicitly recognized on the diversity web page of Northwestern State University, BMX has contributed to the access and success dimension of the institution's campus diversity initiative as articulated by the staff of the program, the mission of the program, and the institution. NSU did label it one of the two "targeted programs" on the Multicultural Center's web page and on other web pages found on NSU's site, which listed BMX as one of the student services offered to current students.

Diversity philosophy paradigm shift. There has been a paradigm shift in the institutional philosophy of diversity from a focus on racial, ethnic, and gender issues to one focused on overarching issues of class, access, literacy, poverty, sustainability, and civic engagement. Many of the new programs developed under the current institutional leadership have not targeted specific races or ethnicities. The foundation of the programming efforts have been more focused on correcting social and political injustices as seen in the formal language used and promotion of diversity at NSU to the community. 
Mr. King provided a link to a NSU promotional video that was produced to discuss the new shift in diversity. The conclusion of the video incorporated several questions of its viewers challenging them to embrace the responsibility as a university to solve the economic, social, and political challenges through a new set of goals for teaching and finding ways to increase the cooperative work towards changing the world (Northwestern State University website). Under the embedded video, a description stated that the focuses of NSU were on increasing access for all students to pursue higher education, providing a global perspective for students, linking the knowledge and learning to practice and action, and charging all institutions of higher education to "differentiate from one another" to produce "more solutions to more problems."

Mr. King has spent the majority of his 19 years in higher education at NSU, and he shared his perspective on the shift in diversity efforts at NSU from race, gender and ethnic based programming to broader social, economic, and civic challenges. He stated, "when you see diversity, it depends on what you want to see. Do you want to see something that says we have something for this group or these groups? NSU is moving away from that.” The promotional video highlighting NSU placed several broad questions along with several state, national, and global statistics about children in poverty, illiteracy, along with some of the achievements that have already come to pass with the new broader movement; there was no direct mention of any specific program or signature program or office. As we viewed the video in Mr. King's office, he provided his commentary on the main points:

They're talking not about segregation; they're talking about lack of water, a child born in poverty, not a Black kid, not a White kid. Talking about achievement, but not giving you color terms, talking about tolerance, the entire university, not multicultural services. It's about the individual...It doesn't include color, because NSU knows the majority of the 
students are not White Americans. It doesn't get caught up in it. It's on a different level. It's challenging status quo, a new dimension challenging the whole university. The overall message and new brand of the institution that the video succinctly represents is that the institution needs to rise to the challenges of answering all the important questions about issues of justice, sustainability, economic welfare, and educational and social issues from a multidisciplinary perspective. BMX like other race- and ethnic-based programs were developed at the beginning of or prior to the new institutional leadership's vision for diversity. The video and other branding materials present a language that exemplifies the new university philosophy on diversity. It describes a sophisticated way of tackling the issues; yet it does not negate the importance of race, ethnicity, and gender as it answers questions that have local and global implications.

Mr. King further explained:

There's a message there, and there's also a statement about diversity there. And I share this because much of what's on your initial [web] page that I talked about was created before this dynamic... Before, a university felt vulnerable to the charge of not being able to (be) supportive of all students and an inability to say, "I have this here for your community." Now, the university and certain figures, progressive, or whatever the case may be, they're saying, "What I'm doing is, I'm saying the university has very high challenges for itself. And I'm interested in people regardless of culture and identity, and heritage." It's valuable. I understand that. But I'm interested in people who want to work together towards these ideals. And the resolution of these ideals will positively impact all sort of human beings to include those probably over-impacted because of history. But it is done in an intellectual way. It's not this notion of, "I'm colorblind." No no, it 
acknowledges. So for example, it might say, okay kids are going to predominately minority neighborhoods because they're living in segregated issues. They don't look at that as a historical injustice issue. That may come out from the historian. But they look at that as a political issue, a socioeconomic issue, an educational reform issue, a corporateprivate-public-business partnership issue. And they want to mobilize people who have the power, the strategies, and the ideals to resolve that.

The philosophical paradigm shift has left BMX and other racial and ethnic programs examining their place in the campus diversity initiative with regard to resource allocation and overall relevance. In speaking about the entire multicultural center, Mr. King believed they were approaching a time of redefinition of purpose, "[The Multicultural Center] certainly has to reexamine it. And at some point, we'll have to re-articulate it, absolutely. Or re-invent itself, or align itself, or turn the chapter, turn the page."

The institutional resources currently dedicated to BMX were considered more than substantial by the staff. Mr. Brown stated, "The university [is] doing exceptional in putting resources toward a population like that. That's a commitment." Although staff believed there was a strong commitment to the program despite not being recognized as one of the main initiatives of the campus diversity agenda, there were questions about how the race- and genderbased initiative fit into the overall diversity plan with the new philosophical shift. When asked "What institutional actions have been necessary to sustain these programs and services over time?" Mr. Douglass moved to what needs to still happen and stated:

One would be, probably, is that the university supports [BMX]. That they believe in the mission of $[\mathrm{BMX}]$ and they want $[\mathrm{BMX}]$ to excel. It becomes a rallying call for all other 
staff members on campus to really understand that $[\mathrm{BMX}]$ is a part of the issue and accepting that everyone has to support.

Mr. Douglass' comment implied that the initiative was not yet institutionalized, but the belief that it was possible. Mr. King also provided comments showing reservation of how BMX would be sustained over time, due to the changing institutional philosophy about race and race-based programs:

That's the problem. And we're seeing this nationally, where people are beginning to challenge and push back. Whenever the proverbial race card is thrown up, it has a lot more scrutiny and examination that it has in the past. In many cases it's welcomed. In many cases it's an emboldening of a consciousness that hadn't been there before.

Mr. King further expounded about the relevance of and resource allocations to BMX, stating:

This is the direction. This is where higher education is going. To where it doesn't necessarily co-sign on ethnic specific things. It doesn't shun away from the issues, but it's more comfortable now in policy and strategic partnerships toward problem resolution than investing the dollars towards targeted entities.

Despite the changes surrounding diversity work at Northwestern State, BMX as a race- and gender- based initiative had a space in the shifted philosophical diversity paradigm, and it remained relevant due to its focus on retention and access to higher education.

\section{Institutionalizing BMX}

One critical issue concerning the initiative has been the institutionalization process. The process of institutionalizing new innovations was identified and described by Curry (1992) as a linear process starting with mobilization (where a system or organization prepares for the new 
program and change), leading to implementation (change is then introduced to the system or organization) and finally to institutionalization (the system or organization is then stabilized incorporating the new change). The stages are "interwoven throughout the life of the innovation" (p. iii). Curry wrote that "the innovation is likely to be terminated despite how well it may be communicated and implemented" if it does not reach stability at the institutionalization stage. This prognosis makes institutionalization crucial for BMX at Northwestern State University to be more than a short-term programmatic change, but a fully integrated initiative. Curry explained the relationship between organizational change and institutionalization as "change is difference; institutionalization is making that difference last" (p. 6). Identifiable factors influence the likelihood of an innovation having longevity and being institutionalized including:

(1) The intensity of direction and support from organizational leadership;

(2) Decision-making and communication concerning the essential factors and direction of the innovation; and

(3) The incorporation of the dissident voice in the planning and execution process (Curry, 1992).

Several major points were expressed by administrators about institutionalizing BMX and how integrated the initiative has been within the Northwestern State University community. According to BMX staff, Northwestern State University was invested in the initiative. The surrounding community partnerships and campus and community awareness of BMX have been important factors in the institutionalization process. Although resources have been invested and reporting on BMX progress was commonplace at NSU, BMX administrators desired that the initiative have a larger impact and visibility within the institution's story. 
Student Affairs leadership support. From the mobilizing phase, leadership of the institution provided resources for the program. The ongoing dialog about the structure and resources for BMX was established in 2004, as NSU administrators held preliminary meetings and organized to develop an initiative to increase the retention and graduation rates for Black undergraduate males. Mr. King detailed the discussion where the idea was introduced to him and how he played the role of what Curry (1992) labeled "the dissident voice" among the major leaders involved, including the Vice President of Student Affairs, the Dean of Students, and the Director of Residence Life.

The dissident voice, as defined by Curry (1992) was necessary to meet a standard of reasonableness when introducing the process of change and the decision-making processes for the creation and execution of innovations. It "offers a test of the premises upon which innovations are based, challenging standards implicit in beliefs about the kind of change necessary to improve the organization" (p. v). It also "helps to create a balance between vision and the realities inside and outside the organization" (p. v). This voice is an ongoing check and balance as an innovation moves from mobilization, to implementation, to institutionalization and serves to improve the design of the innovation.

In the creation of diversity initiatives or programs, very often leaders look to what other institutions have done, choosing to emulate trailblazers that are ahead of the curve and more advanced in their implementation. They take other institutions' approaches as the best practice for their own institution, without a thorough examination of their institution's cultural climate, population needs, deficits, and current positive work. These pre-existing elements should be considered when investigating what would be applicable to a campus-wide diversity initiative. The dissident voice is particularly important in this process to create or institutionalize diversity 
initiatives, so that the needs of the entire community are met at the highest level of care and quality. The need to assess the disparities and requirements on all levels (faculty, administrators, students, and outside stakeholders) must be a local practice that occurs before introducing programs and services with the purpose of improving diversity on campus.

The Vice President of Student Affairs and the Director of Residence Life were exposed to the design of a specific retention program for Black males at a conference and approached $\mathrm{Mr}$. King about bringing the program to NSU. At that time, that particular national initiative was "in the budding phases," according to Mr. King:

... and they had been impressed, rightly so, with this initiative...And they said, "we heard about this entity [Student African-American Brotherhood], and we'd like to run it by you and see if it's something that should be done here at Northwestern State University."

Mr. King responded as the dissident voice asking, "What's the model?" and further questioned the structure of SAAB as a fit for NSU with concerns about resources and positioning: And at that moment, I gave feedback when it was appropriate. I think this is a wonderful concept. I think it's needed. I have two concerns: One is I don't want to compete with Black male fraternities. I have a little sensitivity about that. And then the second one was, I don't want it to be an add-on. If we're going to do this, I think we ought to do it with some budget, to include a position and some operation dollars. And you have to remember, there was precedent with Éxito de Hermana [pseudonym]. So that was understood, and heard.

In the process of considering specific programming for the retention of Black males, $\mathrm{Mr}$. King's initial comments served as the dissident voice and helped administrators avoid taking the direct cookie-cutter route by adopting SAAB in its original form without any scrutiny of how it 
fit into the NSU campus culture. Instead, his input allowed administrators to see what was already present at NSU and what would work best to make sure the initiative would be successful in meeting the needs of the Black male students and local Black community. As the dissident voice, Mr. King addressed the danger of NSU managing diversity through another program for a specific racial group, versus becoming transformational in its leadership approach to diversity. He asked questions and introduced ideas that caused the leadership involved in initiating BMX to think about what would be the best approach for their campus environment. Later, the Director of Residence Life followed up by supporting the program with a graduate assistant and a programming budget. The Office of Residence Life continued to serve as the funding source for the programming budget and the salary for the full-time program coordinator who runs BMX, while the program has been structurally situated within the Multicultural Student Center. This served as additional evidence of support according to Mr. King:

...you have the director of an entirely different area that says, I'm going to provide the missing element, and that was fiscal resources. Now, in some cases, and you do know this, I'm sure, auxiliary entities, entities that make money, they're appended in some cases. to where they form a lot of things not out of their own choosing, but out of pure necessity to fund from sources where the university makes money. The funding and staffing for a program of this nature goes above and beyond other similar differentiated programming for students at NSU.

Mr. King explained that the current support is:

Huge: full-time staff position, a very healthy operations budget. In addition to an existing model, where we have one staff person with primary responsibility for 
supporting and serving and advising and working with given communities, BMX is distinctive from the student coordinator position...so this is above and beyond that. Mr. Brown echoed the level of the support and how it helped in the institutionalization process. Restating a previous quote from Mr. Brown on how the support substantiated the institutionalization process, he said support is “... exceptional, the university is doing exceptional in putting resources toward a population like that. That's a commitment.” Mr. King further emphasized the support of the institutional leadership in creating the initiative and implementing it; pointing out that BMX began based on leadership concern and not by Black student advocacy:

I think for purposes of full transparency, is that the concept of a Black male organization on a college campus came from a conference in which another similar program piqued, at least the topic, piqued the interest of the Senior Vice President of Student Affairs. So you have university interest, curiosity, at the senior level that also, to say this bluntly, BMX is not created through Black advocacy. It wasn't, "We need this!” It was, "Have you thought about it?" You see? Even though we had been thinking about it in terms of equity, but the formal launch of the initial conversation came from the Senior Vice President of the institution... And so I think the interest and the initial prompt came from the senior administrations. I think that's something unique.

It is also important to note that BMX was not formed from student request and pressure; the group who initiated BMX on the campus was a racially diverse group of male administrators. Mr. King detailed that the Vice President of Student Affairs was a White male, the Director of Residence Life was a Black male, and the Dean of Students at the time was Latino. It was not just the Black administrators or faculty that saw the need to implement a Black male retention 
initiative, it was a need seen by leadership across racial groups. Curry (1992) stated that "innovations cannot become lasting without a rather significant role from leaders" (p. iv). The top Student Affairs leaders initiated BMX. It moved beyond mobilization with the support of the institution's leadership, to implementation where the change for Black male retention has been introduced to the system with staffing, resources, annual programming, and reporting of progress back to leadership. According to Mr. King (and other administrators interviewed), the university support has been stable and consistent:

The university supports it. BMX along with any other program is talked about directly or indirectly over the last couple of years whenever we talk about fiscal resources, or even philosophy. But, I haven't had to advocate or push back. It's not on the chopping block.

Leveraging relationships and partnerships. Both community and institutional partnerships have played an important role in developing and sustaining the retention initiative. Residence Life partnered immediately, providing the funding for the programs and the staff, who took the institutionalization process from mobilization to actual implementation. Mr. King, as one of the initiators and leaders for BMX, shared the significance of the Residence Life partnership:

Now initially, I guess this was institutionalizing creating financing, because Res Life is... set it in motion so that initially it kind of reported through his shop. It went through a whole different kind of, it was launched in a different way that was very high, very strategic, very lofty on paper, but it didn't really have any members. And I think it had something to do with the fit, the person that was in the position. So I was involved, but more so from a team kind of environment. 
Another partnership that helped to move the initiative from mobilization to implementation was with the staff of the long-standing Latina retention initiative, Éxito de Hermana. It served as the established precedent at the institution for providing access services to underserved students and helped to leverage the BMX staff's connections to the school districts for the pre-college component, as well as providing the structural skeleton for the workshops for high school participants. Mr. King stated:

Leveraging [Exito de Hermana], we were able to get right to the superintendents. Who then handed off to whoever the go-getter was, and we were able to invite parents of African-American men to the district office for a presentation to all of the parents who would attend.

Leadership support, again on the public school level, played a role in moving the initiative forward from an idea and concept to an actual program that provided services to students. The strategy of developing the relationships prior to initiating services was intentional by the BMX staff and important to the successful implementation of the precollege component. Mr. Brown recapped the strategies used to build relationships:

We knew that the precollege program was going to take a while to set up and build the relationships, so we said, why don't we spend the first semester, fall semester, building the relationships, the next semester recruiting, so then coming into '05 we actually can have students in a program. So I began to build relationship with people ... I met with some principals.

Mr. Douglass discussed the importance of the ongoing partnerships that have been established at the University level to present information about admissions, financial aid, and other important 
workshops that prepare Black male high school students for life at NSU and to assist with the mission to increase access to higher education for Black males:

We still have partnership with undergrad admissions, financial aid, res life summer bridge program. Many of the university departments are still intimately involved with BMX, and we're continuously expanding those relationships. Those are integral parts to understanding college in itself.

Mr. Brown goes on to explain other partnership and relationships that were critical at the beginning phases of marketing and recruiting students and parents for the precollege access program:

We had a good partnership with admissions. We used to have these people called coordinators... who were assigned certain schools in certain districts. Those were some very strong partnerships, very strong relationships where they would either take our information to the places, or they would actually work with their contact there to set up the sessions where we could come in and recruit. Additional partnerships that assisted in moving BMX, specifically the precollege component, from a mobilization stage to implementation were developed with community leaders. Mr. Brown and Mr. Douglass included in their list of specifically developed relationships, the Black-owned newspaper, the local Jack and Jill organization, the Black Chamber of Commerce, the local chapter of the Boulé (Sigma Pi Phi Fraternity), and a historically Black, Greek fraternity’s graduate chapter's youth mentoring program. Mr. Brown said, "I got with all these people. I already had my own initiative, and I connected all these people who had access to young people and began to let people know about the program, make relationships and see what would be best." 
Mr. King recalled the intentionality of the community connections:

When we set it in motion, we said that we wanted this to become sort of community authenticated. And we figured that between two entities (Black-owned newspaper and local Black political circle), we could get enough groundswell, enough grassroots awareness that this thing would saturate into the community.

Institutional relevance. BMX assisted in achieving the institutional goals of improving access and increasing relevance to the Black community. According to Mr. King, the precollege program component has helped increase the institution's visibility to Black community members and has served as one of the primary programs to improve access:

From the University's perspective, the outreach, the perception among the community that NSU has things that are institutionalized focusing on a culture to the Black male certainly resonates in a community of people who are very aware of the problems and the challenges facing education, also facing Black men. And so its institutional existence that can be called upon to address random or frequent questions about what is NSU doing for [them]. So there's some value added there.

Curry (1992) explained the role organizational culture plays in institutionalization and stated that mission, values, and goals of an institution are significant factors in how an innovation is embraced and absorbed, stays on the perimeter as a piecemeal program, or even worse, is rejected by the institution and discontinued. The access component to the mission of BMX has assisted in advancing the program from mobilization to implementation because of the institution's focus on increasing access to historically underserved populations.

Although the institution recognized the need to recruit and retain Black males, the staff of BMX has been concerned about BMX's level of acceptance, relevance, and integration as an 
institutionalized initiative. Curry (1992) labeled this point in the institutionalization process as boundary expansion or boundary contraction (p.12-13). Mr. King shared his concerns about the economic pressures that act on decision-making at the institution and for the vulnerability of BMX in the current state of financial scrutiny:

The other thing too is that an institutionalized program, particularly in difficult economic times, is going to have questions about impact upon allocation of college resources, which is essentially a volume question. And a program like BMX, even if it has 70 members and impacts $800-900$ kids via a program, it still has to ask difficult questions about impact. And so because it's a program and not necessarily a department, it's like other programs. At some point, it faces a higher degree of scrutiny. And so those are some of the challenges. It's about having a targeted, gendered cultural organization in a climate, in a world that is beginning to challenge the legitimacy or the timeliness of those types of things.

Based on Curry (1992), boundary expansion is the practice of accepting, on some relevant level, a new innovation into an organization or system. Boundary contraction is the practice of excluding an innovation. At this point in the development of BMX, it was considered accepted by the institution. Its successes, events, and statistical information about retention rates and graduation rates were included in reports that are given to the Vice President on a monthly basis. It was recognized as one of the top student organizations in garnering student leadership awards.

But even with staff discussing the success of BMX, Mr. King grappled with the thought of what happens next for the initiative, as far as its continued existence, development, and acceptance at NSU. As Associate Dean of Students, monitoring the initiative fell under his 
leadership. As one of the original Student Affairs leaders who initiated the program, Mr. King introduced the idea of whether, in retrospect, he would have created BMX, knowing the current needs and future direction of the institution when dealing with diversity and retention efforts:

Leaders must always think about in creation and this establishment of something. They must always think about what they create and whether or not they will have to disestablish that. And at some point, an ethical question has to be asked, do we set something in motion that will have to eventually be disassembled? And the answer to that is yes at times, but I think you at least have to deal with the question. And even in dealing with the question, it doesn't necessarily mean that the purpose or intent is outdated, but one has to ask the question, is the purpose and the intent best facilitated in this construct, and is there not another construct that it can be facilitated.

Other staff also questioned the current importance and relevance of BMX — even after the award recognitions and the building of partnerships between admission, student affairs, community and school leaders in executing the access and precollege programming. Mr. Douglass hoped that eventually:

...the university supports BMX, that they believe in the mission of BMX and they want BMX to excel. It becomes a rallying call for all other staff members on campus to really understand that BMX is a part of the issue and accepting that everyone has to support. Mr. Brown shared the idea that the institution has yet to fully embrace BMX on a level that can be considered institutionalized, when he questioned the program's relevance in telling Northwestern State University’s story. He wished that NSU would:

Embrace the BMX model, and at this point in six years the legacy that has been created, and kind of use that in telling the story of the university. I don't know if this is kind of 
one of those situation, you know, of proximity and appreciation. I don't know if the program is appreciated as far as telling the university story as much as it could be, because it is a part of the university. But people could read about it in books, people who study [BMX] like yourself, people who interact with the young men; they realize that they are dealing with an exceptional program, and I don't know if institutional-wide it's part of telling the whole NSU story.

\section{Student-faculty relationships}

Student faculty interactions are one of the significant factors in student persistence and academic attainment. Since Pascarella and Terenzini’s (1979) quantitative study of incoming freshmen, where they controlled the influence of multiple social and cognitive factors, they, along with other scholars (Astin, 1993; Kuh \& Hu, 2001), have concluded the quality and regularity of student-faculty relationships were a significant and consistent indicator of persistence. Swail, Redd, and Perna (2003) emphasized the importance of "informal facultystudent contact" as one of the five objectives under the academic services component of their Geometric Model of Student Persistence and Achievement. They suggested that as an institutional factor, the academic component is one of the most important and most diverse when providing opportunities for students to engage with the institution. This engagement with academics can be accomplished through tutoring and mentoring, academic advising, undergraduate research opportunities, and suggests that faculty provide and "support the academic development of students outside of class time" (p. 101).

BMX members understood the value of interacting with faculty, but I had to clarify during interviews the difference between the relationships they've cultivated with BMX staff versus faculty they had as instructors. Their support was seen as first coming from the BMX staff 
and secondly from faculty. When asking about how students cultivated their relationships with professors, I specifically had to ask BMX members to clarify whom they were speaking about. To the students, the BMX staff members were viewed as their faculty. Jermaine stated, "No, I'm thinking like professors and stuff. I go to office hours and stuff, but like faculty I am most close with would be [Mr Brown], [Mr. Douglass], and [Mr. King]."

Once clarified during interviews, the way student-faculty relationships factored into their success was a noteworthy point of discussion with the members of BMX. They understood the importance of the relationship between connecting with faculty in and outside of the classroom. Graduating senior member, Ivan, said:

So I think interfacing with faculty, I make it a point and encouraged anybody that's up and coming in BMX or just up and coming in to college. Talk to your professors on multiple occasions, even if you don't have a question. I mean, just go out the class and introduce yourself. And the best time to do it is at the beginning of the semester to say, “Hey, I read the syllabus. I'm looking forward to your class blah, blah, blah. I really like your style. I really like the discussions," whatever it is. Just go and talk to them. Other valuable reasons students saw for developing relationships with faculty were for networking, getting the benefit of the doubt when grades were on the line, and because faculty could provide recommendations when the time came for jobs and internships.

Some BMX members cultivated regular contact and relationships with faculty within their major. This was the case with Edward, an out-of-state junior and film production major. He was bi-racial and was raised by his mother, who had some college education but did not graduate. Edward found BMX after first being involved on campus as a member of the water polo team. He seemed unconventional to some, since he came to NSU pushing a skateboard, 
having never touched a basketball or football. The BMX student leaders and staff welcomed Edward into the organization and supported him while he played for the water polo team. He remained very close with the founding student members, who have since graduated, and he took great pride when Mr. King often told him that he reminds him of one of the founding members. Edward showed a deep passion for the mission of BMX, stating during his interview:

There are, in my opinion, too many people walking around with a BMX shirt that don't exemplify what BMX is and what it originally was... Once you put that BMX shirt on, you need to have that mentality that every single brother counts.

He served as a past parliamentarian and took the lead on the Martin Luther King, Jr. rally as a sophomore. In his three years at NSU, he has taken the opportunity to represent BMX at several national networking and leadership conferences. When speaking about the relationships he's cultivated with the faculty within his major, Edward stated:

I think it's super good to have a good relationship with teachers and for me personally, since all my classes are film classes. All my professors are actually - they're not just simple teachers. They actually all are connected in the film world, so it would be kind of idiotic for me not to have a sustainable relationship with them. Like when my documentary production professor, she's like an award winning documentary filmmaker, and the fact that she's Black too, like she's got a lot of stories, films on like the Black Panther Party - and so these people know people, and so it is really, really, really helpful, in my opinion, to know them personally.

Other students concurred with Edward and felt that it is more important to develop relationships with faculty within their major. They did not see the value in cultivating relationships with faculty who taught general education courses. Nic stated: 
I feel like right now, where I'm at, I don't need to know the teachers, because I'm not in my major yet. I'm not taking any classes for it yet. So, I don't know what my astronomy teacher would do to help me with a thing with my business management major, so I feel like if I should talk to faculty - I should start knowing them, I should wait until I'm in my major.

As they took on membership and leadership roles in academic-affiliated student organizations, faculty and programs within their colleges became more important. They valued the additional contact with faculty who were active in advising the student organization, or those faculty who took time to interact with the student leadership within the departments they teach.

Criminal justice major and history minor sophomore, Andre, viewed the development of faculty relationships as part of his responsibility as a good student. He stated that he uses a combination of face-to-face contact and other means as well:

A lot of the communication I have had with faculty has been office hours, a lot of email correspondence; I won't say that I don't email teachers frequently, because I do. The way I find that is most effective is when usually going to their office hours or even just going up before or after class. Because you find that you do that once, you come to their office hours once, you email them a couple times, they are going to remember you. And when you sit in class in that same seat every day, you are right in the front. I mean, they could honestly not even know who I am, but I feel like they do. And so that is usually what is good for me, when I feel like I have a personal face-to-face relationship with the professor and they would recognize me outside of class, then I have usually done my job in that class. 
For some of the members, engaging faculty was seen as a risk factor. DJ, an out-of-state sophomore business management major talked about the fear he had when engaging faculty. $\mathrm{He}$ was raised by both of his parents in an upper-middle class neighborhood and was a secondgeneration college student with his mother earning a master's degree and his father a bachelor's degree. He said:

I don't talk to them [faculty], unless I'm assigned to. In one of my classes, I was assigned to do an interview with one of my teachers and that was the first time I ever went into one of my teacher's office hours since I've been here. I don't know why. For some reason I feel scared. Basically, I feel scared because I feel like they are going to want to start talking about something that happened in class, and I feel like I might not have been paying attention for that period of time, and I won't know what they're talking about or something, so, I don't know. I just feel scared to talk to them.

In recognizing their fear and discomfort in speaking with faculty, students believed that faculty were equally uncomfortable and feared speaking with them as Black male students. Ivan stated:

I think they are as uncomfortable as we are. They are as uncomfortable interacting with us for whatever reason... So it may be hard to go talk to your college mathematics teacher, who's probably a White Caucasian female. It's probably hard to just build up to whatever. When you see her, she's pulling her little briefcase, and y'all are crossing the street. You say, "Hello professor. I really enjoyed the unit on, whatever." For her, that may be very uncomfortable outside of a classroom setting, because you are what you are. Other students believed there was a blatant lack of interest on the part of the faculty to interact with them outside of the classroom. Some students had a better relationship with Black 
faculty than others. Ernest, a sophomore double majoring in film and media studies and criminology stated:

At least from my perspective, I interact with my African-American teachers and faculty more than I do with my Caucasian just because, I don't know. Maybe I feel more comfortable with talking with them. Yes, so I mean I wanted to add that in also because some teachers you go to and you know try to talk to them, and they're very like distant. They are like, "Just email me" and things it like that. And no, I want to have a personal one-on-one connection when I talk with you, maybe to get better grade in the class.

The staff of the BMX has had a positive influence on the students' college experience. Students acknowledged that the staff, the programing and program planning process, as well as the book club were important means for them to increase personal identity, leadership development, and Black cultural awareness. Their brotherhood bond has increased and they have gained a sense of responsibility to each other by participating in BMX. The student monitoring done by the staff, upper-class men BMX members and their own self-monitoring all have developed because of their connection to the organization. There is an expectation for members to uphold high standards. The staff serve as role models of model Black men and are admired by the students. They are viewed as resources for student success. There was a personal consciousness that others in the university community were watching and that they have an obligation to represent Black culture on campus responsibility.

The precollege preparation program component was not exactly as perfected like the student organization at NSU was, but the value of it was noticeable in the access and success efforts of the university and the outreach to constituency communities that NSU finds valuable to have in its student population. Students believed that the shifts and maturation were due to the staff of 
the BMX pushing them. Many students also believed that the BMX was the one factor that was keeping them at NSU and doing well. With all the positive feedback from students, it was hard for administrators to figure out the next step for BMX in the institutionalization process as Northwest State University began to mature the language, approach, and emphasis on what is significant when acknowledging and discussing diversity issues in the university community. 


\section{Chapter 5}

\section{Case Two: Southern State University}

Southern State University (SSU) holds a basic classification by the Carnegie Foundation (2005) as a Research University with very high research activity, publicly controlled as a large four-year, primarily residential institution with 25 to $49 \%$ of students live on campus and a high full time undergraduate population (at least $80 \%$ of total student population), with a more selective admissions requirement and a high percentage of transfer undergraduate students entering each fall. According to the institution's online newsroom, it is located in the Southern region of the United States founded under the Morrill Act of 1862 as a land grant institution initially as an agricultural and mechanical college. Early on in its development, university leadership expanded the mission to provide a wider base of academic programs, and it became the flagship institution of its home state (SSU newsroom, 2010). The university has several campuses across the state with the Black male initiative, the Woodson Black Male Resource Center ("the Center" or "Woodson Center"), housed at the main campus, which also serves the largest number of students.

The institutional vision is to become one of the world's great universities, advancing the home, state, and the global community through creating new knowledge (SSU Academic plan, 2000). The institution operates under four core elements to achieve this vision: becoming a national leader in the quality of academic programs; being universally recognized in the quality of learning experience offered to their students; creating an environment that is truly enriched by and values diversity; and expanding the land-grant mission to address society's most compelling needs (SSU Academic plan, 2000). Its core values assist in focusing SSU leadership to achieve the vision through several strategies, among which are constructing one of the world's finest 
scholarly faculty, cultivating a welcoming and diverse community, and becoming one of the top land grants in the US (Southern State University Academic plan, 2000).

In 2010 at the time of the study, SSU had approximately 31,000 full-time employees, including approximately 5,000 faculty. Fall 2009 total student enrollment was 64,000 with 55,000 of those students attending at the main campus. Of that total, 50,000 were undergraduate students, 10,000 were graduate students, and 4,000 were professional students. Approximately $51 \%$ of the total students were male, and $49 \%$ of the total students enrolled in the fall of 2009 were female. Minority students comprised $14 \%$ of the total student enrollment across all campuses with over 4,000 international students, not counted as minorities, enrolled as well. Black students comprised approximately $6 \%$ of the total enrollment at SSU, reaching nearly 4,000 students total. The university was accredited by the Southern Association of Colleges and Schools Commission on Colleges (Southern State website, 2010).

Southern State University offered 170 undergraduate majors, 130 master's degree programs, and 100 doctoral degree programs. These programs were organized under the Office of Academic Affairs with over ten different colleges. The Office of Academic Affairs had a graduate school, Office of Strategic Enrollment Planning, and Office of Undergraduate Studies. The Office of Academic Affairs also housed approximately 20 central support units, including the University Libraries, Student Affairs, Institutional Research, and the Office of Minority Affairs, where the Black male initiative was housed (Southern State University website, 2010).

The total retention rate for new freshmen, as defined as the number of total full-time, first time freshmen returning for the following year, was last recorded before 2010 and reached approximately $92 \%$. The African-American new freshmen rate of approximately $89 \%$ in 2009 fell below the overall total. The African-American, second year retention rate and third year 
retention rate held the consistent gap between African-American males and the institutional total with the university registrar reporting about $84 \%$ for African-Americans compared to $88 \%$ total for two-year retention, and about $78 \%$ compared to approximately $84 \%$ total for the three-year retention rate. Graduation rates showed a similar trend with the total four-year graduation rate reported prior to 2010 being close to $51 \%$ overall, and only around $40 \%$ for African-American students, a five-year rate of approximately $61 \%$ compared to around $74 \%$ for the total student population, and a six-year graduation rate with approximately $61 \%$ for African-Americans compared to an overall total six-year retention rate of almost $75 \%$ (Southern State University website, 2010).

When I first arrived on campus at SSU, I realized the moment I switched from driving on a regular urban city block to hitting campus boundaries. SSU is an urban campus, yet due to its massive square mileage, it stands independent of the city surrounding it. The buildings told the story of the place over time, where the center of campus housed traditional gray brick and mortar of the late $19^{\text {th }}$ century. These buildings had been given a simple face-lift to preserve the old, large, state-campus atmosphere. The old refurbished buildings were mixed in with newer energyefficient buildings and other structures under construction, which were covered with scaffolding and decorated at their bases with detour signs directing heavy traffic in the middle of the day. Life on the self-contained campus trudged along during the day with sudden breaks in class schedules when students poured onto the sidewalks, rushing to get across the enormous campus, hopping onto campus buses that looped and looped around. Being on campus in April allowed me time outside to see how students interacted. Students and faculty alike moved at a hastened pace. 
The campus was in constant movement by the time I arrived every morning. The Woodson Black Male Resource Center was housed on what was considered the west side of campus. It was in one of the newest buildings on campus that housed several student services offices as a one-stop-shop. Students came alive early on in the day, as they entered the building to handle financial aid issues, make payments to their student accounts, and visit the scholarship offices housed as neighbors to the Woodson Black Male Resource Center. Everything about the campus seemed larger than life, from the landscaping, to the buildings, to the throngs of students consistently moving about.

\section{Student Participants}

Twenty-four students were interviewed for the study at Southern State University (SSU) in the spring of the 2009-2010 academic year. Eight students were individually interviewed for approximately one hour each. The remaining 16 student participants were interviewed in focus groups averaging four students per group and lasting an average of one hour and 47 minutes. No focus group exceeded four student participants. Participants were purposefully selected through an email recruitment message sent to the Woodson Black Male Resource Center email list with the help of the programming director who served as the institutional liaison. The programming director and the other staff of the Center asked some students to participate, who have been active with the retention initiative and were available during my visit to campus.

Seven participants (29\%) self-identified as Black, one as Biracial (from an African nation and White-American) and 16 students (66\%) as African-American. All 24 student participants reported their sexual orientation as straight or heterosexual. Two students reported their nationality from the same African country; and two additional students reported nationalities from two different African nations; and one student hailed from the Caribbean. The majority 
$(96 \%)$ of undergraduates attended public high school, and one attended a private high school. The mean self-reported high school grade point average was 3.70 on a 4.0 scale.

Forty-six percent of the student participants were raised in two-parent homes (11 participants). Six student participants $(25 \%)$ were raised in single-parent homes headed by their mothers. One participant was raised in a single-parent home by his father, one by a non-parent guardian. One was raised by his biological father and stepmother. One student participant was an emancipated independent child; and two participants $(8 \%)$ were raised by two parents that were divorced; and the last one was raised by his mother and noted that his father was actively involved in his upbringing.

Fifteen participants (63\%) were raised in a middle class environment, four $(16 \%)$ in an upper-middle class environment and three (13\%) in a low-income environment. One student participant reported being brought up in an upper class environment; and one participant did not report his socioeconomic background.

A total of six participants (25\%) reported their mothers' highest level of education was a bachelor's degree; five participants (21\%) reported their mothers' highest level of education was an associate's degree; and four participants (17\%) reported the highest level of education for their mothers was a high school graduate and some college. Three reported their mothers' highest level was a master's degree (13\%); and one each reported the highest level as some high school and a professional degree.

For the highest level of education obtained by their fathers, student responses varied as well. Eight students (33\%) noted the highest level achieved was some college; and six (25\%) reported their fathers earning a bachelor's degree. Four (17\%) reported the highest level was completion of a high school degree. Two (8\%) reported the highest level attained was a master's 
degree. One each reported the highest level of education was some high school, an associate's degree, and a professional degree, Seven (29\%) SSU undergraduate student participants were seniors; an additional seven (29\%) students were juniors; three (13\%) participants were sophomores; and seven (29\%) participants were freshmen.

With the 160 majors that Southern State University offered to undergraduates across 14 colleges or schools, in addition to the university's exploration program for undecided students, the student participants collectively were majoring in programs across the College of Engineering, social work, education and human ecology, arts and sciences, the School of Physical Activity and Education, and the School of Business. Almost 60\% (14 student participants) were majoring in programs under the School of Business and College of Arts and Sciences, while another $21 \%$ (five participants) were majoring in programs within the College of Engineering. One participant each reported his major in the following areas of specialization: exercise science and pre-med, pharmacy, social work, and sports studies. A total of 11 student participants (45\%) selected to take a minor. The participants' self-reported mean cumulative grade point average while in college was 3.14 on a 4.0 scale.

The undergraduate students in this study reported that they participated in an average of three clubs or other organizations, with a high count of five organizations by three participants and a low of no identified memberships in student clubs or organizations by two participants. The average student participant reported having one leadership position in a college club or other college organization. Two participants reported a high of four leadership roles each in their respective organizations and clubs. In reporting their university honors, awards, and achievements, 46\% (11 participants) reported no such awards, and 13 participants reported receiving at least one university level award, honor, or recognition. The participants reported 
participating in an average of three programs or services offered by the Woodson Black Male Resource Center, with the highest participation rate of seven activities, programs, or services offered by the Center reported by two student participants.

\section{Administrative Participants}

Thirteen administrators were individually interviewed for the study at Southern State University (SSU) in the spring semester of the 2009-2010 academic year. Each interview lasted for approximately an hour and followed a semi-structured protocol. Participants were purposefully sampled based on their interaction with the retention initiative and selected with the help of the institutional liaison.

Four of the 13 had current or past positions with responsibilities directly related to running the retention initiative. The remaining 11 participants' responsibilities at SSU did not directly relate to running the day-to-day operations of the retention initiative. These participants were connected to the Center through partnerships or partial job responsibilities to assist in executing the university's mission. Of the 13 administrative participants, one had the title of assistant director; five others had the position title of director; and one held the title of psychologist. One had left higher education and was currently self-employed. Two had assistant senior level positions and served under academic affairs with SSU's Office of Minority Affairs. Two participants had associate senior level positions at SSU with one of those two serving in athletics. One served as the chief diversity officer at SSU. The average length of time the participants had been in higher education was approximately 20 years, with the most serving about four decades and the least serving fewer than 10 years. The average length of time the administrators spent at SSU for their years in higher education was 12 years, with the low being four and the highest being nearly 40 years. 


\section{Case Overview}

The Woodson Black Male Resource Center at Southern State University (SSU) has had a global vision to be the premier, interdisciplinary research center to address the challenges facing Black males. The Center's global vision has been to be recognized for presenting solutions to the issues of Blacks in society and for academia. This vision has not negated the administrative staff's focus on student retention, networking opportunities, and leadership programming efforts that have helped to engage currently enrolled Black male undergraduates. The Center has been a hub of influence that has helped Black male students to connect to the institution and each other and to succeed in graduating from SSU.

As Southern State University has continued to build a national reputation as a leader in diversity and inclusion, the university has fully supported the Woodson Center as one of its most successful diversity initiatives. SSU has provided resources and has highlighted the Center above and beyond many other diversity efforts at the university, actions that have assisted in advancing the process of institutionalizing the initiative. The Woodson Center staff has understood the necessity of fundraising to fulfill the global vision for the Center. Leaders in the surrounding city, student affairs personnel, and academic affairs administrators and faculty have engaged with the Center and have been viewed as partners and resources by the administrative staff.

Southern State University's overall diversity initiative was advanced and established within the university strategic plan, based on a charge from the President's office that has been renewed across several presidencies. Both accountability and transparency were expectations for the Center and other student affairs and academic units in the annual reporting of their inclusion and diversity work. The majority of the institution has embraced its responsibility as a land grant institution to provide access and the opportunity for the success of historically underserved 
populations. This campus-wide responsibility assisted in the Center receiving support from many stakeholders, both in general support and financial support. The formal institutionalization process for the Woodson Center was considered by leaders when establishing the Center's reputation and building its authority on campus as the principal campus resource for the retention of Black male students. The leaders were strategic in their plans to develop the Center, recognizing the resources and support that would be needed to make it a long lasting initiative. Through a data-driven focus, the Center administrators have shown the positive difference made in the retention of Black males and have contributed positively to the university's diversity goals to increase student access and success.

The Woodson Black Male Resource Center focused on encouraging servant leadership through role modeling, contact with SSU Black male faculty and staff, and student exposure to successful Black male alumni and other famous, established, Black male leaders. The leadership development and networking activities, along with programs and service experiences, were grounded in theory and research. The Center administrators focused on having everything they presented to the campus and Black male students as assessable and improvable. The founding administrative leaders were heavily influenced by their experiences with historically Black colleges and universities when they developed the programming and strategies used to foster student engagement.

The Black male students have attributed their growth into their adult male identities to the Center's programs, the character and care of the Woodson Center staff, and the exposure to other regularly engaged campus administrators and partners. Students valued the leadership skills they have learned, as well as an understanding of self-accountability. There was also an emphasis on being accountable for other Black males on campus and in the community. The Center provided 
strong messaging from the beginning of the Black male experience that success is about bringing others along with you and supporting something greater than personal goals. Student engagement with the Center has fostered a sense of brotherhood. The Center has engaged both students and their parents early in their SSU career and has provided a safe space on campus where Black male students can connect and get referrals to other resources on campus when needed.

\section{Mission of the Black Male Resource Institute}

The Woodson Center at SSU had three major focuses when carrying out the mission: (1) research, (2) retention and success, and (3) excellence and leadership. The production of new ideas about what affects Black males in society has been a major component of the work done by the Center. The retention and success of current SSU Black male students has been accomplished through programming, mentoring, and role modeling. Also a high level of excellence and leadership has been modeled by the staff; the students were expected to adopt these qualities as an anticipated outcome of the programs and workshops. The staff promoted high levels of student personal accountability and expected students to hold each other accountable for excellence in academic and other goals. The philosophy of excellence and leadership that was expected to be adopted by all Black male students once they connected with the Center on campus was influenced by both the overall institutional mission and the individual staff members' educational and professional experiences. The historically Black college careers of many of the administrators have heavily influenced the Center's programming and standard of excellence. Upholding excellence and high ethics was important to the administrators responsible for managing the Center.

Research. The Center has sought to conduct research on Black males as part of their mission. When asked about the mission of the current Center, all administrators, those currently 
serving as well as those who served in leadership for the Woodson Center in the past, stated that research was a large part of the Center's mission. The research focus was specific to understanding and finding new ways to improve the quality of life for Black men across their lifespan and across disciplinary studies (i.e. education, justice system, politics and government, medicine, etc.). The focus on research was validated by the expertise of the director, Dr. Deal.

Being the director and senior leader of the Center held new responsibilities for Dr. Deal. He not only served as the primary contact for the Center's research agenda, but also for the fundraising and endowment activities. He drove the mission and revised the vision of the Center. Dr. Deal has been in higher education in both administrative and faculty positions. He worked at several state institutions prior to coming to Southern State, including a historically Black university. He held previous positions as Director of Retention Programs that focused on tutoring and summer bridge programs. At the time of data collection, Dr. Deal had been a faculty member at SSU for about 10 years, was tenured, and had secured several large research grants. He was partnering with other institutions to examine how African-American males and females successfully matriculate. He specifically identified research as a part of his role sitting in the director's position:

I changed the mission or expanded the mission to look at African-American males throughout the lifespan. And really when I think about education, education is one of those quality of life indicators. And so, Black males are not only functionally optimal in higher education, but in K-12, in the workplace, and in a number of social institutions in American society. So I said, we can play a role as a resource for African-American males, whether it's in education, whether it's in the criminal justice system, whether it's the workplace; so we expanded that mission to do that. 
His expertise was noted by several of the interviewed administrators for providing the Center with creditability for its research agenda and mission, particularly by Mr. Winters, the programming director. He too had been with SSU for almost a decade and in higher education longer with programs focused on student internships and mentoring. His role with the program started close to the beginnings of the initiative as one of the two program coordinators on staff. Now with the title of Programming Director, he managed the day-to-day operations and programming initiatives for Black male students at SSU. He was the person most of the Black male undergraduates met when they were introduced to the Center. He commented on Dr. Deal's role and the expansion of the mission to include a research component:

Having Dr. Deal on board is great. It gives the Center validity in regards to the research side that we want to push the Center towards. Dr. Deal has done extensive work, has an extensive body of work on researching African-American males.

Beyond the national grants secured by Dr. Deal, there was a secondary research component that helped to advance the mission. Current graduate students at SSU were able to work at the Center as researchers. Their research interests and agenda focused on the Black male experience within their respective disciplines. Dr. Deal gave them support in pursuing their research agenda through mentorship and guidance; and they received the distinguished title of research fellows. Dr. Deal explained the fellows program as:

A program to help nurture and develop the next generation of social scientists, who are equally as passionate about this work as I am and my staff, who can serve as a resource, who can do the research and help others even when they leave after graduating from Southern State. 
Other ways the initiative carried out its research mission were through its program design and management. Mr. Winters spoke about how programming was developed based on research and theory that speak to how Black men learn and engage. The Center planned to model for other initiatives how to develop programs and partnerships across the K-16 education system. One example he spoke of was a new outreach program with the local middle schools and high schools that focused on mentoring and literacy:

We want to develop a model for how universities can work and collaborate with surrounding school districts as it relates to African-American males. So we're working on a group mentoring model...Right now we're trying to work on a model of utilizing emotional intelligence and other-some other theories that can be effective in working with African-American males to help and motivate themselves to do better in school academically and socially.

The middle school mentoring program received its seed money from a prominent Black male law professor who came to campus for a speaking engagement. He connected with the current male students through a round table discussion held in addition to his official lecture and decided to donate the start-up money prior to leaving campus. He wrote the donation check to Dr. Deal immediately upon the conclusion of his round table discussion. He stipulated that the use of the funds needed to have a literacy component, where the Black male undergraduate mentors read and discussed literature with the younger Black male middle school students.

Enacting the research component of the mission served as a foundation for several aspects of the vision Dr. Deal has had for the Center. Beyond a mission for the Center, he has had an overall vision for how it will serve society. His vision has included conducting research 
across disciplines about Black males that addresses questions and issues across age groups. He wanted the quality of research that is published out of the Woodson Center to be viewed as the most reliable resource for research on Black men:

When people have concerns or questions about Black males, I'm hoping that the Center will be that place, whether it's government, whether it's the educational institution, whether it's the faith-based institutions. That they will see us as being the premier resource on the African-American males, whether it's just general information, whether it's providing technical assistance, doing research. That's my goal. That we will be the psyche of various sectors of our society as it relates to African-American males.

At the time of data collection, Dr. Deal's vision for the Center started to materialize. He was contacted by several international higher education institutions about the Center, his research, and was serving as a consultant to help them address the issues of retention and performance of Black males. He has provided guidance to people at the highest levels of government. His specific research mission for the Center has been to fill in the gap with a positive perspective when it concerns researching Black males. He stated:

As you know, there is a lot of deficit research that is produced around African-American males, whether we're talking about health, whether we're talking about education, whether we're talking about the criminal justice system, or whether we're talking about relationships with our loved ones. I'm hoping that we will be able to shatter the myths and share the realities from a strength-based perspective. I hope that we'll be the pulse of issues around African-American males and that our staff will remain centered, having one foot in the academy and one foot in the community, to be able to bridge the gap 
between the academy and the community. Not only to produce high quality research, but having a hand in its dissemination to the masses.

Dr. Deal labeled the Center an "applied center" where the work done is applicable across disciplines and levels of education — with the current Black male students at SSU always a focus:

We don't just do research for the sake of it. If we do research that may not necessarily impact, I mean directly impact our African-American males, but indirectly, whether it's through policy and legislation, we want to remain a major force on this campus as it relates to African-American males at the undergraduate and graduate level.

Dr. Deal has been the public face of the center and also believed the collective work of all researchers and practitioners who formally research to solve the issues that affect Black Males were relevant to the Center's work:

My philosophy is that we'll never improve the plight or the landscape for African American males if we don't bring all those who potentially can help us improve that landscape together. And so we try as much as we can to involve as many to the table, and that's whether we're talking about philanthropic work, or whether we're talking about volunteering time or even resources to the Center. So we work very hard to cross borders, if you will... We're very excited that we have these projects. And these projects, we believe, will be able to shape public policy once we complete these studies.

The institution carried the land grant and extensive research university rank that helped focus the staff of the Center as they carried out their mission for research. The Center staff members viewed themselves as an extension of the institutional mission for excellence in research and carried out their responsibility to the local community, state, nation, and globe by 
being associated with Southern State University. By providing consulting based on the research conducted at the Center and modeling best practices in retention of Black males, they have been an extension to the state and global research communities, across discipline, when it comes to improving Black male retention. Dr. Deal emphasized the need to be an "applied center," and Mr. Winters confirmed the research goal of the mission was in alignment with the institutional mission in regards to being viewed as the most reliable resource for research on Black males:

The way that we go about doing that is through providing research on the various areas that critically affect Black males; in addition to providing research, looking for best practices; also in looking for best practices, developing models ourselves. So having the practical side of it as well, doing consulting with universities, with school districts, other organizations or institutions; providing consulting as it relates to the African-American males.

The administrators at the Center specifically viewed their role in finding answers to the problems that systemically affect the lives of Black males as essential to their program mission and to the institutional mission.

Retention of Black Male Students. Another important element of the mission was the retention of current Black male students enrolled at SSU. Part of the Center's mission to retain Black male students overlapped with the program's focus on research, as they researched the best retention practices to share with others concerned about retention of Black males in higher education. SSU expressed significant concern at the highest institutional level of leadership about the retention rates of Black males. Southern State's concern about the low rates was the catalyst for the first formation of the Black male programming initiative prior to the development 
of the current Woodson Center. There were several offices housed in both Student Affairs and Academic Affairs that hosted different programs for Black undergraduate males to help engage them and to help with their academic performance before the Woodson Center was created. The Center established its annual programming based on the initial piecemeal retention efforts that already existed at SSU, in addition to the research on best practices for retention; some of the original programs other offices offered have become signature programs at the Center (for instance, an annual themed retreat). Even with the expansion of the mission's scope and staff to carry out the mission, retention has remained at the heart of the staff's work. Dr. Deal mentioned that the mission to retain current Black males enrolled at SSU was still a major component of their vision and purpose when stating that the Center was not "neglecting our humble beginnings for looking at retention and the issues of students on campus, but we just expanded it.”

Dr. Richardson, retired Chief Diversity Officer, was able to provide the historical context for how retention of Black males served as and has continued to be a major component of the Center's mission. Dr. Richardson has been in higher education for several decades, including a historically Black institution. He served the majority of his formal professional years in faculty and administrative positions at SSU. His last position at SSU as the chief diversity officer was the most influential on the creation of the Center. It was in this position that he initiated the concern about the retention of Black males to the campus and formed the early stages of what became the Woodson Center. He was still very involved in the Center in an advisory and consulting role even after his retirement. Dr. Deal has stayed in contact with Dr. Richardson about the progress of the Center, and they both represented the initiative on a national and international level when called to speak about the successful increase in Black male retention at 
SSU. Dr. Richardson explained that the purpose for the initiative was to initially look at retention issues:

To put it in perspective, I was trying to increase the number of persons from the underrepresented groups receiving degrees from Southern State. So that is looking at everyone. And it was in this effort of seeing who is graduating and who is not, and who's making it, that I decided, okay, try to put something in place that is going to be the blanket here; we're going to catch this at the lowest and take care of others. That they're going to rise up with this thing as well. So in some effort of trying to look and take care of everyone that I fell into this with the African-American male. But also I felt that if this was where we're having the problem, then let me take this on as a challenge to see what we can do.

The Center was a direct descendant of the early partnership on Black male student retention initiated by Dr. Richardson as Chief Diversity Officer and by the Vice President for Student Affairs. They both delegated to other faculty and administrators the responsibility of gathering the data, which enlightened the campus community that Black males were the least retained student group at SSU. The initial research of the first task force on Black male retention provided administrators and faculty an idea of the Black male experience on campus at SSU and the students' needs.

According to Mr. Wind, the first program coordinator of the Center, the first action steps taken to achieve the goals of the initiative were focused on retaining Black male students. Mr. Wind has served in higher education for almost a decade in both the community college setting and at SSU as an administrator. He attended a historically Black institution and has offered 
consultation on leadership with a focus on Black male clients. Dr. Deal stated that Mr. Wind "did an outstanding job creating a sense of community for our students and developing programs and collaborating with other units across campus." Mr. Wind added additional reasons for the start of the initiative, "What came out of that research [on retention] was that the current Black males at that time on campus were feeling very isolated, not connected with the university."

These research findings led Mr. Wind to focus the new initiative goals and efforts to implement ways to improve retention:

We started that process making sure that — one of the first things we did was put together a committee that included the Office of Admissions, the Office of Minority Affairs, SSU alumni, Black male professionals that were teaching at that time. And my first conversation with them was primarily: how are we, we collectively, going to make sure that this cohort of Black males that we were recruiting matriculate though this process in a four or five year time process and become successful.

Ultimately, the staff of the Center desired the Black male undergraduates to be engaged with the institution, knowing from research that student engagement improves retention and success. Programming, role modeling, mentoring, and creating a sense of accountability and high excellence all have been ways the retention component of the mission has been executed by the Center.

Student engagement as a means to retain students. Getting undergraduate men involved on campus has been a large part of the Center's retention efforts. From Mr. Winters' perspective, it has been an ongoing effort to increase Black male involvement and engagement on campus: 
That is still something that we're still hearing, that we're still working to improve on. Having that voice that has not been represented as much as it should have been in the past, I think is really adding to the diversity. Having that voice within the different areas, whether it is undergraduate student government, whether it's serving on the Trustees Board, whether it's working over in the Alumni Affairs; just in various areas having African-American males there serving, adding their ideas, their input, their suggestions, I think is vital to the University and further goes to adding to the goals of diversity here at the University.

When students discussed how they have changed and adjusted at Southern State and what helped them with those adjustments, they noted the important role the Center played specifically in their leadership capabilities, social skills, communication and networking skills, and study skills. All have been developed by their connection to the Center and participation in the Center's programs. Lucas, an out-of-state, junior, sociology major, specifically discussed his development as a leader, how he increased his responsibility and engagement on campus over time, and the role the Center played in this development. He was raised by his mom in a singleparent home on the east coast, but his father was involved in his upbringing. He has a Caribbean family background. He was first-generation Virgin Islander. Lucas shared:

My goals and responsibilities, actually what takes place in the Center has changed every year that I've been here. I feel like my role as a freshman and as a sophomore was to listen and learn. Like, just observe from all of the outstanding young men that were there before me, kind of learn from them, studying how they went about things. And the Center does a great job in preparing their young men to be leaders when opportunities for leadership come up. 
Peter, an in-state, pre-med student attributed his leadership development to his participation in the Center's leadership workshop series. He was a student-athlete and was successfully completing his fourth year at SSU on an academic scholarship. Originally holding on to dreams of going to college out of state, he decided to attend SSU at the last minute during his senior year. He considered the cost for his mother, a single parent with no financial help from his father. Both of his parents were college graduates and student-athletes as well during their collegiate careers. Peter credited advancing his leadership development and practical skills to the Center:

I knew I was a leader, I just didn't know what kind of leader I was. I didn't know how to go about talking to people in groups. Especially when you're in that leadership role, how to delegate things and what kind of leader do you have to be on a certain day? What is an effective leader supposed to look like? What are you supposed to portray? To get things done, what do you need to actually do as a blueprint? How to do those things, I didn't know - all I knew was my sport, I tell people what to do, they believe in me. I give them some pep talk and whatever and that's cool. But that's sports. It's not like I'm trying to run my own program like I'm trying to do now. And now I know how to do that.

After completing the Center's leadership programming, Peter felt that he could confidently step into leadership roles instead of maintaining the typical status of participating as a general member.

Ronald, a graduating senior, specifically commended the center for developing his ability to manage conflicts during his time as a leader of an organization. He was completing a dual degree in political science and chemistry during the time of data collection and was making plans 
to remain at SSU to attend graduate school. He said the way the Woodson Center helped him to stay engaged and involved was advice on his leadership skills: “They've helped me by giving me advice, just giving different opinions and perspectives about how I should maybe go about doing things." He recalled, "I had to deal with a member [in his brotherhood organization] or some of them were very combative. So, it was a tough time and I was like [sighs]. Yes, starting junior year mainly it happened, so I was pretty much in [the Center] almost every day."

Mr. Winters believed that increasing involvement and engagement has been directly related to retention. The visibility of Black males in student leadership positions started a trend of what was considered normal as far as their level of engagement with the campus community. Mr. Winters posited that it created a certain culture of engagement and excellence among Black male students. He specifically spoke about the past students and current upperclassmen involved in planning one of their signature programs, their early orientation for new and transferring Black male students:

I think one of the strengths is the culture. With the culture I think through the years of building up the concern and raising that agenda and going from that [piecemeal activities across campus] to the Center, we've been around now really since 2005 . Looking at that first early orientation for Black males to now, and so what we're trying to do is build a culture of excellence for African-American males. Where, for students once they come in to Southern State and they see other students who are serving in different capacities and different areas, you know they see a person running for SGA as a governor or see another person who is serving on the student program planning committees, once they see some of these different things I hope it inspires them, increase their self-efficacy in regards to doing these things themselves. I think that is a strong point, the culture from that aspect 
with students who they see here who are already involved and engaged and coming back to help out with the early orientation program.

Lucas, Peter, and Ronald served as examples of the Black male undergraduates who grew their leadership experience and skills over time as a result of their engagement with the Center.

In addition to engaging students as leaders, the Center provided Black male students the opportunity to get involved on campus helping to orient incoming Black male students. Through programming they strategically provided Black male students the opportunity to help other students who identify as they do, as Black men finding ways to manage and successfully matriculate through a predominantly White institutional culture. The upperclassmen volunteer opportunities offered by the Center helped students understand another important value the Center focused on teaching and exemplifying — accountability for the engagement and success of fellow Black male peers. Mr. Winters stated this as a strategy to get students involved and thinking about their engagement on campus and the impact they can have on their peers:

How can I support another student on campus, someone who I know is struggling, what more can I do to help him out? What more can I do in regards to a student who is thinking about leaving? How can I help this person out, or someone I know whose priorities aren't completely on the straight and narrow. Or somebody I know who is extremely talented and doing well, but they're just not getting out there and getting involved in extracurricular activities, things that could really benefit them.

The students felt a level of social responsibility that came from their involvement with the Center. They felt they were responsible for giving back to the community and giving back to and bringing up the next group of Black males that entered Southern State. There was a sense of 
accountability to each other to make sure they made it through and graduated, as expressed by Lucas. He spoke about the accountability and responsibility the Center taught him:

It's funny, because you receive these emails about these programs, it really does seem to attract the individual, like, this is what's going on, we highly encourage that you come out and volunteer for it or support it or, you know, just be exposed to the event. You might learn something. And then when you actually, you know give them your RSVP accepting, and actually go to the event, you go there thinking that, you know, you're going to learn something to kind of personally grow for yourselves, and that does inevitably happen. But I think the really interesting thing is the more that you do it, the easier it becomes for you to translate what you learned into your everyday life, but more so into the lives of your brothers, the people that use the Center. And I think it gives you a sense of accountability and the sense of responsibility. So I think that I've changed just by the basis of being a part of the Center and taking advantage of its resources and its opportunities, I've almost automatically changed from a mentality of, like, trying to better myself to kind of making decisions and acting in a way that will better my brethren and the people that use the Center with me, and as well as those without it.

Outside of volunteering to help with the early orientation program and other student programs hosted by the Center, students were able to hold paid work-study positions and internships. It was seen as a way of helping other students and also as a means of financially supplementing their educational costs. There were several work-study students on payroll during my visit on campus; four of the students working at the Center were Black male students. 
Students were engaging faculty in and outside of the classroom, taking advantage of scholarship and research opportunities, and connecting with other Black male students through the Center and through ethnic-specific organizations within their respective schools and colleges. James, an in-state, junior, engineering student active in his campus's National Society of Black Engineers chapter and the College of Engineering Minority Academic Services Program, shared the good news of his acceptance into a summer undergraduate research faculty mentor program. Eli, a graduating senior, was awaiting his acceptance results into the same state program during the time of data collection. Both were introduced to the idea of applying from the Center and were able to get faculty to endorse their applications. Eli acknowledged and credited the Center with recognizing him as a potential candidate:

I'm hoping if everything goes well, that I think it's good. If I do get selected, I will be pretty happy. And it would change my life, because, you know, I never had an opportunity like [this]. So just having [the Center] even sending me the email to give me the opportunity, because of all the work they said I put in, I get to know that it will open up other avenues for me to enter into my career role, so I'm hoping it works out. That would translate into a change in my life.

Students saw the importance of engagement for networking purposes and for increased academic success. They have sought help academically through faculty, tutors, and other university staff, and have had mixed experiences inside and outside of the classroom with faculty. They encouraged each other to make it a priority. Ronald was adamant about the need to seek out tutors and other help aids during his focus group and expressed it to the participating underclassmen. Specifically, he recapped the help his chemistry tutoring experiences provided 
him to the freshman Daniel, who was aspiring to be an ophthalmologist and was in the middle of his chemistry series of courses:

RONALD: Stay in that piece! You got to do it.

DANIEL: Because I'll look good especially for lab.

RONALD: You got to do with trust. You got to be in there.

DANIEL: Last quarter, it was like, I had no idea even where to start and then I just went there and sat down. One of the TAs talked to me for like five minutes.

RONALD: Yeah, you just got to keep going. Yeah, every time it's open, you know or maybe another TA working there or something. You got to go in there. I was going in there at least twice a week. Straight up.

DANIEL: Yeah, I have one. I think I have a gap actually right before my chem lab. RONALD: You got to go.

The administrators at the Center desired students to have a sense of accountability to each other. They desired students to understand that it takes more than themselves alone to make it at SSU; they needed to develop help-seeking behaviors. The Center's mission was focused on teaching students how to engage their academic environment inside and outside the classroom. The administrators realized that students must learn help-seeking behaviors to succeed and retain. They taught it as a vital skill from the first encounter they had with the students, which was usually through the Center's early orientation. Through the combination of teaching students to engage with the Center and SSU as a whole, and by promoting a culture of accountability, the staff at the Center has multiplied their efforts to retain students through upperclassmen modeling and adopting the practice of engagement as commonplace. 
Networking with faculty, with other students in and out of the classroom, and with the staff of the Center and other student services staff has helped the students adjust and succeed in college. Todd, a freshman sports studies major, spoke about the significance of the Center's early orientation program on his adjustment and his desire to find a better balance to do more Center activities:

But I'm part of the Early Orientation, and I went to a couple of the little workshops or whatever, but I kind of wish that I wasn't so busy with school and I could attend more of these, because this quarter and last quarter I've had late classes. So, it's hard to try to attend them, but I'm going to somehow, some way. I'm going to try to make more time to attend some of these Center events provided because it only makes me better as a student and person. So I think I need to make time to do that.

Peter and Eli, a senior African Diaspora major with an international study minor, both discussed having great experiences in their major-specific courses and with faculty in their departments. They viewed networking as a highly productive activity that has helped them remain at SSU and succeed academically. They actively have sought out ways to get connected and engage in co-curricular activities as well as academic activities to help themselves and other students. Peter expressed great satisfaction with his major-specific faculty and academic support system within his college, stating:

In my college, in exercise science, my experience was amazing. They help you with everything, they want you to get involved in every research project that they have, and they recommend you for so many different things. It's amazing there. 
He also spoke about his initial contact with Southern State University's Office of Minority Affairs through the freshman summer bridge program, and how he moved from a disengaged student to an engaged one:

It has been amazing, I think. For me, it had to grow on me. One, because I just didn't want to be here, but I knew I had to be here; I had to make the most of it. But once I started getting involved in the summer bridge program, because I was here early, that was real cool.

Programming as a means of retention. In addition to providing students the opportunity to volunteer to help with executing certain programs hosted by the Woodson Center, the programs themselves were a tool used in the retention efforts. The Center's signature early orientation program has been a way to help both the Black male students and their parents get acclimated to the institution. The literature spoke of the biculturation that minority students operate in when shifting from their home life to college life on predominantly White campuses (Rendon et al., 2000). Some students have described feeling a weight on their shoulders to maintain close relations to home life while attempting to be acculturated to their new higher education environment; both worlds have distinct cultures. When a blended or balanced management of the two environments is not successfully achieved, it can increase the likelihood for a student to drop out.

The early orientation program provided both Black male students and parents the opportunity to receive important information to help ease the adjustment period. Parents had a connection to the institution through the Center, which was a calculated strategy of the initial 
staff. Mr. Wind spoke about the success of the orientation program with connecting parents and easing their anxiety about what support their Black male student would have at SSU:

I'm old school, so you had to make sure that mom knew that Jonathon and Maleek and her baby was going to get taken care of at this institution. So you had to listen to your cultural relevancy that came with this also. It wasn't so much the academic aspect, but who’s really going to be there to take care of my nephew, my son, and my grandson.

Dr. Deal reaffirmed the success of the parental connection and peer bonds made through the early orientation program:

Now there are a number of early orientation programs on campus; in fact, ours is probably the shortest, it's only two days. But for some reason, that brotherhood, that fellowship and being able to meet faculty and students and to reduce the potential anxiety of feeling like a number is having a humanistic connection. I think that's what we do, not only that, we connect with the parents. I think we get at students, because when parents realized that we have a program that's going to focus on their babies, I think they get really excited. Because when people see how comprehensive we are, even with staff that we have, I think parents walk away saying, "I have someone I can connect to if I need to connect with a big place like Southern State.”

Even with some students experiencing a deep dichotomy between home and school life, family has been a major contributing factor to students and their persistence. They have relied heavily on the encouragement that parents and other family members have provided to keep them focused on their academics and success. Kenneth talked about the support his family has provided him and his deep connection with them. He was an in-state freshman majoring in art 
history and industrial design with a minor in business. He identified as coming from a lowincome, single-parent home, raised by his mother. His family support system and their educational backgrounds were important to his persistence as he shared what has helped him to overcome the challenges he faced at Southern State. His family recognized the opportunity Kenneth had at Southern State University and encouraged him daily to persist:

I talk to my mom every day, my grandma every day. Basically, my uncles and stuff, they didn't complete high school, some of them didn't even get out of middle school back then; but they want the best for me, because they see I have so much potential. And it's not that they're banking on me, but they know from me growing up how God, going through my life and stuff, that you can make it. And they just want the best for you and they push you and they support you, and it's like they don't want you to do anything that you will regret, because they love you and they want you to be the best and they always want the best for you regardless. Having that connection and having someone to talk to when you're upset and you feel like you just want to quit. It just builds you up like, man, I can do this, I can stay in school a little longer, I don't like school, but I'm going to do this, I'm going to grind this out, get what I came here for, and then go on about my business.

Another program that has been used as a retention tool was the seasonal campus-wide assembly open to all Black male faculty, SSU alumni, administrators, staff, and graduate and undergraduate students. This program was designed to promote role modeling and to provide a networking opportunity to build mentoring relationships across the generations of Black men connected to SSU. Mr. Wind described the effect the semesterly program has had on students: 
We would bring together Black male faculty, upperclassmen, and underclassmen and also alumni in the setting at the university to do a meet and greet and network. Well, if you're an incoming freshman, first of all, you haven't seen that many Black men on campus at one of the football games or basketball games or a party, if you will, to kind of get your groove on. So then today it was, "Wow, I'm walking into a setting, man. This is all about business and networking. I'm meeting Dr. So and So, or Professor So and So, or Alum So and So," they felt a connection with them during that time period.

Dr. Deal further described the benefits of this particular networking program sponsored by the Center. He explained the opportunity for the intergenerational support and sharing of wisdom that the Center has provided the Black men of SSU. Research has not been the only mission component focused on providing a lifespan effect. The programming aspect of the Center was in alignment with the mission of reaching across the lifespan as well, where Black men at all stages of life have been able to connect to each other and affirm their identity through fellowship and building a brotherly bond:

We create an environment of brotherhood, not only just for students, but for my colleagues. We create a safe space for staff and faculty, who have the same trials and tribulations as the students. It's sort of like when you think about Ralph Ellison's highly acclaimed Invisible Man, you know, the notion of feeling, what that really means is one's sense of humanity, it's not being affirmed. And what we do, we affirm each other; we represent the past, the present, and the future. And we have that lifespan in the room when we have events for the past, the present and future. Some choose to be in the past, it's hard for them to move forward, but we don't give up on them. And some, they don't want to learn from the past, they're just so future-minded, and they make pitfall mistakes. 
But what we're trying to do is those three moments in time are very important, and we try to focus on those three moments in time.

Students have credited the Center for their increased ability to build healthy networks and socialize in college. Freshman student, Matthew, talked about the increase in his ability to connect and meet people in college, and how the Center has helped him develop those skills:

I know, socially, the Center has made me approach people and be more comfortable with approaching people, especially with my peers. Sure, it started in high school a little bit, but, when I came here, I felt like it built off of a progression in high school socially. Like, before high school, say I was here [motioning his hands low], after high school I was here [motioning his hands slightly higher], and through the Center, it got bigger. So I'm becoming more and more comfortable with just me meeting people.

The Center has been credited with helping to develop both their personal and professional communication and networking skills. Third-year student, Barack, discussed his increase in confidence to go after both types of opportunities because of his connection to the Center:

Just being more aggressive as far as social stuff and even with career stuff, too. I guess it just exposed us to a lot more opportunities. I try to take advantage of more opportunities than if I wasn't in it. When I came in, I came in with the Center's program.

Marquise, who is completing his first year at SSU, spoke about the summer internship he has earned, based on the networking and communication skills he developed participating in the Center's workshops: 
It's like initiative and, like, being aggressive, but I definitely wouldn't have approached people for, like, internships or anything if I never attended the workshops. But I'm pretty sure I have one, like, this summer, that I never would have got if I didn't network myself out, "Well, I'm thinking about staying in town this summer so, like, I would like to know if there's an offer." I'd actually, like, get business cards, and I'll follow up and call them back so I know where they're at.

Role modeling as a retention tool. In addition to the networking program where Black men connect each semester at SSU, other successful Black males across professions and disciplines have been invited to speak and to serve as role models for current students. Students have been able to engage with these role models through the Center's programming. The staff members of the Center were considered role models for the students as well. The Center had three full-time staff members, a graduate assistant, the research fellows, and five work-study students. The purpose of role modeling was made apparent by Mr. Winters. He discussed how students were to be accountable not only to themselves but also to each other; making sure that they were academically successful and engaged on campus. They served as role models of successful student behavior to each other. The Center also had the expectation that great students would identify other Black male peers who needed to step up and increase their engagement. He shared that role modeling was directly related to building up the students' sense of accountability: "In some ways I guess you could attach that to accountability as well with some of our different programs, with some of our role modeling that our staff does and other people that we bring to campus do."

The positive effect that role modeling has had on Black male retention and success was shared by Mr. Wind: 
So often for Black males the question is, "Show me somebody who looks like me. Who's doing what I want to do? And then I'll go to college, and I'll stay in high school, but don't tell me to read somebody's book, who I can't really touch and feel.' I'll do that, because I know there is knowledge with that, but we have to make sure that they can touch and feel real life examples on a daily basis.

Dr. Deal added to the emphasis on role modeling. He spoke about how he has explained the importance of being role models to his staff:

What I believe personally, fundamentally, and that's a philosophical belief I constantly try to model it, and I try to share this with my staff, is that we're teaching. We're teaching even if we don't say anything. And pulling from some of the old sociological schools of thought [with] the looking-glass self, what we're doing is we serve as counter-narratives to things that they've heard that are erroneous. Not only that we serve as counter narratives for those who work with these students, who may not look like these students or live, come from the same place as these students. We're teaching, you know.

He credited this focus on role modeling as a way of retaining Black male students with the influence that the Black male faculty and administrators had in their own historically Black undergraduate institutions, known for their noteworthy graduates. The influence that many of the administrators have had from their own careers as students at historically Black institutions has served as the basis for the development of the mission, how programming has been done, and the philosophy of excellence that was expected by all Black male students once they engaged with the Center. Mr. Wind as the first programming coordinator implemented many aspects of his undergraduate experience and was given the freedom to do so by Dr. Richardson. They both 
went to the same undergraduate college for their bachelor's degrees, where the tradition of role modeling and excellence as a standard was the norm. Once appointed Programming Coordinator, Mr. Wind told Dr. Richardson that he would implement the model used to build up young men from their alma mater:

When he called me, I basically said I'm going to download the model into what we're going to do at Southern State University. That model was basically how to build a strong community where Black males were on a peer-to-peer basis and also with Black males on a professional standpoint.

The Woodson Center has provided current Black male students the opportunity to interact with famed and well-established Black males in different professional fields through intimate discussion sessions. When these individuals have been brought to campus, either by the Center or other campus offices, the staff has arranged for the Black male students to have contact with these professionals in a closed-door setting.

The intention of these types of settings has been to encourage the development of professionalism and excellence in the students. Dr. Bryant, who was first responsible for managing the development of the Center alongside Mr. Wind and Mr. Winters, shared the initial concern they had about Black male leadership. Dr. Bryant was a veteran administrator at SSU with more than two decades of experience at the university. Dr. Bryant was in charge of several initiatives that academic affairs launched over the last 20 years, including federal TRIO programs and other minority retention initiatives. He was directly involved with managing the Center in the first three years of its existence, before relinquishing his direct responsibilities to handle other new initiatives. Dr. Richardson solicited his help to make sure there was a senior 
leader and someone with institutional history directing the initial day-to-day operations and programs. Dr. Bryant explained the focus on creating Black male leaders from the beginning:

Our mission principally focused on producing young men who would contribute to and become leaders in the creation of a viable Black community...And basically our thinking was that, if you considered the Black community and you considered the current state of, say, number of young men who are not, say, matriculating all along the way, then at the end when you're looking at college graduates, if you take, say, a cohort of 100, then probably fewer than ten of those young men would even be, would even get college degrees. And so that seemed to us to say something about the future of our community; if we're not producing many young men, in comparison to, say, to young women who are educated and who are able to take their place....our mission was pretty much focused on what to do about these young men...trying to create young men who would become leaders.

Dr. Deal reiterated the same sentiments about excellence, building informed Black male leaders with strong identities that were developed over time through their SSU student experience and with the staff and Black male campus guests of the Center:

Excellence without excuses, that's what we're trying to foster. So they learn professional development. Believe it or not, some of the young men do not know how to tie a tie...So we're acclimating them to the professional world, not necessarily saying what is acceptable, but what kind of message do you want to convey to the world, and helping them to think about the messages that they want to convey. And ensuring that people interpret those messages accurately and to ensure that they convey messages consistently, 
a lot of who they are and where they want to be. And so that's what we try to do. It is not to try to change someone. I mean, change is evident when you choose education, but sometimes they don't know that and we don't approach them with "you'd better do this to make it." No, no, no, we teach, we bring people to inform, we have others who come in and say the things that sometimes is very difficult for us to say to some of them. Sometimes we just say it.

Developing standards of excellence for the individual students that interact with the Center has been cultivated over time and through student exposure to programming, mentoring, and role modeling. According to Mr. Wind:

The key to that was, as a young incoming freshman, you were kind of dull around the edges, and our goal was to make sure we identified sharp Black males to sharpen you. So by the time you came out of the [Center's] programmatic pieces, more important, when the time came for graduation, you were sharp. You had cried, you had gotten some scars, you had been rejected, you had been accepted, and you had gone through enough of the matriculation process with your ego being crushed and everything else that you now understood I have to be humble... I'm sure they're continuing this now; you know, there is a humbling process that you go through... I really don't care about your last name. I really don't care that your tuition is paid or not paid. At the end of the day, I'm going to tell you what's waiting for you and you ain't ready yet! They were like who is [this] crazy guy in my face? So now when I see the guys that I've helped are working for the J.P. Morgan Chases and the Price Waterhouses, and I see them downtown now passing me, "Hey Mr. Wind good looking out. I'm now working and thanks that you told me 
about the politics in the office, because I'm learning. I remember what you told me about how to survive, and I'm now living it."

Students continued to build up their network with each other through participation in the programs and connection to the Center. Jason spoke about how the Center has provided a concentrated effort to recognize and bring Black men together regularly:

I think for some reason that we're maybe $6 \%$ of the school population, and so it's so easy for us to get lost in the mix, even though we are the easiest to pick out. But aside from that, being such a small number, we need to come together to pack a powerful punch. And the Center gives the opportunity.

They viewed the Center as a source of accountability and brotherly bonding. Matthew again tied his current friendships and bonds back as far as his first program, the early orientation:

I think they have your best interests at heart. When I went to the early orientation, and just to see the positive role models on staff and upper classmen that were there to help you, guide you through those first few days, and you still see them on campus, like now, they want, they genuinely want to be your friend. And as far as staff, they always check your progress, always want to talk to you, see how you're doing, and they never hesitate to help you in any way that they can. Just the comradery that I felt with a whole bunch of guys at the Center, it's great. It's like I had a home base that first few days.

Because of the immediate positive connection to the Center early on in their careers, Black male students at Southern State have had a great connection to the institution that has assisted in their adjustment and has helped to secure their success. The display of upperclassmen and staff role models has served as a visual reminder of successful Black men. Other speakers 
and presenters that have assisted in executing programs also reinforced diverse yet all positive role models for the students. Students have been able to get a wide variety of training on academic and professional skills needed to persist through to graduation and to have successful college careers. They have gained access to role models who have provided advice about persisting to graduation and managing the academic rigors of college. Peter, a fourth year senior, said the program helped him stay connected to others and to stay focused on persisting:

So to have a program like this where you can go, see other African-American males successful that's giving back and who just want to help you, it makes you want to be the best person that you can be, and that you can be in their shoes and do something like that. I think it's just like "iron sharpens iron," like the saying is that they have.

The Center has been a safe place of support to the students, where they have matured and have been nurtured in college, and the focus on their persistence has been strongly encouraged and monitored. Junior sociology major, Samuel, stated:

So it's not like you can just be, like, "Oh I'm just done with school," and just leave. I mean, I really think it would probably be impossible for any of us that are in the Center or out of it, to just get to this point and just give up. I feel like there's somebody that probably will just be like, "No you can't do that. You got to keep going."

Students anticipated the applied pressure from the Center's staff to intercede and keep them at the institution through graduation. 


\section{Diversity Initiatives at Southern State University}

There has been a concerted effort at SSU to integrate a campus-wide diversity initiative as a major component of the institutional culture. SSU defined diversity as an effort for inclusiveness of people and ideas without the fear or imposition of discrimination. The focus of the original strategic plan was specific about providing equity for racial minorities, women, and sexual orientation for students, faculty, and staff of SSU. In the recent, second revision of the plan, the SSU diversity strategic planning committee has broadened the scope of diversity to include how diversity affects the scholarship, curriculum, and institutional environment as a whole, and to eliminate discrimination for all groups specifically recognized in both federal policy and university policy (i.e. age, color, disability, gender identity or expression, national origin, race, religion, sex, sexual orientation, or veteran status). The Woodson Center at Southern State University has had major support from the institutional leaders as one of their important diversity initiatives. This level of support has existed since the beginning of the initiative due to SSU's commitment to strategic diversity planning and the exposure and promotion of the Center within the diversity plan.

In addition, the staff of the Center has been intentional with their plans for the sustainability of the program and its alignment with the institutional goal to integrate diversity into the university culture. The Center staff focused on the positioning of the initiative within the diversity plan and viewed the program as a vehicle to support the institutional priority to increase structural diversity through their focus on retention of Black male students. The staff also focused on creating and providing sufficient financial resources and public exposure for the initiative, in order to increase the likelihood of longevity at SSU beyond the current institutional leadership's support for diversity. Finally, strong partnerships and institutional buy-in from other 
departments have been present since the inception of the initiative, due to the collective effort across academic and student affairs divisions in the formal development of the campus diversity initiative and the work done to improve retention of Black males.

Institutional support for the integration of diversity. SSU leadership, including the president, supported the diversity initiative. Diversity has been a major component of the strategic plan for each president who has served during the lifetime of the Center. All presidents had specific goals for diversity and campus climate improvement within their strategic plans, or made important leadership decisions to increase support for diversity initiatives on campus. The diversity strategic plan has been on a five-year review cycle since its establishment, based on the information provided in the annual departmental report cards. The diversity report card has been a part of the annual reporting in assessing and evaluating the institutional strategic plan.

The work of SSU presidents came in three stages. A president appointed a diversity planning committee with resources to review the current campus climate and made formal efforts to improve diversity by creating the first formal campus diversity plan. It was a president who made sure that active support for diversity was not interrupted during transitions by filling several high positions in faculty leadership, academic administration, and athletics with Black professionals and women who were supportive of the initiatives. This was not always well received or popular, but retired Chief Diversity Officer Dr. Richardson stated that in his circle of other campus diversity officers, "people couldn't believe that!" And by "that", he meant the efforts that had been made for integration of diversity into high level strategic planning and action at SSU compared to his fellow chief diversity officers' institutions. Over time, the president has led the discussion to incorporate global excellence in the overall institutional mission and has added an international focus to the details of the diversity mission. Mr. Wind 
confirmed the current president's concern for more domestic diversity issues and its importance, along with his global vision for Southern State. He discussed the president's comments about low graduation rates of Black male students with him upon the start of his current presidency:

You have a great vision leader in the president. One of the things he said to me was, "I appreciate that you were able to get a retention level double of what it was"... at that time it was 45 or so percent. Because that was something that really quite honestly bothered him to a certain extent. Why is this potential low with this particular cohort, why can't we get it higher? It really got to the point of being able to say, we're able to really put these kinds of pieces together, make these kinds of resources happen the way that they can happen. The vision ties into the institutional aspect. It's really when we look at the whole value of why I should come to Southern State as a person of color, it comes from a cohort standpoint. It's really key that it's not just about diversity.

The concern for the retention of Black males and other historically underserved students has remained a priority for improvement with the current president. Most recently when given the opportunity to address the public about the institution's top accomplishments of the previous year, the president's highlights included the impressive retention rates of Black and Latino/a students in comparison to both public and private institutions.

Even with the recent history of Southern State leadership supporting the integration of diversity into the institutional culture of this historically White institution, Dr. Deal expressed the concern most administrators have faced when charged with missions similar to the Center's:

Well, the major challenge is that it's making sure that we're aligned with what the stakeholders deem is important... Recruiting and retaining the best advisers, faculty and 
staff, and students, outreach, making a difference in the state and across the world. It's making sure that we're relevant, because you know at the end of the day diversity tends to be very strong in various social domains in society when we have a strong economic situation. But when economics are not strong, when we have a decline in resources, diversity is not as important.

Dr. Richardson expressed the concern of keeping the level of importance and the significance of diversity at historically White institutions and spoke about the importance of having "support from the top," stating, "We were lucky enough to get it, but you can lose it in a hurry."

Dr. Richardson was appointed as Chief Diversity Officer under the first president who made diversity a priority. His mathematical background and White heterosexual male identity makeup did not indicate him as the historical prototype of a strong advocate for increasing diversity efforts. But throughout his career, he has used his position and influence to protect and promote diversity efforts on a national level. He spoke about the president's approach to introducing the importance of diversity to SSU staff:

He had not made that known to Southern State, what his interest was for this diversity. He said to this group, "Do you want to know what's on my mind and what is important to me? Diversity." And I must admit even with that staff that I had of 130 people, I probably had no more than six or seven persons in the room listening. And so one said, "Why is that?" He gave the case as to why that is important.

According to Dr. Richardson, throughout his career, the president made diversity a larger part of his professional philosophy of what makes institutions great and viable in the $21^{\text {st }}$ century. In leadership positions prior to SSU, the president fought to create programs that diversified the 
disciplines with known homogeneous demographics. He believed that diversity fostered excellence and the production of the best ideas. After Dr. Richardson's appointment to Chief Diversity Officer, the president provided him a venue to speak to the other vice presidents and deans about diversity and the strategic plan he expected to implement at SSU. The plan had a high accountability factor and a specific diversity report card per unit that had to be reported on annually as a part of the evaluation of the university strategic plan. Dr. Richardson remembered the president's words in that first meeting with the vice presidents and deans like it had happened the day before, recalling:

I'll never forget that day. He had asked me to give a spiel pertaining to diversity and maybe what I envisioned...everybody has to be involved; various colleges had to be involved. Then he said that we're coming up with, and this is back to the top and how throughout the whole unit, a diversity strategic plan...It was after my appointment that he did this talk, said that "We are going to put out a report card." Then he went further to say, starting over here [pointing to space as if reenacting] "And you people around the table are not going to let me down." Some of the persons just froze. One person, you would assume that he hit them like Abraham Lincoln. Like he said, "I can't believe this." They went after him in a very nice way "that you're also saying that we are trying to be an institution to increase quality?" And he was saying, "You cannot have that without diversity." [Chuckling] And with that diversity strategic plan, which was separate, yet it was a part of the academic plan. So all the things that we had that they were saying we're going to achieve and that they indicated about those particular goals, diversity was a part of that. They were not separate. From the very top, we got someone to express that to the 
faculty and, because everyone is usually looking for the person who is in that seat for direction and often go with it.

The necessity for a high level of accountability from institutional leaders was recognized by the diversity strategic plan planning committee. They stated in the first formal plan that people in leadership had to take diversity seriously and hold people accountable using whatever tools are at their disposal (Southern State Diversity Strategic Plan, First edition).

Established standards for communicating the institutional support for diversity. The way that diversity was communicated and represented internally to the SSU community and to external university stakeholders was another major focus of the diversity strategic plan. The institution kept the level of excellence, high standards of quality of information and visual presentation, and in the amount of financial resources that SSU has invested on all publications and media representation about the successful diversity efforts at the institution. Dr. Deal stated that SSU "spends more money on diversity than any university in America." He went on to state:

I think we spend over $\$ 17$ million in some kind of diversity activity, whether it's scholarships or whether it's program, or whether it's outreach. You know, so we just fall in line with the everyman mission. Whether it's true or not, many have indicated that the Center is probably on the top agenda in terms of visibility and impact, because our retention rate for the first year African-American males is arguably one of the highest retention rates at a public university in America.

The support was visible to the SSU community and others through their media publications and diversity website. This objective was connected to the goals outlined by the first diversity strategic planning committee to ensure an environment that nurtured student 
development and student success and to measure the institution's effectiveness (Southern State Diversity Strategic Plan Executive Summary). SSU has demonstrated ongoing commitment to these goals.

The planning committee was very explicit in the suggested directions for how to initiate the diversity strategic plan. The committee specifically assigned the maintenance of diversity statistics and disseminating reports of best practices and newsworthy achievements to the Vice President of Communication. The committee also suggested the creation of new staff positions to regularly monitor the data. They stressed that the communication efforts were to be for both internal university and external audiences and were to focus on all forms of communication and media outlets. This included an ongoing campaign to support a welcoming campus climate through an updated diversity website and other annual publications, regular campus-wide diversity discussions and forums, campus climate surveys, and student, faculty, and staff recruitment and retention data reporting.

Communicating to the university community and external stakeholders the importance of diversity at SSU was a major goal of the strategic plan. The diversity webpage was easily accessible from the Southern State University home page and was one of the prominent links that viewers could access along with specific links targeting future students, current students, faculty and staff, research, outreach, international, athletics, and a link providing history of the institution, and university cultural traditions. When reviewing the diversity website established to communicate the institution's centers, offices, and services related to diversity, SSU presented them in clearly defined categories that helped to shape their approach to the campus diversity initiative: Centers and Offices; News and Information; Disability; Religion; Sexual Orientation and Gender Expression; Nationality; Veterans Affairs; and Women and Gender. These broad 
categories were consistent with the first goals of the diversity strategic plan to focus on creating a climate of inclusion with a level of attention to the specific goal to increase ethnic minorities and women at all levels. The Center's retention mission created the opportunity for it to be highlighted as an initiative worthy of national recognition based on the diversity strategic plan goals.

There was a high level of visibility on the web for the Center compared to other diversity units at the institution, considering where it fell in the structure of the institution. The Center was a unit within the Office of Minority Affairs. The Office of Minority Affairs was a division of Academic Affairs led by the Chief Diversity Officer, who reported directly to the Provost and was labeled as one of the senior leaders of the division. The Center's webpage link was featured as an individual link on the institution's diversity webpage as a prominent office alongside the Office of Minority Affairs. Also, it was listed again on the Office of Minority Affairs webpage as one of the 13 highlighted resources for current students of color alongside the mentoring program, scholarship services, summer bridge programming, Black Cultural Center, and tutoring services. The Office of Minority Affairs was charged with overseeing academic services, compliance with the American Disabilities Act, scholarship services for racial and ethnic minorities, recruitment and retention services, as well as college access programs, the diversity lecture series, and the Black Cultural Center.

The actual webpage for the Center provided information to web viewers about its history, development, and mission. The diversity webpage links have provided a cyber-stage for the Center to present itself to other institutions and entities interested in Black male retention. Explanations of the focal points of the mission were given equal space on the page. Viewers were able to read about the mission, the established signature programs for students, the research 
activity of the staff and research fellows, the achievements and success stories of individual Black male students, as well as information about the sanctioned student organization that served as an extension of the Center. The use of the latest social media tools (YouTube, Twitter, Facebook, LinkedIn, and Flickr) gave viewers the opportunity to stay connected electronically to the current events, photos, and news.

By using the web as a tool, the Center worked to be a central part of the overall campus diversity initiative. It focused on providing members of the SSU community and external stakeholders an opportunity to learn about how they can engage and partner with them. Dr. Bryant stated:

I would like to think that [the Center] is becoming a major player in that [campus diversity initiative]. It certainly has contributed to the improvement of things for AfricanAmerican males, and which I think then contributes to the diversity of all. And I think that they, in terms of how they partner and those kind of things, then to a certain extent maybe even serve...kind of as a centerpiece to create some synergy for people addressing diversity issues. So I think that they've been very central and very open and willing to work with anyone in terms of improving diversity here at the university.

He went on to state that the focus on becoming a national resource for retaining Black males was a major strength of the Woodson Center and the overall campus diversity initiative. Their web presence has helped them to achieve the exposure needed. He believed this was achieved through highlighting the work the initiative was doing and then building partnerships to expand the work:

I do think that we, that the Center is viewed as a leader in this area now. And so I think one of the things, challenges, is going to be to stay there and make sure that everyone 
around us and even nationally looks here, that we're one of the places that they look when they need assistance in terms of how to deal with or answer questions about the AfricanAmerican males.

\section{Diversity planning assisted in cross-divisional attention to retention issues. Black}

male student retention at the start of SSU's formal diversity initiative was lower than the national average and a major concern for the Vice President for Student Affairs and Dr. Richardson as Chief Diversity Officer. Both saw the need to place their staffs in a position to examine the Black male experience at SSU due to their lack of academic success. Dr. Richardson recalled the partnering of Academic Affairs and Student Affairs to address the issue of academic success during the same time period as the diversity strategic plan developed:

It was the lack of performance of African-American males at Southern State. When one would look at a grid and stratify the population according to gender and race, the group that experienced the greatest challenges in getting through had been African-American males. I am pleased to say that in the role, and my interest in the work that I have been involved in, and as an African-American male, that not only did I look at this and say, "Hey, we have to do something about it." At the same time there was a White male, the Vice President of Student Affairs, looking at it — this information — and came to me, and we were both saying we must respond to this.

Integrating diversity into the institutional culture. Diversity has been seamlessly incorporated into institutional planning for growth and excellence. Specifically the institutional diversity plan has focused on improving the climate, classroom diversity, structural diversity on multiple levels, retention and access, and interactional diversity. In the creation of the plan, the 
top leaders were intentional about incorporating the voice of students (both graduate and undergraduate), staff, administrators, and faculty on the leadership team charged with assessing the climate and the other major needs and goals to be addressed in the diversity strategic plan. Low recruitment and retention numbers of historically underserved ethnic and racial populations on the student, faculty, and staff levels played a central role in the goals set within the diversity strategic plan. Retention of underserved populations was one of the six specific goals that the first presidentially appointed diversity committee stated was important to increasing the diversity on campus. Mr. Wind discussed how the Center specifically helped with interactional diversity, going beyond structural diversity, to provide a space for those who do not identify as Black males on campus to use the Center as a resource for them to understand Black male identity:

I think the Center becomes a great educational component. I know when I was there as a director, I would always enjoy when White students would come to visit, and it wasn't Black history month. It was like, 'I'm coming there. I've got a paper that I'm writing about the culture of the young Black males outside of sports.” Oh, I was elated, because what that young White male was saying was, “Look, I don't need a pass to come up to the Center because I'm not Black.” First of all, this is being paid for by taxpayers. I think the key to that is when you start talking about what the Center has done; it has given all students total access to learn about Black males. That's a key component.

The Center was positioned in a place of significance in relation to the diversity strategic plan, having a mission focused on retaining Black males at SSU. When the first strategic plan was implemented, Black male undergraduates were the least retained students on campus. The institution gained a reputation, like other similar public land grant institutions, of increasing their standards for admissions. This caused a concern about the number of students of color admitted 
and the issue of the population's under-preparedness for college. The first diversity strategic planning committee made note of this when developing the plan. They specifically stated in the first written diversity plan the need for retention efforts and initiatives created specifically for those underrepresented populations admitted to SSU—-how SSU had to increase the pool of minority students if they planned to be a leader of diversity in higher education. They expressed the need for those initiatives to be supported by leaders across all major institutional divisions, to be fully funded for optimal operations, and to be regularly assessed for effectiveness (Southern State Diversity Strategic Plan, First edition).

Mr. Wind, as the first programming coordinator of the Center, aligned the initiative mission with the diversity plan goals by focusing the integration of Black males who enrolled at SSU into academic disciplines where they historically lacked presence:

So the retention aspect was, I think at that time, close to maybe about 45 to $50 \%$, if I'm remembering correctly. So there were some opportunities for growth. This was separate from even student-athletes being on campus. We knew there were opportunities, that these young men were intelligent enough to get into the Southern State University, so the goal was, let's make sure you finish...And so I think one of the challenges for the university in certain ways is how do you broaden that net to get not only the best and that brightest but those who have the passion for higher education? So often when you look at the lack of representation in certain programs: pharmacy, engineering, even getting into the School of Business, construction, and those different areas-logistics, foreign languages. So when you really start talking about why don't we have Black males in this particular discipline, that goes by the mission of the institution or university. 
The Center was strategically placed at the center of the university's diversity strategic plan's major goal to recruit and retain racial and ethnic minorities. Its formation was the end result of Black male student focus groups and the examination of the retention statistics at SSU that revealed Black male undergraduates as the least retained students, who have the most isolating and difficult time at SSU. Because there has been an increase in retention statistics of Black male students, the Center has been viewed as a successful diversity initiative.

SSU completed their first five-year plan, and, at the time of data collections, was approaching a second round of review to assess the progress of meeting their initial goals of:

(1) increasing the internal and external visibility for institutional support of diversity;

(2) increasing structural diversity by funding and supporting recruitment and retention efforts for ethnic and racial minority faculty, staff, and students; and

(3) increasing funding toward diversity and raising the accountability on all levels at SSU for the incorporation of a safe, diverse, and inclusive university community.

An assessment of progress and revision of those goals for the second edition of the strategic plan was underway with a new planning committee, the current president and provost. The commitment for diversity was still present on the presidential level. The composition of the second diversity planning committee listed on Southern State's website embodied a broad representation from students to senior leadership. They were charged with crafting the language and setting the goals for the next five years. This committee makeup was in alignment with the values of inclusiveness expressed in the creation of the first committee and implementation of the first edition of the diversity strategic plan. 


\section{Institutionalizing the Woodson Center at Southern State}

Curry identified and described the steps toward institutionalizing new innovations as linear with unclear starting and ending points (1992). Mobilization is the first step (where a system or organization prepares for the new program and change), leading to implementation (change is then introduced to the system or organization) and finally to institutionalization (the system or organization is then stabilized incorporating the new change). The stages are "interwoven throughout the life of the innovation" (p. iii). Curry wrote that "the innovation is likely to be terminated despite how well it may be communicated and implemented," if it does not reach stability at the institutionalization stage.

Boundary expansion, profitability, and compatibility were three concepts Curry included in her design of the institutionalization process, built on Levine's (1980) research. These three concepts were important to the current position of the Center, based on where the initiative was in its institutionalization process. One form of boundary expansion explained by both Curry and Levine was boundary diffusion. This is the most successful form of the final stage of institutionalization. According to Levine (1980), boundary diffusion happened when the organization accepted the innovation, "whereby innovation characteristics are allowed to spread through the host organization" (p. 14).

In this case, SSU was in the process of accepting the Woodson Center; the leaders of the initiative were focused on institutionalization via boundary expansion as a final goal to secure their longevity on campus. They considered both the factors of profitability and compatibility of the initiative to SSU culture and interests; these two concepts from Levine (1980) "play an important part in the institutionalization or termination of an innovation" (p. 17). Profitability of an innovation to an organization exists, "when the needs [of the organization] are effectively 
satisfied" (p. 18). Compatibility is "the measure of the appropriateness of an innovation within the existing organizational boundaries" (p. 19); it measures the consistency of the norms, values and goals of the innovation to the norms, values, and goals of the organization. The more the innovation or initiative is compatible with the organization, the more likely that the initiative will be institutionalized. The less change the organization has to go through to accept the initiative, the more likely that institutionalization will occur.

Curry explained the relationship between organizational change and institutionalization: "change is difference; institutionalization is making that difference last" (p. 6). In making the difference last, profitability and compatibility with the host organization or institution are necessary. Several factors influence the likelihood of an innovation having longevity and being institutionalized, including:

(1) the intensity of direction and support from organizational leadership;

(2) decision-making and communication concerning the essential factors and direction of the innovation; and

(3) the incorporation of the dissident voice in the planning and execution process (Curry, 1992).

Two components in the institutional process were particularly evident at the Woodson Center. It moved from a piecemeal initiative with programmatic responsibilities for Black male student retention scattered across many different departments and administrators, to a centrally staffed initiative with no set operating budget. Finally the Center has been accepted and supported as a center with the recognized responsibility to develop Black male students at SSU. The Center maintained its programmatic mission while fulfilling the charge to strengthen the University's mission of excellence in student retention. It has been regularly highlighted in 
official university documentation and statements of SSU leaders. The staff has worked to secure an endowment that will allow its programs and team to have continuous funding and to increase the likelihood of permanence. Leaders have established partnerships with other student services on campus, and they manage constant outreach to community leaders and alumni to help in the retention efforts with financial support, as well as other means.

Support from different constituencies was necessary in the development or mobilization phase of the initiative. Endorsement of the initiative from institutional leaders was vital to the process. Since the university's first efforts towards improving retention rates, support for advancing the initiative has come on many different levels, in different forms, and from different stakeholders, including students.

SSU's senior leadership gave power, position, and authority to the initiative's leadership. The administrators charged with developing the initiative were collaborative and strategic in building partnerships, marketing the programs and successes of the initiative, and lobbying for the Center to hold a relevant place in the university's success stories. With every step toward advancing their programming structure and increasing the success of Black male students, they did not lose sight of the financial stability needed for longevity. Mr. Wind served as the first program coordinator of the initiative prior to the naming of the Center and in the first months after the naming of the Woodson Center. He stated:

When you look at the model in the Center, first of all, it has to be a part of the institution's mission. It can't be an add-on, because you're trying to get dollars for that particular cohort. 
The process to institutionalize the Center has continued with the current director, Dr. Deal. He commended the first program coordinator, saying, "Mr. Wind was the first program coordinator, did an outstanding job creating a sense of community for our students and developing programs and collaborating with other units across campus." Dr. Deal focused on institutionalizing the initiative with every decision he made about its marketing, image, programming, and development.

SSU embraced the initiative at its start, and it moved from the mobilization phase to the implementation phase - notably without initially meeting the usual university financial resource standards for naming a center. Financial stability has been a focus of the Woodson Center since its inception and continues to be a major strategic step in the institutionalization process. Dr. Deal has connected the need for fundraising and financial stability with institutionalizing the Woodson Center at Southern State. His focus has been on his responsibility as lead administrator of the Center to meet endowment fundraising goals:

And as long as we have an endowment, they're going to have to institutionalize us. That's what money does at institutions of higher learning. See, people don't understand when you give money like the Rhodes Scholars, put money into it to keep its legacy going...they didn't have it for persons of color, but they changed it and so that's why it's very important for us to raise this money for this endowment.

The program was positioned more as an academic retention initiative versus completely embracing the identity of a diversity initiative to gain support, to strategically differentiate it from other diversity programs, and to assist in securing its longevity on campus despite the favorable climate surrounding campus diversity. Dr. Deal explained: 
When you place yourself in a position to be of service you'll always be relevant. We don't want to be national just to say look at us, we're you know, we want to be relevant. And it's just like a faculty member writing in a top journal, you get kudos from your colleagues but it does nothing for the people who grew up... where I grew up, it does nothing if it has no relevance to them. So relevance is important and we're defining the relevance. If you make yourself relevant to that degree you will always have a place, whether it's here or any other place. It's very hard for the university not to take us seriously because we have quickly developed a lot of interest around the country.

The marketing of the individual programs and successful retention rates were managed with a calculated plan that provided important leaders within SSU, community leaders connected to the institution, and the larger higher education community access to their greatest accomplishments. The identity of the initiative as an applied center and a research-based resource helped the Center to advance the institutionalization process as well.

Support, resources, and campus mobilization. All administrative participants in the study discussed the amount of support needed to launch and maintain the Center. There was a strategic mobilization of campus and community leaders, staff on all levels at the university, as well as SSU alumni to engage with and buy into the mission and goals of the initiative.

Leadership endorsement. Dr. Richardson, SSU's Chief Diversity Officer, served as the program's initial leader and was given power and authority to rally important stakeholders around issues of developing campus diversity, and specifically the retention of Black males. There was no evident dissident voice in the development of the initiative. Dr. Richardson did not identify a person or group that questioned his work while mobilizing. Dr. Richardson was given 
power and authority without the questions and visible doubts of other leaders in this case. This is unique to this case of introducing an innovation to an organization. Usually in the development of an innovation, the dissident voice provides the checks and balances to make sure innovations are considering all the reasonable avenues for decision making and challenges leaders in their thinking and planning by introducing different ideas from the main stream. Curry (1992) stated that one of the characteristics of a learning organization was the allowance of the dissident voice to be heard in the process innovations under consideration. Support from SSU leaders and others associated with the university played a large role in the movement towards institutionalizing the initiative. Having the endorsement of top leaders who allowed administrators to focus on the issue of Black male retention was critical to the process of institutionalization.

The president and provost supported Dr. Richardson in several ways in his pursuit of resolving the retention issue. They provided a position high in the SSU Academic Affairs hierarchy when designating Dr. Richardson as Chief Diversity Officer. Curry (1992) asserted that this shows value for the work. She wrote, “A look at an organization's management hierarchy could provide insights into the power vested in individuals charged with implementing innovations or organizational change" (p. 10).

They then made retention of minority students a top priority when creating and implementing a diversity plan for the campus-wide diversity initiative. Curry (1992) suggested that this level of valuation usually occurs as part of the final phase of institutionalization, which the Center has yet to reach. She wrote that evidence of valuation of an innovation can be found in the organizational structure through documents, revised missions, goals, budget, administrative appointments or the hierarchy of administrative structure, or other official documents. The creation of the Center started with a piecemeal initiative for Black male 
retention that came as a direct objective of the institution's first official diversity strategic plan. Of all the possible specific objectives that the institution could have focused on in starting its diversity plan, the president and provost endorsed the diversity strategic plan task force's recommendation to focus on the retention of minority students as one of its major objectives. The strategic plan specifically charged Dr. Richardson as well as other high officials at the institution to create programs, services, and scholarships to help recruit and retain in-state and out-of-state minority students.

The Center used the diversity strategic plan objective to successfully recruit and retain more minority students as their purpose for existing. It provided the increased likelihood of the Center to reach the final stage of institutionalization by having a convergence of boundaries between the innovation and the established university community. Curry (1992) called this boundary diffusion, where “the innovation's characteristics are allowed to spread through the host organization" (p.13). The institutional approval for the Woodson Center to move from a piecemeal initiative to an actual center was noted in the second official Southern State report reviewing the success of the diversity plan. The Center was specifically highlighted in the report examining the progress of SSU over the first six years of formal implementation of the diversity strategic plan. SSU celebrated the naming and establishment of the center in the report among all the new diversity initiatives and programs. The report also highlighted the "substantial increase in the retention rate of African-American males." The Black male first year retention rate was higher than Black female students six years into the institution's campus-wide diversity initiative effort. This pattern of retention was opposite the national trend, where Black female students were retained at higher rates than Black males. 
Dr. Richardson recalled the support the president and provost provided him in the process of getting the Woodson Center named as one of few official centers at SSU. This process eventually required the approval of the SSU Board of Trustees:

I'm going to give a lot of credit there; I had the idea of this going forward. I first went to the provost...and if she had not been on the board [of trustees], she was a big supporter and especially of the [Woodson Center], of this whole idea. She was a big supporter of diversity. So I was lucky there. When I developed the particular material, she endorsed it and wanted to make sure that it gets to the president... [the president] was very supportive of it. It had to go through the steps, of course. It went to a particular committee; we went before that particular committee, and from that committee, it went to a committee on the board, then before the board...No, it was a committee in the Office of Academic Affairs. And then that committee looks at any proposal coming up to them with centers or the word center in it.

In addition to top institutional leaders' support, Dr. Richardson had collegial support from peer administrators, specifically the Vice President of Student Affairs. Mr. Winters worked for Minority Affairs in a different capacity at the time the Center was in the initial mobilization phase. He remembered the support that the Vice President for Student Affairs provided Dr. Richardson to get the conversation and research started on the issues surrounding Black males at SSU:

The concerns, from what I heard, had always been there. But the VP of Student Affairs, from what I heard, was one of the people who really brought attention to this... And so at the time, the graduation rate was around $30 \%$ for six years, which at that time was even 
lower than the national average, which was 35\%. And, of course, [the national average] really hasn't climbed that much since then.

The partnership formed between Dr. Richardson and the Vice President of Student Affairs early on in the mobilization process facilitated the conversations among those who had staff and resources to invest in finding answers to the issue of retention. Dr. Richardson, a Black male, newly appointed as the Chief Diversity Officer, and the Vice President of Student Affairs, a White male, had a similar passion about the issue. They made time in their schedule to resolve the issue and approached it looking for solutions on both the academic and the co-curricular sides of the Black male experience. Dr. Richardson explained:

That was easy because you had two people of the same mind. You had — and I must admit, surprisingly when this happened, that he and I, we didn't spend as much time as the two of us have spent together at one time. It was often following, to be blunt, it would come after a president's cabinet meeting or something of that nature. We always sat together for some strange reason. [Laughing] As soon as that meeting was over, one would turn to the other and start talking about this particular topic and what we're doing. That would last no more than about 15 minutes. That has happened almost weekly, we had this meeting weekly, and so it was just by chance we would see each other and know that at the end we're going to turn and say something. Or we would call and - now the things that we would be discussing at that point because our staff were doing their job related to financing; that it appears that there might be a cost here. And it's amazing neither of us-like if he mentioned it to me if he had read a set, of course we would take care of that. Whenever I said that to him it was, "of course." It was never-it happened 
on one occasion. We were saying that, "No, I don't have the dollars, no that's too much, no that's not important to us."

A partnership between Student Affairs and Academic Affairs was in motion from the beginning and was the impetus for the development of the initiative. These two leaders shared the responsibility of mobilizing the initiative and providing the initial financial support needed to launch and market the piecemeal programs to students, helping retention efforts prior to the official naming of the Center.

Community and alumni support. Leaders gained the buy-in for financial and word of mouth support to market and promote the initiative in certain circles in the surrounding city, to the university community members, and to alumni. There was a campus mobilization as well as an outreach to SSU graduates and other donors and stakeholders to provide the necessary support for the mission of the Center to move forward in institutionalizing the initiative. It was the President of SSU alongside Dr. Richardson, who went on tours throughout the state to promote the new campus diversity initiatives that SSU was implementing. Black alumni and supporters of SSU were able to see two top leaders of the institution express the importance of the institution's diversity efforts. Dr. Richardson explained the president's plan, "mainly he was trying to get to the Black alums and the leaders, a combination of them in the larger cities in the state, to say this is what we're going to do and we're going to show you."

Most of the administrative participants discussed the idea of "cultivating the community" to rally behind the initiative as the solution to the major retention issue with Black male student - to see the Center as a success story. Mr. Winters, the programming director, discussed the present-day campus atmosphere and culture that the Center staff and other stakeholders 
developed surrounding both diversity and retention as an important issue. Those on and off campus have recognized the Center as the primary solution to the problem of retention:

I think one of the strengths is the culture. With the culture, I think through the years of building up the concern and raising that agenda and going from that to the Black male initiative to the Center, we've been around now really since 2005, looking at that first Early Orientation to now. And so what we're trying to do is build a culture of excellence for African-American males.

The financial support received from the Center's Lecture Banquet, which has served as their annual fundraiser over the last five years, and from faculty, administrators, and staff on all levels, has served as important examples of the buy-in and the cultivation of the community that has assisted in advancing the institutionalization process. Dr. Deal stated that these donations have played a large role in securing the Center's endowment. The success of the annual fundraiser over the years and a committed pay-deduction pledge from SSU employees have been other signs of the buy-in that helps in the institutionalization process. Dr. Richardson stated that the fundraiser helps to "pay back what we should have had up front" prior to the official naming of the Center. Normally, centers at SSU are named only after a certain amount of money is secured. Dr. Richardson's success in getting the Center named and mobilized was recognized by the university staff. The initiative moved forward in achieving one of the largest steps in the implementation stage with the naming of a physical center on campus to serve as the location of the initiative. Dr. Deal believed these SSU staff donations along with their annual fundraising event are how the endowment will be achieved: 
Again regardless of the reason why we have the support, support comes at various levels. I don't want to just focus on the top, because we do get that support...But not only that, we got program staff who have money drafted from their checks monthly going into our endowment, because they either knew who Mr. Woodson was or they believe in what we're trying to do, or because they have a nephew or uncle or father or cousin or that young child just right across the street who are not functioning optimally... So the support is widespread, you know, from the employee who does not make probably thirty thousand dollars or forty thousand dollars but having twenty five bucks drafted from their check or thirty bucks drafted from their check. It's quite amazing.

Dr. Richardson summarized the idea of cultivating a community to support this agenda:

Two things that I would like to get across. I certainly felt that the effort here has been Minority Affairs and our Student Affairs, but I have to pull in to some extent more of the total university as well...They're joining in. It has been something that has been endorsed and encouraged. It's the total university, and now we're pleased about that. Now I don't know if one could back and say that maybe you cultivated the community, and maybe that's what one has to do to get the word out, and certainly sharing the good news with others to get on board, to say, "Oh what is happening?" People like winners. They like to see something that is successful and get on board with you for that.

Support for the Center has come from other high ranking Black male administrators and their families, who invest time and energy to create their own mentoring groups. They have joined in and developed annual student cohorts that they work with throughout the academic yearbuilding up the cohort members' self-confidence and professional skills, helping these students 
to identify future goals, and focusing on success. An administrator initiated one idea and connection, and Dr. Deal shared that having a program developed outside the Center but for the Center was a huge positive. One administrator opened up his home and shared his social capital as one of the top executives in the state. Many of the Black undergraduate male students have recognized the mentoring experience as one of the highlights of their development and a positive connection to the Woodson Center.

The SSU president and communication team helped promote the positive image and good news about advancing diversity and increasing the Black male retention rate. Despite the extreme effort it has taken to bring some of the academic department chairs and deans around to buy into the overall campus diversity initiative, the message of success has come through publications to alumni across the state and nation. The diversity publication was another objective of the diversity strategic plan and its quality of writing and presentation moved and inspired alumni and community members for SSU's diversity efforts. Dr. Richardson said of the diversity publication:

It didn't go looking second-class or second-rate, but first-class, like anything coming from Southern State. That's what I started hearing from Silicon Valley, from our alums there. They came to me and said, "I commend you. This is first-class, first-rate, and the way we expect things from Southern State to look."

With the buy-in from alumni and community members for the overall diversity initiative, many alumni have played a role in the programs hosted specifically by the Center. Many Black male alumni, faculty and administrators, and community leaders, have come back and presented to the current students during the academic year. The more successful ones in business and 
professional sports were given keynote opportunities at the Center's annual fundraiser and other retreats and male gatherings with the current undergraduate Black male students. They were able to draw the larger SSU community and surrounding city to events and also to help in the fundraising efforts. This support and buy-in not only has helped the Center in its goals towards establishing an endowment through fundraising, it also has been a high profile opportunity to expose current Black male students to role models and potential mentors in their development and academic success.

Strategic positioning. There were strategic steps taken during the mobilization and the implementation stages to help secure the longevity of the Center at SSU. Dr. Richardson shared the process for the naming of the Center as one of the steps. In the case of the Woodson Center, they "went on faith," as Dr. Richardson stated, and had not secured the usual required funding prior to going before the board of trustees for a vote; yet the Center still got approval to be an official center on campus. The second tactical positioning strategy used was the marketing of the main message about success of the Center, focusing on their achievements with retention versus a focus on being a diversity initiative.

One major factor in the approval of the Center on campus was the idea that it would be a resource not just for Southern State to use, but one that other institutions could look to as a resource to help them manage their campus issues with Black male retention and success. The Black male retention issue was significant enough to the president and provost at SSU that Dr. Richardson and other administrators were allowed to move forward mobilizing the initiative. The physical location of the center provided the space for the initiative to receive local attention, and to gain influence on campus with other faculty and administrators. It became known as the university's answer to combat low retention rates for Black male students. The staff did the 
initial groundwork and created the programs to improve the retention rates with a sufficient amount of institutional and community support and fiscal resources. The key to the strategy was taking the credit when the rates improved. Dr. Deal stated that:

We take credit for a lot of stuff because no one else wanted to take credit for it. They don't focus on this like we do. But if nothing else, we're the beacon of light and advocate for African-American males on this campus. And people have a reason. When they see one (Black male student), they call our office. By default, whether you come or not you are a part of this office.

Dr. Richardson recalled the conversation with the provost prior to the meeting where the naming vote went before the SSU board of trustees. Emphasizing the center as a resource during the decision-making process of naming of the center helped to align the initiative with the SSU president's goal to be a globally recognized, top public university. Dr. Richardson stated that "it probably would not have gotten through," if the term and focus of the Center being a national resource was not introduced to the committee. He said, laughing:

[The provost] heard it over and over, even when it got to committee to make a decision. They would look and say, 'Ok, you have said [resource], so yeah, maybe we'll support it" [laughing]. That one word made all the difference. I think that the message I would say here is that there is more than one way of doing it, and then you sometimes have to be flexible.

Dr. Deal spoke at length about strategically aligning the Center with the goals of SSU's president. Other leaders in other diversity units were concerned when the new president was 
appointed, based on rumors of his opinion and philosophy about diversity in higher education. Dr. Deal viewed the change differently:

I'm going to look at it as an opportunity with his vision, and I learned a long time ago part of my success in life is understanding what institutions value and figuring out what part that I can fit into and take to another level that does not compromise what I believe in.

Under Dr. Deal's leadership, the Center was aligning with the new president's institutional mission. The president was positioning the institution to be a world-class university, solving global issues, and a top producer of cutting edge research and solutions. He went further to discuss the lifespan of the current president and how he planned to have the Center stay relevant regardless of the person in the president's position:

And so I say five years, I never told my staff you're the only person. Only reason why I came within five years, because I just studied the human element, that's what my degree is in, that's what I train others. To do this is a monumental charge, he's going to need a lot of energy, and I can't see him doing it no more than five years. So that's why I'm trying to stay ahead of the curve, because if I'm ahead of the curve, so far ahead of the curve, that we'll be able to sustain ourselves under new leadership.

Dr. Deal's focus has helped to increase both the profitability and compatibility of the Center to SSU. The Center has supplied solutions to the institution's retention issues. It has also served to fulfill the goal of making SSU a diverse community. The staff has recognized both as valuable. Even though retention of Black male students came to the attention of the university leaders under the diversity initiative umbrella, and although the Center was hierarchically located 
under the minority affairs division of Academic Affairs at SSU, they positioned their successes in increased retention rates in a way that has highlighted both contributions to the campus. Mr. Wind summed up the initial thought process to institutionalize the initiative as necessary and a part of the primary identity of SSU at the onset of the institutionalization process during mobilization:

The key is it has to be tied to their institutional cause. If it's not going to be tied to the institutional cause, then it has no relevancy; because this isn't a student organization group that just needs to get funding to have volunteerism and service learning. This is really about an academic matriculation process that, as you are paying tuition, this is now the return on the investment that you will eventually graduate. I think the goal of that is that it has to be a part of Academic Affairs. It has to be a big part of development. How do you tie into and work, if you will, alumni to earmark their dollars for a particular cohort? This isn't just about Black men going to a White college. This ... could possibly be a model of how we really institutionalize all our students. And this particular one has great and rich history of needing additional resources out of the majority White college campus to get through.

The vision of the center has been to solve one of the nation's largest retention issues, while providing answers to other major issues that affect Black males across disciplines and age groups, making the Center valuable to SSU and increasing its likelihood for sustainability.

\section{Evaluation and Assessment of Student Learning}

The Woodson Center has demonstrated early signs of formalized evaluation and assessment practices. In higher education, assessment is defined differently and its practice is 
distinct from evaluation. According to Suskie (2004), evaluation was "investigating and judging the quality or worth of a program, project, or other entity rather than student learning...addressing all the major goals of a program” (p. 5). Suskie (2004) defined assessment as:

The ongoing process of establishing clear, measureable expected outcomes of student learning; ensuring that students have sufficient opportunities to achieve those outcomes; systematically gathering, analyzing, and interpreting evidence to determine how well student learning matches our expectations; [and] using the resulting information to understand and improve student learning. (p. 3)

The process of evaluation measures success based on a review of program design components and on execution of those identified components related to the purpose and mission of the program. Specific learning goals and objectives must be identified at the onset of the program, which, during assessment, are then measured and reviewed; they must demonstrate improvements in how students learn and increase their social, emotional, cognitive and behavioral skills. Assessment reviews student development and student engagement with program components specifically designed to increase students' skills. The process also requires an examination of students' engagement with the program to measure identified student learning outcomes, where program evaluation measures engagement and satisfaction with the program outside of learning objectives. When conducting evaluation, other factors, such as program content, presenter's preparedness, expertise, and delivery, satisfaction with the length, location, and scheduling of the program, can be defined as important units of measurements of success in reaching the mission and goals of the program. 
The formalization of the Center's evaluation processes was more advanced than its regular assessment practices. One of the initial measurements used to report successful programming was the increase in the retention rates of Black male students. They have also formalized their evaluations to include the use of program satisfaction surveys, student focus groups, and staff observations of student behavioral changes. The administrators have been focused on student engagement with the Center and the institution as a whole as the main strategy to increase retention rates.

Programs were specifically designed to improve students' leadership skills, increase their sense of accountability to each other, and to provide students with experiences to develop their personal and professional identity as Black men for life after graduation. The assessment of student learning has become a more formalized practice and has been centered specifically on students learning and developing leadership skills, as proven by the creation of the signature program, the leadership workshop series.

The administrators at the Center knew that they had achieved success in some of the important measures of retention and were able to look at data to confirm and report their success to university constituents, stakeholders, and non-university interests. They have been strategic in the story they tell about student success. Administrators have been prepared and were expected to report their success both internally at the institution and nationally, and they regularly have sought out opportunities to conduct presentations about student success and the Center. Student connection to and learning from the Center has been at the heart of its success. Its success in showing increased student retention has not necessarily shown how and why students were being retained better or what students were specifically learning that has helped to increase their 
retention rate. The assumption was the Center had developed engaging and supportive programs to which students were responsive and were therefore being retained.

They had not established specific assessment practices yet to systematically monitor student learning or to identify specific student learning outcomes for all the programs. The early orientation program has been adjusted because of student feedback, and administrators also planned to formally assess the leadership workshop series. The current strength of the program design and improvements made to individual programs were heavily influenced and relied on the administrators' professional experiences. They modeled many of the programs at the Center based on their personal collegiate experience with model programs from their undergraduate days at historically Black colleges.

Means for evaluation: Retention, Surveys, Focus Groups. The Center has used the retention numbers as the primary source for a baseline to evaluate the success of the program. From the beginning, the objective of the initiative was to retain Black males. Mr. Winters recounted:

We knew we were on to something at that point with the administration that we saw more and more of the community starting to take hold so they didn't feel isolated on campus, didn't feel like they were the only one in engineering, or in going into a lecture with 4 to 500 students and felt alone. They were going to develop their own community in one sense. As we started to track the retention aspect, we started to see that spike. That cohort staying engaged. We also challenged them, they had an obligation to themselves to make sure that they were doing the best they could do on this campus 
Retention numbers have always been reported in presentations about the Center's progress made by staff and other university officials, specifically Dr. Deal's direct supervisor, the Chief Diversity Officer:

I'm sensitive to people at the executive level. They don't want to read so much, so I try to simplify when we talk about objectives and we talk about attendance. And we give them an overview of what our evaluations indicate, and then not only that, we forecast where we're going. That's what we try to do.

Dr. Deal shared information about the Center with the chief diversity officer for the president's cabinet meetings. The chief diversity officer, "wanted to be able to report something. And usually they're reporting on the Center, that we got that award from College Board, or you know, these are some things that we share with our supervisor."

Dr. Deal explained that there was a specific template presentation that they have used when presenting the success of the Center. The staff regularly updated the retention comparison information of Black males to their Black female counterparts and also to White males from its first existence on campus. The retention information has been used strategically by Dr. Deal and the staff to counter the arguments that there are other factors outside of the work of the Center that have contributed significantly to the increase in the retention rates of Black males. The way data have been studied and presented by the staff showed their significance on campus with increasing retention rates. These retention data have been a main part of the presentation used when they have been asked to present on the outcomes of having the Center at SSU. In sharing the data slides of the presentation with me, Dr. Deal broke down the significance of the Center to the retention of Black males. He opened the presentation he had prepared to show me for the 
interview and proceeded to point out specific slides that explained the data related to Black male retention and specific demographic comparisons:

And as I was showing, sharing with you earlier is that, sharing not only data with the Center, but we have a responsibility. It is to request certain data and to present certain data to our staff, so they will be informed about what's going on with male students. So this is one thing, we want to look at retention, or when we think about admission, it was somewhere between 2002 and 2004, some people would say that's why retention is better, that's what APLU's president told Dr. Richardson... But okay let's say selective admissions, but selective admission had nothing to do with males passing Black females for the retention. Our retention is better than Black females. Now, first people would say these are second-generation college students, parents went to college, right? Can I ask? I already know the questions, so let's look. [Pointing to the computer screen] First generation college students, you can see African-American males have the highest jump in comparison to the other groups. Now we lump, we consolidate so people can see that, but let me just show you so you can really see it. [Clicking on another slide] Now of course there are more first-generation black females than males. Cause there's more [Black females]. Now, but you can see the jump [pointing to the more pronounced slope in the increased rate of males to females], the increase is higher for Black males. So we're still outdoing our women here first year. So, selective admissions does not explain that. The Center is the only explanation that you could have, because prior to it, [the Center didn't exist].

Staff believed that it was because of their work at the Center that retention numbers have increased for Black males at SSU. In a separate university media interview promoting the Center that has been used for student recruiting, Dr. Deal outlined the increase in the rate from four to five years prior to the interview, from when the Center was just initiated in 2005, to present time. 
The retention rate for Black, male, first year students was in the "high 60s to low 70s," and the 2010 retention rate for first year, Black, male students was approximately $90 \%$ overall. The data on the retention rates that the Center collected about the students who participated in their first year, student, early orientation program provided the statistical proof that their work with the Black male students was making a difference in their retention. The first to second year retention rate for those Black males that have participated in the early orientation program, which was designed to get them acclimated and settled into college life from high school and to introduce them to campus resources and specifically the Center, was several percentage points higher than the overall first year attending $90 \%$ rate of Black male freshmen who do not participate in the program. The rates for both the early orientation program participants and overall Black male first year freshman are higher than the national average for Black male first year retention. Mr. Wind and Dr. Deal extemporaneously provided different retention rates in their interviews; the specific data collected by the Center, which demonstrated its influence on retention rates, showed the increase to over $90 \%$ overall since the implementation of the initiative. It strengthened their case and helped to prove their success.

Surveys and focus groups were also ways of showing the success of the program. All administrators reported that it was common practice to collect student data through surveys and focus groups, but Mr. Winters was identified as the one administrator who reviewed and analyzed the data from the surveys and focus groups. All other administrators deferred to him as knowing what and how data were collected for program evaluation of success and student learning. He was the main staff member who concentrated on the data gathering activities.

The surveys conducted at the time of data collection were not specifically designed to measure student learning. Surveys have been conducted at each of the individual program 
sessions of the early orientation program, the leadership series workshops, and every other workshop and program the Center has hosted. The surveys covered questions related to (a) whether or not the information presented in the program was valuable to their academic success and transition to SSU; (b) if the program was engaging; (c) if the program allowed for them to ask questions; (d) if students had the opportunity to interact with faculty or other presenters; (e) if they found it beneficial and if they would recommend other students to attend; (f) the best part of the program and parts that could be improved for next time; and (g) if they had suggestions for doing things differently. These types of questions have been asked regarding each program and have not covered what specific, predetermined, learning objective was met by the students, on what level of proficiency or understanding. The questions have helped to make programmatic adjustments but have not adjusted the materials taught to increase student learning or to determine what students learned from the program.

The initiative planned to have an impact on all the regional campuses as well as to have a national presence in the conversation about retaining and graduating Black male student—using both data gathered from other campuses in the SSU system that have not have access to the Center, and presentations of recent success to associations, other institutions, and at conferences. According to Mr. Winters:

We've collected a lot of program evaluations from students. We worked on a campuswide evaluation, a campus-wide survey, but decided to postpone it right now; because what we are hoping to do is a regional campus evaluation, first to look at students on the regional campus, and then from there, we want to turn it into a campus-wide evaluation,, probably something along the lines of a continuation of the qualitative study that was done back in 2003-2004. That'll be one of the major pieces of information that we want 
to collect, in addition to what we get from the program evaluations, as well as the focus groups that we do from some of the different programs that students participate in. Usually we collect it...after programs.

Mr. Wind shared that data collection on student experiences through surveys and focus groups has been practiced since the first years of the initiative, and was ongoing:

I think probably the better person that could give you that [data] would be Mr. Winters. I think, because even when I was there a lot of that was on behavior issues, their comfort zones a lot of times, and I know that Mr. Winters has a lot of that data. Because quite honestly, what came out of that was really how we were developing the programs. We had to get that kind of data from the focus groups and interact with those students to really base what kind of program is going to be needed and then what is going to be the content of that program. Mr. Winters would be a great resource. I think he's done a great job to continue to do that over the years.

Program design and goals were partly based on student input. Prior to the formation of the initiative, it was student focus groups that were used to confirm the need for an initiative and what the initiative would focus on. Since then, students' information provided in the early surveys and focus groups conducted at the start of the Center's program development were used to improve the original, signature, early orientation program and to create new programs. The signature programs focused on adjusting the students' behavior and mindset about themselves and the college experience. Mr. Wind added:

The struggle for Black males a lot of times is, how do I step outside of my comfort zone, because remember, the research already said I'm isolated. I'm not necessarily trying—-don't 
learn about other cultures, but how do I invite other cultures into my world? I think that is for universities that are headed in the future for 2010 and beyond, that has to be addressed in an ongoing basis, because you're now talking about developing leadership for the 21 st century, and diversity has to be a part of it to understanding all cultures and resources. So I think the Center really teaches young Black males how to survive in a majority White cohort environment. A lot of institutions cannot necessarily say that.

The reviews of information from focus groups have been used as a measure of success and a means to make adjustments to programs as well as observations of the staff. The administrators have used subjective observations of students improving on their self-efficacy, confidence, and personal identity development as students engaged with the staff and participate in the programs and leadership training workshops. When Dr. Bryant was asked how did he know that students learned the leadership skills, which he has claimed the Center teaches:

I think that there would be some inkling of it by looking to see how — and you just don't go out and become a leader, I think you have to prepare for it. So I think that we could get some inkling of that by looking to see what they're doing on campus and seeing if they are stepping up on campus and becoming leaders, if they are going out into the community and giving of themselves. So I think that that would give us some idea of whether they're getting that message.

Mr. Winters, whom all other administrators deferred to as the main staff member in charge of monitoring student learning, confirmed the use of observations as a means of measuring student development and learning: 
I think looking at students once they get into that second and third year, and especially when they get into that fourth or fifth year, when they are getting close to graduation. We haven't done it objectively; yet where we're rationally evaluating across, we're evaluating not just program, but actually the student themselves. That's something we probably need to start looking more at. But I see this also with what's this student doing? From the time they were a first year student to the time that they are second, third, fourth year. What are they doing? What are they doing as a person in regards to their behavior and then also what are they doing regarding their academic studies, their career goals, their career development, so both.

Dr. Deal concurred with the use of observations for measuring the increase in students understanding of accountability to other Black men on campus and acknowledgement of the common need to have "one's sense of humanity being affirmed." He said behaviorally he sees changes in the Black male students that engage with the Center in the safe space for identity development to occur:

Well, we hear it in, for example, I can see behavioral changes. I can see that some students used to just walk by, didn’t give you the brotherly endearment, "what's up." Now they do, to connect. I see the transformation in behaviors. Just for example, events, the leadership institute, sometimes it is come as they are, but now they recognize you. You can see that some of the thinking or the behaviors have kind of changed with these students.

Student Learning. Program evaluation was conducted using different forms to measure how students were learning about and increasing their accountability for each other, professional development, academic skills, and student leadership skills. Administrators were able to identify 
these student development goals through the programs they created and hosted. Programs focused on developing students' critical thinking skills, career skills, leadership skills, and positive self-identity and life skills, all with the goal of increasing student retention. One of the administrators' means of achieving success in advancing these skills has come through the programs and the use of role modeling. When asked what students learned from engaging with the Center, these goals were specified across the board by all past and present administrators involved with managing the initiative. Mr. Winters, previously quoted spoke about Dr. Bryant specifically spoke about the idea of teaching servant leadership and accountability:

I would hope that they would learn how to become servant leaders — and kind of internalize that this isn't — that it's not necessarily about their own success. That we want them to be successful, but to realize that this is a much bigger issue, and it's about the success of African-Americans, and that they will leave here after having interacted with the Woodson Center not only successful and become successful in whatever they are going to do, but also have within them this understanding that it's going to be up to them to work with the communities to try to make things better for African-American males wherever they are.

Mr. Winters specifically addressed the issue of students learning accountability as a goal of the Center as well as using role modeling to specifically teach it:

I hope they learn accountability. They can't come to college and think they're responsible for just themselves, getting the dean's list, graduating with honors, having a great internship, and going into a great job opportunity or becoming self-employed. It has to be, "I'm responsible for myself, but I'm also accountable for how other African- 
American males do here at the university...Really helping students with accountability is one of the things we're really trying to teach. In some ways I guess you could attach that to accountability as well with some of our different programs, with some of our role modeling that our staff does, and other people that we bring to campus do.

In the focus groups, students discussed their developed sense of brotherhood and accountability for each other as Black men at SSU. Matthew, a freshman business major, shared how his interaction with the Center has helped develop him and other students:

The way I see it, I know my potential. The Center sees my potential. They are willing to do anything and everything they can to help me maximize my potential, and they do that via all different programs that they have structured around me. And not only for me, but for the other guys as well. And so we're all in that group trying to have our own individual potentials maximized. We see that in each other, and not only does the Center help us out, we help each other out. And then going back to the whole fraternity thing, and that's how we're able to form these strong bonds and friendships at the same time better ourselves.

Both Mr. Wind and Dr. Deal spoke about the students learning how to develop a professional self. It has guided professional development without strict “dos and don'ts," but with the understanding that at least an examination of who students said they were as Black men was necessary when deciding what students presented to the world after SSU in their work life and communities. As quoted earlier in this case, Dr. Deal explained:

We're acclimating them to the professional world, not necessarily saying what is acceptable, but what kind of message do you want to convey to the world and helping 
them to think about the messages that they want to convey. And ensuring that people interpret those messages accurately and to ensure that they convey messages consistently, a lot of who they are and where they want to be. And so that's what we try to do, is not to try to change someone. I mean change is evident when you choose education, but sometimes they don't know that, and we don't approach them with "You'd better do this to make it," No, no, no, we teach, we bring people to inform, we have others who come in and say the things that sometimes are very difficult for us to say to some of them. Sometimes we just say it.

Lucas described the effect one program had on his involvement with the Center and his understanding of how he defined his masculine identity. A facilitator was brought in to teach the program; it was Lucas's first attendance at the annual themed retreat:

I remember that retreat, vividly. That was the first event that I went to under the Center that kind of gave me a fundamental grounded sense that I belonged with the men that were part of that program. Because before that event, the Center was just a place for me to, you know, go once or twice a term as I had my meetings with Mr. Winters, just to, you know, see how I was doing academically and everything like that. But after that moment, I feel like I fully gave my attention and my efforts and my energies towards the Center and everything it was about. And I remember at that event, you know, we learned about an acronym "MAN UP," and you know, what does that mean? You know? Because oftentimes when they say that, when you have young men telling you that, it's kind of like, it kind of hearts down on not only you as a person, like, your manhood, but also kind of denounces our female counterparts, like, you're not acting the way a man should, because that's how girls acting. And we learned that we should really say in the sense of 
Mastering And Nurturing your Unlimited Potential, the potential and that's what MAN UP should stand for. [emphasis added]

There was a consistent mode of teaching presented by staff members in regard to role modeling as the mode of students learning how to present their professional selves and to understand and develop leadership skills. There was a focus on developing the students' identities as a whole and encouraging their self-efficacy, that they were worthy and belonged at SSU as students learning. Dr. Deal stated his personal philosophy on the importance of this lesson and modeling it:

What we do is give our young men opportunities to be exposed to luminaries on campus and off campus. People that we see on TV who are held in high esteem in our community, mostly African American males...So you will be constantly exposed to luminaries, you know so when you're in a classroom you'll see these individuals and they will be able to help you navigate the terrains of academic or the terrains of the workplace and create opportunity exchange. We have state senators; we have a number of luminaries, so students will also be exposed to individuals and they will be able to help you navigate the terrains of academic or the terrains of the workplace and create opportunity exchange.

This model of teaching students was influenced by many of the administrators' own experiences as undergraduates at their alma mater historically Black college or university and their early professional careers. Along with the initial student focus groups conducted that informed the programming of the Center, the administrators relied on their experiences in program creation. Professional experience and personal collegiate experiences of the staff were 
used to guide the structure of the initiative and changes made in the program. The development of most of the early signature programs, including early orientation program, faculty, staff, and student network gathering events, and the leadership institute were developed based on the administrators' professional experiences at other institutions or their own undergraduate success and failures.

Students recognized that they increased their level of responsibility over personal and professional decision-making and increased their overall maturity level because of their connection to the Center. Samuel, the Junior sociology major, recognized that he "got stronger as an individual" over his three years at SSU and by being involved in the Center's activities and programs. He conceded some credit to the Center for his increased strength, specifically in decision-making:

I've gotten stronger as a person, with the decisions I make, the day-to-day, or, like, long term or short-term decisions. I mean, yeah, I just feel like I've gotten stronger that way. Some of the things that I've probably changed I wouldn't say I credit to the Center because I feel like I probably would've done it on my own, just because I know myself. But, I feel like they've swayed my decision-making a little bit in a positive aspect.

Even as early as their freshmen year, students were recognizing that something personal was developing in a positive way. Matthew, a second semester freshman, expressed this thought when discussing how the Center has helped him grow and change:

I still don't know yet. I mean, it's been two semesters. I'm sure I'll know further down the road, but I just know that they're helping me, and I'm allowing myself to be helped. 
And hopefully when I do recognize the change, I'll, I know that, yeah, this was the right decision.

Life skills, such as goal setting, long-term planning, and critical thinking are other topics that students learned according to the current programming director, Mr. Winters:

I hope that students learn critical thinking, some challenging the way they were thinking also, but with critical thinking. Not taking something as is, but actually sitting there and kind of chewing on it and seeing what it means to them. Some of that comes a little bit from all of our programs but definitely through the leadership workshop series and the annual retreat.

Students attributed learning how to think critically directly to Mr. Winters, the programming director. Students referenced him the most for being available to the students to speak to individually, providing great advice, and overall support through their development over time. His position at the Center was to create, promote, and assess the programs and workshops that the Center conducts. He was in charge of the day-to-day operations of the center and regularly made himself available to students. Shannon spoke about his relationship with Mr. Winters:

When you come in, he like "What's up?" And he straight up, not talking about the world and stuff, he gets personal. Like what's up with us, what's going on? And he listens to us, as opposed to, there's not a lot of people we feel comfortable going out and they will be like, you know people talk about themselves, but they don't ask you about yourself. And it's like having somebody to do that, it makes you more relaxed and more comforted. Where it's like, I've got somebody that really wants to hear what I'm saying, that's actually interested in what I'm going to do, what I'm going to become and trying to help 
me. So, having that connection with someone that's a real listener, not somebody that just talks in your ear and stuff. Like you got TA's and their job is to teach you, and it's like his job is he listens, and he gives advice. But he listens first. And I think that's really crucial and that makes him really special, because not too many people have somebody down here on campus that will listen to them. So, they can have it all bottled up, and they have to go through the hardships and stuff, and they, at the end of the day, it's like, if I would have told somebody, it could have been this much easier. I could have had an outlet. Because we've always got some type of outlet, like one form or another.

Graduating senior Ronald summed up the caring help the Center provided him throughout his undergraduate career:

When you come, you know that the people here are interested in your life and care about you, want to see you succeed, and want to do everything they can to help you succeed. A big thing for me is the people who are here really make me understand what it is. Dr. Deal and Mr. Winters... they are the people who make me want to come here and take advantage of everything they have to offer me. Because being around them has expanded my knowledge base and given me opportunities for research, or other things like that, but really just, I think, it raises my college experience and my life.

Having students learn the skills to manage life planning was important to the program. The start of developing this skill set began with the first Center program the students took part in when they came to campus, the early orientation program. Mr. Winters expressed the goal and life planning: 
Planning is another area to try to work with students to begin to develop their plans and goals early. We talk about that a lot in the early orientation program with students. The

first year you have to concentrate. You have to do well, but you should also start thinking down the line, what are my goals? What are my goals? What is it that I want to do while I'm at the university? Help-seeking behavior for a lot of students. I know from my personal story from when I was in college, I did well, but I probably could have done even better if I would have sought out more help. Focus students with help-seeking behavior, to seek out resources when they need it.

The early orientation program was designed for students to learn and acknowledge the need to develop help-seeking behaviors in college by exposing students to all the resources available to them prior to starting their first day of classes. The subsequent workshops and programs have continued to cultivate the initial groundwork that the staff of the Center and their university partners across campus instilled in the incoming freshmen each year with the orientation program.

Development of Evaluation and Assessment Practices. Individual program surveys have been constructed to monitor student satisfaction. Assessment cycles have not been fully present for all Center programs, but were being developed for specific programs. The administrators have developed the most evaluation and assessment practices surrounding the early orientation program, because it was one of the first programs that the Center hosted on campus. The administrators in charge of the Center have made changes and adjustments to the orientation based on survey evaluations and focus groups. The staff has used these data received from students and parents from past years, hoping to increase its effectiveness. When administrators spoke about the changes they made based on assessing the student learning 
occurring with their programming, the early orientation program and the leadership workshop series were cited as two of the programs that had been reformed due to student feedback. Dr. Deal was shifting the leadership series into a more experiential set of activities for students, which was intended to help focus the activities and workshops towards achieving specific student learning objectives:

This year we changed the leadership workshop series. I'm going to say Mr. Winters as the programming director has done [an] outstanding job. I challenged him by saying, let's do more than have a didactic part, let's have an experiential piece. How do we know whether or not they can demonstrate what they learned in a class? So they'll have a ten-week class, and then they'll have to develop competences. And what we're going to do is find some kind of way to acknowledge that those who do the full completion of this. It is my goal. The Center's goal, not just mine; the Center's goal is that we hope that at least $50 \%$ of our students will go through this experience.

There have been promising signs that the Woodson Center will formalize a system of assessment for their programs. Staff has recognized the need to assess, check in with students, and gather data to prove their value on campus and the impact they are making in the development of students early on in the Center's history. Their professional experiences have helped to initiate the creation of solid programs, and assessment will help them to maintain the proof that those programs have been valid methods of executing the overall mission of the Center: to retain Black male students, to engage Black male students, and to graduate Black male students with the right tools and skills for leadership in their respective professional worlds. 
Students recognized the Center's role in their development. The students acknowledged that the Center played an important role in their professional, academic, and overall development, as well as their ability to overcome challenges and persist at Southern State University. They spoke about specific skills needed to succeed at SSU and behaviors and habits they have improved; many attributed their progress to their involvement with the Center. These outcomes have been different, yet related to what administrators shared and identified as the main goals of the Center. Students consistently and directly referenced the Center when discussing their transformation as students over time in areas that were initially challenges to them. James, a junior engineering major, spoke emphatically about the Center's role in his development:

I'll say the Center has done so much. I mean, without the Center, I would not have gotten into Summer Research; without the Center, I would not have these social skills; without the Center, I would have lost my sanity a long time ago.

He went on to share, "Every time that I go to a Center event, I always come out a better person...Y You grow as a person each time. You grow, each time you go here."

Some students have developed a higher level of sophistication in their communication skills. They have developed critical thinking and listening skills to personalize conversations based more on the individual they are speaking with, and their understanding that the nature of their relationship with different people requires tailored adjustments. Peter discussed this growth in his communication skills: 
As far as when I'm talking to people, I'm slow to speak, so I think about what I'm saying a lot more than I used to. I guess I gauge the person before I talk to him now, because I still kind of do it, just with the right person.

Students also shared how they have developed over time when dealing with the differences of race, culture, and the negative stereotypes about Black males held on campus. They discussed their developed techniques for managing relationships with White faculty and peers. Lucas shared how campus events he attended helped him to see the broader issues of racism on campus and his ability to now differentiate between intentional blatant racism, institutional racism, and the pure ignorance of privilege. He noted that although not a personal challenge for him to overcome and develop, other Black males on campus must develop ways to properly respond to incidents:

I mean, this isn't a personal challenge of mine, but I do realize that one of the bigger challenges among African-American male brothers on campus is taking instances where there may be unintentional racism, like thrown towards them, and not getting upset at those, because they are unintentional. Like, I went to a program a couple weeks ago where racism was the topic of discussion. You know, it was kind of delineated across three realms; there's the blatant overt racism, there's the institutional racism and there's the racism of ignorance, so to speak. And I think it's in those instances that may be challenging for most Black men, because even in the instances where the racism is kind of unintentional or based off of the other person's ignorance, it's kind of hard to acknowledge that and refrain from getting upset. And it actually does more damage when you respond, when you retaliate with anger rather than with understanding-like knowing that, you know, they don't know what they're doing or what they're talking 
about. The way I like to put it is, like, you can't get mad at water for being wet; it is what it is. Right? So like don't-you can't get upset at someone's ignorance, because they simply just do not know. You know, they can't help it. So it's your responsibility, and it's an opportunity therefore to make the relationship better by educating them.

As early as their first year, students were making the adjustment to the environment and developing a level of personal insensitivity to the stereotypes and racism and push past them. Second semester freshman Shannon discussed the shift:

The challenge I had to face was the whole predominately White thing, 'cause where I'm from, it's like all Black people. My high school was mostly Black people, and then you come down here, and it's like a class of seventy people, probably more than that, and there will be like two or three Black kids in there, and that's not easy for me. But, I've adjusted to it, and now it really doesn't bother me so much.

Before, the shift Shannon admitted, "I did not know how to connect with White people." Students have developed ways of coping and managing faculty relationships when peers and faculty act negatively and make specific comments to the Black male students based partly on a belief in negative stereotypes of Black males. Students like Eli, a graduating senior, recognized how the challenges in the classroom of choosing how to respond to racist or derogatory incidents has helped him grow into a better person:

I have to say I evolved as a person, and I think being here helped; because if people don't challenge you, then you can never honestly consider yourself accomplished-because you never had challenges. So this university has challenged me, and in that challenge, I've been able to adjust myself. For instance, there's a situation in a classroom where a 
student, a fellow student made a comment that was pretty derogatory, in my opinion. And normally, I would probably go out of my shell and say something probably indignant or try to stoop to their level, but I realized, you know, it's a time and place for everything. So I approached that situation in a manner in which that I learned, you know, I learned as I've been here, I've learned how to approach situations in a certain way.

Daniel, an out-of-state freshman, discussed his development of effective communication. He talked about how the skill has led him to develop an appreciation for diverse ideas of others on campus; "I think I'm learning more how to communicate with people, how to accept that people have a wide variety of perspectives on different topics."

Students have also developed skills over time, which have helped them manage their academic course work. Samuel summed up the ongoing work necessary to shift to a more concerted level of effort when it came to studying to obtain academic success:

Studying is an adjustment I'm still trying to make. Because if you go four years of high school and you really don't study, I think it would be really hard for you to get acclimated to studying in one year. Even too, for me being a third year now...It still feels like it's something that's going to take time still. I'm still trying to get used to it, because everything plays a role into how you study.

One specific communication skill that directly related to students' overall academic success was developing the way they interacted with faculty. Students, like freshman Marquise, recognized the need to develop faculty relationships outside of the classroom: 
'Cause I think we got, like, maybe even office hours too. Like, I probably wouldn't have gone to this, like, if people didn't say, for example, it's important to get to know your professors. You stand out so, they actually know your face, like, in person.

Another important development has been their time management skills that helped them juggle the different workloads of their courses. The Center has taught them time management skills that they have been implementing and mastering. Barack, a junior, discussed the improved daily habits he developed to manage his time over the past three years:

Just writing stuff down, I write everything down as appointments. I've always written stuff down, but I used to only write half of the stuff or just the major, important stuff; but now, I write down everything. Like for exam dates or when papers are due, I write all that down at the beginning of the semester.

Another student, Eric, talked about how began using the whiteboard that Mr. Winters taught on in the Center's time management workshop as a tool to stay organized between school work and his extracurricular activities:

Yes, the whiteboard helps out. It helps out a lot. Before I used to forget a lot of little things like, “Oh, no, I got a quiz today, but I forgot.” But now, I'm doing better. I'm not saying it is $100 \%$ better and everything, but it's still better.

They recognized the need to increase their mastery of time management to be successful in college, compared to their ability to study and manage their schedules and assignments in high school. Freshman Kenneth specifically spoke about developing his reading habits and how much of an adjustment it was for him: 
Me, I didn't like to read. It was, like, I took this English course, and I had to do extensive reading, and I don't like to read. I like drawing. I'm a visual learner, but I don't like words. I like using words to describe images but not using words to depict images. So, I had to do reading, and I had to do it extensive in the first semester in the fall. I didn't like to read, I had to force myself. And the second one, it's like, it don't matter what you like, you need to do this if you still want to be here.

He noted the support he received from the Center to help him develop his study habits:

The Center-basically just bonding with people, coming out of your comfort zone basically adjusting to high school to college, like growing-basically growing up for things. Like, you feel like you're at home when you're in high school. You feel like you're a man, like you can do this, you got this. But it's like down here [at the Center], it's like a team-effort kind of a thing. You're not by yourself. It's like the work that you do depends on habits, and the things that you bring to the table. Basically those are your tools, your study habits are your tools. Your extracurriculars, or the study table, or your group discussions, those are your tools to help you get through all the hardships that come your way.

Students recognized the Center as a place for them to connect to other positive Black males on campus, including the staff of the Center. Ronald spoke about the staff's overall assistance in his overall maturation and development:

Listening to their perspective and being open, being open to not being right all the time. More so, coming from a perspective that I was probably wrong, even if I was right. Coming from that perspective really opened me up and humbled me about other people, 
so I could overcome what I needed to overcome... They really helped me with my personal problems and gave me perspective, telling me about certain workshops that we're having, some roundtable discussions that I should go to. They've really helped my own self-cultivation, but really just being there as a support network as mentors and friends.

The students recognized that the Center had a positive influence on their college experience. They viewed the staff of the Center as authentic, and they saw that there was honest care for students' wellbeing and success shown by the staff. Peter spoke about the Center being a gift for Black males on campus:

As far as being students and being African-American male, it's a Godsend. It's a place where a lot of African-American males that are very successful as I, and they are there to help you. Then, you get to meet other students that you never ever met before, AfricanAmerican males that are doing good, just like you are...You see different people, people pushing you; you always have somebody that is accomplished to see you through, to help you out with everything.

He went on to specifically address the importance of the staff being Black males, and the impact it made on him as a Black male student to have that push coming from someone he can identify with—race and gender-wise:

It's always good to see an African-American male in a position like that, because it helps you. It's okay to probably have a woman advisor, that's an African-American female. It's cool, but it's even better when your advisor is an African-American male. It's different...it's just better to see an African-American male there. 
The staff of the Center has had a positive influence on the students' college experience. Students acknowledged that the workshops and programs were important means for them to increase personal, academic, and professional development skill sets, self-confidence and humility, and overall understanding of their Black male identity and brotherhood. Students have developed a level of personal accountability and responsibility for themselves and other Black men on campus, and have placed high value on the brotherly bonds they have developed by engaging with the Center. The Center has concentrated on retaining students by developing annual programs and opportunities that focus on networking and workshops on leadership and academic skill building. Students stated that the Center has conveyed a safe and caring environment and has practiced role modeling and mentorship. Students were successfully adjusting to Southern State University and maturing, affectionately calling their attachment and engagement with the Center, "a lifestyle." They believed that their participation with the Center was essential to their success. At no point after students entered the university did they separate their changes in attitudes, beliefs, and development from their engagement with the Center. 


\section{Chapter 6}

\section{Case Comparison and Conclusion}

Both Northwestern State University's Black Male Exchange and Southern State University's Woodson Black Male Resource Center have demonstrated respectable levels of success in developing the student participants and in supporting the institution's diversity and retention efforts. Each initiative was different in the systems and methods used to achieve the similar outcome of retaining Black male students at their respective institutions. In this chapter, I provide a brief case comparison of the initiatives, concentrating on the similarities in program philosophy and strategy, goals, implementation, challenges, and outcomes. I also delineate the salient distinctions between the two programs. Finally, I present implications for future practices in higher education, suggestions for policy, and subsequent scholarly research questions to consider when studying student retention and diversity initiatives.

\section{Comparing the Programs: BMX and the Woodson Center}

Both programs have comparable components and focus on similar goals. Some goals were tactically driven using similar methods, while the leadership of each initiative has differing philosophies on how they approach the same to successfully increase the retention of Black male students. Both intend to develop resilient, mature, confident, academically sound and successful Black male graduates with a strong sense of self, social responsibility, and personal accountability. Administrators at both institutions also shared similar struggles with regularly engaging student athletes to participate. The manner in which administrators engaged students differed, one rooted in developing a sense of pride in their heritage and raising students' Black culture consciousness, the other based on creating servant leaders that operated from a 
considerable amount of humility, great self-efficacy, and a healthy understanding of interdependence.

Each program has reached different levels of visibility and recognition as working components of the diversity plans at their respective institutions; both have dealt with changes and shifts in the overall institutional philosophy concerning inclusion and diversity. Administrators have demonstrated different levels of effort towards moving the program in the direction of successful institutionalization and towards ensuring the staying power of their programs. Although the administrators at each institution valued the practice of evaluation and assessment, their energy towards formalizing systems of assessment were different, as were their understandings of how to approach the task. They each spoke anecdotally about the changes they saw in the students, yet both agreed more effort was needed to move towards systematizing data collection on what and students have learned from engaging with their programs.

Execution of the Mission. The Black Male Exchange and the Woodson Center both have included similar goals to reach the mission of retaining Black males at their institutions. They both wanted to produce students who were leaders. Administrators at each case site discussed how there was a lack of Black male students who were prepared and trained to take positions of leadership on campus. Each program presented ways of developing the leadership skills of Black male students.

Developing leadership skills. Administrators charged with leading the BMX used more of an active learning approach with student members when teaching leadership skills compared to The Woodson Center staff. The student organization was the known entity of BMX on campus at NSU. Involvement in the initiative meant a Black male student was a member of the 
sanctioned student organization. They then participated in monthly administrative meetings and planning of campus events or workshops for the high school pre-college preparation program. If not engaged on the planning level, students were at least taking part in the monthly educational or annual social events; administrators then anticipated students' desires to contribute on a more committed level later on. The administrators built a system where students took the lead on planning or were members of the planning committee for one or more of their established campus or community events. Developing leadership skills was important enough to the mission of BMX that one of their eight annual programs was a themed leadership conference open to the entire campus. The members of BMX were able to practice leadership skills by partnering with other student organizations to plan campus events, by collaborating with the teachers and counselors at participating high schools in the surrounding school districts, and by leading their Black male peers and fellow BMX members in executing the organization's annual programs. All the administrators leading the retention program shared their desire for members to branch off to other leadership opportunities at NSU outside of BMX, and they gave multiple examples of their student members taking leadership roles on the campus programming board, fraternities, and other student organizations. They saw BMX as an incubator to teach and to grow students into capable leaders for the entire campus and beyond the college years.

The mission of the Woodson Center emphasized developing leadership skills and took a more didactic approach than BMX. Although the Woodson Center had a student organization that served as an extension of the Center to the student population at SSU, the organization was not the focal point of the initiatives efforts to build students leadership skills like the BMX at NSU. Mr. Winters served as the adviser for the student group, as did Mr. Brown, but the student leaders of the organization operated independently of the programs planned and hosted by the 
Center. In a clarifying conversation I had with Mr. Winters after data collection on campus, he discussed an increase in his connection to the student organization by meeting with the executive board to help plan events, and checking schedules to make sure there were no program conflicts between the student organization programs and the formal programs of the Woodson Center. The first several years of the organization, Mr. Winters allowed the student leaders a high level of autonomy from the Center. Whereas, BMX was the initiative to most at Northwestern State, the Brotherhood organization at SSU was not identified the same way.

The Woodson Center staff strongly desired full participation of Black males in the leadership workshop series hosted by the Center. They would have liked all men engaged with the center to complete the series. This was their primary way of developing leadership skills in students. They hosted workshops that taught and discussed the characteristics of different leadership styles and the skill sets needed to be great leaders. Some students have subsequently implemented their own personal initiatives in the community surrounding SSU or in their hometowns based on the knowledge and skills they gained through the Center's workshop series. Administrators discussed their expectation and theory behind the workshops. They posited that students who participated in the workshops would then seek out opportunities to practice what they learned on campus as leaders of different student organizations, as resident assistants in the halls, as senators in student government, or to create their own way to demonstrate their leadership. Dr. Deal shared plans for making the leadership workshop series more experiential for subsequent student cohorts who experience the training, so there can be an element that requires demonstration of the learned skills upon completion.

Another instructive approach the Woodson Center practiced to help increase the leadership development of Black male students was through roundtable discussions. Students 
were able to participate in these discussions with distinguished members of the community and prominent Black male figures and to hear their anecdotes, philosophies, and advice on how to lead, and then also ask questions of known leaders in their respective fields of expertise.

The Center did not host a major annual event focused on leadership development that was open to the campus like BMX. BMX's approach to leadership development occurred over a period of time, as students continued to engage with the student organization and to step into more responsibilities for the production of and follow up to their traditional annual programs on and off campus. The Woodson Center hosted several smaller workshops on career and healthy study habits, but relied heavily on the leadership workshop series as its leadership development component. The Woodson Center planned to add a practical experience into the current programming for students and recognized the importance of students demonstrating learning through action.

Developing student identity. Both program missions had an emphasis on developing Black male students with confidence and a strong sense of identity and accountability. They also both expressed an expectation of excellence in their students, in both their academic pursuits and in their professional development. Both administrative teams in the study identified these expected outcomes as they discussed their missions, and both stressed these expectations as important to the overall mission of retaining Black male students. The approaches they have taken to help students build confidence, responsibility, professionalism, and maturity varied. Building up leadership was one underlying piece used in the process of developing students and subsequently retaining them, but the other major piece affecting these goals was the philosophical foundation behind the programming and interaction with the students during their time on campus. These philosophies varied significantly and influenced the overall nature of the 
programs and how the students described the origins of their newfound confidence and ability to focus and persist in college. Yet each program produced students who experienced transformational change in their self-perceptions, behaviors, routines, and critical thinking skills. Students engaged in both programs, gaining a strong understanding of the gendered and racial components of their identities. The students came to understand what role they played in their interactions with others and the way they built relationships within the university community and off campus.

BMX approached developing the students' sense of self and confidence through strong cultural identity and a Black heritage context. They believed that developing the students' sense of cultural identity increased their likelihood of overcoming perceived obstacles and negative stereotypes in order to persist. This approach helped students develop a strong self-identity and helped them engage with others in the community from a place of confidence, because they had a better sense of the depth and richness of their culture. They were able to have comfortable interactions with students and faculty in class and around campus with a more complete understanding of all the historical, political, and social nuances related to being Black and being male in America. Because Black cultural identity was the philosophical foundation of the administrators who created the BMX, it was seen in how the programs were developed; how students were recruited and engaged in dialog about who they were and how they related to the world; and how the expectations were set for students to achieve as members of BMX. They specifically hosted their book study for this purpose and explored Black male identity through literature. The books read served as a basis for discussing and exploring in a safe closed-door environment. Students confirmed that cultural exploration and identity development have been the foundational components of BMX that helped their persistence and achievement at 
Northwestern State. The Woodson Center has not hosted a formal program that uses media or literature as a teaching aid to facilitate ongoing discussions about Black male identity.

The Woodson Center had a different approach to the same outcome of developing confident, engaged Black male students. The Center's philosophical foundation was service, and it focused on developing a sense of humility and the idea of creating servant leaders for the campus and the larger community. Administrators have instilled a sense of interdependencyletting students know they cannot succeed in college without asking for help. Both programs encouraged students to practice help-seeking behaviors; to take advantage of tutoring, advising, and other student services on campus; and to develop a sense of accountability to the community and each other as Black male peers. The Woodson Center, through their messaging and one-onone engagement with students and through programs and workshops, has focused on developing a sense of humility to help students understand the need to serve others, as well as to ask for help from others when appropriate. They have focused on keeping students humble toward the goal of graduation. Unlike the BMX approach, where each program had an identifiable connection to Black culture and heritage, a more subtle approach emerged from SSU students' individual experiences and relationship to the Center.

The role of the student organization. The sanctioned student organization that each program advised was used differently at their respective institutions in the execution of the mission. Both organizations were recognized student organizations by the institutions. BMX conducted all of its programming through the student members. The students planned all the programing, which was used to establish BMX's presence on campus and engage other students. The annual programs students plan have been established as far as purpose and theme since Mr. Brown created the structure of BMX, and there have not been many changes to the 
organization's programmatic strategy. The actual student organization was the first component of the two main programmatic pieces that were formed. Programming was the core of the college component of BMX, and students took the lead every year as the face of BMX. Staff was then able to focus efforts on the one-on-one student monitoring system they had in place and to manage individual student issues as they arose. Staff were also able to focus on expanding the impact of the precollege school program by reaching out to more schools, developing relationships with school leadership, and refining the workshops presented to the participating middle and high school students and parents.

The Woodson Center had a different relationship to their student organization affiliate. The student organization was seen as an extension of the Center. There was a distinct delineation of identity between the two. The Woodson Center conducted its own signature programs, like the early orientation, leadership workshops, and annual retreat. The student organization was young. They had yet to establish signature events. The idea of advising a student organization was not a part of the original plan of the Woodson Center. It was an additional responsibility taken on by the staff after students requested permission to form the group with the Center director as its campus adviser. The Center was still establishing its relationship with the student organization and already had a separate established identity as a strong and successful retention initiative prior to the formation of the student organization. The two were not synonymous with each other at SSU, unlike the relationship with the administrative office of BMX and the actual student organization BMX. BMX on campus was seen as the student leaders conducting well attended purposeful events for the campus community and also recognized as the first institutional resource identified to help retain Black males at NSU. 
The brotherhood organization at SSU was only viewed as an extension of the Woodson Center. It was supplementary to the Center's mission and what they have already established in their efforts to retain Black male students. Based on my follow up conversation with Mr. Winters after my campus visit, the staff of the Woodson Center has begun working more closely with the students to help them with their programming by providing funds, and some direction. Center leadership was currently increasing its involvement and understanding the potential ways the Center may use the student organization to help carry out the mission.

Engaging student athletes. The leaders of the programs at both institutions recognized the importance of engaging student athletes and assisting in their matriculation. They each have had mixed results in consistently engaging student athletes, particularly Black male student athletes in the revenue driven sports of football and basketball. This was a noticeable concern at both institutions. Both schools were Division I National Collegiate Athletic Association (NCAA) institutions and reflected the Graduation Success Rates (GSR) trends; although Black male scholarship recipient student athletes in basketball and football were being retained at rates higher than Black male non-athletes by approximately $4 \%$ according to the last NCAA cohort statistics, these revenue producing athletic scholarship students were trailing their White male student-athlete counterparts by approximately 19\% (NCAA, 2011). These differences in GSR were concerns for the administrators of the retention programs at SSU and NSU considering the access both populations of student-athlete males have had to resources and support. Both administrative staffs had similar relationships with their athletic departments at their institutions. They had an existing, yet underdeveloped relationship with those student services and academic counselors charged with assisting and supporting student-athletes. They desired to connect Black male student-athletes to the programs and services offered by the retention initiatives, but have 
not been successful incorporating them into the fold of brotherhood and support that has been part of each program's mission.

Engaging gay Black males. In general, students who were engaged designated the Woodson Center and the BMX as safe places on campus for them to be themselves and let their guard down as they grew and developed. They provided personal stories of the one-on-one care and support they received and how the brotherhood among the students helped them to persist through college. This was true for the majority of the student participants. One student identifying as openly gay expressed mixed feelings during his focus group about his engagement with the BMX at NSU.

This freshman, Vincent, disagreed with the rest of his focus group. As an openly gay student, he expressed the personal issues he had connecting to his Black male peers in BMX. Vincent came from a single mother home. He was an out-of-state student from a small town he described as "one of those small towns that, like, if you leave, that means that, like, you do something with your life." He identified as having a low-socioeconomic background, even sharing that part of his senior year in high school he and his family were homeless. He was at NSU on a full, need-based, academic scholarship to the chagrin of his high school guidance counselor who only halfheartedly believed enough in his abilities to encourage Vincent to apply to the local community college. Vincent stated that he knew college was the way to have the life he always wanted and saw on TV, always kept in the back of his mind, despite the fact that his mom discouraged him from going:

I felt like every time I turned around someone was like - they were setting standards really, really low for me. My mom was doing it, to kind of protect me. Because I just felt 
like she realized how hard it was to get into college and also like to stay in college and do all these things - just, like, sitting there failing and it not working out. And so I think that she thought she was softening the blow, and a lot of other people told me I should start off slower, it was just lower expectations.

Vincent has engaged with both the BMX and the LGBT alliance student organization his freshman year hoping to find a solid social group he could relate to in college. He expressed extreme frustration during the focus group when we discussed making social connections at NSU, where he felt in the minority about BMX. He stated neither one of the student organizations, or even his current engagement with other student groups on campus made him feel socially integrated:

It's actually weird because the two organizations that I thought that I would be like the most accepted in, I also feel the most alone in, I guess. Because, at the end of the year, I should feel like a part of this organization, but I don't. Like I don't understand, like why I'm why am I not like everybody else? And, like, why don't I like working at it? So decided with other organizations and stuff, I've done a lot of stuff that, like, get my name around campus and, like, just be really, really involved, and all this other stuff, like, it's fulfilling. People tell me, you're doing a really good job, but at the same time, like, I don't feel like it's going anywhere. Like, I don't feel fulfilled personally with any of the organizations that I'm a part of.

Specifically speaking about reaching out to take advantage of the brotherhood that BMX promotes, he devaluated the source: 
And I think friends are people you can call regardless, and I don't feel like any person in BMX, like, I can call if I'm having a really rough day, you know what I mean? And you know, granted, there's some people at BMX that would be willing to, like, sit there to, like, listen to my problems. But, would I do anything of value? Would I feel comfortable? The answer is no.

The three other participants immediately responded to Vincent, one sharing his own story of moving from an outsider freshman year to taking advantage of the brotherhood, to then exemplifying it by reaching back to the freshmen like Vincent. They demonstrated the care that the administrators showed toward them daily, but Vincent still was hesitant. Vincent confirmed that they as group never made him feel like an outsider because he was openly gay. He admitted that he has had issues with connecting with and relating to Black men all his life. He also shared an improvement he experienced his first year, where there was a major shift of having anxiety attacks prior to BMX meetings to now being more comfortable around Black men, because he continued to stay connected.

Even though no student participants in the study from SSU's Woodson Center identified as gay, in a follow up conversation I had with him after initial data collection, Mr. Winters acknowledged that they needed to do a better job of engaging gay Black males to participate. He has had one-on-one meetings where students have come out to him; most were shocked that he was not surprised and treated them the same once they disclosed their sexual orientation. He observed that those who identified openly as gay have slowly decreased their involvement with the Center as they continued to matriculate through SSU. Mr. Winters has made consistent efforts to reach out to make them aware of events and to schedule one-on-ones with them, but they haven't responded. He stated that he planned on making connections to the student 
organization for Black LGBT students to let them know that, as a Center, they are welcomingnot just him as an individual. The intersection of major identities has been a sensitive area specifically with gay Black men, due to culturally accepted hostility and disapproval that has only recently begun to subside. It was something that both initiatives needed to consciously overcome and to compensate for when working with Black gay men entering college and promoting their mission that all Black men be retained and graduate from their respective institutions.

The Momentum towards Institutionalization. Each program had a defined character on campus, based on how the mission was carried out, how results were presented to the university community, and how successes were shared as a part of the institutional story to stakeholders and others in the community. The foundations of both initiatives were grounded in the identities and personal experiences of the administrators charged to lead the programs. The mission of each initiative was driven tactically by the leadership's past collegiate and professional experiences. These experiences shaped retention initiative leaders and influenced program design, cultural norms, and the experiences they provided for students. Leaders' personal experiences heavily influenced the character and culture of the retention initiatives at each institution and their identities on the two campuses. The ability of a leader to blend in with or stand out from the established institutional culture has affected the conformity of the programs to the broader community and institutional mission. Their philosophies also impacted how the institution has accepted the initiative into the campus diversity initiative and to what degree the initiatives have moved through the process of mobilization, implementation, as well as the likelihood of reaching institutionalization. 
The influence of personal and professional experience. For BMX, Mr. Brown's

personal experience as a community activist had strong influence on the initiative. Its design was an extension of Mr. Brown's community activism, professional history, and his personal Black culture social consciousness. His background prompted the approach to structuring the retention initiative and how its programs were presented to the campus and community, where each had an underlying goal of teaching Black males pride in their Black culture as well as developing leadership.

In addition, Mr. Brown's common link to both Mr. King and Mr. Douglass through their shared fraternal bond informed and fed their approach to brotherhood and how they interacted with students and the community. Leaders of BMX stated they wanted to be an incubator for young men to pursue any and all fraternities available to them and not be seen as competition to the fraternities on campus, but a complement to them. For many years at NSU, fraternities were the only way that Black male students were able to engage the campus and experience leadership development. Mr. King expressed "sensitivity to that" when speaking with the other student affairs senior officers during the early discussions to create BMX; these discussions took place in the early mobilization phase of institutionalization. Mr. Douglass, Mr. Brown, and Mr. King all provided the same "come as you are" philosophy when describing the welcoming culture in the recruitment and retention efforts of BMX and the same focus on showing each Black male the intracultural diversity that has made the Black community strong and resilient.

The administrators at SSU specifically "downloaded" the philosophy and program from their HBCU alma maters to help break the mission into tangible working components. There was support to an opposite view for the benefits of emulating those same principles and practices within the creation of the Woodson Center, because the administrators were all successful living 
proofs that it would produce positive and professional Black males. Mr. Wind described the tenets they focused on when working with the students and developing their professionalism, leadership traits, and self-efficacy. He shared the epiphany he had as a freshman in college; that he was one of many talented students at his institution, and it would take hard work, networking and personal development to make it through school and be successful. The staff at the Woodson Center has passed on this focus to the student.

These foundational philosophies have affected the priorities of the initiative, the image and marketing of each of the programs, and their overall fit within the institutional context. Southern State University has focused on being the best public research institution in the world and the Woodson Center has made fundraising activities a priority to increase the likelihood of sustainability and improve their programing so they can mirror SSU as the best Black male retention initiative in the world. Fundraising is also a focus to increase funding for research on Black men across disciplines to assist other institutions as well as the government and private sectors. The administrators' focus on teaching students “excellence with no excuses" meshed with the institutional focus and image of greatness.

Institutional endorsement and support. Leadership at the Center has fallen in line with the president's vision very well. The president consistently has spoken about and has highlighted the Center's initiative when discussing the successful diversity programs that have been a part of the overall institutional diversity initiative. The administrators consciously have thought about what the president has said regarding the image of the university and about its diversity and inclusion efforts. The leadership strategically leveraged their place in the institutional story, reporting minority successes that have made good sound bites. The president has used the fact that the retention rates of Black males from freshmen to sophomore year are one of the highest 
rates when disaggregated for gender and race. This exposure provided the momentum to bring other partners in the institution and community to join in the mission to help retain Black male students and to provide quality data on the Black male experience across disciplines.

The Center has received a reasonable amount of web publicity and through other media sources used to market the university. The Woodson Center administrators have seen this as an example of the value the institution has placed on its success. The personal financial investment from faculty and staff at every level and the partnerships have grown, in addition to the number of offices across campus that wanted to partner with the Center to help develop programs and opportunities for Black male students. There was a long list of administrators that Mr. Winters provided to me as potential study participants who have been involved to some significant degree with advancing the Center's mission. The Woodson Center has shown progressive signs of institutionalization due to compatibility with Southern State University’s norms, values, and goals.

Administrators at the Woodson Center focused priorities and attention on strategies for institutionalizing the program that were different from the administrators in charge of BMX. The Woodson Center has shown more actionable strategies for moving the initiative from implementation to institutionalization. Mr. King, Mr. Douglass, and Mr. Brown at NSU all revealed during their interviews that they have found themselves in a place of uncertainty in their institutionalization process. They placed BMX at a solid place of implementation. They received an annual budget for funding the program. Other offices at NSU recognized BMX as a part of the effort to increase the access and success of historically underrepresented groups because of the precollege high school prep program. The program was also recognized across campus as one of the top student organizations, acknowledged by senior administrators for their 
annual events that draw a large number of attendees and have been recognized for the award winning student leaders they have helped to develop who have been achieving in the classroom and as student leaders outside of BMX.

However, with the president's vision to redefine how the institution identifies diversity and inclusion campus-wide, specifically access and success, the administrative leadership of BMX have been questioning their relevancy. Leaders specifically stated that they believe the BMX story should be more in the fold of the NSU story told to the public and stakeholders. They also have questioned if BMX, as an ethnic and gender specific initiative, would be implemented today if it were not already established, due to the shift in how diversity was defined, inclusion initiatives were developed, and institutional dollars were being spent. The leaders were in an introspective phase more than a strategic phase. Although they desired to have more connection to the institutional story, they did not specify ways they planned on moving the initiative towards institutionalization. Mr. King was even cautious about stating that more needs to be done in order to please the Black community constituents that desire a larger Black student population at NSU, because the demographics of the state were mirrored with the current statistics at the university. Unlike the Woodson Center, there was no definitive plan provided during my interviews with them to strategically gain momentum towards institutionalization.

The Retention Initiative within the Diversity Initiative. Diversity was important to both institutions. Both institutions have visibly dedicated resources, time, and publicity to promote the commitment. Both institutions have concentrated on developing several aspects of their campus-wide diversity initiatives, creating forward momentum in all four major areas of well-developed campus diversity initiatives according to Musil, et. al (1999): retention, access, and success; campus climate and intergroup relations; mission, vitality and viability; and 
scholarship and curriculum development. Both Black male retention initiatives identified their role in the overall campus diversity initiative, have faced similar questions about the programs, and have each identified different programmatic pieces that were important to the way they carry out their role within the campus diversity initiative.

Both retention initiatives have had a primary role to help advance the institution's overall efforts to increase the access and success for historically underrepresented students. They concentrated on developing a strong student experience for Black male students. They served their respective institutions as the main program focused on retaining Black males. They each have adopted similar pieces of their initiatives to see this particular population thrive and graduate from their respective institutions, including: a strong student monitoring system; a strong campus resource referral system; leadership development components; professional development; social and educational programming; mentoring and role modeling; regular academic recognition; a sense of accountability, responsibility and brotherhood. They both were designed to decrease Black male student isolation on campus and increase their retention and engagement.

One major difference between the two program designs was the formal college preparation program that BMX implemented. This major component covered both the access and success aspects of the campus diversity initiative for this population. Information was disseminated to parents and students as young as $8^{\text {th }}$ grade, including information about the college preparatory process, financial aid, the college application process, application timelines, and overall college life survival skills. It also began the more psychologically driven, affirming process that is necessary for successful graduation with the academic recognition of crossing the milestone of high school graduation and awarding of small academic scholarships. The Woodson 
Center has recognized the need. They have known the research that argues the importance of early intervention and early access to college preparatory information, but they have had no formal component that has reached out to the local high schools to present this information to potential SSU students and parents. This could possibly be addressed through the formal research conducted by the Center on K-16 education and college preparation, but was not a programmatic piece.

Another major difference between the two programs was their actual target audience for their programs and the attendance. The Woodson Center's programs were open to all students, but the major population that attended was the Black male students. Many of the programs were smaller workshop settings covering leadership, academic study skills, and professional and career development, where the majority of the attendees were the Black males who have been engaged with the Center. Compared to BMX, where the student organization presented campus events for all students, which drew a large number of the campus' entire Black student community, and for some of the annual programs hosted, the surrounding Black community. This audience reflected the strategic planning of the leaders of each initiative with regards to their measure of impact within the campus diversity initiative. Mr. King, Mr. Douglass, and Mr. Brown fell under an administration that measured impact through numbers. The dollar amount spent on a program was viewed as valuable depending on the number of students it reached. The Woodson Center measured impact differently, mainly focusing all its efforts on the retention of Black males and their personal and professional developmental success.

Both have faced the critical question about the retention of Black female students. All administrators interviewed mentioned that the question has been brought up by the female students, community members, and other administrators. All believed it was a valid question to 
ask when an institution chooses to have an ethnic and gender focused retention initiative under the overall campus diversity initiative. Northwestern State University had not answered with a formal program for Black female students. They had a Black student union organization that both males and females participate in, historically Black Greek-lettered sorority chapters that women can join, and a summer bridge program in which female students can participate to help provide a jump start on knowing about college social and academic life. Southern State University actually created a non-Greek affiliated female student organization to counter the Black male brotherhood student organization associated with the Woodson Center. The student organizations have partnered on some of their programs throughout the year, but for the most part the female organization has acted independently of the Woodson Center but was available and open to all Black females to help support them through their collegiate years at SSU.

Reviewing Evaluation and Assessment Practices. Academic and co-curricular college programs have increased the routine practice of formal assessment as a way to provide evidence of students learning. Assessment was a form of accountability for both Student Affairs and Academic Affairs. Quality indicators for programs were identified as assessment and program evaluation, where the criteria reviewed was broader covering participant satisfaction, effectiveness of the presenter or speaker, and quality of educational materials used. Both leadership teams stated the importance of assessment, but differed in activity level. The evaluation markers for both programs were similar and used to tell their story to the university community.

The BMX leaders were not able to pinpoint any regular formal assessment practices. Mr. Douglass, the current program coordinator, was confused about what formal assessment was. He had mistaken formal assessment for qualitative research methods. After I explained the 
difference in purpose between assessment and research, Mr. Douglass, as well as all of the other administrators stated that formative assessment of student learning was not taking place. They were able to identify anecdotal information about student development that they noticed developing over time in the members of BMX who were participating in the programs and meetings. Mr. King stated that assessment was something that they could be doing, possibly as a pre- or post-test of skill sets with a set number of incoming freshmen members, but did not have plans to implement it as a practice due to the difficulty he believed he would have with identifying and tracking a full cohort from freshmen to senior year. All three administrators believed the top increase in learning that students were experiencing was their leadership skills, their personal sense of identity as Black men, and their understanding and pride in Black culture. They believed their observations of students' behaviors, attitudes, and demonstration of skills unofficially monitored over time to be the best indicator of student learning and development that they could implement considering the nature of the program. Most of these observations were one-on-one meetings with students, how they engaged in the monthly administrative meetings, their willingness and ability to lead the planning committees for their events, to speak at events, their participation in the book study group, and their overall shift in decision-making.

The information collected by BMX leaders was evaluation data. They periodically (monthly and annually) created reports for the numerical data captured on program satisfaction, retention numbers of student members of the BMX college organization, number of members in BMX at NSU, number of high school and middle school Black male students who attended the precollege prep workshops, the number from the precollege program that actually entered into NSU when they graduated high school, and number of attendees at their campus events. These numerical reports as well as the recognition and awards student members received were provided 
to senior administrators, the Dean and Vice President of Student Affairs. Mr. King stated he was unsure of how often the information reached the president, but knew that the highlights have made it to the vice president of Student Affair's report. The numbers and the recognition were what they use as the evaluation of the program. The administrators focused on numbers more than learning outcomes, even though each one asserted that students grew in knowledge and tangible skills. BMX was at a level of basic evaluation in their assessment and evaluation practices. The potential impact of assessment and more advanced evaluation practice on the advancement and development of the initiative was not known.

The Woodson Center assessment practices were developing. Leaders have understood the importance of assessing what students are learning. The Woodson Center, like BMX, has relied on the anecdotal information that has been observed in the maturing of the Black male students who attended programs and workshops and interacted with the Center staff one-on-one. Both Dr. Deal and Mr. Winters discussed the change they have seen over time in the behavior and attitudes of the students in how they interacted with each other and how the students interacted with the Center. They noted that the decisions students made were more mature and they were thinking more broadly about their future and their personal impact on the campus and larger community.

Beyond the indirect assessment of anecdotal stories and observations, there have been some formal assessments conducted periodically with specific programs. Both Mr. Winters and Dr. Deal shared what the Center was currently doing to collect information on student learning. The early orientation program was one of the programs that has been formally assessed through the use of focus groups. The staff of the Center conducted focus groups several weeks into the semester with the first year students to gauge the influence the early orientation program had on 
students' adjustment to college. These focus groups have been done over the last few years and adjustments to the orientation have been made due to the data collected during focus groups such as adding more social time in for students to network, including an additional campus tour to help with orientation, and increasing the time that upper-class students have to share their experiences. Another area where Dr. Deal has challenged his staff was with the annual retreat. He did not want the retreat to be the usual retreat he has witnessed at other campuses, where the focus is on masculine identity and with only a didactic approaching to presenting information. He has been challenging his staff to produce a retreat that evokes measureable change in the students who participate. His goal was to make it more experiential as opposed to a social event with some identity awareness aspects. He wanted the retreat to have tangible learning outcomes that the staff will be able to measure.

The Center at SSU has collected satisfaction surveys from students to determine their level of satisfaction with the program and degree of understanding of the topic and materials presented to them. This practiced form of evaluation has allowed them to capture the numbers like BMX has done, but they were not reviewing them under the same context of impact as BMX. The Center programming did not have the obligation like BMX to show impact, numerical or student learning to the greater campus community. The majority of their programs were designed to advance Black male students' skills and professional development.

\section{Implications for Policy, Practice and Research}

In this study I presented cases of Black male retention programs and how they have affected the overall campus diversity initiatives and promoted student development and success. Although there was a common motivation for these initiatives to retain Black male students through graduation, the philosophies inspiring the two programs proved to have different 
influences upon how they have executed their missions. The different approaches reportedly yielded increases in retention rates at each university. The distinctions between the two demonstrate there are different methods that work in overcoming the major obstacles that prevent Black male student retention. There are factors to consider as important when the initiative is reviewed within the individual institutional context.

The findings and new understanding about how these initiatives fit into the overall diversity initiatives on their respective campus can have broader implications for innovative institutions. The need for diversity and inclusion to move from an idea to common practice is not a passing trend or current hot topic. The need to cultivate more inclusive environments is a matter that is heavily influenced by the realities of the national K-12 pipeline. The number of historically underserved, underprepared, and underrepresented high school graduates is increasing at rates that cannot be ignored when considering access and success plans for students. These historically White institutions will have to keep pace with what is necessary to serve the demographic character of the new college-bound student population. In the past noncompleters all looked the same, but moving forward, institutional failures to meet the academic and social needs of students will be visible in a different way. Institutional leaders are focused on how they define and carry out a campus diversity initiative to promote what was historically an isolated population that did not fare well in the environment. Their programmatic efforts to retain students through graduation and the policies in place that have some related effect on or that directly govern the practices and decisions to increase Black male student retention will have to be examined. If they do not exist, they will have to be created, because the students are coming. A better understanding of how to be successful with this population is necessary and can help with subsequent populations that have high attrition rates as well. 
Policy Implications. Policy is a driver of institutional change. When working to build diversity initiatives as a central component of strategic planning, the policies that are approved and followed largely influence how well diversity is institutionalized. Leaders move from espousing the idea of diversity to actually making it a part of the institutions' identity and practices. The suggested policy implications identified from this study primarily come from the administrative data; from the decision-making processes that were made during the development of both retention initiatives and the maturation of the campus diversity initiative.

Policy reviews are necessary when implementing new initiatives into a diversity agenda. The institutional definition of diversity and inclusion needs to be clearly articulated and widely shared among the university community and with stakeholders. A thorough review of any language that could be interpreted as incendiary or vague must be removed from formal policy and replaced with clear and detailed definitions of what the institution believes when they speak about inclusion and diversity. This task in developing policy is even more pressing with the increase of the anti-affirmative action movement that is challenging the constitutionality of programs designed to promote diversity and inclusion. Crafting the language used when starting programs that are gender or ethnic specific can be tedious and need to be cross-referenced with the governing laws that regulate the constitutionality of program and services offered by institutions of higher education. Legal counsel must be versed on the latest case law and court decisions that could potentially challenge any program, service, or scholarship that is created to advance the diversity initiative.

The importance of retention, access, and success needs to be a part of the mission and the institution's strategic plan. The plan also needs to include and delineate the importance of the other components of climate and intercultural relations, scholarship and curriculum, and the 
strength of diversity as foundational to the mission of the institution. Who the institution defines as populations that may be recognized under the factors of access, retention, and success is critical. Once the populations are identified in the written policy, action can be taken in a strategic plan to move forward to achieve the goals for the identified population with a solid foundation to guide the process.

How the institution decides to tackle the climate issues and plans to increase the interactional diversity activity on campus needs to be stated explicitly in the diversity plan. How the campus intends to increase diversity in scholarship and curriculum also needs to be clearly stated. There have to be measureable objectives or benchmarks included and given to departments to reach with periodic checkpoints within the plan provided to departments, specifically identifying the leadership within departments who will be in charge of carrying out the responsibilities. Consequences or costs for not achieving benchmarks need to be clearly stated in the policy. A board or council should be formed to provide oversight to the written policies that govern how the institution carries out its diversity agenda. The institution as a whole must know that diversity and inclusion are not just ideals, but concepts that are active and tangible. Divisions and departments that are resistant to change are more likely to honor structures in place as defined in policy than espoused ideals of leaders who are incorporating something that might be viewed as peripheral — versus essential to the foundation of the institution's livelihood and successful functioning. The processes to review those departments or offices that fall short of achieving benchmarks need to be included. All departments must report their activity on diversity measures including:

1. Nondiscriminatory recruitment and hiring of faculty and staff 
2. Actions they have taken to directly address the climate issues in their department and in the classroom

3. How they have engaged students of interest under the diversity plan and have addressed their needs

4. Their retention efforts for students, faculty, and staff

5. Their training and programming efforts to increase awareness and cultural competency (staff and student development)

It is important for leaders to clearly articulate their decisions about how funding, staffing, and other resources are managed for those populations that benefit directly from improved access and retention. Policy surrounding how decisions are made when advancing the diversity initiative needs to be data driven. At both institutions in this study, specifically at Southern State University, the development of the retention initiative was made possible and gained creditability due to leaders highlighting that Black male students had the lowest graduation rates. They used the numbers, and this was the argument that was communicated in writing as they were mobilizing the initiative. Leadership must know their numbers, and update policies and procedures based on the latest statistics of the student populations that are not matriculating successfully.

There should also be a regular review of the policies that govern the decision-making processes for funding recruitment and retention programs for diversity initiatives. The leadership of the institution must clearly articulate the diversity plan components and hold accountable all departments, faculty, and administrators who bear the responsibility or carrying out the objectives for each component of the campus diversity initiative. 
How these recruitment and retention programs are funded is a major policy decision. Hard money has to be identified and allocated to initiate the programs. Unlike the Woodson Center who initiated their work on faith, there must be visible line-item dollars dedicated to the work. Regularly reviewing the processes and policies governing the allocation of funds to student organizations is important. Leaders should review the process for fairness and nondiscrimination. The process for approving student organization funding for programs needs to be aligned with the institution's diversity statement and used as a vehicle to create experiences that promote positive climate and intergroup relations.

Implications for Practice in Higher Education. There are several suggested practices I have selected that may be executed across higher education that can enhance initiatives similar to BMX and the Woodson Center, as well as practices to consider when implementing a campus diversity initiative. Some implications are based on the actual practices shared by administrators in the two cases. Others are potential enhancements that participants identified as practices they believe would improve their respective initiatives. I derived additional suggestions from the data analysis from student responses in each case study, from the comparison of the successes and challenges of two cases program, and from the evolution of the overall campus diversity initiatives at Northwestern State and Southern State Universities.

Engaging alumni. University leaders charged with retention initiatives like BMX and The Woodson Center should focus on engaging alumni and keeping them connected directly to the program. As the pool of former program students increases, it is good practice to find a way to keep them engaged as now successful graduates who can donate many forms of capital back to the program. Organizations should send out information to them periodically to let them know about the current undergraduate students and share celebrations of individual student success 
with them. Engaging them to come back for networking programs and to be guest speakers or panelists is likely to be a good practice as well. Having them discuss their professions and help current students figure out the next steps after graduation, exposing them to multiple options adds value both to the student experience and the alumni-institutional relationship. Organizations should consider engaging alumni by requesting them to become formal mentors to current undergraduates. Providing opportunities for alumni to speak about their past and how the peer and mentor relationships that mattered to their success continue after graduation further reinforces the value of the program.

Administrators should connect regularly with the institution's alumni affairs for funding assistance from identified potential donors. Media and marketing materials that tell the story of the program and highlight alumni successes should be created with top quality and in the hands of development officers. As an institution grows its campus diversity initiative, supporters and allies to the program and to the mission of these retention efforts will surface. This is a strategic way to stay connected with those recent graduates who attended the institution when diversity was valued and incorporated in the mission. It is important for leaders to tell their own story and also allow development to share the story to graduates who can be cheerleaders for it and support it monetarily to help with the institutionalization process.

Instituting a chief diversity officer. Campus diversity initiatives need time, effort, and resources invested to help secure their longevity and success. One chief factor that made the difference between where each case was in their institutionalization process was the presence of a Chief Diversity Officer. Having a diversity officer is necessary when carrying out a comprehensive campus diversity initiative. The Woodson Center had a person solely focused on moving the campus diversity initiative forward, who had power, authority, and influence with 
other senior leaders. He was seen as an equal on the president's cabinet. Because of his specific focus on Black male retention, the program received a lion's share of the attention. Diversity as a whole must be promoted and indoctrinated into the institutional culture; it cannot be just one program in isolation.

Internal connection of diversity programs and services. Even with a chief diversity officer in position at Southern State University, I noted that administrators at both institutions lacked a strong understanding of other diversity efforts on campus, with Northwestern State administrators the more unknowledgeable of the two. This shows a lack of connection between diversity offices and services. There needs to be more communication among those who are leading or are a part of diversity initiatives at higher education institutions; better on-campus publicity and visibility of what the institution is doing is needed when promoting diversity as a campus-wide initiative. To rectify a lack of connection, regular meetings are necessary, or additional mechanisms to report what these campus diversity initiatives are doing. Whether an unit is charged with advancing access and success, improving climate and intergroup communication and relationships, developing culturally comprehensive curricula and scholarship, or are involved with shaping the mission and external appearance of the institution to constituents, progress needs to be regularly shared with the entire institution. There must be a consistent answer to the question: What are we doing to advance our diversity initiative?

These programs specific for Black male retention as well as other diversity programs need to be seen as a unified part of the institution early on in the mobilization process. Any way administrators and institutional communication and media offices can incorporate the institutional logo, mascot, maxims, traditions, and mission into the initiatives, the more culturally suitable the initiative will appear to be within the university activity. Institutions need to include 
the programs like the Black male retention programs and others in their recruitment materials that are sent to potential students. Administrators need to give the retention programs visibility to high school administrators, parents, and potential students who are considering the institution; they must also bolster the connection of conventional campus offices (for example, Admission) with the campus diversity initiative.

Faculty development and expectations. The component of faculty development and recruitment is critical to the diversity initiative and needs to be a priority. Faculty's contribution to the advancement of the diversity initiative must occur on two levels: classroom teaching style and proficiency, and personal cultural awareness and development. Institutions need to consider creating faculty development offices that work with faculty to assist them in their course management, to be more engaging and inclusive in their teaching, and with practices to help in reducing student isolation and disengagement. Faculty needs training on creating classrooms where teaching, management styles, and course materials reflect an inclusive curriculum, one where a diversity of ideas and concepts is considered within their disciplines.

Student success is largely dependent on classroom success. Given that reality, institutions should provide training to faculty across their roles - teaching, research, and service. The second important part to improving the contribution of faculty members to the diversity initiative and to the retention of Black male students is for them to improve their own awareness of personal biases, privileges, and acts of oppression. A focus on developing awareness, as well as understanding how compassion and understanding can lead to increasing their ability to support as allies, can create the informal interactional diversity and the classroom diversity needed for the initiative to succeed. 
There must be a clear directive from deans, provosts, department chairs and other academic affairs leaders to recruit, hire, and retain quality faculty of color. Students in this study consistently reported relating to faculty who had similar cultural backgrounds as them. The importance of classroom connections with faculty is increased when there is common ground as opposed to fear and an uncertainty about how to connect. A greater sense of community among faculty and students is possible.

Conducting regular climate surveys. Leaders at institutions need to review how faculty impacts the overall campus climate. Climate surveys should include questions about faculty interactions with students. Students need a place to express to leaders how their faculty is faring when it comes to engaging them. There needs to be an assessment tool used by those in charge to advance the campus diversity, where data can be disaggregated by college and department. Experts in assessment need to create a climate survey schedule with unidentified submissions, where faculty, staff, administrators, and students are all able to periodically share their experiences at the institution and have those results inform the actions, the resource allocation, and the level of focus and priority.

Engaging Black male graduate students. There are ways to improve recruitment and the integration of Black men, as well as other students of color into institutions of higher education. Leaders should try to engage graduate students (administrators in both cases recognized that they are not focused on graduate students enough). Leaders can come up with writing workshops and research workshops to help them matriculate through their programs. Graduate school can be more isolating and emotionally daunting for students of color, specifically Black males because of the small numbers. Leaders should come up with fellowship opportunities and ways for them to connect regularly with others who are in different graduate school programs. Supporting the 
creation of safe community spaces would help their retention. Leaders can include or develop formal mentoring as a part of these programs. Mentoring and role modeling played a large role in the students in the study. Seeing other Black male graduate students and the opportunity to have open frank discussions with them helps teach lessons that graduate students can apply immediately to help them adjust to their programs. Some students mentioned improving the program by providing scholarship dollars to students. Many students in this study had financial stresses and mentioned the need to get more help with paying for college; financial reasons played a role in their Black male peers leaving prior to graduation.

Replicating retention programs on regional campuses. Programmatically, replication of the initiative on regional or satellite campuses (if they exist) to reach all Black males associated with the institution would be a plus. The institution should invest in finding staff (depending on the distance between campuses and population numbers) to operate and connect the initiative at various sites. Administrators at both institutions in this study stated they needed to do more at those campuses and were making plans or strategizing how they can make a change happen across the regional campuses. A formal early intervention or orientation program could prove to be a beneficial practice to get the students connected and engaged with the Black male retention initiative. Such a program would allow students to move in early, tour the campus, network with each other, meet and connect with university resources (tutoring, career services, counseling, etc.), and get an early start on getting comfortable in their new community and environment. Moreover, to help student engagement across all institutional divisions, it would be a good idea to create a student success board or committee of representatives from important offices that need to communicate regularly about the high-risk attrition populations (like Black males). The committee should represent those whom Swail, Redd, and Perna (2003) identified as the 
institutional factors in their model for persistence. This includes representatives from financial aid, scholarship office, student organizations/activities, study abroad, civic engagement, service learning, counseling center, career services, tutoring, and advising, as well as alumni affairs.

Engaging K-12 schools. Finally, engagement should start earlier in the college decisionmaking process, and administrators should engage with the K-12 system as early as possible. Early intervention to students about the idea of college can help increase the likelihood that first generation students of color would consider college as an option after high school. Using the current undergraduate students as role models for the high school students in the surrounding campus high school district begins the role modeling and mentoring early. Future Black male students need to physically see others like themselves pursuing college to help them visualize themselves in the same situation. There must be some organized outreach from college to high school that includes college campus visits, where the program connects to the middle schools and high schools, providing the information and motivation to move forward and apply to college.

Choosing the right staff members. The administrators heading these retention initiatives for Black males have a very important role in the overall success. They have to be able to communicate with students well enough for the students to gain their trust and to have them believe in them as a part of their support system. Administrators also need to be able to role model professionalism, and to practice it at a high level with colleagues. It is important for them to learn effective ways of representing their dominant identities, as Black men, when discussing diversity and inclusion, when the conversation at these institutions around diversity is evolving beyond race and ethnicity and gender. There are certain characteristics necessary to fulfill the job of leading these retention initiatives and mentoring Black male students, based on the reaction 
and connection that the students made with male staff and the high level of student engagement and positive reaction to the administrators as role models. Institutions need someone who understands university contexts and politics to help administer the program and maintain it, as well as having someone students believe to be authentic.

Improve assessment knowledge and practice. These professionals not only have to relate to students and understand the politics and campus dynamics surrounding diversity and inclusion initiatives, but they also have to be versed in assessment practices as well. In order to assess, there has to be a concerted effort to measure student cohort learning. Institutional assessment offices should guide the evaluation process of these initiatives. The experts on campus charged with managing the assessment of programs can provide the strategic vision and steps needed to identify the student learning outcomes that are most salient to the development of the student participants. Administrators need to identify program components that can serve as an entry point and formalize student cohorts that will allow them to trace retention trends and student learning. Well developed assessment skills are important to advancing the program and proving its effectiveness. Institutions should provide assessment training for administrators over retention programs, so that formal assessment can be made on the programs and workshops to see what students are learning and how the initiative is helping to advance the institutional mission and facilitating the academic goals and learning objectives.

Implications for Future Research. I developed several more questions about retention during this study. Some are related to sub-populations of Black males and their interaction and engagement with the program. Due to the low number of commuter students represented in this study, and based on their responses to questions specifically related to the retention initiative, further research should be conducted to explore how these Black male retention initiatives affect 
the success and development of commuter students. The few commuter students at both case institutions struggled with engaging with the program, but recognized the value in staying involved as best they could, given their schedules. Another sub-population of Black males that should be considered is Black male transfer students. In addition to these sub-populations whose identities are about geography and movement, the sexual orientation sub-population is one of research interest as well. The Black gay student is one that raised conflicting information in this study. I realized with just the one student participant, Vincent, in the Northwestern State case, that the intersection of class, race, gender, and sexual orientation is one that needs further examination, especially when studying their adjustment to college with multiple identities impacting their persistence and performance.

One of the most identified sub-population of Black males mentioned several times by both administrators and students was Black male athletes. They have a higher graduation rate than non-student athlete Black males, but still have lower graduation rates than white male student-athlete counterparts. Studying how Black male athletes, specifically on revenue-driven college teams, engage not only the specific programs designed to increase Black male retention, but any type of retention services offered to them would help institutions understand the best way to engage them and to serve them. Also, research exploring the significance in the academic success and graduation rates of Black male student athletes, who participate in retention initiatives compared to those who do not, would be a great addition to validate the effectiveness of these programs. Overall, any sub-population would be a smaller number within the student population, but each has different cognitive and social factors to consider when examining their experiences at predominantly White institutions. 
Two other interesting populations to study in relation to retention initiatives and the effect on students are Black male alumni and Black female students. A longitudinal study on Black male alumni who participated in the program, specifically looking at their community engagement and their current engagement with the program as successful graduates would be of value to see the longstanding influence of participation. What other long-term effects does participation in a gender and ethnic specific retention program have on Black male alumni? A measure of their self-efficacy, professional/career outcomes, and their likelihood to give of their time, talent, and treasure to their institutions would be worth studying.

Since both cases in this study mentioned the challenge presented to administrators about Black female students and their needs for services to increase their retention, studying their experience at predominantly White institutions could lead to ways to effectively intervene. Specifically, determining which factors affect their persistence to graduation would help practitioners in designing programs and services to meet their needs. There are other retention initiatives that exist on PWIs for other historically underserved student populations to which researchers could apply the same inquiries like Latinos, Asian and Pacific Islanders, and Native Americans.

Future research should consider the study of faculty perceptions of Black student academic preparedness. There is something that influences faculty perceptions and biases. In this study, there was perceived cultural dissonance between the Black male students and faculty that made them question building relationships with faculty. Looking at how faculty biases are manifested can help practitioners to identify potential interventions to shift those biases. A study of how White faculty shift their perceptions and behaviors based on diversity trainings would help illuminate the level of significance participation in these types of trainings can have on 
faculty and their interaction with Black male students and other historically underserved students.

A major discussion point with both case institutions was institutional context. Similar studies should be conducted at different types of institutions of higher education that have institutionally driven Black male retention programs. Liberal arts colleges have a different context compared to state universities. Another type of institution where this study can be replicated with significance is at the community college level. Black male enrollment is high at these two-year institutions and successful completion of a two-year degree can serve as a bridge to other higher education opportunities. Like four-year institutions, some two-year institutions have invested in retention initiatives for Black males that should be studied.

Finally, a study on the implementation of the campus diversity initiatives could be a wellfounded study that could take on several questions. Focusing on development through the institutionalization process can help other leaders understand how to properly develop initiatives because of a better understanding of the core processes. Research can explore how effective institutional leaders are in promotion of key diversity and inclusion components of mission, scholarship, climate, and access and success for students.

\section{Conclusion}

I began this study asking how Black male retention initiatives affect campus diversity initiatives and promote student development and success. This exploration started with a basic assumption that there would be a positive impact on the institution and on student participants. Although there were important distinctions between the institutions and programs, as well as distinctions among students and their experiences, I have found it to be the case that 
Northeastern State University, Southern State University, and their Black male students were positively impacted by their respective Black male retention programs. The Black male retention initiatives have contributed to the increased retention rates of Black males at each institution. Each institution's diversity initiative considered the retention program as a part of their access and success component; one program, the Woodson Center, has played a more central role in the campus diversity initiative. I believe one of the most important factors in this study is that each case represents an institutionally driven initiative. This characteristic is critical to the success of these programs getting mobilized and fully implemented. The final steps of becoming an institutionalized program that has longevity and is seen as a major program takes more than just a focus on Black male retention; to increase the likelihood of becoming institutionalized is to present a larger contribution to the institutional mission like the Woodson Center. The cases demonstrate the evolution of diversity initiatives and the changes in the discussion as an institution matures in their diversity initiative. The direction a diversity initiative takes depends on leadership. When leadership considers Black male retention important, it logically falls in line as a part of the institutional access and success mission, and student experiences become visible to the administrators who have the power to make decisions and change the university climate and community for the better.

The Black male retention initiatives at each institution played a central role to student success and development. Even though the philosophy underlying administrative approaches to student engagement differed between the two cases, the use of role modeling and leadership development opportunities was present in both programs. The initiatives were a safe place for the Black men to discuss their issues on campus, to network and connect to other Black men. The students' level of isolation decreased as their confidence and self-efficacy increased. They 
matured into Black men with a solid identity and understanding of the complex dynamics of being both Black and male in the United States. Both programs provided a way for them to grow and develop on campus, which may have been reflected in the retention rates at both institutions, but was certainly evident in each student account of their college experience. Students attributed their successes to these programs. 


\section{References}

Allen, W.R. (1992). The color of success: African-American college student outcomes at predominantly white and historically black public colleges and universities. Harvard Educational Review, 62(1), 26-44.

Allport, G. (1954). The Nature of Prejudice. Cambridge: Addison-Wesley.

Antonio, A.L. (2001). The role of interracial interaction in the development of leadership skills and cultural knowledge and understanding. Research in Higher Education, 42 (5), 593617.

Association of American Colleges and Universities. (2007). College Learning for the New Global Century. Washington, DC: Association of American Colleges and Universities.

Astin, A. (1993). What matters in college? Four critical years revisited. San Francisco: Jossey Bass.

Bean, J.P. \& Eaton S.B. (2000). A psychological model of college student retention. In J.M. Braxton (Ed.) Reworking the Student Departure Puzzle. (pp.48-61). Nashville: Vanderbilt University Press

Beilke, J.R., \& Yssel, N. (1999). The chilly climate for students with disabilities in higher education. College Student Journal, 33(3), 364-372.

Bloomberg, L.D. \& Volpe M. (2008). Completing your qualitative dissertation: A roadmap from beginning to end. Thousand Oaks, CA: Sage Publications.

Braxton, J.M., Brier, E.M. (1989). Melding organizational and interactional theories of student attrition: A path analytic study. Review of Higher Education, 3(1), 47-61. 
Braxton, J.M., Brier, E.M., Steele S. L. (2008). Shaping retention from research to practice. Journal of College Student Retention Research, Theory, \& Practice, 9(3), 377-399.

Braxton, J.M., Hirschy, A.S., McClendon, S.A. (2004). Understanding and reducing college student departure. ASHE Higher Education Report, 30(3).

Braxton, J.M., Sullivan, A.S., Johnson, R. (1997). Appraising Tinto's theory of college student departure. In J. Smart (Ed.) Higher Education: Handbook of Theory and Research (Vol. 12). pp. 107-164. New York: Agathon.

Cabrera, A.F. \& La Nasa, S.M. (2000). Understanding the college choice of disadvantaged students. In A.F. Carera \& S.M. LaNasa (Eds.), New Directions for Institutional Research, Vol. 27. (pp.5-22). San Francisco: Jossey-Bass.

Chang, M. (1996). Racial diversity in higher education: Does a racially mixed student population affect educational outcomes? (Doctoral dissertation). Retrieved from Proquest Dissertations and Theses. University of California, Los Angeles

Chang, M. (2002). The impact of an undergraduate diversity course requirement on students' racial views and attitudes. The Journal of General Education. 51(1), 21-42.

Chickering, A. \& Gamson, Z.L. (1987). Seven principals for good practice of undergraduate education. AAHE Bulletin, 39(7), 3-7.

Cross, W.E. (1995). The psychology of nigrescence: Revisiting the cross model. In J.G. Ponterotto, J. Manuel Casas, L.A. Suzuki, \& C.M. Alexander (Eds.) Handbook of Multicultural Counseling. (pp. 93-122). Thousand Oaks, CA: Sage. 
Curry, B. (1992). Instituting enduring innovations: Achieving continuity of change in higher education. ASHE-ERIC Higher Education Report, (7). Washington D.C.: George Washington University Press.

Cuyjet, M. J. (Ed.). (1997). Helping African American men succeed in college: New directions for student services. San Francisco: Jossey-Bass.

Cuyjet, M. J. (Ed.). (2006). African American men in college. San Francisco: Jossey-Bass.

Davis, M., Dias-Bowie, Y., Klukken, G., Pollio, H.R., Thomas, S. P., \& Thomspon, C.L. (2004). "A fly in the buttermilk": Descriptions of university life by successful black undergraduate students at a predominantly white southeastern university. Journal of Higher Education. 75(4), 420-445.

Eckel, P. \& Kezar, A. (2003). Taking the reins: Institutional transformation in higher education, Westport, CT: Praeger Publishers.

Edgert, P. (1994). Assessing campus climate: Implications for diversity. New Directions for Institutional Research. 81(1), 51-62.

Erikson, E.H. (1950). Childhood and Society. New York: W. W. Norton \& Company.

Feagin, J.R., Vera, H., \& Imani, N. (1996). The agony of education: Black students at white colleges and universities. New York: Routledge.

Fischer, M.J. (2007). Settling into campus life: Differences by race/ethnicity in college involvement and outcomes. The Journal of Higher Education. 78(2), 125-161.

Fleming, J. (1984). Blacks in college. San Francisco: Jossey-Bass. 
Freire, P. (1993). Pedagogy of the oppressed. New York: Continuum Publishing.

Fries-Britt, S.L. \& Turner, B. (2001). Facing stereotypes: A case study of Black students on a White campus. The Journal of College Student Development. 42 (5), 420-429.

Fortson, S.B. (1997). An evaluation of a program to influence academic self-concept among African American male college students. Journal of Employment Counseling, 34(3), 104 107.

Garibali, A.M. (2007). The educational status of African American males in the 21st century. The Journal of Negro Education. 76(3), 324-333.

Guffrida, D.A. (2006). Toward a cultural advancement of Tinto's theory. The Review of Higher Education, 29(4), 451-472.

Gurin, P., Dey E.L., Hurtado, S., \& Gurin, G. (2002). Diversity and higher education: Theory and impact on educational outcomes. Harvard Educational Review. 72 (3), 330-366.

Hall, R.M. \& Sandler B.R. (1982). The campus climate: A chilly one for women. Washington, DC: Association of American Colleges \& Universities.

Harper, S.R. (2006). Peer support for African American male college achievement: Beyond internalized racism and the burden of "Acting White." Journal of Men's Studies. 14(3), $337-358$.

Harper, S.R. (2007). Black male students at public flagship universities in the US: Status, trends, and implications for policy and practice. Washington DC. Joint Center for Political and Economic Studies Health Policy Institute. 
Harris, S.M. (1991). Evaluating university programming for ethnic minority students. In H.E. Cheatham, Pluralism on Campus. (pp. 183-202). Alexandria, VA: American College Personnel Association.

Helms, J. (1990). Black and white racial identities: Theory, research, and practice. Westport, CT: Greenwood Press.

Horn, L.J. (1998). Confronting the odds: Students at risk and the pipeline to higher education. (NCES Report No. 98-094). Washington, DC: US Department of Education.

Hossler, D., Braxton, J., \& Coopersmith, G. (1989). Understanding student college choice. In J.C. Smart (Ed.), Higher education: Handbook of theory and research: Vol.5. (pp. 231288). New York: Agathon Press.

Hossler, D., Schmit, J., \&Vesper, N. (1999). Going to college: How social, economic, and educational factors influence decisions students make. Baltimore: The Johns Hopkins University Press.

Hrabowski, F., Maton, K. \& Greif, G. (1998). Beating the odds: Raising academically successful African American males. New York: Oxford University Press.

Hurtado, S. (1992). The campus racial climate: Context and conflict. The Journal of Higher Education, 63(5), 539-569.

Hurtado, S. (1999). Reaffirming educators' judgment: Educational value of diversity. Liberal Education, 85(2), 24-32

Hurtado, S., Milem, J., Clayton-Pedersen, A., \& Allen, W. (1999). Enacting diverse learning environments: Improving the climate for racial/ethnic diversity in higher education. 
ASHE-ERIC Higher Education Report, 26(8). Washington, DC: George Washington University Press.

Jones, L. (Ed.). (2001). Retaining African Americans in higher education: Challenging paradigms for retaining students, faculty, and administrators. Sterling, VA: Stylus.

Kelly, B.T. (2003). Focus groups. In K. Manning \& F.K. Stage (Eds.) Research in the college context: Approaches and methods. (pp.49-62). New York: Brunner-Routledge.

Kezar, A. (2007). Tools for a time and place: Phased leadership strategies to institutionalize a diversity agenda. The Review of Higher Education, 30(4), 413-439.

Kim, D. (2004). The effect of financial aid on students' college choice: Differences by race. Research in Higher Education, 45(1), 43-70.

Kinzie, J., Gonyea, R., Shoup, R. \& Kuh, G. (2008). Promoting Persistence and Success of Underrepresented Students: Lessons for teaching and learning. New Directions for Teaching and Learning, 115, 21-38. DOI: 10.1009/t1.323

Kinzie, J, Umbach, P.D., Thomas, A.D, Kuh, G., \& Palmer, M.M. (2007). Women students at coeducational and Women's Colleges: How do their experiences compare? Journal of College Student Development, 48(2), 145-165.

Kuh, G.D. (1993). In their own words: What students learn outside the classroom. American Education Research Journal. 35(2), 24-32.

Kuh, G.D. (2003). What we're learning about student engagement from NSSE: Benchmarks for effective educational practices. Change. 35(2), 24-32. 
Kuh, G.D. (2007, June 15). How to help students achieve. Chronicle of Higher Education. ERIC Document Reproduction Service No. EJ771702.

Kuh, G. D., Cruce, T., Shoup, R., Kinzie, J., \& Gonyea, R. M. (2007, April). Unmasking the effects of student engagement on college grades and persistence. Paper presented at the annual meeting of the American Educational Research Association, Chicago, IL. Retrieved from http://nsse.iub.edu/uploads/AERA_2007_Kuh_et_al.pdf

Kuh, G.D., \& Hu, S. (2001). The effects of student-faculty interaction in the 1990s. Review of Higher Education, 24(3), 309-332. doi: 10.1353/rhe.2001.0005

Kuh, G.D., Kinzie, J., Buckley, J.A., Bridges, B.K., Hayek, J.C. (2007). Piecing together the student success puzzle: Research, propositions, and recommendations. ASHE Higher Education Report, 32(5). San Francisco: Jossey-Bass.

Lagdameo, A., Lee, S., Nguyen, B., Liang, C., Lee, S., Kodama, ...McEwen, M.K. (2002). Voices of Asian American Students. New Directions for Student Services, Vol. 97.

Lee, W.Y. (1999). Striving toward effective retention: the effect of race on mentoring African American students. Peabody Journal of Education, 74(2), 27-43.

Lett, D. F. \& Wright, J.V. (2003). Psychological barriers associated with matriculation of African American students in predominantly White institutions. Journal of Instructional Psychology, 30(3), 189-196.

Levine, A. (1980). Why Innovation Fails. Albany: State Press.

Loo, C.M. \& Rolison, G. (1986). Alienation of ethnic minority students at a predominantly white university. Journal of Higher Education, 57(1), 58-77. 
Majors, R. \& Mancini Billson, J. (1992). Cool pose: The dilemma of Black manhood in America. New York: Touchstone.

Manning, K. \& Stage, F.K. (Eds). (2003). Research in the college context: Approaches and methods. New York: Brunner-Routledge.

Maton, K.I., Hrabowski, F.A., Ozdemir, M., \& Wimms, H. (2008). Enhancing representation, retention, and achievement of minority students in higher education: A social transformational theory of change. In M. Shinn \& H. Yoshikaw (Eds). Toward positive youth development: Transforming school and community programs. (pp. 115-132). New York: Oxford University Press.

Murdock, T. A. (1990). Financial aid and persistence: An integrative review of the literature. NASPA Journal, 27(3), 213-221.

Musil, C.M., Garcia, M., Hudgins, C.A., Nettles, M.T., Sedlacek, W.E., \& Smith, D.G. (1999). To form a more perfect union: Campus diversity initiatives. Washington DC: Association of American Colleges and Universities.

National Center for Educational Statistics. (2007). Status and Trends in the education of Racial and Ethnic Minorities (NCES 2007-039). Washington DC: U.S. Department of Education. Retrieved from http://nces.ed.gov/pubsearch/pubsinfo.asp?pubid=2007039

Neumann, A. (2009). Professing To Learn Creating Tenured Lives and Careers in the American Research University. Baltimore: Johns Hopkins University Press.

Pascarella, E.T. \& Terenzini, P.T. (1979). Interactional effects in Spady's and Tinto's models of drop outs. Sociology of Education. 52(4), 197-210. 
Patton, L.D., Morelon, C., Whitehead, D.M., Hossler, D. (2006). Campus-based retention initiatives: Does the emperor have clothes? New Directions for Institutional Research, $130(1), 9-24$.

Patton, M.Q. (2002). Qualitative research and evaluation methods (3rd ed.). Thousand Oaks, CA: Sage.

Perna, L.W. (1998). The contribution of financial aid to student persistence. Journal of Student Financial Aid, 28(3), 25-40.

Perna, L.W. (2000). Differences in the decision to attend college among African Americans, Hispanics, and Whites. Journal of Higher Education, 71(2), 117-141.

Piaget, J. (1971). Biology and knowledge. Edinburgh: Edinburgh University Press.

Rankin, S. R. \& Reason, R.D. (2005). Differing Perceptions: How students of color and white students perceive campus climate for underrepresented groups. Journal of College Student Development, 46(1), 43-61.

Rendón, L.I., Jalomo Jr., R., \& Nora, A. (2000). Theoretical considerations in the study of minority student retention in higher education. In J.M. Braxton (Ed.), Reworking the student departure puzzle. (pp. 127-156). Nashville: Vanderbilt University Press.

Rodgers, K.A. \& Summers, J.J. (2008). African American students at predominantly white institutions: A motivational and self-systems approach to understanding retention. Education Psychological Review, 20(2), 171-190.

Sedlacek, W.E. (1987). Black students on White campuses: Twenty years of research. Journal of College Student Personnel, 28(6), 484-495. 
Sen, R. (2006). A positive future for Black boys: Building the movement. Cambridge, MA. Schott Foundation for Public Education.

Smith, D.G. (1995). Organizational implications of diversity in higher education. In M.M Chemer, S. Oskamp, \& M.A. Costanzo (Eds.), Diversity in organizations: New perspectives for a changing workplace. (pp. 220-244). Thousand Oaks: Sage Publications.

Smith, D.G. (1997). How diversity influences learning. Liberal Education, 83(2), 42. Retrieved from EBSCOhost, March 21, 2011.

Smith, D.G., Garcia, M., Hudgins, C.A., Musil, C.M., Nettles, M.T., Sedlacek, W.T. (2000). Assessing campus diversity initiatives; A guide for campus practitioners. Washington DC: Association of American Colleges \& Universities.

Smith, D.G. \& Schonfeld, N.B.(2000). The benefits of diversity: What the research tells us. About Campus. 5(5), 16-24.

Smith, D.G. \& Wolf-Wendle, L.E. (2005). The challenge of diversity: Involvement or alienation in the academy? ASHE Higher Education Report (31)1. San Francisco: Jossey-Bass.

Srivastava, P. \& Hopewood N. (2009). A practical iterative framework for qualitative data analysis. International Journal of Qualitative Method, 8(1), 76-84.

Stake, R. (2000). Case studies. In Y.S. Lincoln \& N.K. Denzin (Eds.) Handbook of qualitative research 2nd (ed.). pp. 435-454. Thousand Oaks, CA: Sage.

Steele, C.M. (1997). A threat in the air: How stereotypes shape intellectual identity and performance. American Psychologist. 52(6), 613-629. 
Strayhorn, T.L. \& Terrell, M.C. (2007). Mentoring and satisfaction with college for Black students. The Negro Educational Review, 58(1-2), 69-83.

Strayhorn, T.L. (2008). The role of supportive relationships in facilitating African American males' success in college. NASPA Journal, 49(1), 26-48.

Suarez-Balcazar, Y., Orellana-Damacela, L., Portillo, N., Rowan, J.M., Andrews-Guillen, C. (2003). Experiences of differential treatment among college students of color. The Journal of Higher Education, 74(4), 428-444.

Suskie, L. (2004). Assessing Student Learning: A Common Sense Guide. Bolton, MA: Anker Publishing Company, Inc.

Swail, W.A, Redd, K.E., \& Perna, L.W. (2003). Retaining minority students in higher education:

A framework for success. ASHE-ERIC Higher Education Report 30(2). San Francisco: Jossey-Bass.

Tan, D. (1994). Uniqueness of the Asian-American experience in higher education. College Student Journal, 28(4), 412-421.

Taylor, J.D. \& Miller, T.K. (2002). Necessary components for evaluating minority retention programs. NASPA Journal, 39(3), 266-283.

Terenzini, P.T., Cabrera, A. F.,Colbeck, C.L.,Bjorklund, S.A.,\& Parente, J.M.(2001). Racial and ethnic diversity in the classroom: Does it promote student learning? Journal of Higher Education. 72(5), 509-531. 
Tinto, V. (1993). Leaving college: Rethinking the causes and cures of student attrition, ( $2^{\text {nd }}$ e.d.). Chicago: University of Chicago Press.

Torres, V. (2003). Student diversity and academic services. In G.L. Kramer \& Associates Student academic services: An integrated approach. (pp. 333-351). San Francisco: JosseyBass.

Wang, H. (2001). A systemic approach to assessing retention programs: Identifying critical points for meaningful interventions and validating outcomes assessment. Journal of College Student Retention: Research, Theory, \& Practice, 2(1), 59-68.

Williams, D. A. (2008). Beyond the diversity crisis model: Decentralized diversity planning and implementation. Planning for Higher Education, 36(2), 27-41.

Williams, D.A., Berger, J.B., \& McClendon S.A. (2005). Toward a model of inclusive excellence and change in postsecondary institutions. Washington, DC: Association of American Colleges and Universities.

Wilson, T.L.Y \& Banks, B. (1992). A perspective on the education of African American males. Journal of Instructional Psychology, 21(1), 97-100.

Yin, R.K. (2003). Case study research design and method (3rd ed.). Thousand Oaks, CA: Sage. 


\section{Appendix A}

\section{Letter to liaisons at participating institution for study}

(on WVU letterhead)

Date

Address

Dear__liaison's name)__:

Thank you for agreeing to serve as liaison for my dissertation research study at (name of institution). I greatly appreciate your assistance in conducting this study as part of my dissertation research on retention programs designed to examine the experience of African American males involved in retention programs at predominantly white institution. For the purpose of my study, I am defining retention programs as planned academic and student affairs activities, programs, and services provided by institutions. The overarching goal is to improve African American males' success in college. Services, programs, and activities I am writing to outline the specifics of my research on your campus and to clarify your participation.

I am planning to visit your campus on $<<$ DATE $>>$, and would like to conduct five to six student focus groups with African American Undergraduate males who ideally have been actively participating at a moderate to high level of engagement in the retention program services and events provided. The focus groups will last approximately 90 minutes and will host 4 to 6 individuals from the eligible participants you identify. For undergraduates you provide contact information for who meet the criteria and are unable to meet at a common time and participate in the scheduled focus group interviews, I would like to conduct separate individual interviews.

I would also like to conduct individual interviews with faculty, staff, and administrators who are available and identified as having a role in the development, execution, and evaluation of services and opportunities offered by your program. The individual interviews of undergraduate students and faculty, staff, and administrators will last approximately 75 minutes. I will also be analyzing relevant documents such as annual reports, evaluations, assessment data, and strategic plans that will enhance my understanding of the design and development of your retention program. I plan on visiting your campus to conduct the focus groups, interviews, and document analysis during $<<<$ Month of Visit $>>>$.

I want to emphasize that the results of this study will be used specifically for my dissertation, and that I will maintain confidentiality of data and preserve the anonymity of the focus group participants and interviewees at all times. With this letter, I am requesting that you supply me with a list of individuals you believe can contribute to my study from which I can solicit to schedule for focus group times and request individual appointments for interviews during my visit. Please use the enclosed nomination forms to list the identified individuals who meet the research student participant and faculty, staff, administrator criteria. To adhere to my research schedule, please provide this information by _(date)_. I will also need your assistance in obtaining relevant documents, which you may forward to me in advance or help me locate when I am on campus. 
I greatly appreciate the willingness of your institution to participate in my study, and am grateful that you have agreed to assist with the arrangements for my site research. I look forward to visiting your campus in $<<$ Month of Visit $>>>$.

Sincerely,

Gabrielle St. Léger

Doctoral Candidate

West Virginia University

(614) 425-7151

gstleger@gmail.com 


\section{Appendix B}

(on letterhead from case institution)

Date

Ms. Gabrielle St. Leger

149 Bryan Drive

Morgantown, WV 26508

Dear Gabrielle,

I approve of your doctoral dissertation research study at (name of institution). I am happy to assist you in contacting coordinators of the programs regarding your study, and recruitment of student participants for your interviews and focus groups. In addition, I will assist you in collecting documents pertinent to annual program reports, strategic plans, program evaluations, action plans, and other relevant documentation.

You may schedule interviews with myself, students, faculty, and other administrators included within the scope of your research study and schedule focus groups with student participants. I understand that interviews will last approximately 60 minutes, the focus groups approximately 90 minutes and that this collection of data will occur in the Spring 2010 semester.

We look forward to seeing you on campus soon.

Thank you,

Dr. XXXX

Title 


\section{Appendix C}

\section{Student Demographic Questionnaire}

Please PRINT clearly and fill out completely to the best of your knowledge. This questionnaire is solely to capture demographic information about the group participating in the study.

Please do NOT write your name on this questionnaire to keep your identity anonymous.

\section{Academic Information:}

Year in school: $\square$ Freshman $\square$ Sophomore $\quad \square$ Junior $\quad \square$ Senior

Major(s)

Minor(s)

Final High School GPA: /4.00scale or (other scale:

Current Undergraduate Cumulative GPA: /4.00 scale or (other scale:

High School Type (Please check ONE category):

$\square$ Public $\square$ Private $\square$ Other

Race/Ethnicity: (Please check ONE category)
African American
$\square$ Black
Biracial/Multiracial

Ethnicity (ies): Please specify if applicable

Sexual Orientation: (Please check one category)
$\square$ Heterosexual/Straight $\quad \square$ Gay
$\square$ Bisexual
$\square$ Questioning

\section{Background Information:}

Family Structure: (Please check one category)
$\square$ Two Parents
$\square$ Guardian (not a parent)
$\square$ Single Parent Household (mother)
$\square$ Single Parent Household (father)
$\square$ Other (Please Specify) 
PLEASE TURN OVER TO COMPLETE SECOND PAGE. THANK YOU.

Parental Education:

What is the highest level of education that your mother completed?

(Please check ONE category)

$\square$ Not Applicable

$\square$ Some High School $\quad \square$ High School Graduate $\quad \square$ Some College

$\square$ Associate's Degree $\quad \square$ Bachelor's Degree $\quad \square$ Master's Degree

$\square$ Doctoral Degree $\quad \square$ Professional Degree (J.D., Pharm.D, M.D.)

What is the highest level of education that your father completed?

(Please check ONE category)

$\square$ Not Applicable

$\square$ Some High School $\quad \square$ High School Graduate $\quad \square$ Some College

$\square$ Associate's Degree $\quad \square$ Bachelor's Degree $\quad \square$ Master's Degree

$\square$ Doctoral Degree $\quad \square$ Professional Degree (J.D., Pharm.D, M.D.)

Socioeconomic Background: (Please check the BEST category that fits your family's experience)
$\square$ Low Income
$\square$ Middle/Working Class
$\square$ Upper Middle Class
$\square$ Upper Class/Affluent

Future Career Aspiration(s): (Please specify)

$\square$ Unsure at this time

PLEASE MOVE ON TO PAGE 3 THANK YOU. 


\section{College Experience:}

Please list ALL the undergraduate organizations and activities you are involved in:

Club/Organization(s)

Leadership Positions Held (if any)

University Honors, Awards, and Achievements

Year it was received/awarded

What activities under the retention initiative have you been engaged with or participated in?

(For example: workshops, seminars, service projects, discussions, round tables, study groups, mentoring, advising, movie nights, book readings, intramural athletic events, etc.) 


\section{Appendix D}

\section{Student Focus Group Protocol Pilot Study}

Good Morning/Afternoon/Evening. I first want to thank you for volunteering to participate in this interview. I really appreciate the time you are taking in your schedule to help. My name is Gabrielle St. Leger and I will be asking you a few questions today about your participation with (said initiative) at (said institution). This interview will be part of the pilot study research collected to complete my dissertation at West Virginia University under the supervision of Dr. Elizabeth Jones. She can be reached at Elizabeth.Jones@mail.wvu.edu or via phone at 304-2931886.

The purpose of the study is to find out your experience with and participation in the retention initiative at (said university) that's created to help Black Males adjust and succeed at (said university).The group session is schedule to take no longer than 90 minutes. I will ask questions to the whole group and facilitate a discussion where all will be encouraged to provide information or feedback to each question. This session will be audio recorded in order for me to capture as much of our discussion today for later analysis and keep the flow of questions and conversation going throughout the discussion. Upon completion of the focus group, I will be soliciting your feedback on the clarity of questions and ask you to critique the cover letter. Do you have any questions for me at this point?

To reemphasize the information that is provided on your cover letter, please note that:

(1) You may leave the study at any time. If you decide to stop participating in the study, there will be no penalty to you, and you will not lose any benefits to which you are otherwise entitled. Your decision will not affect your future relationship with (said institution). I just ask that if you do, please leave as quietly as possible as to not disturb the group.

(2) You will be given a pseudonym for your name in any written documentation that is shared in order to protect your identity and to keep a high level of confidentiality. Information shared in the interview will not be able to be connected to you specifically in any. Every effort will be made to keep your personal information collected during the study confidential. However, there may be circumstances where this information must be released. For example, personal information regarding your participation in this study may be disclosed if required by state law. I can promise that I will keep your information confidential, but I cannot promise that the other participants in the focus group will. All transcriptions of the interview, audio recordings, and other data collected will be destroyed via shredding and permanently deleted from all password protected computer files once requirements for research and the dissertation is completed.

(3) Before we begin the discussion, I am asking all participants to complete a Participant Profile questionnaire which asks for specific and personal background information that will help me later on when I am reviewing our taped discussion. Please fill out the form as completely as possible. This information will be solely used for documenting the characteristics of you as a participant in the study. Please do not put your name on the form. This information will be kept secure and private.

Now please review the cover letter again. If you have any questions about it, please ask me. 
I have name tags for everyone. These will help me in calling on you individually and to keep a good flow of conversation through the discussion. Please neatly print your first name large and clearly with marker so that it can view it from across the room by me and the other participants.

I am providing you with the participant profile questionnaire now. Please fill this out clearly and neatly and to the best of your ability. Once you are done with it, please hand it into me and we will then get started on our discussion. Do you have any questions about the form?

Now let's get started, shall we?

Not assuming everyone knows each other, let us take a moment for some brief introductions and have everyone here today state your name, rank, major, and hometown.

(1) Why did you decide to attend college?

(2) Why did you choose [said institution]?

(3) How would you describe your student experience at [said institution]?

(4) What has been the most rewarding part of being at [said institution]?

(5) What adjustments did you make to be a successful student here at [said institution]?

(6) What have been the challenges that you've faced as a student at [said institution]?

\{Probe: Are there any current challenges?\}

(7) Given the adjustments and challenges you've faced, what has helped you overcome them?

(8) How have you made connections with others here at [said institution]?

\{Probe: How have you made your friendships in college?\}

(9) Can you describe your interactions with faculty at [said institution]?

(10) From your perspective, what purpose does [said initiative] serve?

\{Probe: What are the goals of [said initiative]?\}

(11) How has the [said initiative] helped you with the adjustments and challenges you've faced here at [said institution]?

(12) What events or services have you taken part in that are offered by the initiative? Let's each go around the room and each take a turn sharing these.

(13) What have you learned from participating in [said initiative]?

(14) How have you changed as a result of [said initiative]?

\{Probe: What have you done differently now that you've participated in the program?\}

\{What are some of differences you've noticed in yourself?\}

(15) How often do you interact and engage with the programs and services offered by the initiative?

(16) What new knowledge and skills have you learned from participating in [said initiative] that you have found useful in your adjustment to college?

(17) How have you changed your routines and behaviors as a result of [said initiative]?

\{Probe: What have you done differently now that you've participated in the program?\}

\{What are some of differences you've noticed in yourself?\}

(18) What social connections have you built as being a part of the initiative?

\{Probe: Are there other social connections that you now have at [said institution]?\}

(19) Suppose I was a Black male high school student trying to understand what it takes to succeed in college; what advice would you give to this student about how to be successful in college? 
(20) What do you think are the benefits of having [said initiative] at [said institution]? \{Probe: What are the strengths of [said initiative]?\}

(21) Finally, can you share with me what ways the initiative can better help you adjust and succeed in college?

(22) Thank you all so much for sharing throughout this discussion. At this point, is there anything else you want to share about your college experience?

That's all the questions I have for you today. Thank you so much for taking time out of your schedule to assist me in my research. If you have any questions or concerns I will answer any questions to the best of my ability. Again, you can contact Dr. Elizabeth Jones who supervises this research with your questions. If you don't have any questions, you are free to go now.

Thanks again. 


\section{Appendix E}

Adapted Interview Protocol for Student Participants (unable to attend Focus Groups)

Good Morning/Afternoon/Evening. I first want to thank you for volunteering to participate in this interview. I really appreciate the time you are taking in your schedule to help. My name is Gabrielle St. Leger and I will be asking you a few questions today about your participation with (said initiative) at (said institution). This interview will be part of the pilot study research collected to complete my dissertation at West Virginia University under the supervision of Dr. Elizabeth Jones. She can be reached at Elizabeth.Jones@mail.wvu.edu or via phone at 304-2931886.

The purpose of the study is to find out your experience with and participation in the retention initiative at (said university) that's created to help Black Males adjust and succeed at (said university). This interview should take no longer than 60 minutes. This session will be audio recorded in order for me to capture as much of our discussion today for later analysis and keep the flow of questions and conversation going throughout the interview. Upon completion of the interview, I will be soliciting your feedback on the clarity of questions and ask you to critique the cover letter.

Do you have any questions for me at this point?

To reemphasize the information that is provided on your cover letter, please note that:

(1) You may leave the study at any time. If you decide to stop participating in the study, there will be no penalty to you, and you will not lose any benefits to which you are otherwise entitled. Your decision will not affect your future relationship with said institution.

(2) You will be given a pseudonym for your name in any written documentation that is shared in order to protect your identity and to keep a high level of confidentiality. Information shared in the interview will not be able to be connected to you specifically in any. Every effort will be made to keep your personal information collected during the study confidential. However, there may be circumstances where this information must be released. For example, personal information regarding your participation in this study may be disclosed if required by state law. All transcriptions of the interview, audio recordings, and other data collected will be destroyed via shredding and permanently deleted from all password protected computer files once requirements for research and the dissertation is completed.

(3) Before we begin the discussion, I am asking all participants in the study to complete a Participant Profile which asks for specific and personal background information that will help me later on when I am reviewing our recorded discussion. Please fill out the form as completely as possible. This information will be solely used for documenting the characteristics of you as a participant in the study. This information will be kept secure and private.

Now please review the cover letter again. If you have any questions about it, please ask me.

I am providing you with the participant profile questionnaire now. Please fill this out clearly and neatly and to the best of your ability. Once you are done with it, please hand it into me and we will then get started on our discussion. Do you have any questions about the form? 
Now let's get started, shall we?

(1) Can you state for me your name, rank, major, and hometown?

(2) Why did you decide to attend college?

(3) Why did you choose [said institution]?

(4) How would you describe your student experience at [said institution]?

(5) What has been the most rewarding part of being at [said institution]?

(6) What adjustments did you make to be a successful student here at [said institution]?

(7) What have been the challenges that you've faced as a student at [said institution]?

\{Probe: Are there any current challenges?\}

(8) Given the adjustments and challenges you've faced, what has helped you overcome them?

(9) How have you made connections with others here at [said institution]?

\{Probe: How have you made your friendships in college?\}

(10) Can you describe your interactions with faculty at [said institution]?

(11) From your perspective, what purpose does [said initiative] serve?

\{Probe: What are the goals of [said initiative]?\}

(12) How has the [said initiative] helped you with the adjustments and challenges you've faced here at [said institution]?

(13) What events or services have you taken part in that are offered by the initiative?

(14) What have you learned from participating in [said initiative]?

(15) How have you changed your routines and behaviors as a result of [said initiative]?

\{Probe: What have you done differently now that you've participated in the program?\}

\{What are some of differences you've noticed in yourself?\}

(16) How often do you interact and engage with the programs and services offered by the initiative?

(17) What new knowledge and skills have you learned from participating in [said initiative] that you have found useful in your adjustment to college?

(18) What social connects have you built as being a part of the initiative?

\{Probe: Are there other social connections that you now have at [said institution]?\}

(19) Suppose I was a Black male high school student trying to understand what it takes to succeed in college; what advice would you give to this student about how to be successful in college?

(20) What do you think are the benefits of having [said initiative] at [said institution]?

\{Probe: What are the strengths of [said initiative]?\}

(21) Can you share with me what ways can the initiative better help you adjust and succeed in college?

(22) Finally, is there anything else you want to share about your participation in the [said initiative]?

(23) Thank you so much for sharing throughout this interview. At this point, is there anything else you want to share about your college experience?

That's all the questions I have for you today. Thank you so much for taking time out of your schedule to assist me in my research. If you have any questions or concerns I will answer any questions to the best of my ability. Again, you can contact Dr. Elizabeth Jones who supervises 
this research with your questions. If you don't have any questions, you are free to go now, thank you. 


\section{Appendix F}

Interview Protocol for Administrative Participants-Pilot Study

Good Morning/Afternoon/Evening. I first want to thank you for volunteering to participate in this interview. I really appreciate the time you are taking in your schedule to help. My name is Gabrielle St. Leger and I will be asking you a few questions today about your participation with (said initiative) at (said institution). This interview will be part of the pilot study research collected to complete my dissertation at West Virginia University under the supervision of Dr. Elizabeth Jones. She can be reached at Elizabeth.Jones@mail.wvu.edu or via phone at 304-2931886.

The purpose of the study is to find out your experience with and participation in the retention initiative at (said university) that's created to help Black Males adjust and succeed at (said university) and to explore how the initiative components and goals are developed and have evolved since the beginning of the program. This interview should take no longer than 60 minutes. This session will be audio recorded in order for me to capture as much of our discussion today for later analysis and keep the flow of questions and conversation going throughout the interview. Do you have any questions for me at this point?

To reemphasize the information that is provided on your cover letter, please note that: You may leave the study at any time. If you decide to stop participating in the study, there will be no penalty to you, and you will not lose any benefits to which you are otherwise entitled. Your decision will not affect your future relationship with said institution.

You will be given a pseudonym for your name in any written documentation that is shared in order to protect your identity and to keep a high level of confidentiality. Information shared in the interview will not be able to be connected to you specifically in any. Every effort will be made to keep your personal information collected during the study confidential. However, there may be circumstances where this information must be released. For example, personal information regarding your participation in this study may be disclosed if required by state law. All transcriptions of the interview, audio recordings, and other data collected will be destroyed via shredding and permanently deleted from all password protected computer files once requirements for research and the dissertation is completed.

Now please review the cover letter. If you have any questions about it, please ask me before we continue on with the interview.

Now let's get started, shall we?

(1) What is your current title?

(2) How many years have you been in higher education?

(3) How long have you been at [said institution]?

(4) What lead to the creation of the current retention initiative here for Black males at [said institution]?

(5) A. Who developed the retention initiative? 
B. What were their responsibilities?

\{Probe: Who else was involved?\}

\{Probe: What did they do?\}

(6) What was your involvement in the creation and execution of the retention initiative?

(7) Who is currently involved in executing the programs and services?

\{Probe: What are their current responsibilities to the initiative?\}

(8) In what ways does the retention initiative support the institutional mission?

(9) What other diversity activities and initiatives are at [said institution]?

(10) What, if any, effect has this initiative have on the diversity agenda at [said institution]?

(11) What is the current mission and goals for the retention initiative?

(12) What kinds of partnerships across the campus have developed to assist in carrying out the goals of the program?

\{Probe: Which of those partnerships are primarily with academic affairs?\}

\{Probe: Which of those partnerships are primarily with student affairs?\}

(13) Suppose I am a new freshman Black Male that has just been accepted to [said institution]; Take me through a year of the initiative.

\{Probe: What expectations of the program should I have?\}

\{Probe: What will I do as a participant in the programs and services?\}

(14) Based on your experience, what would you say are the strengths of the initiative?

(15) What are the major challenges to developing and maintaining a retention initiative for Black males at a predominantly white institution?

(16) What have students learned from actively participating in the programs and services offered by the initiative?

\{Probe:-How do you know they have learned this?\}

(17) A. What information about student learning and development have you collected from participants?

B.When do you collect this information?

(18) Can you share examples of changes or revisions that have been made to these programs and services based upon data or information you have collected from participating students?

\{Probes: Can you expand upon your example? What was changed? Why?

When were the changes made?\}

(19) A. How is information shared?

B. How often is there information about the initiative's progress shared with others at the university?

C. Who receives information about the initiative?

(20) What institutional actions have been necessary to sustain these programs and services over time?

(21) How does the support given to the Black male initiative compare to support given to other aspects of the diversity agenda at [said institution]?

\{Probe-If there is a difference in support, what do you think is the difference?\}

(22) What should I have asked you that I didn't think to ask? 
(23) I am also conducting a review of relevant documents about the program. Are there any documents you think are important that I review that will help provide a full picture of the initiative?

(24) Is there anyone who you think would be an additional good contact to find out more about the retention initiative?

That's all the questions I have for you today. Thank you so much for taking time out of your schedule to assist me in my research. If you have any questions or concerns I will answer any questions to the best of my ability. Again, you can contact Dr. Elizabeth Jones who supervises this research with your questions. If you don't have any questions, you are free to go now.

Thanks again. 


\section{Appendix G}

\section{Pilot Study Feedback Questions}

Pilot Study Interview Questions

Thank you for taking the time to complete a focus group and/or interview for my dissertation study.

Today, I would like to ask you a few questions about the focus group and/or interview process to help strengthen it for the actual study with students and administrators, faculty, and staff at the participating institutional sites.

\section{Cover Letter}

1. Was the purpose of my research clear in the cover letter?

a. Dr. Turner asked for clarification, are there particular, "are you looking for/to see which initiatives are working, which ones are not working, how to improve initiatives, is it that pointed? He asked because it's a different process of research than what he was use to.

2. Were the potential benefits of the study obvious in the cover letter?

3. Were you motivated to assist and participate in the study after you read the cover letter?

4. Was the cover letter easy to read and understand?

5. Were the instructions for participation clear?

6. Was anything missing in the cover letter?

\section{Focus Group}

1. Were the purpose, instructions, and procedures for the focus group clearly stated prior to beginning the questions?

2. Were you given an opportunity to ask questions prior to beginning the questions to the group?

3. Were any questions difficult to answer? Why?

4. Were there any terms in the questions that you did not understand?

5. Did the organization of the focus group make sense and flow smoothly?

6. Was the length of time for the focus group reasonable?

7. Did you have sufficient opportunities to actively participate and engage in the focus group discussion?

8. Do you have any other suggestions for improvement?

\section{Interviews}

1. Were the purpose, instructions, and procedures for the interview clearly stated prior to beginning the questions?

2. Were you given an opportunity to ask questions prior to beginning the interview?

3. Were any questions difficult to answer? Why?

4. Were there any terms in the questions that you did not understand?

5. Did the organization of the interview make sense and flow smoothly?

6. Was the length of time for the interview reasonable? 
7. Do you have any other suggestions for improvement?

\section{Student Demographic Questionnaire}

1. Were you given enough time to fill out the questionnaire?

2. Were there any questions or items that were not clear?

3 . Were there any directions that were not clear?

4. Were there any questions that were difficult to answer?

5. Did the organization of the questionnaire make sense and flow smoothly?

6. Do you have any other suggestions for improvement?

Thank you for your time and effort in this important project. 